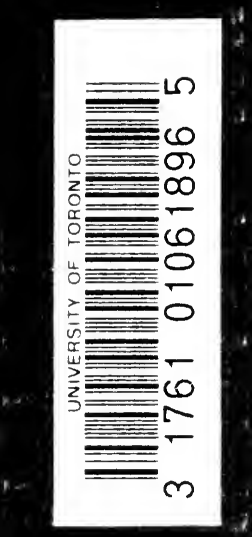




$$
\begin{aligned}
& \text { HANDBOLND } \\
& \text { AT THE } \\
& \text { LNIVERSITY OF } \\
& \text { TORONTO PRESS }
\end{aligned}
$$





THE

\section{ORIGIN AND SIGNIFICANCE}

\section{OF \\ HEGEL'S LOGIC}

\section{A GENERAL INTRODUCTION TO}

HEGEL'S SYSTEM

BY

J. B. BAillie, B.A. (Саmb.), D.Phil. (Edin.)

Das erste Subjective im Studium der Wissenschaften ist Ehrlichkeit gegen sich selbst.

Hegel.

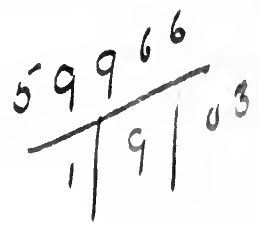

\section{Zlomoan}

MACMILLAN AND CO., LIMITED

NEW YORK : THE MACMILLAN COMPANY

I90 I 
30 
To

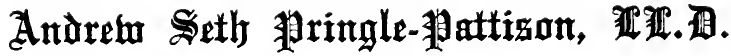

THIS BOOK

IS DEDICATED

WITH WARMEST GRATITUDE

BY

THE AUTHOR 



\section{P REFACE}

The student of Hegel usually finds the Logic the most forbidding and impossible part of the System. At the same time he is aware, not merely from Hegel's own statements, but from the general nature of Hegel's philosophy, that unless he can discover the clue to the tale of the categories, Hegel's System will remain for the most part a sealed secret. In his perplexity he generally abandons, after a short struggle, the effort to understand the System, and regards it either with contempt or despair according to his temperament.

The difficulties felt are due partly to the strangeness of the System, the absence of apparent points of contact with ordinary thought, and partly also to the fact that Hegel has made no confession regarding the path which led him to his final result. Other difficulties of course remain, even when the preliminary obstacles are overcome; but they are of a different kind and hardly so paralysing to continued interest. It is one thing not to understand what an author means in given context, for this difficulty arises from what we already know of the author and the 
context in question; it is quite another matter not to be sure what the author really intends to say in any context at all.

It is the aim of the present work to attempt to remove these initial difficulties more particularly in the way of understanding the Logic, but also regarding the point of view of the System generally. The author has tried to show how the Science of Logic as expounded by Hegel arose in the course of the development of his System, and to state its general meaning. He has thought that if the way could be indicated by which the Logic grew up in the mind of its author, much of the preliminary obscurity which hangs over it might be removed, and such philosophical value as it claims to possess might be more easily appreciated. The purpose of the inquiry is thus primarily historical. So far as the author has deviated from this, it is mainly to bring out by critical suggestions the connexion between one period in Hegel's development and the succeeding. The concluding chapter is devoted solely to criticism, in order to refer, as shortly as the scope of the inquiry would allow, to some of the points of importance which must be taken into account in estimating Hegel's result. It does not claim in the least to be exhaustive or even, as it stands, quite sufficient; but to have done less would have left the work more incomplete than it is, and to have done more would have been to go beyond the natural limits of the inquiry, and probably of the patience of the reader. 
The same may also be said of the Notes appended to Chapter IX., the subjects of which could not possibly be treated fully in short compass. Such views as have been expressed the writer expects to develop in a further treatment of Hegel's System, which he hopes shortly to undertake.

The method of exposition adopted may seem at times a little misleading. The author has identified himself so much with Hegel's point of view that, it may be objected, it is difficult to distinguish Hegel from his interpreter. There is perhaps something to be said against this method. Still it seems the best in the circumstances, if one is to avoid the unsympathetic attitude of the mere onlooker, or, what is quite as common in expositions of Hegel, the mere restatement of Hegel's position in his own words. But in fact the method is not so dangerous as it seems, for it will be easy to detect at what points the writer is giving his own views, and where the narrative is purely historical.

It ought perhaps to be mentioned that all the stages in Hegel's development are not equally important for the understanding of the Logic. The reader who is interested simply in finding how the later Logic arose may skip altogether the First Stage (Chapter II.). The statement of his earliest position is of slight value in itself, and is merely retained for the sake of completeness in the historical account. Hegel's views at this time were obscure, and the obscurity is, the writer feels, not 
entirely removed by the statement of them which has been given. But the account could hardly have been made shorter without increasing the degree of obscurity, nor longer without needlessly adding to the amount of it. On the whole, this chapter will be found of interest mainly to the specialist.

As to the value of the Logic itself in the System it must be admitted that, so far as the interpretation of Hegel's philosophy is concerned, the Logic is of primary importance. Doubtless the truth of Idealism does not depend on the worth of the Logic, f- but rather conversely. Still, for the appreciation of Hegel's own position, the judgment on the Logic is the judgment on his System as it stands. The other parts of his philosophy are more accessible; they are certainly more directly fruitful, and on the whole the essential value of his principle is more - evident there, (e.g. in the Philosophy of Law), than in the Logic. But for Hegel himself there seems little doubt that the construction of the Science of -Logic is the supreme expression of Idealism.

Apart, however, from its place in Hegel's System the Logic has still a unique value for the student of philosophy. Indeed, it would be somewhat astonishing if such a stupendous intellectual achievement as Hegel's Logic had merely an esoteric interest. It is doubtful if there is any better or more important - discipline for the student of philosophy than simply to -reflect on the exact significance of the general terms -which are the current coin of ordinary communi- 
cation. We use perpetually and without any effort of thought such terms as "something," "reality," " existence," not to say "cause," "substance," and so on. But we might be sorely put to it to say what exactly was meant by such ideas, and why we . used them in certain cases and not in others. Such an inquiry is not useless, for in point of fact it has somehow to be done when practical necessity calls for a precise distinction, e.g. in the legal definition of a "thing," or the chemical conception of "substance." And the inquiry is certainly not impossible; for it is a paradox to say we use terms perpetually and yet do not know what we mean by them. Indeed one would think that nothing could be easier than to determine exactly what everyday terms mean, and the thorough-going discussion of these common conceptions ought to be, as Hegel says, in a sense the easiest of all sciences. It is just such an inquiry as this which is undertaken systematically in the Science of Logic. And so long as it remains necessary, as it will always be important, to understand the definite significance of everyday notions, Hegel's Logic will be indispensable; for though it is of course a system of conceptions and not a dictionary, yet the system cannot be constructed unless the fundamental conceptions at the root of common. thought are first of all accurately grasped.

Within recent years considerable attention has been directed to the Logic. Wallace's Prolegomena 
and Mr. M'Taggart's Studies in the Hegelian Dialectic have each given assistance to students of the Logic; the former by an exposition of the various conceptions peculiar to the System of Logic, the latter by a criticism of a special feature of it-its Method. Neither of these professes to give the historical evolution of the Logic; and the same may be said of M. Noël's La Logique de Hegel, as well as of the most recent work on Hegel-that of Prof. Kuno Fischer, who has just completed his exposition of Hegel's Leben und Werke. The works to which the author is directly indebted for help in the present inquiry are: Schaller, Die Philosophie unserer Zeit; Schmid, Die Entwickelungsgeschichte der Hegelschen Logik; Haym, Hegel und seine Zeit; and above all the great store-house of Hegelianism, Dr. Stirling's Secret of Hegel.

The chief sources used in the investigation are Hegel's Werke, Bde. i.-vi., xvi. and xviii., and Rosenkranz, Leben Hegel's. As various editions of the published works have appeared, and as even the volumes in the same edition have not all been published at the same time, the date of the volume referred to is given the first time the volume is quoted in the foot-notes. It has been sought in this way to avoid all ambiguity in the reference.

In conclusion I can only very imperfectly express my indebtedness to those who have given me encouragement and help in the preparation of the work, and but for which, indeed, I should 
not have ventured to offer for the assistance of other students the results of such an investigation. I desire more especially to acknowledge my obligations to Professor Seth PringlePattison, to Dr. Caird, and to Professor Adamson, for the kind suggestions and criticisms on different parts of the inquiry, which have enabled me to present the work in its present form. And I shall always look back with pleasure to the hours spent in discussion with Mr. J. E. M'Taggart of Trinity College, Cambridge, some of the fruits of which have doubtless appeared in the present volume.

ST. ANDREWS,

August igor. 



\section{CONTENTS}

\section{CHAPTER I}

\section{INTRODUCTION}

Hegel's interest in philosophy originated in ethical and religious problemsInfluence of Kant and contemporary idealism-Importance to Hegel of the study of History-Influence of the Greek life and thought-The affinity and the antithesis between Humanism (or the Modern Spirit) and Hellenism (or the Greek ideal) sets the philosophical problem for Hegel - His early acquaintance with the History of Philosophy, more especially with Greek Philosophy $\quad$. $\quad$. $\quad$. $\quad$. $\quad$ Pages I-20

\section{CHAPTER II}

\section{FIRST STAGE-FROM I797 TO I 8O0-HEGEL'S EARLY LOGIC}

Hegel's general position at this time-The Absolute is Spirit-Philosophy and Religion-Logic and Metaphysic-The Scheme of Logic-The contents of Metaphysic-Commentary and criticism on the foregoing schemeIts anticipations of his later views-Slight influence of Fichte and of Schelling-Influence of Kant-Uncritical and tentative character of this early system . . . . . . . $2 \mathrm{I}-56$

\section{CHAPTER III}

\section{SECOND STAGE-FROM I8OI TO 1807}

Characteristics of this period-Criticism-General position-Logic and Metaphysic-Subject-matter, source and procedure of Philosophy-Reflexion and Anschaumng - Reason and Understanding - Logic of Reflexion- 
Metaphysic of Anschaunng-Commentary on this period-Hegel's chief points of advance on his early views - His Principle - Procedure Approximation of Logic to Metaphysic-Method-Defects Pages 57-98

\section{CHAPTER IV}

\section{HEGEL AND HIS CONTEMPORARIES}

Community: of view-Criticism of Kant-Value of his position for HegelCriticism of Fichte-Criticism of Schelling-Agreement and difference

\section{CHAPTER V}

TRANSITION-ORIGIN OF THE PHENOMENOLOGY OF MIND AND OF THE LOGIC

Criticism and advance on the second period and recasting of previous viewsSupremacy of Spirit-Relation of this idea to the content and method of Hegel's Philosophy-Absolute is Subject-Origin and purpose of the Phenomenology-Scope and division of the inquiry-Different points of view from which it may be regarded-Practical and theoretical aim of the inquiry-The "Proof" of Hegel's position-Development-Origin of the Logic.

\section{CHAPTER VI}

THIRD STAGE-FROM I8O7 TO I8I2-I6-THE PHENOMENOLOGY

Nature of the inquiry-Knowledge and Truth-Subject and Object-Ideal and actual Knowledge - The Method of procedure - Outline of the argument - Absolute Knowledge - Its origin and nature - What it contains

\section{CHAPTER VII}

THE PHENOMENOLOGY (continued)-PHENOMENOLOGY AND LOGIC

Relation of Absolute Knowledge to other forms of Experience-This can be stated from two points of view-The distinction between Absolute : 


\section{CHAPTER I}

\section{INTRODUCTION}

IT will greatly facilitate the appreciation of the history of Hegel's views on Logic if at the outset we give some indication of his attitude to the problem of philosophy as a whole, the direction from which he approached philosophy, and the primary influences which helped to determine the course of his mental development. Hegel's earliest conception of the nature of Logic has at least this in common with his latest, that Logic is no mere appendage or accident in his general system, but an integral element of it. The statement, therefore, of his general philosophical point of view will throw no inconsiderable light on his theory of Logic.

Hegel's intellectual development illustrates in a very suggestive manner a peculiarity of his own system. It consists in holding in succession opposite positions, along with the strenuous attempt to reconcile these opposites in such a way as to do complete justice to the importance of each. This, perhaps, may be taken as an indication that he possessed an unusually profound intellectual insight into the limitations inherent in the very nature of principles taken by themselves and in 
isolation; but more probably it was due to the - natural sanity of a well-balanced personality which instinctively recoils from over-emphasis on any one part, no matter how important, of that single and completed whole whose life it shares. Hegel's mind was continually and keenly alive to the value of the divergent aspects of the reality presented to it. So much so, indeed, that a positive statement in one direction is unhesitatingly pitted against, and even "turned round" at times with bewildering facility into, its very counterpart-a modus operandi which is to a large extent the source of the perplexity found in deciphering his meaning. This appreciation of contrariety amongst the facts of experience is prominent at the very outset of his intellectual development, and determines it from first to last.

The first stage in Hegel's career after leaving the gymnasium was devoted mainly to Theology. No doubt in his case, as in that of many another Weltkind, the capricious hand of fortune had most to do with deciding the course his earliest steps should take; but on this occasion fortune's fingers turned the key of destiny at the first trial. For, whatever may have been Hegel's interest in school theology, and in spite of the fact that he ultimately abandoned the intention of directly serving the Church, it is unquestionably Hegel's intense - appreciation of the aims and objects of religion that gives the dominant tone to his whole philosophy. Not only is this evident from such records as we have of his studies during the years immediately succeeding his residence at Tübingen Theological Seminary, but we shall find it impossible to under- 
stand the position he assigns to religion in his final scheme, ${ }^{1}$ and the incessant recurrence of its fundamental ideas and problems throughout his work, unless we assume this peculiarly intimate connexion in his own thought between religion and. philosophy. The problems of the religious con- $r$ sciousness of his time compelled him to seek some satisfaction for them in philosophy; and in the light of this origin of his inquiry his subsequent development must be interpreted.

This pronounced influence of religion on Hegel's philosophy must not, however, be understood in any narrow sense; for with it there was inevitably associated the problem of morality. The content of morality and religion is fundamentally the same. Both express what in man is most concrete, most universal, and most vital to his interests, and hence both directly appealed to a mind like Hegel's, which from the first was awake to all that was deepest and most real in human life. These then must be taken together as supplying the objects with which Hegel was primarily concerned.

Now this native predisposition for ethico-religious inquiry put Hegel at once en rapport with the dominant spiritual movement of his time. The wave of the new Humanism had at last (by I 794) broken over Germany, and carried with it everything and every one of affective significance during that epoch. Not only had the new Copernican metaphysics become the passionate creed and conviction of the leading philosophers of the day, led for the

1 Cp. the "Philosophy of Mind" in the Encyclopadia, where Religion is the highest stage in the life of "Mind" excepting Philosophy itself. Also the "Introduction to the Philosophy of Religion," which establishes the closest possible relation between Religion and Philosophy. 
most part by Fichte; the influence of precisely the same ideas was also at work in the outpourings of the poetic genius of Goethe and Schiller, who were the princely embodiments of the new spirit. On Hegel the effect of this intellectual environment was not simply unconscious; he was ever closely in touch with the various agencies at work in the life around him, and found it easy to be sympathetically appreciative of the work of other minds. Thus his own innate mental proclivities, combined with the spiritual forces operative at the time, brought Hegel at the earliest stage of his intellectual development under the immediate influence of the master-builder of the new epoch-Kant. And though Kant's influence is peculiarly associated with this first period of Hegel's career, we shall find that it remained effective to the last.

At the outset, however, it was not primarily the value of Kant's principle and result for philosophy proper that made them of such interest to Hegel; their importance lay rather in their bearing on religion and morality. For their purely speculative import he did not profess much concern. He was prepared to study the development of the Kantian doctrine by Fichte, Reinhold, and his friend Schelling; but in these matters he was content to be a "learner," to leave "theoretical " problems to others. ${ }^{1} \mathrm{He}$ was aware, indeed, of the supreme theoretical value of the principle, and from the complete realisation of its meaning he expected a "Revolution in Germany " ; ${ }^{2}$ but Hegel's own attention was absorbed by it

${ }^{1}$ v. First letter to Schelling, Rosenkranz, Leben, pp. 64 ff. (Hegel's Briefe, vol. i. pp. 6 ff.).

2 Third letter to Schelling (Briefe, i. p. 14). 
because of the flood of light it threw on what was then of most interest to him-the problems of the religious consciousness. His mind is alive with the new spirit of freedom infused into intellectual life, with the new rationalism that is investing the discussion of religious questions. He speaks with all the vigorous contempt for the established order which is engendered by the newly awakened insight of youth into the seriousness of the problems of life, and confidently foretells the doom of the old orthodoxy, like any other irresponsible prophet of the Aufklärung. He eagerly welcomed Kant's ethical principle, and his natural insight into the import of great ideas saw in it the germs of a new religious life, and of a transformation of man's appreciation of the meaning of his destiny. Some expression for his inchoate conceptions and anticipations Hegel found in the daring reconstruction of Fichte's Wissenschaftslehre (I 794), as also in Schelling's early essays. But his own attempts at reinterpretation were confined to the discussion of specific aspects of the problem. He endeavours to apply Kant's conclusions regarding the practical reason to the ideas of providence, and the place of the notion of purpose in the physical world. "Moral theology," he thinks, could thus be used to throw light on "physical (natural) theology." 1 In the philosophical justification of the dignity and worth of man he finds the clue to the reform of . religion and politics at once; for these go hand in . hand. "The former has taught what the latter under the form of despotism wanted and gave effect to." ${ }^{2}$ The religious doctrine of communion with

1 Rosenkranz, Leben, p. 68.

2 ibid. p. 70. 
God he seeks to understand, and to harmonise with the "primacy of the practical reason" and its postulates. ${ }^{1}$

Such disconnected efforts to reconsider current religious notions are all that we find recorded of Hegel's philosophical activity during his residence in Switzerland (1 794-97). They are too indefinite to convey accurate information regarding any precise results to which he might have arrived, but they are sufficient to indicate his essentially religious interest in the philosophical ideas of his time. His attitude at this period was not strictly philosophical ; so far as it can be determined at all it was a crude blend of philosophy and theology, much more allied to mysticism than to clearly developed systematic thinking. This is confirmed by what is recorded of the influence exerted upon him by the German mystics, Eckhart and Tauler, with whom at this time he became acquainted. The same tendency too is seen in the fundamental conceptions he employs in expounding his views. "Love" in its mystical sense he regarded as an ultimate principle of explanation in religion, and found in it all that was characteristic of reason,- - unity, and harmony of opposites. Love, in fact, was the "analogue" of reason. " "Life," again, was treated as the supreme category by which to determine the essential nature of reality; and religion was constituted by the relation of "finite life" to the "infinite life," and by the active union of these, a union which found complete expression in the idea of Love.

Hegel did not confine himself solely to the analysis of the actual problems of religion. Another

1 Rosenkranz, Leben, p. 72.

2 ibid. p. 45. 
influence was at work which was of supreme importance in his development. This was the study of History, the full appreciation of which alone would give Hegel a unique place in modern philosophy. It is impossible to over-estimate the part played by this subject in determining the character of Hegel's philosophy. From the very start Hegel approached the study of a fundamental problem from a consideration of its history, either in order thereby to throw light on the solution of the actual problem itself, or in order exhaustively to appreciate its full significance. ${ }^{1} \quad$ It was because the one human spirit was alive to its purposes and destiny in diverse times and in diverse ways, that Hegel sought aid in the comprehension of the present by direct appeal to the past. The life of the past was to him not the monotonous intonation of recurrent but identical formulas, still less the mere wail of the multitude, which is no sooner uttered than it is vanished for ever. Rather every pulse in that life was necessary and significant, because a contribution to the revelation of the full meaning of humanity. It was the perennial human value of human deeds that led Hegel to learn of the past to appreciate the present. And this too determined the nature of his interest in historical facts. It was not their external character, their existence as mere facts that appealed to him, but their inner significance, the kind of spiritual forces and movements which they showed to be at work. Not the pragmatical importance of events, but their interpretative value lent them meaning; and this conception of them determined his method of study.

${ }^{1}$ Cp. Haym, Hegel u. seine Zeit, pp. $44 \mathrm{ff}$. 
This method is pursued not merely in the case of political history, but still more in dealing with religious history, with which he was more directly concerned during the early years of his development. In the former he looked for the explanation of the trend of a nation's history in the inner life, the ideas and ideals which peculiarly characterised the mind of the people. His interest in the history of religion was concentrated not on the outward events but on their essential religious worth, their actual contribution to the realisation of the meaning of religion. Thus the life of Christ, to the study of which Hegel continually recurred during this period, ${ }^{1}$ was of importance solely for the light it threw on the essential nature of religion, or more particularly of the Christian religion. And it need only be mentioned here in passing that precisely the same point of view was adopted when later on Hegel's philosophical interest was fully aroused, and he appealed to the history of philosophy to aid in the comprehension of the nature of philosophy, and even in the solution of its problem. The supreme importance of the history of philosophy in the determination of Hegel's own philosophy was continually insisted on by Hegel himself, and cannot be over-emphasised by his interpreters.

But what above all gives such significance for Hegel's developments to this natural penchant towards the study of history is that he was thereby brought almost at the outset of his career into contact with the mind and life of Greece. [For Hegel's intense appreciation of the Hellenic spirit, and his

${ }^{1}$ He wrote about this time a History of the Life of Christ (Ros. Leben, pp. 52 ff.). 
enthusiasm for it became, next to the influence of religion already mentioned, the dominant factor in his mental history.] His love for the Greek ideals was awakened as early as his school days. It was fostered by his friendship with the poet Hölderlin during and after his life in Tübingen. It was no doubt strengthened and deepened by that revival of Hellenism which was initiated by Lessing's Laokoon, and carried forward with splendid devotion by Goethe, and which by the time of Hegel's apprenticeship was in full possession of the best literature of the day.

The point, however, in regard to which the Greek ideal first decisively influenced Hegel's intellectual attitude was the character of Greek religion. ${ }^{1} \quad$ This seemed to him to embody the highest purposes and essential meaning of religion ; for in it was realised the oneness of the individual with the universal-a oneness which was so complete that nothing further than the realisation of this universal was ever desired by the individual. Devotion to the all-sufficient and supreme ends of the state exhausted the highest aims of the individual citizen; his gods were his own ideals clothed upon with the life and passions of humanity, sharing the common struggles and triumphs which were necessary for the common good. Above all they were inhabitants of the earth, of the woods, the rivers, and the hills; citizens of this common world, glorifying it by their presence; the companions and guardians of the children of men. Such a religion realised the great harmony of the

1 v. Haym, pp. 474 ff. Haym publishes some valuable extracts from Hi igel's literary remains, not found in Rosenkranz. 
jarring discords of life, filled up the clefts and gaps in human insufficiency, and transformed man's existence into a poem of nature's own creation.

The attractiveness of this ideal was brought out still further by its contrast with the religion of the Jews, a contrast to which Hegel incessantly recurs at this time. ${ }^{1}$ Here man is separated from his God; man's ends are not exhausted by the state, for even the state is not self-sufficient, but subserves another, a divine, will outside itself. The law of life is not an inner principle, but an external command; reconciliation is mechanical, being in fact no more than a truce between alien spirits, not the reacknowledgment of an essential union. The Jewish religion exalts God so far above man, that even the dignity and worth of man as a religious th being are themselves threatened; and the life of religion, far from being a harmony of the discords of finitude, is the perpetual struggle of man to satisfy impossible demands.

Comparison with Greek religion, again, threw Christianity ${ }^{2}$ itself into an unfavourable light. For this had essentially the same framework as the Jewish religion. God was set far above man as his law-giver and judge, who did not live in the hearts of men, but governed them from an inapproachable altitude, employing as his representative the voice and will of the Church. The Church, its worship and ordinances, reflected with accuracy this view of God's relation to man. The moral code it regarded not as the inner purpose and meaning of man's spirit, but the expression of an external will with

1 Ros. Leben, pp. 490 ff.

2 Hegel has in view primarily Christianity as it historically originated. 
which it was in no essential harmony, but which it had to obey on pain of guilt and punishment, either at the hands of the Church or in some future state. The religious life was a continual confession of the slavery, the fallen state, the worthlessness of man, a degradation which became the greater the more God was exalted, and the farther off he was placed from the living world of passion and pain. ${ }^{1}$ For God's exaltation above man did not affect man's ability to know him; it was a moral and metaphysical exaltation, not an elevation beyond the range of man's knowledge; men, indeed, "began now to have an amazing amount of knowledge of God." God was wholly and simply objective to man, a being apart and outside himself, a God who revealed himself and urged conviction through wonders in place of reason, and in whose name, and for whose sake, just because he was outside the heart of man, deeds were done absolutely alien to the native instincts and natural laws of the conscience of his devotees. ${ }^{2}$

We need not expand these statements into a digression; enough has been said to indicate the character of Hegel's criticism. It is clear that both in regard to Judaism and Christianity his objections have precisely the same basis, his analysis is guided by the same general principle. In both of them the realisation of the highest religious life by the organic incorporation of the ethical content of man's experience, through which his spirit is developed and

\footnotetext{
1 " The objectification of God went step for step with the degradation and slavery of man": $v$. Haym, p. $48 \mathrm{I}$.

2 "Such a distortion of moral principles was only possible because at such a time God must have entirely ceased to be subjective, and become solely an object ": $v$. Haym, p. 482.
} 
becomes substantial and concrete, was rendered impossible by the removal or elevation of the divine far out of the reach of the world in which man actually lived. The result in both cases was the degradation of man, the transcendent superiority of God, and that distortion of the meaning of man's life which was the inevitable consequence of bringing two such heterogeneous realities into relation. And Hegel found the key to such religious attitudes in the political situation of the time to which they belonged. For it was in proportion to the extent of the deterioration of the national life of the Jews that their own confidence in themselves and their destiny failed them, and they looked outside themselves for a deliverer, a Messias who was to come; while again it was the entire destruction of national life at the time when Christianity appeared which withered the marrow of men's moral substance, and induced them to seek God's glory through their own infirmity, and to look for the blessedness of a distant future state as a compensation or substitute for the helpless incompleteness of the present. ${ }^{1}$

All this, as Hegel points out, stands in decided contrast with the national religion of Greece and . of Rome. There the life of the individual was absorbed by the universal aims and life of the state; in fulfilling the highest purposes of the state each fulfilled his own best will. The idea of his Fatherland was his mainstay and ideal end, and before this idea his own individuality simply disappeared ${ }^{2}$ he desired for that alone, security, continuance, and life. Thus religious conceptions which have become of supreme importance in Christianity find

1 v. Haym, pp. $478 \mathrm{f}$.

2 Haym, p. 476. 
no counterpart in the religion of Greece and Rome. For example, "'Piety' and 'Sin' are two notions which do not belong to the Greeks in the sense understood by Christians. 'Piety' is to us a sentiment proceeding from reverence towards God as law-giver; 'sin' is an act which transgresses commands so far as they are of God. But ärıov, àvárıov, pietas, impietas, express sacred feelings of human beings, and sentiments or acts which are suited or contrary to such feelings." 1

Now, while the influence exerted by Greek life and thought upon Hegel is perfectly manifest from the above religious views which he held at this time, it is not difficult to see that there was considerable affinity between Hellenism, as Hegel now understood it, and the Kantian principle, with which, as we saw, he was also in immediate sympathy. It was indeed in the light of that new doctrine that he examined and criticised the religious life of the past and of the present. Kant's principle had secured or rather re-established the essential value and dignity of man's place in the world; had raised him to a knowledge of his worth by proving his own self, his vital reason, to be the source of the order and meaning of his life, the measure and guarantee of its divinity; and had shown the idea of Freedom to be at once the key and the treasure of human existence. The wealth hitherto lavished upon heaven must therefore now be refunded to its rightful owner; and man's first duty was to enter into his natura' inheritance. Hegel found this principle of freed $m$ concretely realised and implied as an end in the religion and life of Greece; that

1 Haym, p. 482. 
religion revealed the spirit of a free people, and could be a religion only for freemen. Hence the influence exerted upon him by the Greek ideal; it was a concrete historical embodiment of what seemed to him the essential aim and meaning of man's life. The Hellenism of antiquity incarnated the spirit of the new Humanism of his own time.

Now these two influences above sketched (Kant's principle and the Greek ideal) may be said to be the guiding threads of Hegel's mental history. They undergo transformation in the course of his development, and their meaning becomes truer and deeper; but essentially they remain the dominant factors throughout. At first, as we see, they exerted their influence side by side, and that in the restricted sphere of ethico-religious inquiry. There was no sense of any opposition between the essential significance of Kantianism and Hellenism; they seem even to have been regarded as in harmony with each other; and there was no attempt at this time (1794-97) to extend them to other fields of inquiry. But closer consideration shows, and further reflexion on Hegel's part made it evident, that there was a rooted antithesis between the principles of the two. On the one side the governing idea was that of individuality, self-development ; this was of the very essence of Kant's theory. On the other hand, however, the essential import of the Greek ideal was universalism, the limitation of the individual for and by the universal end of the state. The former attached a sipreme worth to the individual will and purpose; the individual was the supreme end; the latter gave him no worth at all except in so far as he was determined by the 
higher and complete whole (the state) which was the end, and which he subserved. The one emphasises the value of the individual in himself in virtue of his autonomous and inexhaustible spontaneity; the other absorbs the individual into the single harmonious unity of the common life. The one, in short, implies self-development; the other selfannihilation.

That this antithesis could be no mere fiction of Logic was plain from the fact that in the latter case an organised national life was the indispensable condition of the realisation of the end of the individual. Should the condition cease to be, as it did in the case of Greece and Rome, the life of the individual will also crumble under the ruins of national disaster. And yet the individual can and does survive the decay of the state. How then can an individual exist solely for the universal ends of the state? Moreover, religion-particularly religion in its highest forms-is a direct relation of the individual to God. But, if so, is not such a relation independent of any national life and sufficient for itself apart from it? And did not Christianity itself emphasise at its origin precisely this self-containedness of individuality? From both these sides, therefore, the antithesis between Kantian doctrine and the Greek spirit is seen to be no mere superficial contrast, but a deep-seated opposition of fundamental principles. The individual does and can exist in the world apart from the universal, and has a supreme value of his own; and yet, on the other hand, the life of the state seems to make real and concrete that of the individual.

Now there seems little doubt that it was Hegel's 
appreciation of the full significance of this opposition, and the struggle to resolve it and harmonise the elements it contained, that determined his further development. He came to see that the antithesis, in the form in which he had hitherto considered it (that of the sphere of religious life), was merely one instance in which it appeared; that the general opposition of individual and universal pervaded every sphere of knowledge and experience, contained, in fact, implicitly all oppositions of whatsoever kind which experience manifested. Hence it was that the struggle to resolve this antithesis gradually compelled Hegel to leave the limited sphere of religious inquiry, and raise the whole problem of philosophy itself, and thus led him finally to devote his life solely to philosophy. This indeed was the inevitable avenue of his development. For religion attempted to satisfy the essential nature, the ultimate needs of man; and the attempt fully to understand the meaning and problems of religion could only be realised by an inquiry into the final meaning of ultimate reality and man's place in it. The living relation of the individual to the universal whole, or God, was the subject-matter of religion; the truth regarding the individual and his relation to the Absolute was the object of philosophy. The fundamental antithesis found in the former, therefore, necessarily led Hegel to seek a fuller appreciation of it through the medium of philosophy. How close he always considered the affinity between the two to be we shall find as we proceed.

Hegel did not at once appreciate the significance of the problems with which he was occupied. His discovery of their nature, and indeed his deeper 
interest in their solution, could of course only come through steady devotion to philosophy. And to a mind of Hegel's order no conclusion was ever admissible unless it appeared as the result of accumulated knowledge and laborious reflexion. However much he may have occupied himself with certain philosophical problems during his residence in Switzerland, it was his departure for Frankfurt in 1797 that marked the beginning of his exclusive devotion to the study of philosophy. Henceforward the task of philosophy is the task of his life. Religion, as such, falls into the background; its questions form part of a large problem, the solution of which itself contains their answer. ${ }^{1}$

His intensified interest in philosophy did not merely induce him to face independently the actual problems of philosophy as they appeared to his own time; he began also to direct his attention to the history of philosophy, and thus to call in the aid of past solutions to throw light on present problems. This method of procedure was, as we have already seen, characteristic of Hegel's mind; but it was in philosophy that its application produced results of such profound significance. It did not merely help Hegel to appreciate the meaning of the task before him, and to find some solution to the questions he had raised; but the very meaning of the history of philosophy itself, became an integral and essential moment in the solution of the whole problem of philosophy. This gradually dawned on Hegel as his development proceeded.

1 During this period too, no doubt, Hegel finally abandoned his original purpose of serving the Church; his relations with Schelling and the circle at Jena helped to open up the possibility of engaging in the more congenial work of a university. 
At this stage the importance of his appeal to history lay in the fact that thereby he was from the outset of his work in philosophy made acquainted with the ripe results of Greek thought. The influence of Greek speculation on his intellectual life, it is safe to say, marked an epoch in his development. It was impossible for Hegel to breathe the clear air of Greek philosophy without finding his mental constitution profoundly modified. That native objectivity of mind on which his biographer lays so much stress could not but find its natural affinity with the genius of the Greek spirit; and his selfabandonment to the study of Greek thought would inevitably issue in the transformation of his intellectual attitude to the world. In Hegel there thus met for perhaps the first time in the history of philosophy the deepest influences which have moulded European culture-the thought of Greece and of Protestant Europe, the objectivity of the Greek mind, and the subjectivity of the modern spirit. It was the characteristic of Hegel's genius to be equally alive to the significance of both of these divergent attitudes of human thought; and it is his strenuous effort to satisfy the aims of both that constitutes his unique claim to the place he holds in the history of human opinion. His philosophy, in fact, may be regarded as simply the systematic attempt to reconcile the essential tendencies and ideals of Greek and modern thought, to harmonise the monistic universalism of the one with the monadistic individualism of the other. If we consider, as we fairly may, the objective attitude of the former as the characteristic mark of the scientific spirit, and the prevailing subjectivity of 
the latter as the special feature of the religious type of mind, then we may say that Hegel's system is the reasoned reconciliation of science and religion.

We have seen already how during his residence in Switzerland Hegel dealt with the opposite attitudes in the restricted sphere of religion. In the Frankfurt period he was brought face to face with fundamentally the same antithesis in the more comprehensive field of philosophical inquiry. It was during this time that the opposition between them was felt most keenly, because seen to be an essential opposition of principles; and it was then that the struggle to harmonise them had once for all to be undergone. Little light is thrown by his biographer on the silent labour and strenuous patience of these three years at Frankfurt. The results, however, as we shall find, are seen in the earliest productions which came from his pen immediately after he emerged from the obscurity of the Frankfurt days into the philosophical arena at Jena, and there from the first took his place as a unique luminary in that bright constellation. We are informed, however, that it was Plato's influence ${ }^{1}$ which was most pronounced during the Frankfurt period. The greater metaphysical dialogues, such as the Parmenides, claimed special attention, and we may safely conjecture that from them he first discovered the significance of what he afterwards named the essentially dialectical nature of individual conceptions. There seems little doubt that the concrete illustrations of the instability of isolated notions and one-sided truths, which forms the perpetual subject-matter of the Platonic dialogues,

1 Ras. Leben, p. 100. 
were of the utmost importance in suggesting to Hegel the value of dialectic as the appropriate method of philosophy. Kant's "antinomies" in the Critique of Pure Reason were merely particular cases of precisely the same peculiarity of the contents of human reason, illustrated by Plato. We have no facts, however, to show in detail how Hegel's view of dialectic arose from Plato's.

But while Hegel was thus engaged in assimilating the results of the past, his own reflexion was not in abeyance. His thoughts began to take systematic expression even during this Frankfurt period. What gives this early system its importance to us is the fact that in the course of it we meet for the first time with a discussion of what is here of more particular interest to us-the problem of Logic. The treatment in itself is short, and is on the whole of slight value; still it is necessary to deal with it ; and we shall find that in some measure it contains even at this stage the germs of his later Logic. With this his earliest systematic view of Logic, therefore, our inquiry must begin. 


\section{CHAPTER II}

FIRST STAGE-FROM I 797 TO I 8OO-HEGEL'S

EARLY LOGIC

Hegel's earliest attempt to construct a philosophical system is of great interest to the student of his development. The mere fact that from the first he expounded his views in the form of a rounded system is of itself peculiarly characteristic of Hegel's mind. Philosophy was for Hegel always • synonymous with system. This indicates at once that from the beginning to the end of his career his conception of philosophy and its problem remained fundamentally the same. Its object was the Absolute, the totality of things; its aim was to organise the whole by some single unifying principle. • Philosophy was not an inquiry into the nature of knowledge, but actual extension of knowledge. It was not disconnected and spasmodic excursions into various problems of philosophy, still less sceptical distrust of its essential purpose. Nothing, in fact, short of systematic exposition of the complete truth would fulfil the task it gave itself to do.

But while this idea of system is thus the necessary correlative of his conception of the problem of philosophy, we must also note that at the outset this conception was itself doubtless determined by 
the methods and results of the new philosophical movement which was led by his contemporaries Fichte and Schelling. It was the essential characteristic of their attitude to abandon the examination of knowledge, to assert as constitutive of experience principles which for Kant were merely regulative, and to attempt systematically to organise the whole content of experience. With this position Hegel - was fundamentally in agreement; and hence consciously to regard the Absolute as the sole object of philosophy was to assist that development of philosophy with which he had the closest sympathy, and by which he was during his residence in Frankfurt and for some years afterwards radically influenced.

But this early scheme is significant in another respect. It contains in its general outline the essential features of his final system. We have what corresponds to the later Logic, Philosophy of Nature and Philosophy of Mind. There is indeed the greatest contrast between the earliest and the latest scheme; more particularly, as we shall see, in the treatment of the first part of the system. But the tripartite division of the whole of philosophical science is the same, and the general nature of the subject-matter dealt with in each part is also the same throughout the history of his system. The difference lies in the clearness and completeness of his conception of the subject, and more especially in the absence in the early scheme of a precise method. Thus we see that the history of Hegel's philosophy is the gradual development of the meaning of a subject-matter whose general character was determined at the beginning. The same 
problems therefore faced him from first to last. The relation between nature and spirit, and between the "ideal" and "real" content of experience, was not a problem for his final system only. It engaged his attention all along; for it inevitably arose when he attempted to connect into an organic whole those three parts of philosophy, which were originally taken primarily as distinct and relatively independent + of each other. Their separateness was for him the preliminary fact ; the question of their relation arose from regarding them to begin with as in some sense independent of each other, and yet as moments of a single system. ${ }^{1}$

It is again important to notice that in this earliest system Hegel adopts his fundamental philosophical tenet-that Ultimate Reality is Spirit (Geist). From this position it is safe to say, in spite of appearances to the contrary during the Jena period, - he really never swerved. The principle of Idealism is thus the basis upon which Hegel's first con- structive efforts were raised; and if Geist be taken as the pass-word of idealism, Hegel's system is idealistic from the beginning of its development. There seems no doubt, however, that at the outset - this position was rather a dogmatic assumption, or at - least a mere intuition, and not a principle arrived at after a process of preliminary critical inquiry. And indeed even to the last it remained in a sense an assumption of his philosophy, in the sense, namely, - that it was always the starting-point of his system -a characteristic of Hegel's principle, which was perhaps inevitable in a system whose sole aim was a direct construction of the Absolute without 
preliminary inquiry into the nature of knowledge, and which, as we shall find, led him to adopt a peculiar view regarding the kind of proof of which such a principle could be in reality capable.

To begin with, however, his fundamental principle can hardly be said to have been established by proof in any sense. The reasons for his adoption of it must be sought in the facts of his previous mental development, the history of which we have given in outline above. In the first place, and chiefly, the determination of the Absolute as Geist was due to his deepened appreciation of the nature of the religious and ethical consciousness, with which, as we saw, he was primarily concerned at the outset of his career, and which, as we shall find again and again, is the Leitmotiv of his mental history. Not that now for the first time he used the term to designate the reality of religion; but hitherto it was used, and that only occasionally, alongside another which was regarded as a more adequate, because more concrete, determination of the Absolute-the notion of "Life." While, however, this somewhat indefinite term with its counterpart "Love" might suffice to characterise the active concrete nature of religious consciousness, and might fulfil all that was required for the halfmystical interpretation of the facts with which Hegel was then satisfied, they could not be regarded as sufficient when Hegel's interests became predominantly philosophical, where a principle not merely concrete but capable of systematic develop$\checkmark$ ment was called for. Hence we find him declaring that though "Love is a more appropriate, and a more comprehensible expression for God, yet Spirit 
is more profound." 1 This conception moreover, as Hegel gradually began to perceive, could alone enable him to reconcile the opposition of individual and universal in the various forms in which, as we have seen, he discovered them-in religion, in the state, in morality. This notion alone had in it the potentialities of a harmonious union of elements, a union which at once did justice to their differences and established their inner connexion. Spirit exhibited infinite diversity; it contained radical contradiction and opposition within itself; and yet it overcame by itself alone all its opposites, for it remained always their concrete organising unity. " Its reality therefore lay "deeper," was more fundamental than such notions as "life" and "love." And it lay, too, in the nature of Spirit (as was not the case with the previous obscure terms) that it was capable of explicit conceptual determination, of being used, in fact, as a self-developing philosophical principle. Hence Hegel's change of conception marks his transition from mysticism to systematic metaphysic.

But there was also a further reason for adopting this notion as his fundamental philosophical position. It emphasised the characteristic principle of modern philosophy, and, more particularly, put Hegel in line with his immediate philosophical predecessors. We saw that from Hegel's early Hellenism a reaction had set in towards the individualism and "subjectivity" of his own day, the all-consuming universalism of the former tendency leading him to emphasise its opposite, the value of the individual as . such. This value found its deepest expression in 
the notion of the freedom of spirit as spirit; and it was here Hegel joined issue with a tyrannous

$\rightarrow \quad$ universalism on behalf of the governing principle of modern life. It was at least as true to maintain that, for instance, the state existed for the individual,

+ as that the individual only had a meaning in the state. Moreover, the cardinal truth insisted upon by the Protestant form of the Christian religion was the supreme worth not merely of the life, but also of the judgment of the free spirit of every man. And this same principle, too, had been established in Hegel's own day as the source and origin of knowledge, and indeed of all experience. Kant had once for all made spirit, self-consciousness (which were for Hegel synonymous), the central reality of an intelligible universe; and with the whole movement inaugurated by Kant, and carried forward by Fichte and Schelling, Hegel had ever confessed his closest sympathy. With Fichte's conception and development of the new principle he must have been ${ }^{1}$ by this time thoroughly conversant and was doubtless influenced by it. And now that his friend Schelling, during this Frankfurt period, followed up his juvenile philosophical essays by a bold and masterly reconstruction of the same fundamental notion, it was for every reason natural that what had so long been a familiar truth and obvious certitude, should come to be regarded by Hegel as a dogma as indubitable as to be accepted without hesitation as an ultimate principle. Thus it was in a way inevitable that Hegel should begin his own constructive efforts by taking Spirit as the sufficient and unquestionable foundation of his system.

I No record of detailed influence is left us. 
With this early system as a whole we are not, of course, here concerned. We must, however, remark, in passing to consider the part with which we have to deal, that we cannot expect and do not find in it the comprehension and completeness of his later views. The scheme is tentative and obviously imperfect. The general point of view is the same in the earlier as in the latest system. He regards reality from the standpoint of the 'Absolute; his philosophy is the interpretation of the universe from the point of view of Supreme Reality. This attitude, as we saw, was primarily determined by his religious interest in the problems with which philosophy deals; for philosophy and religion have at least this in common, that they are concerned with the same Ultimate Reality. His philosophy, therefore, is "speculative" from the start. As in the later scheme also, this early system regards the Absolute as expressible in three fundamental forms or moments - the purely Ideal, Nature, and Spirit. But while these aspects are already distinguished, the manner of their connexion seems of less importance than their distinction. There is still observable also in this early scheme a tendency to drop into mystical or metaphorical expressions, in place of determinate notions. "Spirit," ${ }^{1}$ for example, is spoken of as the "infinite life"; and Nature is termed a "formal" life, one which is in itself, but not for itself.

It is important, further, to note that philosophy has not at this time the same value as a mental attitude which it has afterwards. Philosophy is not the highest form of experience, for religion is re-

1 Ros. p. 94. 
garded as the completest realisation of the Absolute. Philosophy moves in the sphere of reflexion, and reflexion, thought, requires for its activity an opposition-partly an opposition to what does not think, in part too an opposition between thought and what is thought about. ${ }^{1}$ Such opposition is not overcome in thought itself, but is essential to its operation. But in religion all opposition, all finitude, is overcome. What the mind seeks to attain and what thought cannot obtain is accomplished by religion; for in it the finite is a moment of, identifies itself with, the infinite life. Hence he maintained at this stage that "philosophy must leave off at religion." This distinction between the concrete realisation of the absolute attained in religion, and the abstract construction of it sought by philosophy, is a particular form of that distinction between ideal and real which we find appearing throughout this early scheme. Thus Hegel distinguishes ${ }^{2}$ in the construction of Absolute Spirit per se between the other of Spirit which is merely " ideal," and the other which is "real." Absolute Spirit is a self which reflects itself and finds itself in difference. As the knowledge of itself so reflected it is absolute self-knowledge. What it presents or represents to itself is an other; and this "other" is Nature. But this is not merely presented to Absolute Spirit, as an idea is to consciousness. The other is a "living" reality, the absolutely real other of living spirit. Hegel insists that this other, which exists for the simple abstract "Idea" of Absolute Spirit, is not the same as the other for "real" Absolute Spirit. The former is purely a

1 Ros. pp. 94-96.

2 ibid. pp. I I4-I I 5. 
"logical" other, the latter is a "real" other; the process in the one case is logical, in the second case metaphysical. Hegel, however, does no more than indicate the difference at this stage; yet in spite of its obvious obscurity he maintained that the difference was vital.

Such being his general position at this time we must now state in detail his view of Logic. ${ }^{1}$ And here at the outset we must steer clear of an error into which it is perhaps easy to fall, and from which Hegel's biographer seems hardly to have kept himself free-namely, that of regarding Hegel's earliest scheme of Logic as essentially identical with his final view of its problem and content. This is -certainly not the case. The mere fact that Hegel - distinguishes emphatically between Logic and Metaphysic would itself sufficiently make this evident. When we take note that he distinguishes between our knowledge of the Absolute Spirit and the. knowledge which that Spirit has of itself, and again is at pains, as we have seen, to distinguish the ideal presentation of the real from the real itself without exhibiting the inner involution of the one with the other, the difference is clearly very marked indeed between his early and later points of view. And thus it comes about, as we shall see presently, that what is the Idea of Absolute Spirit or the Absolute Spirit quâ Idea does not form part of Logic at all, but rather of Metaphysic. There can thus be only a distant resemblance between the Logic of this period and its later form.

Hegel distinguishes from the philosophy of Nature and philosophy of Spirit what he designates

I Ros. pp. $104 \mathrm{ff}$. 
"theoretical" philosophy. The point of the distinction, which is perhaps not happily named, seems plainly to be that whereas the two former discuss the relations and connexions of concrete real objects as they actually exist, the last treats of the formal abstract concepts as concepts of what exist, not as concepts, but as real. It would be inaccurate to describe it as a discussion on knowledge, for only one part of it is concerned with knowledge; and it is not simply ontology, nor again is it merely Logic; it comprehends all these parts of philosophy.

This theoretical philosophy he divides into Logic and Metaphysic. In the former he deals with the nature and formal character of being and of thought viewed abstractly and generally. The discussion of Logic falls therefore quite naturally into three parts- $(a)$ the determination of the general character of Being; $(b)$ of the general character of Thought per se; (c) of the method by which Being and Thought in their distinctness are related to each other. All these three are determined, and indeed arise, by our external reflexion; we abstract and fix in formal definiteness Being and Thought; not even $(c)$, therefore, is the reflexion of the thing by itself, it is our reflexion on the relation of $(a)$ and $(b)$. Hence since reflexion of any reality through itself and in itself is what knowledge means, and since this requires not reflexion upon the reality, but the reflexion by itself of the content of reality, Logic is not concerned with knowledge; the latter falls out of its province and is dealt with by Metaphysic. Metaphysic is, however, still formal and ideal, because dealing with the conceptual nature of 
that which reflects and relates itself to itself. ${ }^{1}$ "Logic, therefore," Hegel states, "ceases where ti:e relation $[(c)$ above indicated $]$ ceases." ${ }^{2}$ It is true he suggests as an alternative name for Metaphysic "Logic of Reason," distinguishing it thus from "Logic of Understanding." ${ }^{3}$ But such a terminology is quite loose and misleading; for Logic would then be the general name for the whole of theoretical philosophy. In that case the above statement that Logic ceases at the "relation" of Being and Thought and that Metaphysic succeeds to it would have no meaning, and would be unquestionably opposed to Hegel's general position at this time. Doubtless the term "Logic of reason" suggests a closer connexion between his earlier and later view than the term Metaphysic; none the less the term "Logic" is inaccurate and loose in this connexion.

Logic, then, in Hegel's present sense deals with the purely abstract and formal determinations and characterisations of Being and of Thought, taken each in the definite meaning usually belonging to them when regarded as distinct entities. This does not, as we shall immediately see, imply that Hegel conceived them to be fundamentally opposed; all that this division of the subject-matter of Logic means is, that these are the ultimate genera of what is determinable by external reflexion. The discussion in both cases does not confine itself to a single statement or catalogue of the determinations of each; there is a strenuous endeavour to unite by some inner connexion these various qualifications. And this last feature marks Hegel's plan
1 See below.
2 Ros. p. IIO.
ibid. p. 104. 
and method of thinking all along; it is system and systematic connectedness which is his dominant tendance. Not that he is at first clear as to how this connexion is to be obtained, or what is its essential method; all we can claim is that it was an unhesitating presupposition that such connexion must be found, and that he endeavoured in some measure to realise it from the first.

I. The discussion of Being (the real) deals with its categories, which fall into two groups - those which determine Being taken by itself, and those which determine its relations. In the first group we have at the outset Quality; this is the most immediate determination of Being. Quality gives rise to Quantity by virtue of the indeterminateness of its character, which essentially implies limitation; for quality is limitation. Quantity again possesses as its forms the numerical one, numerical plurality, and numerical allness. If, further, we combine the concepts of Quality and Quantity, we shall find that they are constitutive elements of Infinity. For this last is the negation of one quality through another, or of one quantity through another, or of a quality through a change in its quantity or degree. From consideration of these we get two kinds of infinity, that which is the result of a quantitative determination of a quality, and that which results merely from the passing of one definite quantity into another. In this we already find determined the "true" and the "false" infinity.

Without further elaboration Hegel passes to the second group of categories-those, namely, of the relations of Being. These are Substantiality, Causality, and Reciprocity. His conception and analysis of 
these were at this stage, for the most part; the same as what we find in the later forms of "his system. We observe, too, that here, as later, Reciprocity is the category which leads the way to the Notion, or concept as such (Begriff); and since Hegel at this stage takes the concept to be the absolute form of thought, Reciprocity forms the stepping-stone on which we pass from the discussion of Being to that of Thought.

The elucidation of this connexion between the two is perhaps the most substantial and permanent contribution of this early Logic to his later system ; and that he should have made that connexion clear to himself thus early in his development throws considerable light on his general purpose. For it indicates that his idea of system demanded from the first that there should be an inner and necessary relation amongst the determinations of reality, that there should be no gaps whatever separating one constituent element from another, that not even the established distinction between Thought and Being, which ran through modern philosophy and had its roots in the two-substance doctrine of Descartes, could be allowed to stand before a critical analysis of their essential relation. By insisting at the outset on this fundamental unity, Hegel, as we see, is already within sight of the necessary connexion of "substance" with "subject."

IIt was under the guidance of such an idea, therefore, that Hegel proceeded to establish a relation between Reciprocity, or the "paralytic infinity" as he then called it, and the Notion, the absolute self-mediating unity of universal particular and individual. But the attempt to exhibit this 
relation brings out quite clearly the point of view which determined even from the start his whole conception of the content and purpose of Logic. According to this Mind and Object, Thought and

- Being were elements in one total Reality; they existed together side by side, and were forms of - the one comprehensive Reality. The business of Logic (the abstract formal science) was simply to - state the abstract content of this one Reality without limitation of that content to the one element in the whole rather than the other. But just the exposition of this content marks off Logic in Hegel's sense from Logic as ordinarily treated. The latter is "formal"; it deals with Thought only and in -opposition to Being. Hegel's includes both Thought and Being. As contrasted therefore with "formal Logic" in its usual traditional signification, Hegel's Logic deals from the first with what is constitutive of all reality ; it is "Transcendental Logic."

In passing from this discussion of Being to that of Thought, we may merely note the very close similarity there is between these categories of being as given by Hegel and the "table of categories" in the first part of Kant's "Transcendental Logic." In view of his opinion" that the possibility of the "completion of science" was opened up by Kant's system, and would be realised by following out the principle it contained, such a resemblance might perhaps have been expected. As in Kant we hav Quantity, Quality, Relation, so here we have Qualiiy, Quantity, Relation. Modality Hegel omits partly because it is clearly not a category of Being in his sense, and partly for a reason which will pres ently

${ }^{1}$ Leben, pp. $69 \mathrm{f}$. 
appear. But whereas for Kant the order in which the categories were stated was immaterial, seeing that his purpose in the "table" was merely to make a list, a catalogue, and to make it complete, for Hegel the order is of the first importance. For his aim is not simply to state all the categories, but to state them in systematic connectedness with one another; and for this purpose it is obviously essential that he should determine with which to begin. Hence Hegel starts with Quality, and that apparently for two reasons- $(a)$ because Quality is the lowest most elementary determination of Being we can find, and $(b)$ in order that he might connect Quality and Quantity. To establish which should be prior could not have caused great difficulty, because the impossibility of getting Quality out of Quantity was a fairly obvious philosophical commonplace, and nothing was therefore left but to unite them by starting from the side of Quality.

We cannot, however, lay much stress on the similarity between the two schemes of categories, pronounced and unquestionable though that similarity is. Hegel's dependence on his predecessors, which might be apparent in his terminology, is never close ; and we find in this case, when he seems to borrow from Kant, a divergence which must not be overlooked. For Hegel does not mean by Quality, for example, what Kant included under that term; indeed we might say that Quality in Hegel's sense was not a category at all for Kant. With the latter, "Quality" is a general name for certain categories; for Hegel it is in itself an abstract determination of Being. But we cannot pursue further the connexion in detail between them. 
II. The connexion between Reciprocity and the concept or Notion (Begriff) having been indicated, we have now to learn what the essential character of the concept itself is. It is, in the first instance, determinable from its relation to Reciprocity. Substance as the universal differentiates itself, and is not merely differentiated (is not merely passively recipient); it therefore owns the opposites as its particulars, but relates them to itself, and distinguishes itself therefore from them, thereby constituting itself subject of them, ideally (immanently) containing them, and not merely the substrata in which they "inhere." But in so uniting its differences in itself, distinguishing itself from them and yet relating them to itself, it is not a mere universal, nor a mere medley of differences; it is a self-relating individual. And these three are the "moments" of the concept or the "notion." They are not external to reflexion, they are themselves realised in our reflexion, and accepted by it, as its own moments. Our reflexion is their actual reflexion; it is the relation which they themselves possess with one another.

The point of this reference to "reflexion" becomes obvious when we bear in mind the content of the Logic. The categories of Being form one part of the Logic, and in them we have the abstract moments of Being as these are determined by (external) reflexion upon it; they are its reflected moments. In the Notion we have content of mind proper; our mind is the reality in question. The reflexion of its (the notion's) moments is the reflexion of our mind, of Thought proper. Our reflexion is one and the same with the reflexion of the 
moments of the Notion. In the categories of Being, therefore, we have the reflexion of Being as it is; in the moments of the Notion, the reflexion of our Thought as it is, "our reflexion." Thought and Being, however, are not absolutely severed, for the Notion is the "ideal reflexion of Being." But what this further means, and how the "reflexion" in the one case is related to "reflexion" in the other, Hegel does not here indicate.

The Notion further appears as determinate, i.e. convertibly as universal, particular and individual. It appears also as Judgment, and finally as Syllogism. In the form of Judgment Hegel considered two cases, one where the subject is subsumed under the predicate, the other where the predicate is subsumed under the subject; in the former case the predicate is first posited, in the latter the subject. He sought to convert the purely negative character of the predicate in the infinite judgment into a positive character, to consider the negation of being as the denial of a potentially necessary predicate. For this reason he did not mention Modality as a qualification of judgment $;^{1}$ the assumption being apparently that where, as in this case, all judgments become necessary, Modality ceases to apply to them. Syllogism likewise took two forms-a relation of opposed predicates inside a subject which holds their determinations ideally in itself, and a relation of two opposed subjects identified and united inside the reality of the predicates. This distinction gave him the hypothetical and inductive syllogisms.

These various determinations of the concept were not treated by Hegel at great length, and the barest

$$
1 \text { Leben, p. rog. }
$$


outline of his meaning is the most that is indicated. We are simply left to conclude that these moments of the concept have significance for Thought, i.e. hold of Thought specifically.

III. From this Hegel proceeds to deal with the last part of Logic, under the head of "Proportion." This may be regarded as simply an analysis of the method or procedure of Thought. Hegel seeks to establish an "equality" between the universal and the individual, and this by three methods-Definition, Division, and Proof. The first determines a given subject by reference to and in terms of its universal, the second by presenting the differences which the subject in its universality can contain and in which that subject can particularise itself. So far the "proportion" is determined solely by means of our reflexion, our "dialectical" treatment of it. In the case of proof, however, the reflexion is by and through the reality itself; the reality "reflects itself"; it is the actual unity of the universal, particular and individual, and proof just consists in this totality indicating itself through itself. This thorough-going self-mediation can be named "construction," and, from another point of view, that namely of the complete "equality" of the reflexion with itself, "deduction." In connexion with this part of the Logic it is for our purpose necessary to note the identification of the process in "proof" with the process of the real, which, as it were, proves itself. This has clearly a suggestion of the later attempts to determine the character of the real for and in itself, of the Idea as such. To this, however, we shall recur immediately.

With the discussion of Proportion, Logic proper 
ends. What we have there is a somewhat systematic statement of the formal abstract determinations of Reality furnished by reflexion. According to Hegel's view at this time the content of the Logic is not self-mediated, but determined by reflexion from without. It is our reflective activity which constructs the Logic. When therefore an "equality" or union is established between the form of reflexion and the content, when these are indicated through each other, when the content reflects itself and furnishes its own determinations, we leave the sphere where formal conceptions stand in various relations to each other, where, because in relation, these conceptions have a distinctness from each other. The sphere to which we pass is named "Knowledge" (which is the "equality" of reflexion with content). But it is to be noted that the content in question is metaphysical absolute content, and the knowledge is "absolute" knowledge. Hence the name given by Hegel to this sphere is Metaphysic. What he proposes to do, in fact, in Metaphysic is to discuss Absolute Reality abstractly, in its formal but self-determining moments; and since this self-determination is only possible through its content, which is itself, the process of reflexion must implicate the absolute content. We have, in short, "absolute" knowledge, the formal moments and process of "Absolute Spirit."

This knowledge comprehends (I) a System of Principles which form a complete sphere in themselves ; (2) Objectivity; (3) Subjectivity. The first contains the discussion of the principles of Identity, Contradiction, Excluded Middle, and 
Ground and Consequent. Hegel's characteristic conceptions of these principles are already formulated and expressed in this early treatment of them. In particular we find him insisting on the necessity - of contradiction as an element or factor in a concrete identity, which develops and thereby differentiates itself into opposites. His mastery of this fundamental principle at the outset of his philosophical career is significant. His discussion of the second feature (Objectivity) is in itself somewhat strained and unfruitful, though, as an indication of his present attitude, suggestive. By Objectivity he understands the Soul (or "Monad"), the World, and the Supreme Being. These are connected with one another, demand each other. Objectivity is self-sufficient, self-determining reality. This qualification is fulfilled by a self-conserving individuality ; the primary form of Objectivity, therefore, is the monad-soul, or simply the monad. Monads differ, and various individual souls are subsumed under one monad genus as their ground. Thus we get a variety of generic monads, or monad-genera. The totality of these genera make up the world. But as such the world is a mere aggregate; this aggregate, however, has its unity and its ground in the Supreme Being, which contains all differences and is the creative principle of the various monad-genera. The Supreme Being is the genus of the genera. But so conceived, and as such, it is simply the abstract universal for which the various individual genera exist, and over against which they are placed. Consequently a completer, more inner relation between this universal and its elements is found when it determines them as its own moments, 
posits itself as universal in their individuality, raises itself, in short, to self-conscious Subjectivity. Here alone have we that which is Ideality without qualification. Only when the Supreme Being is an Ego can all the endless multiplicity of its content become transparently recognised as its own. But, again, the Ego is theoretical and is practical. In both these cases, however, the subjectivity is not absolutely self-sufficient, for in both cases we have a limit which is not its own; in the former case in what is given to be known, in the latter in what is demanded as that which should be objective. Absolute Subjectivity must therefore be distinct from both of these; it must unite both and be absolutely at one with itself, absolute form and subjectivity and absolute content at once, in which knowledge is eternal without any beyond, its concept immediately realising itself, its reality possessing ideal existence in itself. Such is the idea of Absolute Spirit, of the Absolute Reality. But even when Hegel has so determined this Supreme Being, the double reference which we have noticed in Hegel's present attitude asserts itself here too. For in reference to the formal character of Absolute Spirit, he points out that while Absolute Spirit relates itself to itself and so makes of itself an "other," this relation is one thing to Absolute Spirit, another thing to us. For Absolute Spirit it is that which is in-finite, that which is not, and is not determined as, a limit. For us, on the other hand, i.e. for spirit which is in process of realising itself, that relation is an other to spirit; we take it in its otherness; it is set over against, and thus as limiting, Absolute Spirit. 
This earliest scheme of Logic will be seen on examination to contain at least the germ of his later and final Logic./1t indicates, to begin with, the point of view from which he regarded the problem of Logic, and the function he assigned to it in a system of philosophy. For Hegel philosophy has not to commence with a criticism of "the nature and limits of knowledge." Here at the very start he parts company with Kant. What philosophy has to do is to determine in and by thought the essential nature of Reality, absolute and finite. Acting on the principle which he later described as learning to swim by entering the water, Hegel at once assumes that the knowledge philosophy professes to furnish is possible, is not to be sought or justified by a preliminary inquiry, but has simply to be expounded and exhibited. This was in the first instance due to the fact that Hegel started from a conception or principle (that of Spirit) by which reality was to be explained and interpreted, a conception which, as we saw, agreed with the needs of religion and the general conclusions of the philosophy of his time. . What he had to do, therefore, was to make clear the content and implications of this principle. But in the second place it was also due to the absence of any question regarding the relation of thought to reality (being). Whether thought is able to know, or how far it can know being at all, is a problem which from the start he never seems to have considered, at any rate never discussed at length. These primâ facie separated elements of experience seem never to have been dealt with or regarded by Hegel as if they were absolutely removed by "the whole diameter of being" from each other. It was 
always as elements, factors, contents, in one total Reality, that he considered them. This made it both possible and necessary for him to start from the whole as a whole, as a unity, and thence deal with those ultimate elements simply as different contents inside this one whole. There was therefore no initial problem regarding knowledge, whether philosophical or of any other sort. The only problem was to state in some system the content of this whole.

Now the universal conceptions, the thought-forms constituting Reality, furnished the matter for a science which had been dealt with to some extent by all Hegel's active and prominent contemporaries-the science of Transcendental Logic. There was every reason, therefore, why Hegel, who, for reasons indicated, adopted the principle common to all these thinkers, and characteristic of the philosophy of his time, should also, in presenting his views systematically, have found it necessary to state the fundamental conceptions of reality; in other words, to make Transcendental Logic a necessary part of his system. And because for him there is no abrupt opposition between the two ultimate elements in Reality, thought and being, the Logic contains the formal contents of both, not of the latter only. These elements are from the start members of a whole; are, as such, on the same level; Transcendental Logic, therefore, concerns itself with both, each furnishes content to the Logic. The Logic is thus the exhaustive statement of the formal determining conceptions of his one principle. And this general position on which his Logic is framed, and from which it proceeds, remains virtually the same throughout all the history of his Logic. It is 
the vital principle in all its forms, the common germ from which they all spring.

The Logic, then, is from the first transcendental. So far Hegel comes at once into line with his immediate predecessors. On the other hand, in dispensing with a preliminary criticism of knowledge, he took the side of Fichte and Schelling against Kant. Hegel in all this must be considered, if not the follower, at any rate the independent and confessed ${ }^{1}$ pupil of Fichte and Schelling. But the discipleship seems never, even at this early stage, to have gone beyond the acceptance of the general position adopted, defended, and expounded by them. He was, in fact, too much bound over to Kant, their common master, to be simply a follower of Fichte or Schelling; and, on the other hand, too sympathetic towards, and convinced of the value of the position insisted on by, Fichte and Schelling to make it possible for him to attach himself exclusively to Kant. In short, he preserved that sympathetic independence which is ever the privilege and the necessity of the thinker. Thus we find that the Logic of Hegel markedly differs from that of all these prominent contemporaries; from the start it diverges into a path distinctively its own.

At the time the above Logic was put into shape (between I 784 and I800) Hegel must have been acquainted with the most important works of Fichte which had appeared up to at least I 796-97; and we have distinct evidence that he had carefully studied the Wissenschaftslehre of I 794 as well as the Kritik aller Offenbarung. ${ }^{2} \quad$ Yet there is hardly a trace of

2 v. Second and Third letters to Schelling, Briefe, i. Io-17. 
influence in the details of Hegel's Logic of the peculiar construction of the principle which Fichte expounded in the Wissenschaftslehre; and this in spite of the community of principle between Fichte and Hegel. Even if, then, as is most probable, Hegel regarded the Wissenschaftslehre as a form of Transcendental Logic, we still find Hegel constructing a Logic without direct help either as to content or method from Fichte. ${ }^{\prime} \quad$ Again, Hegel must also have become familiar with ${ }^{2}$ the earlier Fichteanised views of Schelling, as these are contained in Schelling's first philosophical writings-Ueber die Möglichkeit und Form einer Philosophie iiberhaupt and Vom Ich als Princip, etc. (both I795); and Philosophische Briefe über Dogmatismus und Kriticismus (I796). Probably not much detailed help could be found in these works for his Logic, as they did not themselves present a system. In any case they did no more than help Hegel towards an understanding of his fundamental principle; they could hardly determine the course of his Logic. Even Schelling's Philosophy of Nature, we may note in passing, which appeared

1 It is remarkable that the influence of the Wissenschaftslehre on Hegel should have been so slight. We find no trace of an analysis, similar to Fichte's, of the categories of Limitation, Negation, and especially Reality, to which Fichte attached such importance. We should naturally have expected such a discussion as Fichte's to have influenced at least the content of Hegel's Logic. The divergence, again, of Hegel's metaphysic from Fichte's position hardly requires to be mentioned; the difference is too striking to be overlooked. Finally, Fichte's method of deducing or reducing all the content of the Wissenschaftslehre at every step from the pure notion of the Ego finds no acceptance whatever with Hegel. Fichte starts from the reality of the Ego; Hegel from its abstract content. Fichte descends from the Ego; Hegel, if anything, ascends to it. Fichte begins with the highest notion; Hegel with the lowest. And this contrast is of vital importance all along. Perhaps Hegel was acquainted with Kant's public repudiation of Fichte's views in I 799 .

${ }^{2}$ v. Briefe, i. Io ff. 
in I 799, bears little or no resemblance to the content of Hegel's Philosophy of Nature, belonging to this time, so far at least as we can gather from the extracts from it given in the biography. It is possible, however, that Schelling's work may have appeared later than the time at which Hegel's sketch was framed.

Finally, close as is the resemblance, as we have already noted, between Kant's Transcendental Logic and Hegel's early Logic, the differences are too striking to be ignored or to be considered differences of detail. For, indeed, the initial position of Hegel (that philosophy is concerned with the whole, that the opposed elements in this whole are factors in one unity, not radical opposites) distinguishes completely the presupposition of Hegel's Logic from that of Kant's, so completely in fact that "transcendental" a priori hardly means quite the same to Kant and Hegel. For Kant "transcendental" means primarily subject-constituted; it applies to that which the subject (thought, understanding) must have in order that the object may be constituted necessarily, if it is to be possible object of knowledge. It is for the sake of objects that the conception must be transcendental. The essential meaning of the idea of "transcendental" turns for Kant on that initial distinction between thought and thing, subject and object, from the conception of which indeed his whole view starts, and which to the end remains vital for it. Hegel, following Fichte and Schelling, seizes upon the kernel of Kant's theory-the synthetic a priori conceptions , and their "deduction"-emphasises solely their constitutive function and character, plants himself 
on the basis of Kant's whole structure (self-consciousness in its unity), and, casting aside Kant's 'presuppositions, deepens but at the same time transforms the notions which are merely subjectivelytranscendental into notions which are objectivelytranscendental, which are absolutely constitutive, the ground-plan of all reality. Hegel starts from Kant's principle, but avoids his conclusions by refusing to recognise or be influenced by the presuppositions from which Kant started. Hence . it is that for Hegel thought as well as being has also its fundamental "transcendental" conceptions, and these as well as those of being fall inside the Logic. Thus it is that while the categories of being in Hegel's Logic show close resemblance to Kant, the treatment of the notion which forms the " second part of Hegel's Logic above has no analogue at all in Kant, and by the nature of his view could not have. That Hegel should have taken this step so early in his career is extremely significant, and that his Logic should, in spite of divergence from Kant, have held so closely by him as against Fichte or Schelling, indicates very decidedly his historical affinities.

But it must not be supposed that Hegel fully appreciated at this time the significance and importance of Transcendental Logic. The Logic is not a complete exposition of ultimate conceptions. ${ }^{1}$ The conceptions, again, are not exhibited as determinations of his single principle; they are not shown to be moments of Spirit, self-consciousness.

1 It is noteworthy that only the most general categories are dealt withQuality, Quantity, etc. The specific determinations or forms of the categories, e.g. Becoming, Limit, Negation, or Measure, etc., are not mentioned at all. 
, They are assumed to be, and are accepted as, such moments; but how or why is not established. 'In this respect his early Logic does not profess the same thoroughness as Fichte's Wissenschaftslehre. And again it seems that on the whole the Logic is a subordinate preliminary discussion in his present scheme. His main interest, and the important part of "theoretical philosophy," seems to lie in "Metaphysic." It is here that content " reflects itself"; it is here that the Idea is found of which Nature is the "other." His idealism at this period is not at all logical idealism, but rather metaphysical idealism. His principle simply as a concrete fact contains in his concreteness all reality. The treatment of the universal notions of reality seem to occupy a secondary place in the scheme.

And when we pass from such general considerations to take the "theoretical philosophy" in detail, its tentative provisional character becomes apparent.

To begin with, the distinction of Logic from Metaphysic arises from his adherence to tradition. But since Hegel had as yet done little more than named the principle of Reality, and viewed Absolute Reality as such in the light of it without determining completely the nature of that principle itself, such a distinction was perhaps also inevitable on his scheme.

The division, again, of Logic into a discussion of the formal aspects of Being and of Thought (thinking, Denken), shows also in some respects a close , adherence to tradition. Being is not taken in his later sense; it is not in this early view a category at all, rather it has categories. And perhaps it is 
the general use of the term "being " which makes it unnecessary for him to have what afterwards appears as the discussion of essence. The qualifications ascribed to Being are, as we noted, taken directly from Kant. Hegel seems to have been at no pains closely to criticise them. A possible increase to their number does not seem to have occurred to him. The only modifications he introduces are primarily due to the need of systematising them, to weaving them into one texture. Such systematisation, in fact, is the sole contribution of Hegel to the discussion of the categories, and seems to have been his main interest in dealing with them. It is this also which induced him to connect the determinations of Being as such with those of Thinking. In this way Being and Thought, as originally ' separated, are viewed as merely distinguished inside reality; both are forms of reality; hence the possibility of an inner connexion between their qualifications. As in the case of being, so in that of Thinking, the determinations related by Hegel are those currently attributed to it; no extension or examination of them is offered.

The doctrine of "Proportion," while in itself somewhat arbitrary and artificial, is so far of importance for us in that it contains Hegel's earliest attempts to make Logic "objective." In it Hegel seeks to leave the subjective as such (thinking), and to state those formal determinations which the real posits , for itself, and which are not simply attributed to it by external reflexion. This is particularly seen in his interpretation of "proof." Indeed it is difficult to see why, except on the general view above stated

1 In his final sense. 
that Logic contains simply the formal character of the real and is constructed by means of "external" reflexion, "proof" should not have been included under metaphysic. Hegel has not yet identified the mode of procedure, the forms of relation, which hold inside the real, with the reality. Form and content of the real are kept in some way distinct. Hence under the doctrine of Proportion he merely gives the formal character of proof as such, as a mode of procedure.

1 It is only in the Metaphysic that we become acquainted with the content of the real. And here, almost without exception, Hegel has simply adopted the results of his predecessors, and has merely connected them in a manner and for a purpose of his own. The first part, the System of Ground-Principles of the real, contains merely those principles which philosophy up to Hegel's day had shown to be necessary to experience. They are, however, interpreted and expressed in the characteristically Hegelian manner ; they are viewed not as principles necessary solely ' to knowledge of the real, but principles in and of 'the real itself; they are not simply forms of reality, they are reality itself. It is this conception of them, in fact, which seems to justify their place in his Metaphysic; and this is significant for his whole attitude, which on this point at any rate he never , changed. It is, for example, the content of the real which makes contradiction possible, as well as the solution of contradiction. Mere inconsistency of concepts in itself means nothing, for these concepts

' can only contradict if they possess content, and the contradiction they can exhibit is in virtue of that content. Contradiction, therefore, is the essence 
of the real. These principles, however, are not connected in any way with the other parts of his Metaphysic; they are treated as elements of the real, and nothing further is stated of them.

The second part, again, begins quite abruptly with the fundamental nature of the real. This part does little more than repeat the Leibnitz-Wolffian meta- , physical conception of the real, and the difference between it and his later view of "objectivity" is too glaring to need comment. The real is divided in the usual way into the Self, the World, and God, and a monadistic interpretation of reality is given. That Hegel should have accepted without extensive inquiry the monadistic scheme of the world, indicates the uncritical character of his idealism, and of his conception of Spirit at this period.

Yet a view which, like Hegel's, regarded Spirit as the principle of Reality could hardly have done otherwise without a more thorough-going interpretation of Spirit. As we indicated, all he was concerned about in the first instance was to hold his conception of ultimate Reality. He had accepted the view that the selfhood of Spirit is the primary reality, that Absolute Reality was Spirit, and the natural form which such a conception at first could take would be that all reality is spirits; difference in reality meaning plurality of spirits. His idealism at this stage was monadistic idealism; reality is thinking beings, not, as later, reality is thought (logical idealism). That he should have advanced from one to the other is significant for the interpretation of his scheme, and indicates the line of his development. This view of Spirit which he adopted, and this conception of reality as thereby determined, 
accounts for his early view that Logic and Metaphysic are both necessary but distinct parts of philosophy. Hence too it is evident, not only that they are not systematically connected, but that on such a view they do not require to be connected.

It is to be noted that there seems little connexion between his view of the "world" as given in the Metaphysic, and his view of Nature in the Philosophy of Nature. In the latter, Nature is the determination of Spirit, Spirit in itself but not for itself; in the former the "world" is the totality of monad-genera. These views are perhaps compatible, but their agreement is at least not obvious.

Again, in regard to the conception of Absolute Spirit, this early view shows a striking and significant difference from the later. This early conception of the Supreme Reality was Deistic. All reality is not Absolute Reality; nor again are all finite realities "moments" of the one Absolute Reality. Absolute

' Spirit is one reality among other realities; it is the supreme monad-genus. But it is distinct and even separate from the others; for it alone is the absolute union of objectivity with subjectivity. Such a conception was perhaps natural enough on Hegel's early view of Spirit. This conception is a metaphysical idea; but while in some external respects it resembles the determination given to the Absolute Idea, it cannot be at all identified with it. $\mathrm{He}$ is , careful also to point out that this metaphysical idea of the Supreme Reality is only idea, is not the Reality itself-a difference on which we have already commented.

The transmutation of this metaphysical idea into the logical, and the removal of the distinction 
between the metaphysical determination of the Supreme Reality and the formal determination of this Reality in all its completeness, we have to trace in his further development.

It only remains to conclude our discussion of this part by pointing out the unsatisfactoriness of this early attempt to frame a scheme of Logic. Its fragmentary character, its incompleteness, the imperfection of its systematic form, its lack of thorough critical analysis, the ambiguous insistence on the distinction between form and content, thought and the real, a distinction which at one time seems abrupt, at another hardly seems discoverable, the vagueness and indefiniteness in statement, ${ }^{1}$ the merely relative independence of his point of view, and even of his treatment,-all this is quite manifest from the foregoing. He can hardly be said, in fact, to have fully realised as yet the nature of the problem he had undertaken, or the kind of solution which would satisfy those needs on behalf of which he had turned to philosophy. His conception of his problem seems to have been limited and narrowed by his close adherence to the results and views of his predecessors in the field-views which he had accepted perhaps too readily, and which he had not yet fully determined for himself.

Of one thing he seems to have been assured - the necessity for thorough-going system in philosophy, and this, with however limited success, he certainly strove to attain. ${ }^{2}$ That such a demand

1 This is to be traced not merely to immaturity, but to that tendency towards mysticism which we find throughout this early period.

2 The conception of organism, organic unity, which is the basis of Hegel's idea of system, was early realised by him. It is especially emphasised at this period in the sphere of Ethics; v. Leben, pp. $124 \mathrm{ff}$. 
was inevitable on his view of the object and purpose of philosophy is obvious enough. And he seems to have worked parts of his scheme into as systematic a form as they could well admit, e.g. the treatment of substantiality, causality, and reciprocity. On the other hand, it is just as evident that certain parts of his early scheme are not systematically connected, and bear no resemblance, except perhaps in name, to his later results. This incompleteness of system seems due partly to his uncritical adoption and use of terms, but mainly to the absence of any definite method of attaining system. In one or two cases the relation of part with part seems to have that inner necessity of connexion which we find in his later scheme. At another time, however, it is the mere arbitrariness of the thinker who is resolved to be systematic at all costs that brings the elements together. There is about the procedure as a whole an externality and artificiality which makes any result attained by it extremely questionable. One part is connected with another, not because it leads us inevitably to it, not because it is organically connected with it, but because being a part of reality it must stand in relation somehow with other parts. Thus the parts really remain distinct after they are connected; no one is taken as embracing another in itself and containing its "truth." The idea of development which, as we shall find, is essential to Hegel's true method, and the discovery of which marks one of the stages in his history, has not yet dawned upon him. It might, perhaps, at first seem that in the metaphysic there is some attempt to connect Objectivity with Subjectivity by the necessary transition of one to the other which contains it ; but 
this is only possible by construing the connexion by a method only found in his later scheme. In this part of his early system, which is indeed the obscurest part of all, we are no more justified from the statements of the biography in finding any sort of dialectical development at work, than we are (as has been maintained ${ }^{1}$ by one writer,) in finding there Hegel's first attempt to incorporate into the process of his own system the systems of thought which historically preceded him. All this is of later origin, and finds no warrant from the data left us. It is true, indeed, he uses the term "dialectic" to indicate the process of negating, limiting, and defining notions; but as so used it is not a technical term at this period; it has simply the significance which a term current in the school of Kant and of Fichte might have for one who, like Hegel, was in close sympathy with the philosophical movement which they had directed.

The only suggestion of a method to be found in this early scheme is in the idea of "reflexion" which has met us repeatedly in the preceding exposition. But this is in itself so obscure, and its use so confused, that it is hardly possible to state even its significance. There seem as many forms of reflexion as there are objects to be

1 Haym, Hegel $u$. scine Zeit, pp. $106 \mathrm{ff}$. There seems little doubt that the contention of this brilliant critic that Hegel was already in this period fully conscious of the dialectic method, and had made use of it in his early scheme, cannot be maintained. (I) There are no recorded facts or statements to bear it out. (2) Such connexions as are established, e.g. between quantity and quality, do not imply that this was due to a conscious method. (3) The connexion between "Idea" and "Nature" can be explained by bearing in mind Hegel's religious and mystical tendency. (4) It would be remarkable if so important a fact as this method should not have been even mentioned by Hegel and yet employed by him. (5) It is unlikely that a beginner should so early be a master. 
reflected upon. The term is used for the process of philosophy as a whole; it is applied to the content of Logic where we have both "external" reflexion, "our" reflexion, and the "ideal" reflexion found in the notion; while again the term "selfreflexion" is used for procedure in Metaphysic. What is the precise meaning of the various forms of reflexion is not made evident, still less their relation to each other. ${ }^{1}$ We are compelled, therefore, to conclude that there is no single method to be found in this early system : a fact which undoubtedly in large measure accounts for the heterogeneous and incomplete form of the scheme.

All these obscurities, however, are perhaps inevitable in an early scheme which is at best hardly more than tentative, and too much cannot be expected from it. They indicate, however, the course he must pursue if his thought is to become clear in form and complete in content.

1 We shall find a modified form of the same difficulty here mentioned even in the second period of his development. In fact it is not till after the inquiry of the Phenomenology that this difficulty regarding the nature of reflexion in philosophy is removed. 


\section{CHAPTER III}

\section{SECOND STAGE-FROM I 80 I TO I 807}

The deficiencies and uncritical assumptions of his earliest view we should expect to be gradually removed in the course of Hegel's development. And this is what to some extent is found in the next period, to which we now pass. The more prominent defects are removed in the first instance. The difficulties and ambiguities underlying the distinction of Being (Seyn) and Thought (Begriff) are met, and a definite interpretation is arrived at regarding the nature and relation of these two notions. The distinction of form and content as previously understood, and used as the basis of the separation of logic from metaphysic, is dropped; and while the distinction itself is still in a sense maintained, we shall find that it is determined in another way. The discussion, therefore, of Logic and Metaphysic on this new view is in decided contrast to the earlier. With this change the tentative and uncritical adoption of the results, both in metaphysic and in logic, of preceding thinkers, to which we referred, vanishes. The breaking down of the abrupt distinction of content from form leads likewise to an assimilation of Logic to Metaphysic; the latter becomes more "formal," the former more 
concrete. The incompleteness in systematic connexion between the parts of philosophy, as also between the various elements which make up these parts, is in a measure removed, not so much by the adoption of a philosophical method as by determining more definitely his philosophical principle. A method in the strict sense he has not yet obtained. How far completeness of system could have been realised by means of this principle we cannot decide, as no detailed scheme similar to that found in his early view is presented in this period. What we have at this stage is rather the analysis of terms and principles. We shall find, therefore, greater precision and definiteness in his conceptions, which come from a reconsideration and examination of ideas and facts hitherto simply accepted and assumed. We thus have before us the elements and fundamental principles of a system rather than an actual connected scheme.

The material at our disposal for this period will only enable us to determine Hegel's general attitude and the main influences which dominate his thinking. The period is one of criticism. Hegel becomes conscious of his philosophical position and master of his terms. But still the principles adopted at this time are not worked out, and some of his positions are in his later treatment modified or even abandoned. We might, perhaps, expect that Hegel in such a period of criticism would systematically establish and defend the position he actually adopts; but this is not the case. True to his characteristic manner of exposition he works from the principle adopted as ultimate, and we are left simply to state what this is without being informed as to why or 
how he came to adopt it. Hence to bring out Hegel's view of Logic at this stage of its development, our only plan is first of all to indicate his general philosophical position, and then state the place and meaning assigned to Logic.

The period we are considering falls between I 801 and I 807, between the departure of Hegel from Frankfurt for Jena and the publication of the Phänomenologie. Hegel was drawn to Jena in the first place because he felt that his apprenticeship was ended, and that he was capable of sharing, what also his further development demanded, the larger intellectual life of a university; and in the second place because Schelling, with whom he had for years kept up friendly correspondence, and with whose work and thinking he was thoroughly familiar, was teaching at Jena and advised his going thither, the university being at that time the literary and philosophical centre of Germany.

Such a step meant much intellectually as well as practically for Hegel. The hitherto dominant interest in religion pure and simple soon becomes almost wholly supplanted by his interest in philosophy; the religious view of the world gives place to a purely philosophical interpretation of it; the indeterminate concepts of religious thinking are exchanged for the accuracy, definiteness, and explicitness of systematic thought. And with this entire abandonment to philosophy comes a corresponding revulsion from the vague mysticism in which he had hitherto sought light and satisfaction. Mysticism he now ${ }^{1}$ characterises as a pictorial imaginative medium for the expression of the Idea 
or the Absolute; it is neither feeling nor science, but a trübes Mittelding between both; it is a "speculative feeling," or again it is the Idea bound by fantasy and emotion. He describes it roundly as a "splendid rhetoric," which itself confesses the impotence of the medium through which it seeks to express the essence of Reality. He will have this essence brought into definiteness, and that solely through the "clear element" of thought, through the medium of determinate conception; for the "clear element" is the universal, the concept, the notion (Begriff).

The all-importance of the purely philosophical interpretation of Reality does not, however, imply the entire absence of that religious "attitude" which we saw to be the source and characteristic form of his interest in philosophy. This appears not merely from the fact that philosophy is to him a "speculative science," whose object is absolute Reality as such, but also from the nature of the supreme principle of Reality which he adopts, and from the place assigned to religion in his philosophy. He still holds Spirit to be the principle of Reality, ${ }^{1}$ and in one sketch of philosophy he makes religion the final and highest moment of it. ${ }^{2}$ The change of attitude may perhaps be best described by saying that whereas formerly he had a religious interest in the object of philosophy, he has now a purely philosophical interest in the object of religion, the object in both cases being ultimately the same.

It is impossible to appreciate the position he adopts on certain points (more especially the place
I Werke, i. 196 (1845); Leben, p. 188.
2 Leben, p. 179. 
assigned to Mind or Spirit), or to connect the view of the present period both with what succeeds or with what preceded it, unless we keep in mind that all along the Absolute for Hegel is Spirit. Ultimate Reality seems never to have meant anything else for him. We have already indicated the origin of this position which Hegel consistently holds from first to last, and we need not insist further on its significance.

The problem of philosophy as a speculative science is to determine the ultimate Reality, and to interpret finite reality in the light of it. It is not one reality among other realities; if so, it would be a finite reality; it is rather the ground Reality of all realities. Hegel had therefore to deal in the first instance with the most general forms and kinds of finite realities that presented themselves; thereby he would specify more particularly the problems and aspects of philosophy. And he has no difficulty in determining what these realities are; that had already been done, and was in fact an obvious commonplace in philosophy. The most general and distinct finite realities are Nature and Mind. $\mathrm{He}$ takes these as palpably different facts of experience, and seeks speculatively to systematise their contents and to connect them with each other and with the Absolute Reality.

We need seek no other reason or origin than that just given for this distinction of these philosophical sciences, which indeed we have already met with in a certain form in the early period, and which becomes a permanent part of Hegel's philosophy in its final form. He simply takes Nature and Mind as distinct facts, and shapes them into a speculative 
scheme of the universe. It is both untrue and unnecessary to treat them merely as "deductions" from "ideas." For Hegel they are, and seem always to have been, the primary realities of the universe, dependent for this reality solely on the Absolute. It was in these finite forms that Reality exhibited itself, and where it was immediately present and known. There is little doubt that in the lectures repeatedly given at Jena on "Philosophy of Nature" and "Philosophy of Mind," not as "applications" of abstract notions but as they are immediately presented, and sought merely to interpret them from the absolute point of view. Each is in itself so far independent of the other, and can be treated separately. They are and must be also connected as aspects of Absolute Reality, and such connexion is necessary to the completeness of speculative science. But the determination of this latter connexion, while it occupies Hegel in the present stage more than in the preceding, and occupies him still more in the later form of his philosophy, is simply a necessity for a complete system, but does not exclude their peculiar character, does not transform their nature. They have and preserve their own reality, and they, as distinct realities, are of interest in themselves, and must be treated by concepts peculiar to their specific contents. ${ }^{2}$

We have little of distinctive importance regarding his explicit interpretations and conceptions of each of these philosophical sciences. We have, however, some indication of the relation of Mind to Nature

1 Ros. p. I6I.

2 The above considerations are important in view of the relation between Logic and Nature and Spirit. 
as forms of Absolute Reality. There is, indeed, incorporated in Hegel's works ${ }^{1}$ an article from the Kritisches Journal der Philosophie, edited by Schelling and Hegel together at Jena, which deals specifically with the Verhältniss der Naturphilosophie zur Philosophie iiberhaupt; but this article cannot be admitted to have been Hegel's production. ${ }^{2}$ In another article, however, in the same volume, Ueber d. wissenschaft. Behandlungsarten d. Naturrechts, we find the relation of Nature and Spirit as forms of the Absolute determined. From this it appears that the supreme expression discoverable for the Absolute is Sittlichkeit (Ethicality ${ }^{3}$ ), that form of Spirit in which the freedom of a people most completely appears, in which legality as such, and morality as such, are fused and identified. ${ }^{4}$ For here alone are body and soul through and through united; here only is subjectivity also objectivity; ideality and reality posited as identical; individuality, the union of universality and particularity, completely realised. And these are the characteristics of the Absolute. He distinguishes ${ }^{5}$ within the Absolute its actual finite appearance and existence for and in finite empirical consciousness (the body, the visible side of Ethicality), and "the living Spirit, the absolute consciousness, the absolutely undifferentiated union of the ideal and the real found in Ethicality." It is the latter which is the absolute unity above spoken

1 Werke, i.

2 So also maintain Erdmann, Schmid, Ueberweg, Fischer, Haym.

3 I have rendered Sittlichkeit "Ethicality" after Dr. Stirling; for in spite of its cumbrousness it conveys technically Hegel's conception of that form of the moral life which has embodied custom in the institutions and order of an organised state or commonwealth. Sittlichkeit is the visible and substantial realisation of moral activity.

${ }^{4} W W$. i. $3^{8} 3 \mathrm{ff}$.

5 ibid. i. 38 I f. 
of; the former does not completely attain to the "divinity" of the latter, though it still contains "its absolute idea" and is necessarily bound up with it; and hence the place and significance of religion. But this distinction, as he himself indicates, does not affect the determination of the Absolute as above given; it is merely a difference of aspect of Sittlichkeit. This, then, is the essential nature of Absolute Spirit; in it absolute intuition (Anschaunng) of itself is one and the same with self-knowledge of itself; its absolute reality and its absolute ideality (reflexion) are identified. Such a union places Spirit (Mind) higher than Nature; for the latter is "absolute self-intuition, and the actualisation of infinite diversity and mediation," i.e. the endless process of external relation of part with part ; it does not know itself, does not intuit or view itself as itself. Mind does know itself, and is at once the plurality of the universe, which it grasps, and is the implicit ideality of that plurality. ${ }^{1}$

Much more important, however, for our purpose than the determination of the content and relation of the two forms of reality above indicated are the views which Hegel holds at this time on Logic and Metaphysic. An advance on his preceding position is distinctly manifest; and it is here that the influence of Schelling is so pronounced. Logic and Metaphysic together form again, as in the early period, the first of the triad of philosophical sciences; and, as in the case of the other two sciences (Philosophy of Nature and of Mind), Hegel in the first place. treats Logic and Metaphysic simply as an independent and self-subsistent part of philosophy,

$1 W W$. i. $3^{85}$. 
without immediate reference to either of the other two sciences. He does indeed seek more particularly, and perhaps more successfully, to connect the first part of philosophy with the second (Philosophy of Nature)," and tries to establish the "transition" from the "Idea" to Nature as the real, to pass in thought from Metaphysic to a Realphilosophie; but what we must observe is that this for Hegel is another and a different problem from the independent systematic treatment of the science in itself; the latter (Philosophy of Nature) does not depend on or wait for the former, nor are the results and contents of the latter deduced from, or even in this period derived by, the same method as the conclusions of the former inquiry. It is very important to keep this in mind, for the "transition from Logic to Nature" in his later philosophy, when thus regarded historically, ceases to be the riddle and the enigma which it is usually considered. The Philosophy of Nature is all along a distinct branch of philosophy, just as Nature is from the first a distinct form of reality. Nature occupies a sphere of its own, and the treatment of it is as such distinct from that of the others. It is not a dependent branch of philosophy, but a self-dependent, selfcontaired exposition; its distinctiveness of subjectmatter ensures that independence. It is no more independent than the other parts of philosophy; but it is no less. It is so from the start, and it remains so to the end. Thus, as we shall find, even at the last there is no attempt to sink any one part of philosophy in another, or to evolve one part from and out of the content of another (say Nature out of the 
Logic as such). The three parts of philosophy are moments of a single whole, but self-dependent moments, contained in and depending on that whole, but not on each other in their separateness. But this is anticipating.

The independence of this first part of philosophy of the other two parts appeared also, as we saw, in the early period; and that Logic and Metaphysic should be a separate branch of philosophy, and should be in the first instance treated independently, seems obvious enough. They had always formed a part of philosophy, and the nature of philosophy demanded it. For clearly a science is needed to state in the most general way the fundamental character and nature of Reality as a whole; and such an expression of the Absolute in formal "pure," "simple" universality is what this part of philosophy specifically furnishes. Neither philosophy of Nature nor of Mind does this; each deals with a certain aspect or definite content of reality, not Reality in its completeness. In a sense these two sciences themselves demand the other investigation, for only by its results can it be determined where and in what form the Absolute is most concretely revealed. And we find as a matter of fact that the nature of the Absolute as determined by Metaphysic is that which the Absolute possesses in the concrete form of Sittlichkeit above mentioned. ${ }^{1}$

It seems, again, to be in virtue of this character which Metaphysic possesses that it is treated as the first of the triad of philosophical disciplines, and this not merely in the earlier schemes, but in his later philosophy; it furnishes the most universal and 
essential determinations of Reality, not as this appears in any particular aspect (in Nature or in Mind), but as it is in itself.

The name which Hegel assigns to this part of speculation varies a little in the course of the period we are considering, and this variation is partly significant of the development he goes through. At first he calls it simply Logic and Metaphysic, on which in 1802 he proposes to publish a treatise. ${ }^{1}$ This either became a part of, or gave place to, a proposed compendium ${ }^{2}$ dealing with the whole of philosophical science, on which he repeatedly lectured. This compendium, mentioned in 1803 , was to be a complete exposition of his "System of Philosophy." He calls it a "system of speculative philosophy," and includes under it-(I) Logic and Metaphysic or Transcendental Idealism ; (2) Philosophy of Nature; (3) Philosophy of Mind. The two last he designates later (1805) as Realphilosophie. ${ }^{3}$ In I 806 Speculative Philosophy contains Phenomenology of Mind, Logic, and Philosophy of Nature and of Mind; Metaphysic as a distinct discipline being significantly omitted. With this change agrees a division of his system ${ }^{4}$ which must have appeared late in this period, and in which the first part of his system is given as "Logic or the Science of the Idea as such." His own statements, too, in the course of his development during this period ${ }^{5}$ indicate that gradual identification of Logic with Metaphysic which became his final position. But this position is not specifically established nor

\footnotetext{
1 Leben, p. I6I.

2 ibid.

3 This term is preserved in his final view; $v . \log$. i. Vorrede i. ad fin.

4 Leben, p. I79.

5 Cf. $W W$. i. $18 \mathrm{f} ., 315 \mathrm{ff}$.
} 
made explicit in such of Hegel's writings as fall within the period with which we are now concerned.

Hegel's views on Logic and Metaphysic are contained in his various articles in the above mentioned Journal, which are all, with one exception, on subjects falling within the first of the philosophical sciences ("Transcendental Idealism").

Speculative science, he maintains, must start from the Absolute. ${ }^{1}$ This is nothing less than an axiom with Hegel; philosophy, he declares, has not and never had any other object. And this is not a postulate in the sense of being that which is never proved, but which must always be begged in order to make all "proof" possible. Rather it is present in every "proof," and the whole of philosophy is just a laying bare of the content of the Absolute. Nor, again, does it appear as a "demand" or a "problem" at the end of philosophy, in which we are merely to "believe"; it is real throughout, and from the first in all philosophy. ${ }^{2}$

The Absolute has a necessary character; if is the one, the unity, the identity of all that is finite. The Absolute means simply absolute identity, that into which every finite is refunded, which contains all opposites, that in and by which all opposition is conserved, and, at the same time, as opposition, removed. The opposites so united are expressible in various ways; in one form they appear as Body and Soul, in another Necessity and Freedom, in a third as Nature and Ego, again as Subject and Object, or finally as Thought (Begriff) and Being. These, as the most fundamental forms of opposition we

$1 W W$. i. I $57 \mathrm{ff.}$; xvi. $33 \mathrm{ff}$. (1834). Absolute here used not as specifically Absolute Spirit.

2 ibid. i. $18 \mathrm{f}$. 
know, Hegel treats as all involving one another, and uses, for instance, the opposition between Subject and Object to express the same as that between Thought and Being.

The Absolute, then, is the identity of Subject and Object; and the identity of Subject and Object is the supreme principle of speculation, of all philosophical knowledge. But it is likewise presupposed in "common life" as well as in all philosophy; it lies at the basis of the "common sense" of the ordinary understanding. ${ }^{1}$ And in this fact lies the possibility and the need for philosophy. Philosophy is a necessity of consciousness, because, in " common sense" and the "culture" (Bildung) to which it gives rise, this underlying identity is lost sight of, but yet, like the silent destiny of man's Spirit, is implicitly present, and is demanded even though, or rather for the very reason that, the opposites have been fixed as separate and their reciprocal connexion overlooked. Whenever that which is only an appearance of the Absolute is wrenched out of connexion with its source, becomes isolated, independent, and fixed, the power and sense of unity has vanished from man's life, and can only be reinstated by philosophy. " "Disruption, isolation, division, is therefore the source of the need of philosophy." Such a need, says Hegel, is the only "presupposition" philosophy can have; it is all that pre-

1 WIV. xvi. "Verhält d. Scept." ad fin. ; j. I79 ff.

2 ibid. i. $168 \mathrm{ff}$. It is the absence and the necessity for this unity that gives rise to religion also as well as philosophy. Their difference lies in this that what religion does by immediacy, by " belief," by "yearning" after the Absolute, philosophy, as we shall see, performs by mediation, by knowledge, by conception (Begriff). Hence the importance of philosophy in modern life. Cf. Leben, pp. 182, 198 ; $W W$. i. 7 . 
supposition means for it; and in strictness there is no logical "presupposition," for the reason that if there were, this would lie inside philosophy itself. As we see, this "need" is determined by two elements - $(a)$ the Absolute itself, the ultimate $d s$ identity above named; $(b)$ the fact that consciousness has passed out of or away from this totality, has ceased to be aware of itself as only in and for this totality, has therefore " fixed" itself as separate from it, and thereby also splits the Absolute into fundamental but finite opposites reciprocally.limiting each other.

Now this position which we have described is the general intellectual situation out of which Hegel's philosophical (logico-metaphysical) position at this time took its form, from which all his philosophy in fact proceeded, and by which it is to the last continued. His conception of this starting is later on deepened and modified, but it remains, substantially the same to the end. It is the terra firma of his entrance into pure philosophy, and the groundwork of the mature philosophical convictions to which he now began to give utterance. This we shall find as we proceed.

Such being, then, the raison d'etre of philosophy, its business is simply to restore and reveal to consciousness that basal identity, ${ }^{1}$ to reassert the supremacy and primacy of the Absolute by explicitly exhibiting its actual presence in every finite and fixed reality, to show that all finite relative identities are merely "repetitions" of one and the same ultimate Identity, ${ }^{2}$ to reduce all appearances of the Absolute (which are limited and finite expressions of

1 WW. xvi. "Verhält d. Scept." ad fin.

2 ibid. 
it, and are set over against it, as also against each other) to that one "true" and only Reality. There are thus two moments in the procedure of philosophy; the one is the negation of the finite realities as such by the unlimited, infinite Reality, the other the assertion, the preservation of the finite by virtue of its sharing in, and being determined by, infinite Reality.

Now the medium through which this task and procedure of philosophy are carried out is Reason. Reason alone is adequate to the Absolute; "it is the manifestation of the Absolute" ${ }^{1}$ the activity of , reason is the activity of the Absolute. Hegel's expressions warrant us in even asserting that reason is simply the Absolute in us, and therefore in philosophy. For, as we found the Absolute to be is always the immanent principle of all philosophy, so the maintains philosophy' is one in all ages because reason is one and single. The Absolute Identity is a "reason-identity"; the principle of Absolute Identity at the root of all philosophy is a "principle of reason"; philosophy is solely the "activity of reason." 2 Hence the statement that philosophy is the knowledge of the Absolute is made equivalent in all respects to the statement that philosophy is the self-knowledge of reason. The business of philosophy is therefore merely put in another form when it is expressed as the resolution of all finite opposites, fixed and determinate (a determinateness due, as we shall presently see, to the action of understanding), into the one identity, the one infinite of reason. As there is only one reason, and as "every reason which has directed itself upon

$1 W W$. i. 165.

2 ibid. xvi. "WVesen d. philos. Kritik." 
itself, and come to know itself, has produced a true philøsophy," " every philosophy is in itself a constitutive and essential mode or form of reason. And this is the only significance which the various philosophies which have appeared from time to time possess ; and consequently, as far as the inner essence of philosophy is concerned, there is neither before nor after in philosophy, "neither forerunners nor successors." Every philosophy, therefore, finds its place in the one totality of reason, and the most opposed and contradictory forms of philosophy are the result of opposed factors or functions which are constitutive of reason itself. Particular concrete instances of such opposed philosophies we shall presently furnish.

Having, then, established what the aim and purpose of philosophy is, we must now determine by what process it is to attain its result. We have already indicated the two processes by which philosophy attains its end-the resolution or reduction of determinate opposites into the absolute unity of all opposition, the negation of the finite by the infinite, and the positing or assertion of that Identity in all finite opposites, in all relative identities. To these two forms correspond two processes of reason ${ }^{2}$ by which they are realised: to the first, Reflexion; to the second, Transcendental Anschamung, intuition, the direct immediate insight by reason. It must be borne in mind all along that the processes are not processes of our reason merely, in which case they would be distinct from the result, and even from that which is "reflected," and could be thrown aside when the

$1 W W$. i. 165.

2 ibid. i. $174 \mathrm{ff}$. 
result was obtained. Such conception of reflexion is necessarily false, because the whole meaning of Hegel's point of view is that all such distinctions as that between process of our reason and process of the object are merely finite, are not, and cannot be absolute, but are themselves identified, their opposition overcome, in the Absolute, in the "Identity of reason." It were therefore a manifest fatuity if these processes by which philosophy systematically construes the content and nature of the Absolute Identity of all opposites, all distinction, were themselves based on, or were merely a form of the finite distinctions which fall inside that Identity itself. Consequently. the one alternative left is that reflexion is absolute reflexion, reason-reflexion, reflexion which is one with, is the same as that which is reflected, reflexion as indifferent to subjective and objective, which appertains to both equally and neither specially. And similarly of Anschaunng. This will become clear as we proceed.

We saw that philosophy arose out of, or because of, the fixing, absolutising, of finite opposites. This " fixing," " positing," is the work of understanding. ${ }^{1}$ Reality or aspects of reality are isolated, and while set over against each other, and limited by each other, are still taken by understanding to be independent and self-sufficient. Beyond them understanding does not seek to go, and indeed by its very nature cannot go; they are not, therefore, related to anything beyond or more ultimate than themselves. By understanding, then, the task of philosophy could not be accomplished, for it does not attempt to construe the Absolute; there is no 
Absolute for it, there are only finite limited realities opposed to each other, and all existing simply side by side. Understanding is indeed a kind of reflexion, but it is "isolated, isolating reflexion," and is therefore distinguished from reflexion above named. What distinguishes the reflexion of philosophy is just the presence in it, and relation to it, of the Absolute. Since, therefore, the impossibility of construing the Absolute was due to the isolating and establishing of opposites in it, this problem is only solved through negating these by, and connecting them with, the Absolute. Philosophical reflexion is necessarily therefore negative, and this in virtue of the relation to the Absolute; it is "the power of the negative Absolute," "the negative side of the Absolute," "absolute negativity." Reason indeed is active even in understanding; for though the finite factors are fixed, yet one is limited by another, and this other requires a third to limit it, and so on endlessly. Precisely this forced progress to a complete totality sought by understanding is the work of reason. Understanding is rooted in finitude, and never reaches infinity; yet it isolates the former, and, placing the latter over against it, leaves the two side by side, and thereby finitises infinity. But in so positing infinity, understanding in its "conceit" is simply "imitating" reason, for it negates the finite (as reason does) by the infinite, which none the less is itself for understanding a finite, and exists side by side with the finite negated (which is not the case with the negation of reason). But when understanding does oppose finitude to infinity it destroys itself, for the maintenance of the one means the removal of the other. Reason alone, 
however, knows this, and thereby it destroys understanding, and translates its products simply into negatives.

This applies, of course, to all the finite isolated products of understanding. All are left, therefore, with merely reason without any opposites within it, pure reason with all finitudes resolved in it and negated by it. Now this self-identical totality of reason with which they can be resolved may in the last resort be one of two orders determined as distinct by the kind ${ }^{1}$ of reality contained in each, or the way in which the Absolute is expressed in each. These are the objective totality or infinity, and the subjective totality, the "objective world" and the kingdom of "freedom." These are the final opposites presented to reason and by reason. ${ }^{2}$ But they are still not independent and self-subsistent; they are related to and subsist in the Absolute. Reason, therefore, must destroy their opposition and unite them. And that is effected in one and the same act, for it unites them by negating them both. This is the only union they possess, for they only exist by being not united. Both are related to and exist for the Absolute; and the Absolute is one and is the Identity; they are therefore identical, and each is posited as the Identity. ${ }^{3}$ The Absolute is that which negates the fixed finitudes in the "objective world" (world of sense), as also in the subjective world (intellectual world, world of freedom). These apparently different worlds taken in their entirety are simply the totalities of finite realities which qua finite are undoubtedly distinct. But the one Absolute

1 The nature of this distinction in "kind" is determined below.

2 Cf. Spinoza's Infinite Modes.

3 $W W$. i. 176. 
CHAP.

determines them as totalities, and hence they are different forms of the same Identity, and are therefore essentially identical, and their apparent difference is negated by that Reason-Identity which constitutes each.

Thus we see that reflexion from first to last is purely negative, and the Absolute in reflexion is simply the synthesis of opposites. The law of reflexion is therefore "that everything destroys itself"; the life of each finite reality is its death. And this, as we saw, applies universally to everything except the Absolute Identity itself. It would apply even to reflexion itself, if this opposed itself to the Absolute as a fixed element of Reality. It must negate itself likewise, for if it did not, "it would be determining itself by the law of contradiction"; it would assert itself to be reason, and would be obeying the law of understanding only. ${ }^{1}$ It would posit itself absolutely against the Absolute, and yet maintain that the Absolute is the only identity. The only law to which it can rightly conform must therefore be that of self-annihilation. This self-annihilation just means that synthesis of opposites which constitutes the nature of the Absolute Identity. But synthesis of opposites is not really contradiction, but rather the contradiction which abolishes, sublates itself. And this is the signification of antinomy. Antinomy, therefore, is the supreme law of reason as reflexion, of the negative side of speculation.

But, as we saw, there is another moment in the process of "construing" the Absolute. Reflexion maintains throughout that opposites must be 
negated, that their being cancelled in and by the Absolute is their truth. But it does no more than this. There is a process which it even demands and presupposes, and yet which it does not and cannot perform, viz. bring to the light of philosophic knowledge the positive side of reason. This aspect which defies all negation and endures throughout it, is the Identity itself which maintains and preserves the content negated; and this side of reason is Anschaunng. ${ }^{1}$ Anschaunng does not "fix" one opposite over against another; if it did so it would perform the work of understanding. And it cannot make "real," or, so to say, "precipitate," which is "ideal," for this would be simply to determine the other side of an opposition, which only exists as an antinomy, and has already been negated in reflexion. Anschaunng is concerned with the Identity per se, as reflexion is concerned with finite opposites as such; and is present not merely in the case of the Absolute Identity, but also in that of those relative identities into which the Absolute Identity differentiates itself. For these relative identities, e.g. the objective as such, are antinomial; they are not primarily "fixed" identities of understanding, but are related to the Absolute. ${ }^{2}$ And what $A n$ schauung does is to assert and insist upon what is merely indicated by reflexion, to substantiate and preserve what reflexion only demands and postulates. In the identity as such antinomy is immanently present, and in antinomy as such the identity is implied. Anschaunng expresses the immediate oneness of the identity of reason to

$1 W W$. i. 123, $194 \mathrm{f}$.

2 Cf. $W W$. xvi. "Verhält d. Scept." 
reason itself. It may function apart from reflexion ; but in this case it is simply empirical, unconscious, the merely "given"; the relative identity of the objective, e.g., is accepted in this way as divided from the subjective. Similarly reflexion may operate by itself and produce pure antinomy; in which case it furnishes indeed knowledge, but "mere" knowledge, formal negative knowledge, knowledge which refers the content of the Absolute to that identity constituting its substance, but can do no more than produce this reference; it produces, therefore, antinomies and not the Identity. Consequently, if we are to have the truth of speculation in its completeness, we must not have either reflexion without Anschaunng or vice versa. The one is as absolutely necessary as the other. And the union of these two is what speculation seeks; this union is " transcendental knowledge," which alone fully satisfies philosophy. For by it the union of subjective and objective, intelligence and nature, consciousness and the unconscious, thought and being is accomplished, and this is philosophic knowledge, or, as we have put it, the construing of the Absolute. What, therefore, is known or "seen" through Antschannng (Angeschant) belongs to both worlds at once; the one world is essentially identical with the other: being, looked at from the standpoint of thought, is the scheme of intelligence; intelligence, from the standpoint of being, is the scheme of absolute being. And obviously in philosophy, transcendental knowledge and transcendental Anschaunng are one and the same, for in both that Identity is completely present ; the difference of expression "denotes merely 
the preponderance of the ideal (formal negative) or real factor" in the Absolute Identity.

In the construction of the system of philosophy it is, however, maintained that the production of this system is the work of reflexion. ${ }^{1}$ For it alone is concerned with finitudes, the different forms of identity, the manifold content of the Absolute; and it is simply out of this plurality that system is constructed, and owing to which, indeed, philosophy is required. Reflexion therefore, being the means by which this manifold of finitude is finally revealed as a limited determination of the Absolute Identity, is the instrument used in the shaping of the system, and its formal procedure is the synthesis of opposites.

But this being so, it is important to observe that we are thereby debarred from attempting to express through reflexion the Absolute in the form of a single proposition, which shall be the fundamental ground-principle of the system, valid for understanding, and from which the whole system may be known and constructed. ${ }^{2}$ Such an attempt is indeed impossible. For propositions of this kind are limited, conditioned, and do not contain a contradiction. If the expression of the principle contradicts itself it is not a proposition; if it do not contradict itself it is conditioned and limited. Now the Absolute is the unconditioned ground of reflexion; its expression, therefore, must contain contradiction, and cannot be given in a single proposition. Its only expression is in antinomy. What in the

$1 W W$. i. 184. It is not at all obvious how Hegel can maintain this, and at the same time hold the views just stated. There is an obvious ambiguity, if not confusion, in the use of the term reflexion in this period as well as in the preceding ( $v$. infra, p. 134, 135).

${ }^{2} W W$. i. $185 \mathrm{ff}$. 
Absolute Identity is united, the synthesis and the antithesis, must be expressed in two propositions, one expressing the identity, the other the opposition. Hence, e.g., either the propositions $\mathrm{A}=\mathrm{A}$ and $\mathrm{A}$ $=\mathrm{B}$ are quite inadequate to the Absolute, or else each expresses an antinomy, and indeed the same antinomy.

From the foregoing it is easy to see that what philosophy furnishes is nothing short of a totality of knowledge produced by reffexion, and constituting in itself " a system, an organic whole of concepts whose highest law is reason and not understanding." I It is an organic whole whose ground lies in itself, an organisation of moments or forms of knowledge (Erkenntnisse), every part of which contains the whole (through its implication of the Absolute). As he elsewhere puts it, "every unit of knowledge is a truth, every particle of dust an organisation." The method by which this result is to be obtained is neither synthetic nor analytic, but rather development-development, that is, of reason itself, and by itself. $^{2}$ It is not, therefore, the simple negation of its appearance, and mere resumption of it into its essence, but rather the construing of every appearance as a relative identity, and its own identity. No precise account of this method, however, is given, though its purport is sufficiently evident.

In such a system it is clear, on the one hand, how the history of philosophical systems will be regarded, and, on the other, what place will be assigned to particular distinct modes of philosophising which have appeared in the course of that history. For we see that the consequence of maintaining that

1 $W W$. i. 179, 185 ; xvi. "Verhält d. Scept."

$2 i b i d$. i. 195 . 
the problem and object of philosophy have at all times been one and the same, that philosophy is the self-knowledge of reason, is that the history of philosophy is itself one philosophy in different forms. This point of view enables Hegel to give a meaning to the history of thought, and find it other than simply a collection of individual opinions. And thereby, also, we can judge a given system, for we can distinguish what it tried to do from what it actually accomplished, can distinguish the philosophy of the system from the system itself, ${ }^{1}$ and determine its nature and result accordingly. And, in particular, directly opposite forms of philosophy, e.g. Scepticism and Dogmatism, will thus be not absolutely disconnected and irreconcilable modes of thinking, but rather constituent aspects of the one content of reason. This must necessarily be the case, and an analysis of both the forms would show that neither the one nor the other can exhaust the whole of philosophy, but that they really imply and require each other. All philosophy is sceptical and dogmatical at once. Scepticism as opposed to Dogmatism is itself dogmatical, the complementary side to Dogmatism; as an "absolute" philosophy it is simply the negative side of own reflexion. ${ }^{2}$ Dogmatism as an absolute scheme is the assumption by a finite conditioned element of the nature and forms of the Absolute Identity itself. It would be outside our purpose, however, to exhibit in greater detail the position which Hegel here takes up; its general significance is all that here concerns us.

Of great importance is it for us to note that of the foregoing ground-plan of a system of philosophy

I $W W$. i. 195 ff. $\quad 2$ ibid. i. 196 ff.; xvi. "Verhält d. Scept." passim. 
Hegel assigns the name Logic to that part which forms the content of reflexion proper, and per se, and Metaphysic to that which we designated transcendental knowledge, which was convertible, as we saw, with transcendental Anschauung. This is made quite clear from a short statement of the content and character of Logic and Metaphysic respectively, which is extracted by his biographer from the manuscript Lectures of this period. ${ }^{1}$ Here he distinguishes between infinite knowledge, knowledge of the Absolute, and finite knowledge, knowledge of finitude. The former is the knowledge of Reason without qualification (Vernunfterkenntniss); the latter is knowledge of reason as qualified by Understanding. By this he means that what is finite is in the Absolute, has its source in reason; but as it is for reason, presents itself to reason, it is negated by it, has no self-subsistency, is related to the Absolute Identity, and to other finite facts. But in its finitude it can be and is abstracted from the Absolute Identity of reason, and thus, in a sense, robbed of its reason-character; and being thereby fixed in its finiteness becomes finite knowledge, knowledge of finite as such. This is the work of understanding. This knowledge of the finite determines the problem of Logic. For a "true Logic" will seek to state systematically the forms of finitude, the formal elements of finite knowledge. It will include an exposition of those products of understanding, in which, by its abstracting and fixing of finite elements of the content of reason, it "imitates" reason, though the identity it does produce is merely "formal."

1 Leben, pp. 190-192. 
Further, since these forms of finite knowledge are really in and for reason, a constituent part of Logic must be to determine the significance possessed by those forms in this reference to reason. Such a significance we have seen all along is purely negative; hence this concluding portion of Logic consists in the negative knowledge of reason, the sublating of finite knowledge by reason-knowledge.

The Logic falls thus into three parts. ${ }^{1}$ The first states the universal forms, laws, or categories of finitude in general (regarded as objective as well as subjective, or apart from their being objective or subjective), taken simply in their finiteness, as reflexes of the Absolute. ${ }^{2}$ We must keep in mind that these forms are not in the first instance determined as categories of reason. Hegel is stating in this and the successive part the elements which are for understanding per se, the content of finite knowledge, knowledge as it is determined by understanding. Taken by itself, therefore, it embodies, as we shall see presently, no philosophical conclusions ; it is the work of "isolating reflexion," not of philosophical reflexion, which we saw was purely negative. These categories are thus not real identities but formal identities; not identities which are at once subjective and objective, but identities which contain no inner difference, no inner opposition. They are not relative identities in the sense we defined above, but identities which, as against each other, are absolutely fixed. They

1 The notions with which Logic deals can be found, says Hegel, ready to hand in language; notions are embodied in current terminology (Leben, pp. 183,184$)$.

2 "Logic presents the picture of the Absolute in, so to say, a reflected form" (Leben, p. I9I). 
therefore are taken as formal identities of understanding to be qualitatively different, and each merely self-identical. And these finite forms are reflexions from the Absolute; the one light of the Absolute is passed through the angular

- prism of finitude; all reality is thus broken up by it and separated into finite elements. But such finite determinations are only ideally ${ }^{1}$ opposed to each other by understanding; they are not real opposites, for real opposites understanding cannot construe; this can, as we saw, only be done by reason.

The second part of the Logic is still concerned with finite knowledge, "isolated reflexion," understanding as such. In this part are considered the subjective forms of finitude, i.e. finite thought itself, understanding and its processes. These are the usual forms of Concept, Judgment, and Syllogism. It is, in the first instance, the concept, judgment, and syllogism in their purely formal character that he has here in view. He does use the term concept (Begriff) as applicable to the Absolute itself, and employs the expression "absolute concept" in this reference ${ }^{2}$ and again he treats judgment as an unconscious Identity of reason. ${ }^{3}$ But it is not concept and judgment as elements of reason that he deals with in this part of the Logic, but as finite, isolated, "formal." $\mathrm{He}$ expressly points out that although syllogism expresses more clearly the nature and character of reason, and is indeed commonly ascribed to reason, still in this part of the Logic he means syllogism as a formal process of

1 By "ideal" must here be understood abstract as opposed to concrete.

$2 W W$. i. 369.

3 ibid. i. 24. 
thought, as it is for finite knowledge, for understanding. Such a syllogism does not express speculative truth any more than the concept of understanding is equal to the nature of the Absolute. To apprehend the Absolute Identity we must, in fact, remove it from the sphere of such concepts. ${ }^{1}$

In the third part is stated the relation of reason to the foregoing forms of finite knowledge. The first and second parts contain no reference whatever to reason; they state simply facts concerning finite knowledge, the universal forms in which it appears. By its nature it cannot express philosophical truth, and it is therefore not till we come to this third part that we enter upon philosophy; for only here have we knowledge of or by reason. But it is only knowledge (by reason) of this finite knowledge, is only therefore, as we have seen, purely negative in character, it is "negative knowledge of reason," it sublates finite knowledge by bringing it into a new relation, which is at once truer than the relations of finite knowledge as such, and the only true knowledge which the finite forms can really possess. This new relation is the relation to the Absolute Identity. Here, then, we have philosophical reflexion as contrasted with the isolated finite reflexion of the first two parts of the Logic. Here, as we saw, the identities are "relative identities," the opposites real opposites. Reason appropriates concept, judgment, and syllogism, destroys the limited character which they have for understanding, gives them the content and character of the Absolute, and thus elevates them into expressions of infinite truth. In this reference the

$1 W W$. i. $205,206$. 
concept as an expression for the Absolute becomes the "principle of opposition and the opposition itself," the one concept which differentiates itself into a plurality of determinate concepts, and yet remains one throughout the plurality. ${ }^{1}$ So again of judgment. In it the identity of reason is unconscious, but is still operative in it, ${ }^{2}$ and is in fact contained in the copula "is," though by this copula it is not explicitly expressed. Rather this copula tends to obscure the reason element, and in judgment we thus find the predominance of difference. ${ }^{3}$ And syllogism he holds to be the very foundation of philosophical knowledge, the explicit expression of the nature of the Identity of reason.

This third part closes the Logic. He mentions, indeed, that there is usually given an "applied" Logic; but the content of this he holds to be partly too general and trivial, and to be, so far as it contains any philosophical significance, a part of the third division of the Logic. This third part introduces us to the Metaphysic or to "Philosophy proper," where we have the knowledge of reason per se, the sphere of the true Idea, the union of thought and being, reflexion and Anschaunng. ${ }^{4}$ The distinction, therefore, of Logic from Metaphysic is, at least formally, definite and decided. $\mathrm{He}$ maintains it consistently and explicitly, not merely in this sketch but elsewhere. ${ }^{5}$ And he does not strictly co-ordinate Logic with Metaphysic as equally parts of philosophy; two parts of Logic, as was pointed out, have no immediate philosophical significance. Logic, he says expressly, is in a

$1 W W$. i. 350,35 I.

4 ibid. i. $346 \mathrm{f}$.

2 ibid. i. 23.

3 ibid. i. 24.

5 e.g. ibid. i. $177,315 \mathrm{ff}$. 
sense an introduction to philosophy. ${ }^{1}$ This view of Logic, however, while it obviously is justified in a manner by the conception of its'subject-matter and that of philosophy, must be accepted in the light of his present treatment of Logic and Metaphysic. Hegel admits that he takes this distinction between the two, which has been so long maintained, for "the sake of its convenience." ${ }^{2}$ It had been customary apparently to make that distinction in philosophy, and to consider one as introductory to the other. Hegel adopted it as a convenient method of distinguishing problems in philosophy, but pointed out in so many words that if Logic is to be so considered, it must, to be an introduction to speculative science, be treated speculatively. He thus at once preserves historical usage and his own view of the subject. Hence the Logic is not introductory in the sense that per se it is outside philosophy; this it cannot be, for one part of it is knowledge of reason; rather it is a first stage in philosophy.

What philosophy, "transcendental knowledge," or Metaphysic, to which Logic in that sense is introductory, has to accomplish, we have stated already. "It has," Hegel says, "primarily to construe completely the principle of all philosophy," i.e. Absolute Identity, the union of thought and being, of subject and object. This is the essence of philosophy, as of every true science; this is in philosophy the "highest Idea," the "pure Idea." Or " the essence of knowledge consists in the identity of universal and particular, i.e. of what is posited under the form of thought and of
1 Leben, p. I91.
2 ibid. p. 190. 
being." 1 In it all the content of philosophy is taken up and presented in its pure absolute form, determined by its relation to the Absolute Identity. And such a philosophy is necessarily Idealism, because it takes neither of the opposites contained in the identity (subject, object, etc.) abstracted from each other, but holds its highest Idea, its Idea of Reason par excellence, as determining both indifferently, each being by itself unreal. ${ }^{2}$

When we seek more definite knowledge as to how this system can be exhibited, and what precisely its result would be, we can furnish from the remains at our disposal no accurate answer. ${ }^{3}$ We can, however, state that the conclusion reached in such a system, its final result, is conceived in a distinctly Schellingian form. The "highest Idea," he says, is "die Nacht des göttlichen Mysteriums." 4 "Speculation," he says, "demands, in its highest synthesis of the conscious and the unconscious, the negation of consciousness itself. And thereby reason buries its reflexion of the Absolute Identity, and its knowledge as well as its very self in its own abyss." ${ }_{5}$ There is doubtless a certain degree of mere metaphor in such phraseology, though its philosophical purport is quite evident; it is indeed the legitimate consequence of his principle of Absolute Identity. And it is of significance and importance in view of the intimate relation of philosophy and religion in Hegel's thought, as already noted,

$1 W W$. i. 3I 5 f., 347 f.; xvi. " Verhält d. Scept." ad fin.

2 ibid. i. 19.

3 Hegel expressly says that in Metaphysic he can give nothing new, but proposes to reproduce Metaphysic as it had historically appeared (Leben, p. 192).

4 Leben, p. 192.

$5 W W$. i. 184 ; similarly i. 153, etc.; Leben, p. 170. 
that such a conception is in entire agreement with his attitude in religion, where the principle of resignation, with its abandonment of self, its negation of all "subjectivity" and reference to self, is held to be fundamental. ${ }^{1}$

It will have already become evident from the foregoing statement that Hegel in this period has made a decided advance in his conception of Logic. We have, it is true, no systematic exposition of his view, but we have sufficient to enable us to appreciate the distance he has travelled from his earlier position. It remains for us now to conclude this survey of his second period by bringing into relief the main features which characterise this advance. We must also indicate briefly in what essential respects he differed from his chief immediate predecessors, a difference which in this period he already sought to emphasise in his criticisms of Kant, Fichte, etc. And finally, we must point out in what direction his further development proceeds during the next period, the result of which finds its expression in his final systematic construction, the Larger Logic.

We shall find on reflexion that there are four prominent and important results arrived at in this period which chiefly show in what respects he advanced on the preceding. These are-(I) the more complete grasp of his fundamental philosophical principle; $(2)$ the ascertainment of the nature and procedure of the instrument of philosophising; (3) the closer approximation of Logic to Metaphysic, through the assimilation of their content; (4) the naming of the method to be employed in constructing a system. 
I. In virtue of the first-named feature Hegel gains an independence of attitude in philosophy which places him outside the direct influence of traditional or current philosophy. The mere repetition of the results of others which was found in the early period is now no longer possible. He has made up his mind as to what the nature of philosophy is, what is its fundamental principle, a principle which is not only that of a particular philosophy, but is that of all philosophy whatsoever. He does not profess to work out a system. He is rather content to exhibit this principle throughout the history of philosophy than to construct an entirely new system. ${ }^{1}$ From this point of view he starts, and by it he judges all that has appeared as philosophy. The principle is not expounded fully, and requires more exact determination, which, however, it does not receive in this period. An Identity which is the ground and unity of all opposites, that which reason (whose identity it is and which determines the activity of reason) seeks to exhibit at the end of its procedure as the essence of all opposed finite elements, is assuredly a wide enough designation for all that philosophy has done or seeks to do. But it was doubtless natural that Hegel in stating this principle for the first time should have laid emphasis rather on the unity, the identity of import in all systems, than on their special differences. And though this principle receives modification and a more definite content later on, it remains none the less in its general

form fundamental in his system to the last.
It must be kept in mind, too, that this is not $(1-14)$ 
merely for Hegel, at this or at any time, a principle from which to determine the nature of philosophy and its history; it is necessarily also a principle by reference to which all the concepts of philosophy come to possess a really philosophical meaning at all. And if we keep these primâ facie quite distinct spheres, to which this same principle applies, clearly in view, we will see how easy it was for Hegel to take up the position, which he as a matter of fact does later on, of finding the actual counterpart of the sequence of the concepts of the Logic in the history of philosophy itself. It was a common principle which determined the content of both; why then should there not be an exact parallelism between the two? We seem, therefore, warranted in finding one of the clues by which Hegel determined the order and place in the sequence of the concepts of the Logic in this conception of the nature of philosophy and the significance of its history. In passing, we may note that Hegel was thoroughly acquainted with the history of philosophy ${ }^{1}$ before he wrote the Phänomenologie, i806-7, and the Logic did not begin to appear till i8r2. He thus knew what the forms were in which the one principle of philosophy had appeared in the course of its history. What more natural than the suggestion that these had a necessary sequence, that this sequence was a logical one (in his later meaning of Logic), and that thus they afforded a clue to determine the sequence of the concepts in the Logic as such, and even put the thinker on the track of

$1 \mathrm{He}$ lectured in Jena on the History of Philosophy, 1805; and the published Lectures on the History of Philosophy ( $W W$. xv.) are stated by the editor to be substantially the same as those delivered in Jena. 
discovering the law of this sequence? There seems no doubt whatever that Hegel's conception of, and profound acquaintance with, the history of philosophy had no slight influence in shaping the actual content of his own system.

It is further of importance to note that Hegel does not work up to this principle which governs his philosophy; it is simply his starting-point and fundamental notion. It arises from his conception of the need and function of philosophy in life, but has no other "presupposition " and no other warrant as a principle. The significance of this lies in the fact that his system thus necessarily works from that principle which is at once its conclusion and goal as well as its starting-point; and hence it is that the specific character which his philosophic method all along assumes is "deductive." It could not be otherwise with such a beginning. He did not seem to think it necessary to establish his principle in the sense of finding a ground for it. The only proof of which it admitted was to be found when it was systematically worked out and completely presented, i.e. at the end of the system, not at the beginning. ${ }^{1}$ Indeed, it would be futile to try to prove or establish his principle in any other way, as we have already pointed out. And this modus operandi, here for the first time clearly expressed, remains permanent in Hegel's philosophy.

Thus we see that the securing of a definite point of view can remove two prominent defects of the preceding period-( $\mathrm{I}$ ) the indeterminateness of the

1 " The principle of a system of philosophy is its result," is one of his obiter dicta (Leben, pp. 545, 546). 
content of his scheme and its arbitrary acceptance of traditional ideas; (2) the absence of systematic connectedness in the content owing to the lack of a central determining point of reference ; the various conceptions could not be "deduced."

II. Again, the accurate analysis of the procedure of philosophy, the ascertainment of the significance of reason, of reflexion, and of Anschaunng, goes very far indeed to obviate the obscurities and remove the inadequacies of his early view. It is clearly of the first importance as a preliminary to the construction of any system that the fundamental terms, the primary factors and functions necessary to that construction, should be precisely defined. This determination, however, does not give us the system itself, it is merely an essential propædeutic to it.

Hegel, again, does not connect these factors systematically with each other; they are merely formulated independently. But this analysis has not merely a value for the construction of a system ; the determination of these terms indicates the nature of the content of the system. Formerly, we saw, Hegel distinguished the form from the matter in knowledge, the forms of knowledge from knowledge itself, thought from being. In this second period these different factors are identified, and in the above terms he signalises this identification, which, though its form is changed, henceforth always characterises Hegel's system. Reflexion is a process which operates through and by means of this identification; it is a reflexion of opposites, which are relatively identical, are what they are by sharing in the one identity of reason.

It is unnecessary to do more than point out the 
extreme importance of this step, which not merely gives a greater definiteness, precision, and consistency to Hegel's thinking than was found in his early view, but stamps Hegel's position ever after as a form of Identitätsphilosophie. For example, it is simply this same notion of identity of opposites which appears when in the later Logic the universals of thought, the categories, are at the same time determinations of reality (of the object, Gegenstand), or where opposed categories are viewed as moments of their own unity.

We must not, however, import more into his present position than is warranted. Reflexion, for example, must not be taken to be the dialectic, in the later use of this term. It is negative, like the dialectic; and it must be viewed also as dealing, like the latter, with what is both form and content, both thought and being. But, unlike the latter, (I) it has not as such a positive side, it does not conserve the negated factors; $(2)$ the negation is produced by relating each to the Absolute Identity, i.e. is produced by what, in the first instance, is external to the process of reflexion itself; (3) the positive side of "philosophical knowledge" is referred to another sphere, that of Anschaunng. As a matter of fact, the word "dialectic" is hardly used at all in this period. No doubt it would have been in agreement both with his own previous and with current terminology to have used it as a designation for the process of reflexion in the sense already defined $;^{1}$ and from this point of view he could well have called Logic, as understood in this period (Logic of reason (Vernunftlogik)), dialectic. We should still, 
however, have to distinguish this general use of the term dialectic from the latter characteristic and specific sense. In spite of these reservations we are entitled to find in reflexion as defined in this period the direct anticipation of the later dialectic particularly in its negative aspect. It corresponds at this stage to the dialectic in the later Logic. To this, however, we shall presently return.

III. The divergences from his early views already stated necessitate a change which is also an advance in his explicit schemes of Logic and Metaphysic. We are hardly justified in instituting a point-bypoint comparison between the conceptions of the two periods. We cannot find so accurate a correspondence between them. The previous doctrine of "proportion" is simply supplanted by the third part of the new Logic; there is very little connexion or similarity discoverable between them. The second parts of both schemes do indeed correspond somewhat closely; the later seems unquestionably a more definite and precise form of the earlier. In the case of the first part, however, we are not entitled to affirm a close similarity, owing to the absence of any detailed discussion of this part in the Logic of the second period. Doubtless the content of the two must have been similar, but to what extent we cannot fully determine. Both contain forms or categories of reality, but whereas in the early Logic these are categories of "being," in the second Logic they are categories (laws) of finitude in general, both in a subjective and objective reference. Both, again, regard the subject-matter of Logic as belonging to understanding; but while the early Logic is merely Logic of understanding, and 
is illuminated by no analysis of understanding and its relation to reason, the second Logic can be only in part viewed as a Logic of understanding, contains one division devoted solely to the work of reason, and might, in virtue of the close connexion between reason and understanding as already determined, be considered as entirely a Logic of reason. This is, as we saw, in virtue of the nature of reflexion with which Logic deals, and in which the distinction between knowledge, thought, and being (a distinction vital to the early Logic) is removed.

It is an obvious and necessary result of all this that Logic should in this period become metaphysical, that the only distinction which obtains between the two should fall inside Metaphysic itself. The distinction, in fact, is that between reason as primarily negative and reason as both positive and negative at once, reason in relation with finitude as such, and reason as dealing with its "infinite" content, the Absolute Identity.

This approximation of Logic and Metaphysic is of vital significance. Metaphysic itself comes to be dealt with in terminology which holds directly of Logic. " The use of such terms as "absolute notion" (Begriff), "absolute idea" (Idee) for the identity of reason indicates this. All that is required to bring his later position clearly into view is a still further criticism of his terms, and a more thorough systematisation of his fundamental ideas.

VIV. Finally, we have the method characterised by which Hegel would establish his philosophical system. This method is described as Develop-

I In one passage he uses the term logic as convertible with "Idealism," "Speculative Idea," "Speculative Philosophy" (Leben, p. I79). 
ment. As was already stated, we have no complete exposition of the nature and meaning of this method, or of how it actually works in detail. That it should have been named Development, "neither analytic nor synthetic," is a decided advance in precision on the previous period, indicates the form in which his system would appear, and points the direction his further advance will take. The conception of a developmental method (as distinct from the purely "deductive" method of Fichte, and in part of Schelling) was in all probability suggested by Schelling's Transcendental Idealismus, where "philosophy" is stated to be and is expounded as the "history of the steps or epochs of self-consciousness," a history which starts from a position "deduced" as ultimate, necessary, and indubitable, and "allows" the various "acts" of self-consciousness to "arise" in a series representing grades of complexity and explicitness of self-consciousness. ${ }^{1}$ More than this general connexion, however, we cannot indicate, on account of the incompleteness of our information.

In all these ways, then, Hegel has made distinct and ascertainable progress on his early view. For the rest, it is not difficult to discover the defects and incompleteness of his views at this period, and the next steps of advance. But before doing so it will be well to state as briefly as possible the relation in which Hegel's views stood to those of his greater contemporaries, more especially to those of Schelling. We say "briefly," first, because such a statement is rather of the nature of a digression from our

1 v. Trans. Ideal. Absch. iii. Vorerrin, f. xii. ad fin. ; also preface. 
main subject, and secondly, Hegel's views at this time are too generally stated to admit of an indication of any more than general affinities (or the reverse) between Hegel and his contemporaries. 


\section{CHAPTER IV}

HEGEL AND HIS CONTEMPORARIES

WE are not left in much doubt regarding Hegel's attitude during this period towards his immediate contemporaries. His main contributions to the Critical Journal were expositions and critical discussions of their systems. It is important, however, to bear in mind that in these statements he is concerned primarily with the fundamental conceptions of the various systems rather than with their detailed contents; he deals with their principles in the broadest and most general outline, not with special developments of their principle. Hence we shall not find, and cannot expect, that much direct light is thrown on their treatment of the nature and content of Logic by the examination to which he subjects those systems. The main interest for us of his criticisms lies in the fact that they accentuate the central principle which, as we have seen, he had by this time gained for himself, and bring it into relief by contrast with the positions he criticises. They signalise his attainment of a governing conception and his triumphant confidence in its truth, and perhaps, too, in a distant manner suggest the future system into which that conception will develop. 
In all of them, we must observe at the outset, he found the recognition of the same general "speculative idea," the ultimate identity of subject and object. It was not the presence or absence of this conception in its general form which separated Fichte from Schelling, and both from Kant or Jacobi. It was the manner in which this principle was grasped and expressed by each, the completeness and explicitness with which the meaning of that idea was exhibited in their several systems, which distinguished the one thinker from another. This principle Hegel himself shared with all these thinkers; it is his own clear and comprehensive grasp of its nature which is the basis of his criticism, or of his appreciation. His attitude towards all of them is thus at once sympathetic and critical; true to his unvarying objective method of treatment, his criticism is essentially immanent, not external.

Towards Kant and Fichte he takes up a position in the main antagonistic and negative. The genuine speculative element in Kant, Hegel finds in the problem, and in the solution offered to the problem, "how are synthetic à priori judgments possible?" The very expression of this problem indicates and implies the fundamental idea of the unity, the identity of subject and predicate, particular and universal, being and thought. ${ }^{1}$ This unity is not a product of these opposites, but the original and absolute identity of them, from which in fact they sunder themselves. The judgment formed with them as elements is just the original and primal division, or severing (Ur-teil) of the elements in that unity. The possibility of this unity lies in reason; the idea it expresses is an idea 
of reason. This original and ultimate principle of unity appears in Kant's Kritik in various forms. It is found in the "synthetic unity of apperception," " productive imagination," " category," "schema," as also in "the forms of intuition," space and time. In all these forms it is one and the same conception that is actually operative. They describe different functions, but functions of one and the same unity of reason. ${ }^{1}$ It is in the light of this ultimate unity that we are to explain and justify Kant's insistence on the concrete character of knowledge, on the reciprocal necessity of Anschaunng to Begriff. ${ }^{2}$ Unless, again, we regard the "original synthetic unity of apperception," not as a go-between, not as a meeting-place for an isolated subject existing on one side and a world of objects on the other, but as the primal and absolute unity out of which, as from their ultimate germ, subject and object proceed, and in proceeding sunder themselves apart, it is quite impossible to understand Kant's deduction of categories or forms of intuition. ${ }^{3}$ For this reason, then, we must distinguish between the merely logical Ego which "accompanies" presentations, and this all-constituting unity of the subject with its object ; we must separate the one from the other to give meaning to Kant's position-all that Kant establishes regarding the concrete character of experience, its unity, follows consistently from this his fundamental speculative position, and justifies the above interpretation of his meaning.

Still, Kant himself did not fully comprehend the significance of his own ultimate notion. Instead of grasping the essential meaning of that identity, that
1 WW. i. 23-25.
2 i. 22.
3 i. $24,25$. 
is, taking it as a concrete identity with diverse aspects, as the concrete Idea, constituted by reason, and in which the diverse elements were explicitly established as identical, because moments in the one primary unity, Kant regarded the judgment as the fundamental form of that unity. Now in judgment the constitutive elements are exhibited only in their diversity, in their duality; for judgment lays emphasis primarily, and indeed solely, on the diversity of the content. Productive imagination, which is the proximate ground of judgment, and is in fact understanding,' remains (though in reality a function, or potency of reason itself) sunk in diversity. The absolute unity, therefore, never comes to light. The identity, the universal which it contains, viz. the category, remains for ever over against, opposed to the particular with which in judgment it is united by the copula. The identity is merely a relative, formal, or abstract identity. The other element, the particular, does not exist in it, it comes to it as a foreign element from without, which is necessary to it, but not a constituent moment of it. The identity of the two, of understanding and sense, of universal and particular, of notion and intuition, is never completely and adequately established. Hence arise the "thing-in-itself," the "limitation of reason," the emphasis on "human" reason, the dialectic of "pure" reason, the fixed and insurmountable opposition between freedom and necessity, etc. In all this Hegel finds nothing but the consequences of his limited and erroneous conception of the nature of that ultimate unity which it was "his great 
merit" to have laid bare. Not that Kant is not forced in spite of himself to be truer to his own principle than his determination of it will logically allow. The idea of an "intuitive understanding," for example, is the same idea as that of transcendental (productive) imagination; and such an understanding Kant declares to be "necessary." Though he rejects the "real" necessity of it, while admitting the conceptual necessity, "problematic" reality of it, yet the bare admission of it shows his transcendence of his own limitations, while the rejection of the absolute validity of the conception was after all due, Hegel thinks, to his resolution to hold by his limited "subjective" starting-point, and remain consistent with his "finite" formal position." Or, again, his emphatic insistence on the autonomy and spontaneity of reason likewise carries Kant beyond his restricted views; for this conception is in sharp contradiction with the assertion of the necessity of an opposed non-rational element over against, and therefore limiting, that freedom of reason. ${ }^{2}$ How can reason be free and autonomous, if by its very necessities it is for ever limited and hampered, modified, and it may be even indirectly guided in its activity by this foreign material?

Hence, Hegel concludes, Kant's scheme, though certainly in principle Idealism (i.e. a construction from and of the identity of opposites ${ }^{3}$ ), is nothing more than merely formal Idealism. It contains the principle of the absolute unity of opposites, of reasonknowledge; but by restricting itself to knowledge of understanding alone ("finite" knowledge), to knowledge which remains rooted in the diverse

1 WIV. i. 42-44.

2 i. 35 .

3 i. 19. 
counter-posed elements of the one Reality, instead of being genuine idealism, it becomes rather Dualism. ${ }^{1}$ Its "critical idealism" consists in nothing but the knowledge that Ego and Things remain each apart by themselves and unreconciled. ${ }^{2}$ The whole content of the philosophy is not knowledge of the Absolute at all, but knowledge of mere subjectivity, a criticism of the faculty of knowledge, a revised Lockeanism. $^{3}$

Now, through the foregoing criticism of Kant, Hegel lets in considerable light on his own conception of the content of Logic and Metaphysic during this period. We see at once that the above is a review of Kant from the standpoint of a pronounced philosophical principle by which he seeks at once to transform Kant's ostensible principles, and at the same time to adopt them to his own position, in the belief that thereby he is conserving their essential significance. $A$ priori ceases to have the subjective nuance which it has in Kant, its meaning is convertible with "absolute identity"; " universal and necessary $\grave{a}$ priori" means rooted in the reality of the one identity of reason. ${ }^{4}$ It is reason which has a priority, not understanding as such. Again, Hegel seems prepared to regard Kant's notions as expressions or forms of the Absolute Identity itself; but they are no longer mere notions of understanding, but notions of reason taken as finite and loosened from its unity. ${ }^{5}$ Kant's Logic ceases therefore altogether to be regarded merely as a subjective human apparatus
$1 W W$. i. 3 I.
2 i. 27.
3 i. $20,3^{1}$.
4 i. $21,24,32$, etc.

5 Kant himself deserves the great credit, according to Hegel, of not limiting reason to the forms of finitude; but rather placing reason as such above or beyond it (i. 57). 
for putting the tangled complexity of the world into harmonious order, and becomes essentially constitutive of reality, becomes at once objective and immanently determinant of it. And with this comes the introduction of notions of both subjectivity and objectivity, as we have already noted. Hence, too, arises the alteration in the significance of "transcendental." Since the notions of Kant are notions of reason for Hegel, and reason is the ground Identity, the Absolute Reality, Kant's "transcendental" Logic ceases to be that which states "the conditions under which human experience is alone possible," and becomes a "metaphysical" Logic which exhibits the ground notions of all reality. And in general "transcendental" no longer has the limited meaning found in Kant, it becomes in every sense synonymous with "metaphysical." Finally, we find here indicated how the knowledge of the Absolute, the reason-knowledge (which Hegel does not give, but which he all along implies or hints at)could be brought about. Such knowledge is no more than implicit in Kant. But Kant's error just lay in restricting himself solely to judgment as the form of philosophical knowledge. Hence the direction in which true and final reason-knowledge can alone lie is in that form of knowledge which completes the judgment, by making completely explicit, through mediation, the identity which it implies. That form is the syllogism. ${ }^{1} \quad$ It is here that we have most clearly expressed and exhibited that "triplicity which is the germ of speculation," "2 and which it is one of Kant's

$1 W W$. i. 24, 26. With this may be mentioned the thesis defended by Hegel at his " Habilitation" in Jena : "Syllogismus est principium Idealismi" (Leben, p. 157). But too much stress cannot in the nature of the case be laid on his "defence" of such a thesis.

2 WVIV. i. 33 . 
merits to have at least disclosed. It is in virtue of this triple content and character of the one "Idea," that there is and can be no ultimate opposition between $\grave{a}$ priori and $\grave{a}$ posteriori, that one is mediated in and through the other.

The above views, which have now become fundamental for Hegel, agree clearly enough with the general content of the Logic of this period which we have already given. But they do more than this; they indicate the direction any further development on his part would be sure to take.

To Fichte, Hegel stands also in decided opposition-an opposition which he is never weary of reiterating. The ground of it is precisely the same as in the case of Kant, and the criticism only differs slightly from that of the latter. For Fichte the fundamental principle and ground fact is the Ego, Subjectivity, Thought, inward Self-consciousness. This is the Absolute, the Identity. So far his principle is idealistic, and so far it is genuine speculation. But it is of the essence of his conception that nothing more lies in the Ego than the subjective content of the Ego. Yet the subject cannot dispense with the object. Hence all the detailed content which the object possesses comes externally to this mere abstract "empty" form of reality. ${ }^{1}$ The object, however, has no self-subsistence; no reality on a level with that of the subject. Object is dependent on subject, and even produced or created by it. This being so, the identity is not an identity of both subject and object, but an identity of subject only; the object does not share equal rights in the absolute unity; its right to be at all 
is constituted by the subject. The whole system of Fichte, therefore, remains rooted in subjectivity alone; and the very reality of the objective world which he set out to explain does not possess the substantiality necessary to warrant any explanation of it. In short, objectivity per se is not explained at all. So far as the principle has content, that content is subjective only, "sensation," "intuition," "feeling," "impulse"; and these, with their various forms and relations, constitute all that objectivity means for Fichte. ${ }^{1}$ And this remains true not merely in the theoretical construction of reality, but in the complementary realisation of the objective sense-world through the practical act of pure will. For here, too, there is nothing but subjectivity to start with, and out of subjectivity it does not pass, and cannot by its own logic pass. ${ }^{2}$ There is thus in Fichte's view no Absolute Identity; there is only a relative identity, that of the subject and its content. There can, indeed, hardly be said to be an identity at all, for the ultimate fact is a merely formal principle, and the particular, the filling-in, is and remains external to it, or forced into it $a b$ extra. There is no objective content; nature is only sense-content, and has no subsistency of its own. The Absolute Identity, therefore, does not contain diversity of content, but rather one order of content, into which the other is simply merged. It is impossible on this view to deal with Nature per se; it exists merely in relation, and by reference to the empirical subject. ${ }^{3}$ Nature is simply the world of sense-experience. The principle is, therefore, not the Absolute, nor is it con-
I $W W$. i. II $5 \mathrm{ff}$.
2 i. $135 \mathrm{f}$.
3 i. $123,126,220 \mathrm{ff}$. 
crete. Its content is conditioned, its reality solely subjective.

Again, when we consider its method, similar imperfection is found. That method consists in what is called "Deduction." Its nature is, in point of fact, a result, and an implicit recognition of the finitude and incompleteness of the fundamental principle. For the ultimate and universal truth and certainty, pure Ego, pure self-consciousness, is admitted to be itself incomplete; it is limited by an other, from which it is, and must be, abstracted in order to be obtained as ultimate principle. ${ }^{1}$ But this limitation is a conditionedness which, in order to be the Absolute, the one Identity, it must overcome, and overcome by embracing that other. The recognition of this conditionedness, and thereby of the necessity of passing over to the other, of supplementing the incompleteness, of filling up the empty and abstract principle, is the nerve of this "Deduction" of the one out of the other. ${ }^{2}$ It stands in absolutely contrary opposition; it is nonEgo. It therefore is, and remains in itself, foreign to that which it supplements. The deduction is not the result of an analysis of a content, but rather of the absence of any content at all; it is the result of a want, a need, a vacancy. The Ego starts as the utmost abstraction, a mere negation of all except itself, of objectivity in general; objectivity is, for this kind of pure knowledge, simply a minus. The deduction consists in taking up again that which was abstracted from, and in attaching it on to, the pure notion. In short, we merely alter the sign in the process, change the

$$
{ }^{1} W W \text {. i. II7 f. } \quad{ }^{2} \text { i. Irg ff. }
$$


minus into a plus. It is as if one had spent one's money and had nothing left but an empty purse, and then proceeded to deduce money from the fact of the empty purse, the sole meaning of the empty purse just consisting in the absence of money. ${ }^{1}$

It is true that this completion cannot be recognised without the idea of the totality from which the abstraction is made. And there, again, lies the error of the whole procedure. For if this is so, then why was the Absolute merely subjectively conceived? Why was merely one term of the identity, one part of the whole taken as absolute? Why was the start and the construction not made from the whole itself, from the underlying unity? The only reason apparently is that this part, this subjectivity, has immediate empirical certainty and truth-truth which every one can accept at once. ${ }^{2}$ Since, however, Fichte restricts himself to this partial reality, and yet insists on completing it by passing to a further reality, from this again to still another, and so on, it is clear that this process by its very nature, if the whole objective world is to be gathered into the Ego, must go on ad infinitum. No matter how many have been safely housed, there must ever remain still one outside the fold; for without that other still to seek, the Ego would cease to be itself; it must have some other by means of which to realise itself. The totality, therefore, is never really attained; it continues, as always, what "is to be" attained; the complete identity, the absolute unity, which is the goal of philosophical endeavour, remains only an unfulfilled "ought to be," a Sollen. ${ }^{3}$
$1 W W$. i. 120.
2 ibid.
3 i. $114,216 \mathrm{ff}$. 
From all this, therefore, and the above contains the essential errors in the scheme, Hegel concludes ${ }^{1}$ that by Fichte's principle and method absolute knowledge can never be attained. Fichte's Idealism is an entirely barren knowledge, a mere "formal idealism." It is not true knowledge; this must begin from the Absolute; and the Absolute is not an abstraction, nor incomplete, nor a part. Its Idealism is indeed like Kant's, a kind of Dualism; its principle of unity, is merely a principle of determination of one by an other, a causal connexion of one with the other. An insurmountable opposition is the essence of its content and method; contradiction and not the resolution of contradiction is its inevitable result. ${ }^{2}$

It is evident, then, that Hegel's points of difference from Fichte are based on the same grounds as in the case of Kant, and that the correction of Fichte's principle and method was to be found in the fuller and more concrete appreciation of the absolute Identity on the one hand and by the use of "true intellectual Anschaunng" as the instrument of systematisation. ${ }^{3}$ This we have already described above.

It is significant for the understanding of the development which Hegel thinks at this time philosophy should undergo, and the actual realisation of which we may reasonably infer Hegel now (1802) intended, or had already actually begun, to set himself to bring about, that he considers ${ }^{4}$ the philosophical systems of Kant, Fichte, and Jacobi to have completed and exhausted an epoch in the

$1 W W$. i. I 14, 120, 126. 2 e.g. that between freedom and necessity, i. I $23 \mathrm{ff}$. 
development of the new principle of speculation. For in all three that principle has been conceived and expressed in a one-sided, limited, incomplete form, and all possible variations of that single form, which is common to them all, have in their systems been worked out. That form is subjectivity; the idealism in all three is grounded on a restricted reference to one side, one pole of the Absolute Identity, that of the subject. Their idealism is nothing more than the dogmatic metaphysic of subjectivity. In all of them the one primal reality is the subject; the objective world becomes mere appearance (Kant) or affection, determination of the sensibility of the subject (Fichte), or merely that whose reality is supported by and conditional on belief $\left(\mathrm{Jacobi}^{1}\right)$. In all of them the Absolute as such, as Absolute Identity, is a mere beyond, for Kant a Ding an sich, for Fichte a Sollen, for Jacobi a Glauben (for Glauben is the condition both of the objective world and of the Absolute per $s e^{2}$ ). In Kant the Absolute Identity is a mere thought, a merely problematical objectivity, is not actually realised by and in that which for him is the fundamental element-the notion, the form, the universal. In Jacobi the opposition found in experience is only overcome by what is a "beyond" for knowledge, and the attainment of this beyond, which is to reconcile opposites, is merely subjective; it is a "belief," a "yearning." In Fichte there is a union of the bare formal objectivity of Kant with the yearning, the mere subjectivity of Jacobi in the form of a

1 The separate consideration of Jacobi's fundamental ideas ( $W W$. i. 5 I ff.) would yield no more light on Hegel's position, and can be here dispensed with; cp. i. $116,117,152$.

$2 W W$. i. $99 \mathrm{ff}$. 
"demand," which, however, is still not an Absolute Identity, but is confined to subjectivity. ${ }^{1}$ Thus those three exhaust the possibilities of this one-sided conception of the principle of Idealism, without satisfying the needs of absolute knowledge. Their system begins and remains in the process of reflexion, of relativity, of duality, of diversity ; and this characterises their entire exposition. It is because these forms of philosophy complete the cycle of "systems based on the "absoluteness of finitude," and rooted in the one-sidedness and subjective limitation which characterise a time of culture and spiritual development (Bildung), ${ }^{2}$ that a true philosophy may be expected to arise through and by way of the negation of the absoluteness of their positions. And the time for the appearance of such a development of philosophy has now come, says Hegel. ${ }^{3}$ Not that the negation of these systems means their annihilation; they contain what is of essential philosophical significance. For in them thought, by that ceaseless process of negation of opposition and finitude, is recognised to be, what it in truth is, infinite, "the negative side of the Absolute." May" we not fairly discover in all this the words of the herald who was himself to become the founder of Absolute Idealism?

I The disagreement which Hegel shows with the positions of the thinkers above considered is based upon principles which he consciously holds to be in harmony with those of Schelling. That connexion is so close in form and expression at this time that it would involve needless repetition to state and compare
$1 W W$. i. II3, II4.
2 i. 153,154 .
3 Cf. Leben, pp. 214, 2 I 5. 
their several positions. We find the same general conception of the nature and meaning of the absolute identity $;^{1}$ the preservation of both opposites alongside the negation for each per se; ${ }^{2}$ the dividing "negative" function of reflexion $;^{3}$ the character of the Absolute as the neutrum, "the indifference-point" of subject and object; ${ }^{4}$ and the difference between subject and object being simply quantitative, due to a "preponderance" of the real over the ideal factor. ${ }^{5}$ It is to be observed, however, that we have only grounds for asserting a general community of principle; further comparison of the views of Hegel with those of Schelling, beyond what can be gathered from the above, is not possible. Their Logic and Metaphysic would presumably be the same in content; for Hegel remarks, both Fichte and Schelling in their respective ways had, like himself, attempted to state in some systematic form Logic or Speculative Philosophy. ${ }^{6}$ The difference of treatment between Hegel and Schelling on this point, so far at least as discoverable, is that Hegel deals confessedly with Logic as a distinct and separate discipline of philosophy, and acknowledges its importance, while Schelling fuses Logic with Metaphysic proper. ${ }^{7}$ This difference between them seems of less importance at first sight than it really is ; for we shall see that it is just the separation of problems regarded as identical by Schelling that comes to be characteristic of Hegel's own system.

Other instances of divergence between them, of a more pronounced and deliberate kind, can also be
$1 W W$. i. $244 \mathrm{ff}$.
2 i. 245 .
5. 257.
3 i. 246.
${ }^{4}$ i. 257,26 I, etc.; cf. i. 19.
6 Ros. Leben, p. 188.

7 In Trans. Idealismus. 
found to exist at this time alongside the general ostensible agreement. There is a difference in the conception of method in the two cases, a point on which Hegel laid ever-increasing importance as he proceeded. Hegel's fundamental conception is that of development, transition from lower to higher, and ordered involution of the later with the earlier steps in the process. Hints of this we have already had to a certain very limited extent in these schemes or sketches of philosophy and its parts which we have so far stated. The fuller consciousness of its importance grew with his intellectual development till he finally arrived at that conception of the method which he could and did regard as the very pulse-beat of the life of absolute truth, its only final medium of expression. It is the lack of development which he considers the primary defect in Schelling's system. ${ }^{1}$ And this is easily seen to be true of Schelling's system, as exhibited in the work which had appeared just before Hegel came to Jena-the Transcendental Idealismus. There is connexion, for there is both "deduction" and "construction" in the system; but there is no development in any proper sense of the term. Like Fichte, Schelling starts from what he calls fundamental supreme principles, and from these as the highest ultimate of speculative knowledge proceeds to educe or 'deduce' the remaining content of the system as derivative, though of course constitutive and necessary elements in the whole. This is the reverse of a developmental method. And, moreover, there is no inner connectedness of part with part; there is the connexion of a single purpose in the 
system, but not the objective self-connexion of the content itself. It is by the seemingly arbitrary Machtspruch of an external agent that the whole obeys an ordered plan. These and similar defects of method (and it would be easy to discover others) would be readily perceptible to Hegel, to whom system was second nature, and for whom the significance of development was becoming ever more manifest.

And, indeed, he did not rest content with merely recognising this defect in a general way; we find some indication of his views regarding the function of development in the "system of Identity" mentioned in the only article in which at this time he deals with Schelling. ${ }^{1}$ He there points out that while the two philosophical sciences of Intelligence and of Nature are both sciences of the content of Identity, yet because the content of each is itself the one identity, the sciences cannot be left side by side and opposed, but "must be regarded as forming one continuity as one connected science." So, again, Mind is not merely in its totality "Mind, but also carries with it the self-construction of Nature," and vice versâ. Or further, " the original Identity must unite both (the negative synthesis, synthesis by negation and opposites, and real positive synthesis of them) in the Anschaunng of the objective process of the Absolute in its complete entirety." Now this conception of an immediate and necessary continuity between the contents of the opposed sciences of the Absolute may not seem in direct contrast with Schelling's own views as expressed, e.g., in the introduction to the Transcendental 
Idealismus; but it ought to be pointed out that the conception has at least no warrant or support from Schelling himself, for whom those sciences were palpably different ways of stating objective truth, the objective unity of subject and object. They were different because that unity was construed on a different basis in each case-in the one case from object, in the other from the subject; and their respective constructions were as different as object is from subject. Hegel probably supposes he is in agreement with Schelling in his interpretation; but it seems to indicate the presence of a conception alien to Schelling's own view, and peculiar to Hegel himself. Hegel has, however, not shown in detail how it could be brought about, so that it would be valueless to consider this point.

But again, not merely in the method but in the nature and meaning of philosophy, Hegel differs from Schelling. For the latter Philosophy has its origin in Poetry, is by itself a subjective activity, which remains inside the limits of its ideality, and can only be again delivered from its subjectivity, can only pass beyond these limits into complete objectivity, by means of Art. Art is the deliverer, the coadjutor, "the only and true and eternal Organon und Document" of philosophy, the creative productive function necessary to realise the objectivity philosophy demands. ${ }^{1}$ With Hegel, on the other hand, Philosophy has its roots in Religion, has its own functions and instrument complete in itself, is a self-closed activity, lives and moves in the clear transparency of the notion, of conceptions, and as contrasted with religion is the mediating

1 Trans. Ideal. Absch. vi. $§ 3 \mathrm{ff}$. 
reflective process by which the immediate unity of the individual with the universal present in religion is reproduced in the sphere of conception and of thought. It is hardly necessary to point out how this profound difference of point of view, purpose, and content of philosophy would affect the respective systems of the two thinkers.

Finally, there is a specific advance and transcendence of Schelling's point of view. That "quantitative preponderance" of polar opposites in an indifferent neutrum did not long satisfy Hegel. By his work in ethics primarily, but also by other considerations to be mentioned presently, it was not long before he broke through the conception of an indifferent unity of opposites. Mind was seen to be higher than, and not on a level with, Nature. But with such a radical change of conception of the relations of the opposed elements in the Absolute, there would necessarily come a change in the interpretation of the Absolute itself. And this change we shall find taking place. How soon Hegel split with Schelling after their first collaboration in r8or we cannot exactly say. Certain it is that his warm agreement did not last long. We find him remarking in his note-book ${ }^{1}$ during this Jena period that "a short time will make it clear what Schelling's philosophy essentially is. Judgment upon it stands, so to say, before the door; for even already many see through it. Philosophies like these give way not so much before proof and argument as before empirical experience of how far they can lead us." The critical attitude implied in these words would completely loosen the bonds of intimate 
union and intellectual sympathy which had hitherto bound Hegel to Schelling, and leave Hegel again, but at a very much higher level of attainment, in the independence which he possessed before committing himself to the philosophical influences of Jena. 


\section{CHAPTER V}

TRANSITION-ORIGIN OF THE "PHENOMENOLOGY OF MIND" AND OF THE "LOGIC"

IN order to understand the line of development which leads Hegel to the position which he finally adopts, and the reason which induced him to alter the views which he held during the period we have just reviewed, we must bear in mind the demands which from the first he expected philosophy to satisfy. These were that it should be the complete exposition of the knowledge of the Absolute, that the system of such knowledge should be determined by the inner connexion of its content, and that the nature of the Absolute should be shown to be Mind, Spirit (Geist). These are for Hegel simply assumptions, fundamental positions which must be held by those who would fulfil the task of philosophy. He does not seek to prove them at the outset; rather he takes the only possible proof of them to be the actual realisation of them by philosophy. They characterise his distinctive attitude in philosophy, and were the guiding purposes which were active throughout the construction of his system.

Now, in spite of certain appearances to the contrary, Hegel did not give way on any of these points during the second period; they existed side 
by side with positions which were in themselves incompatible with them. It is, of course, on the third point that this seems less evident. It certainly is impossible at the same time to hold that the Absolute, the unity of subject and object, is Mind, and also that the Absolute is the Identity of subject and object which is equally indifferent to both, in the sense that it is indistinguishably both at once and not one more than the other. For the nature of Mind holds more directly of the subject than of the object, and consequently the Absolute could not be equally indifferent to both subject and object. And his original view Hegel undoubtedly allowed to fall in the background at this time; but we are not entitled from the records left us to infer that that position had been even temporarily abandoned. For not to mention that the influence of Schelling lasted at the most for so short a time, after which Hegel brought again, and finally, into prominence the supreme importance of the conception of Spirit, we find throughout this period continual fluctuations between the Schellingian conception of the Absolute, and that which he hitherto held and later established. At one time he regards the Absolute as the "Indifference-point" of subject and object, at another he takes the Absolute to be most appropriately conceived as concrete individuality, that union of universal and particular which is the nature of intelligence. Or again, the Absolute is supremely Sittlichkeit; while at another time it is spoken of as a characterless Identity. Further, when describing $^{1}$ (in semi-theological terms, it is true) the nature of God, he does it in such wise as to

1 Ros. Leben, pp. 192, 193. 
indicate that God per se was not a mere neutrum of reality, but a living active self-consciousness. This attitude of hesitancy and ambiguity he abandoned by maintaining the 'supremacy' of Mind over Nature, of subject over object, the position which, as we already pointed out, marks his abrupt and decisive disagreement with Schelling.

It is important to note that this was no more than the reassertion of that principle which was indubitable dogma with Hegel all along. And having now adopted this position, he sought to establish it and to elaborate its complete import during those years immediately preceding the appearance of the Phänomenologie des Geistes, when his separation from Schelling, or, as Hegel preferred to say, "the Schellingian school," was once for all signalised in the famous preface to that work.

His contention that "Mind is higher than Nature" is no mere secondary and unimportant difference from the view that the one is of the same value as the other for the Absolute, where both are identical. It becomes the foundation of that doctrine of degrees of reality which characterises Hegel's system, it determines the point of view from which a system is to be obtained by stating the fundamental reality in it, and it indicates the line of development which he must immediately follow in order to obtain that system. Let Hegel once abandon the position that the Absolute is the indifferent identity of subject and object, and there was nothing possible for him except to maintain that the Absolute should be per se Mind.

It must, however, be observed, on the other hand, that this did not mean the annihilation of the 
view that the Absolute is unity of subject and object, unity of all opposites. On this he is at one with Schelling and also with Fichte. The question for him is, what most accurately and completely exposes the nature of the Absolute? Mind and Nature, Subject and Object together are the Absolute, and are opposed in it; is the Absolute the neutrum of both, or is it one rather than the other, does one more truly express it than the other? There is no third position possible. ${ }^{1}$ It is stating the same problem to ask, are subject and object on the same level of reality, of value, of meaning, have they both in all and every respect the same nature, or is the content of one higher than, superior to, the other? Hegel maintained for a time the former alternative in the period we have been considering. For it there appears that each is simply a "relative identity"; the "preponderance" of one or other opposite is due to the point of view from which the Absolute is regarded; all philosophy consists in the "repetition of one and the same identity"; the Absolute is the "indifferent unity of both." Henceforward, however, he adopts the second alternative, and thereby breaks with Schelling. All his subsequent philosophy is simply the complete establishment and exposition of this view. The plan by which he sought to obtain this result we shall presently indicate. We have merely to note that this explicit adoption or rather re-adoption of $\mathrm{Mind}$ as the fundamental philosophical principle is what leads

1 We might say that the essential difference between Fichte, Schelling, and Hegel just consisted in the alternative adopted by each respectively. Fichte chose the latter, giving none but a subjective reality to object; Schelling chose the former, giving equal reality to both; Hegel chose the latter, giving merely a superior reality to the subject. 
him to abandon the Schellingian attitude of the second period, and determines finally the current of his subsequent thinking.

The reasons for this advance seem to have been cumulative. We have already insisted, perhaps sufficiently, on the essentially religious and ethical motives which led Hegel to devote himself to philosophy. These fashioned his interest in its problems, and in a manner predetermined the result. Mind always appeared to him as the deepest, most real of Realities. This is seen, for instance, in the place which he assigns to Morality in his scheme in the second period. It is there taken to be the fullest, most concrete expression of the Absolute. ${ }^{1}$ Again, the actual relation of Mind to Nature in moral experience, the very idea of freedom seemed to compel him to place one on a different plane from the other. ${ }^{2}$ And on the other hand, in intellectual experience, the difference was also equally clear. The very meaning of knowledge meant the dominance of Mind over Nature, of subject over object, a superiority and prerogative which had been established by Kant in such a way as to have become almost self-evident. Moreover, the meaning which Hegel gives to philosophy in particular would seem necessarily to lead him to this position. Philosophy, as we saw, was the self-knowledge of reason; the Identity which is the ultimate fact is the identity of reason. But if so, then Reality must be primarily Mind, which is concrete self-consciousness. Reason, or Mind, must contain and not be co-ordinate with object, Nature, or "necessity." It is impossible to treat all philosophy (Philosophy of

$$
1 \text { WW. i. } 38 \mathrm{I} \text {. }
$$

${ }^{2}$ Cf. Ros. Leben, p. 187. 
Nature included) solely in terms of reason, and impossible to speak of "the self-knowledge, the self-intuition of the Absolute," the "absolute knowledge" " which the Absolute possesses of itself, and yet maintain that the Absolute is merely the indifferent identity of both Mind and Nature. By the virtue of that self-knowledge, the Absolute must be Mind rather than Nature; Mind must be "higher than" Nature.

There is further to be taken into account the influence on Hegel for many years of Plato's philosophy, in which assuredly there is little indication of an equality of value or significance between Mind and Nature. And this conception of their relation, derivable from Plato, was found confirmed and more systematically elaborated by Aristotle, with whom in the later years at Jena Hegel became intimately acquainted, and whose influence upon him henceforward is pronounced and effective. Finally, in addition to all this, we must take note of a characteristic of Hegel's mind which made it impossible for him to acquiesce for long in such an identity as Schelling offered. This was his deep appreciation of the richness, the multiplicity of the content of the world. When, therefore, he saw the results to which such a view as he advocated in and out of the Critical Journal really led, and were actually tending inside the school of Schelling; saw how it denuded the universe of its plenitude of difference, and converted it at best into a monotonous repetition of a characterless, indifferent identity, it is small surprise that such a position should not be long attractive to a mind so

${ }^{1} W W$. i. $38 \mathrm{I}$ f.; Ros. Leben, pp. 192, 193. 
fully awake by nature, knowledge, and experience to its varied and complex life. All these factors, therefore, taken together, seem to make it inevitable that Hegel should find satisfaction only in the principle that the Absolute is Mind, and should seek to "demonstrate" that it is so.

The mention of the last of the above influences leads us to another aspect of philosophy which, on his view, must be insisted on and realised, if it is to attain its end-the completeness of the knowledge of the content of the Absolute. This was obviously present and operative in the second period, though it is not itself carried out. As it appears there, however, it is certainly defective and questionable, and it henceforth undergoes decided modification. We found that Hegel made a somewhat abrupt distinction between infinite knowledge and finite knowledge, between the knowledge which is concerned with the Absolute Identity quâ absolute, and that which deals with the finite realities taken as finite. And we found that the latter was dealt with by reflexion per se finite and infinite, was determined by understanding and by reason in its negative aspect, and formed the sphere appropriated by Logic; while the former was dealt with by transcendental knowledge which was one with transcendental Anschaung, was determined solely by reason in its positive aspect, and formed the sphere of Metaphysic and "Philosophy proper." Logic we saw had at best merely a negative value for Metaphysic; the finite had significance for the Absolute only when and in so far as it was negated.

Now such a result was soon seen to be unsatis- 
factory in many ways. For, in the first place, how could the knowledge of the Absolute be complete if the content of the Absolute was removed? And what content remained after all the finite content was abstracted from the Absolute as such? How was it possible to "construe" the Absolute at all when the opposites which appeared were viewed simply as negatives and were merely negated? And since these finite elements belonged to the sphere of Logic, what remained then for Metaphysic, or "transcendental knowledge" to do? All finitude being as such excluded from Metaphysic, nothing was to be done but to show the "repetition" of one and the same Identity throughout all reality. "Construing" it would only mean exhibiting its selfidentity everywhere, not showing how it maintained itself as different or in differences, but showing that all differences were not differences at all but the same Identity. All differences were finite, and could only appear in the view of finite knowledge to be different. For infinite knowledge there was literally nothing but the one Identity. But such a Metaphysic in the attempt to give complete knowledge of the Absolute succeeded, or might succeed, in giving completeness, but utterly failed to give knowledge. Nothing was to be gained or received from the continuous manifestation of the same Identity; in knowing it at one step we knew all that was to be known. In addition, this Identity could hardly be exhibited in the differences, for there were no real differences for it at all. These all held good merely inside the sphere of the finite and were already negated in Logic (in "philosophical reflexion"); the differences were for the 
Absolute indifferent. What made them different was the absence of that positive element, the Identity, found and discussed in Metaphysic; when this appeared or was exhibited the differences vanished. In " transcendental knowledge," therefore, in the "union of reflexion and Anschaunng," nothing could be dealt with but the Absolute Identity which was at best refunded into those realities which had a mere semblance of difference, a procedure which seems either impossible or inadequate and falsethe former if there were no different realities into which the Identity could be refunded, the latter if there were such realities.

Further, it is also evident that such a Metaphysic seems perilously near to a discussion of what is a merely abstract identity of understanding, against which Hegel had already waged war. The Logic had been the negative assertion of an Absolute whose positive reality was exhibited in Metaphysic. But the negative activity of this Absolute which appeared in the Logic had wiped out as with a sponge all the plenitude of content which would have given meaning to the positive assertion of its identity, and left nothing to be considered but a characterless blank. No real knowledge of the Absolute was given in the Logic itself-at best only a knowledge of what the Absolute was not; yet when the Metaphysic seeks to supply this knowledge of the Absolute Identity there is nothing in particular to know except that the Absolute Identity alone is. It is not open to show that this Identity is determined as different; there is no getting back to the differences at all, for the simple reason that they have been already abolished in the Logic in order 
to find place only for the one Absolute. It is as if all the wealth of the world were reduced by a process of elimination to a single species of commodity, which thereupon turned out to have by the nature of the case no exchange value whatever. It certainly seemed, therefore, that with such an Absolute what had been attained was not an identity which substantialised the various opposites of knowledge, but rather one which remained apart from them altogether, and at most destroyed the substantiality they possessed in finite knowledge. It was in fact an Absolute Identity which did not appear abstract, merely because it had established itself by destroying everything which offered itself as a rival to its supremacy - the lion that herded with the flock and became lord of them by the might of its hunger.

And this result was not the fault of the Logic, but rather of the Metaphysic. The Logic because negative of the finite content did not demand the Metaphysic, the Metaphysic rather demanded a negative Logic. It was because the Metaphysic was so conceived that the Logic was negative to prepare for it. For Metaphysic there was literally only one Reality; and yet in spite of this finite elements actually existed. It was plain that the completeness of the knowledge of the Absolute ought somehow to find a place for these finite realities, which would at once do justice to their reality while refusing to take them as merely finite. Hegel appreciated the importance of this intensely, and soon felt it impossible, on those intellectual and other grounds already indicated, to find satisfaction in a picture which secured the harmony of its effect at the price of the monotony 
of its colouring. And he saw that there was only one requisite necessary to attain a different and more satisfactory result-namely, to alter the purely negative character of all finitude. This was the sole ground of objection, the source of all the barrenness of the result of his previous conception, and here accordingly the change was to be effected. The finite factors, the finite opposites should not be entirely negated, and all differences vanish before the one identity; they should be posited.

But note that by retaining as he did the conception of an Absolute which must be infinite, in the sense of including all and determining all, one and identical (just as formerly), the character of finitude as hitherto conceived was not entirely changed, but only partially so. The finite opposites were to be both posited, substantialised, and negated as well. The mere insistence on the latter had turned the Absolute into the immediate tomb of the finite; the insistence on the former alone would give immortality to all finitude, and destroy the meaning of the Absolute. To avoid both these results he had to demand the negation as well as the preservation of the finite.

Indications, indeed, are not lacking that the importance of both these factors had occurred to him even when holding the view which he henceforth abandons. For, as we saw above, the finite realities are related to the Absolute, are therefore in a sense posited in it ; but they are only related to it in order to be finally negated by it. Similarly, again, by asserting that the finite as such was the province of understanding, and yet that knowledge of understanding was "not entirely opposed" 
to that of reason, but rather intimately connected $^{1}$ with it, we have clear suggestion that a positive character belonged even to that which was negated by reason. And when it is maintained that reflexion, negation, is merely one side, the negative side, of reason, the same idea is in a measure contained. The truth is that the purely negative treatment of finitude which is undoubtedly the dominant tone of this period was due to an over-emphasis on the merely negative side of the activity of reason, which was perhaps a natural exaggeration when he had for the first time seized the significance of an absolute philosophy. If, then, the consequences to which this led did not by the nature of the case realise that knowledge of the Absolute which he sought, this purely negative activity of reason necessarily required to be qualified.

Now the positive aspect or moment of reason had hitherto been contributed by Anschanung; and the positive element was, we saw, the Identity. The treatment of this fell apart from reflexion (the negative moment of reason) and belonged to Metaphysic. If, therefore, a positive character was to be contributed to the finite realities as such, it could only come from the Anschaunng of Metaphysic. But in that case the relation between reflexion and Anschaunng must cease to be so external; the one must share the nature of the other, must be found with it. ${ }^{2}$ They must, in fact, become

1 Leben, p. 190.

2 It is true, he says, that transcendental reflexion and Anschauung are united (in transcendental knowledge); but the point is, that in spite of this so-called identification, they still remain side by side as distinct factors or processes; neither is abandoned, or gives way to the other, and they are not alternatives. 
one activity with two inseparable moments, a single current with opposite poles, a functional unity of two factors. Reflexion must function with Anschaunng, Anschaunng must mediate and negate with reflexion ; all externality of relation between the two must vanish. This would then give the completeness of knowledge desired. Nothing finite would in such a case be left out ; every finite would get its due, and find its place in the Absolute, for its positive reality would be conserved by the positive function introduced. Yet the Absolute would likewise hold its place as absolute, because every finite is to be negated, and negation in such a case only comes from the one absolute and infinite Reality. And nothing more nor less than such a unity of negative and positive function would satisfy Hegel's demands.

It is not, be it noted, by laying greater emphasis on understanding as opposed to reason that this new result is to be brought about. True, it had been by the denial of that fixity contributed by understanding that the negation of the finite had been maintained in the Logic. But this fixity, we must observe, was attributed to an unauthorised and indefensible act of understanding, which "robbed" finitude of its reason-character, ${ }^{\text {" and }}$ stemmed the flux of its own essential negativity. ${ }^{2}$ The nature of understanding was determined from the point of view of reason, and as this was purely negative in character, understanding had no right per se to fix and determine finitude, and was much nearer in so doing, at least so far as philosophy was concerned, to illusion than truth. Now, however, when the positive element of the finite becomes
1 Leben, p. 190.
2 ibid. p. I84. 
emphasised and insisted on, understanding assumes another and a most important place in Hegel's treatment. But this is because the positive element sanctions the fixity of the finite which is the work of understanding. It is because reason demands and asserts a positive aspect in the finite in order to attain that completeness of knowledge desiderated that the claims of understanding to substantiate the finite are allowed to hold good, just as it is reason which determines how far they are valid. No doubt the rôle which understanding usually plays, influenced Hegel at this juncture, and no doubt his first reaction from the barrenness of an Absolute Identity would find greater resource and satisfaction in the definiteness, the concreteness of the world as determined by understanding. And this would induce him doubtless to insist on the recognition of its claims per se, which again might suggest the necessity for asserting that positive aspect of the finite already mentioned. Still, in spite of this, and in spite of the extraordinary prominence he henceforth attaches to understanding, which he declares to be "die verwundersamste und grösste oder vielmehr die absolute Macht," ${ }^{1}$ it is clear for the above reasons that it is the positive character derived in the manner and for the purposes stated that gives force and authority to the claims of understanding, and not understanding which fuses a positive content into the purely negative activity of reason. This will become still more evident as we proceed.

Now, since the above considerations indicate the line of development which Hegel is to follow in order to attain that completeness of knowledge of

1 Phänomenologie, Vorrede, p. 25 (ed. I84I). 
the Absolute desired, if we can lay bare the plan and the means he adopted to obtain the method which would realise that end, we shall have gone very far to disclose the clue to his Logic. We cannot, however, accomplish this till we deal with the third essential characteristic of philosophy on which Hegel insisted.

The third characteristic, which in Hegel's view philosophy must have, was, we saw, the systematic connexion of its content. During the period we have considered there is obviously enough an attempt at systematic connexion, and with some measure of success. But it is equally clear that this connexion was not thorough. The parts of the Logic were not directly connected with each other, nor was there any except an external relation between Logic and Metaphysic. There was lacking that inner necessity in the scheme which could only come through development. He had, indeed, hinted that this was the proper method by which to attain the system he required; but the law of this method he had not yet formulated. All the parts of his scheme have so much connexion that they are determined by reason, which alone, in fact, gave them philosophical significance. But more than this they can hardly be said to possess. The law of the Logic is one principle of connexion; that of the Metaphysic another. The former is antinomy, the latter the immediacy of Anschaunng. But one proceeds independently of the other, and no direct relation is established between them. Finitude is laid waste, with no connexion between the finite elements except that of a common ruin by a common enemy; and then without any evident 
preparation we enter at a single stride into the citadel of the Absolute. We are not led up to the Absolute through and by means of finitude; simply by the magic might of Anschaunng the Absolute rises and takes shape before us. How we come by such a method is not established, nor is it shown how we get possession of the two-edged sword of reflexion. These are not so much distinct forms of knowledge as distinct kinds of it, and one is as arbitrary in starting-point and procedure as the other.

Again, the same objections can be raised, and for the same reasons, against the relation which exists between the identity of the Absolute and the finite opposites, the finite differences. These are placed over against each other in unmediated and unreconciled opposition, and no connexion, organic or other, is exhibited between them. The result is, as we saw, they occupy two different spheres; in the one there is no identity, in the other no difference.

There is further no inner connexion stated between the various functions, understanding, reason, Anschaunng; negative and positive reason; and yet all the knowledge supplied in the scheme is derived from these sources. They are, as it were, various closed chambers of knowledge, all important in themselves, but one hardly more so than the other, for each contains distinct information, and with no evident unity or connexion between them except that they all exist together under a common roof.

There is finally to be noted the ambiguous character of reflexion and Anschaung in the scheme. 
At one time he seems to distinguish between reflexion and the object of reflexion, between Anschaumng and what is Angeschaut; at another time he seems to make no such distinction whatever. ${ }^{1}$ The general position he takes up inclines him towards the latter rather than the former; and, as we saw, any other view would make his position meaningless. For its essential import is to insist on the identity of each with the other; and he is concerned not with the psychological process of thought, but with its result. Still, the other view does appear either as a survival from his earlier scheme, or because as a matter of fact the terms in question were ambiguous. The effectual removal of this ambiguity was clearly imperative before any system could claim to be thorough; and its deliberate removal would go a long way to attain that systematic completeness desired. Such an undertaking is, indeed, what Hegel set himself, the result of which appears as part of what we now know as the Phenomenology of Mind.

It is evident from the foregoing indication of the defects in systematisation of the content of knowledge, that if Hegel was fully to attain his ideal of system decided changes required to be made. For the purposes of the construction of the system he desired one thing was absolutely necessary, and would indeed be sufficient; there must be a unity of method governing the whole procedure from first to last. This was the radical defect in the construction of the scheme he had formed in the second period,

\footnotetext{
1 There is also apparently a distinction made between the reflexion of " understanding" and that of "reason"; but doubtless this is another form of the ambiguity just noted (pp. 133, 134).
} 
a defect which was in the nature of the case, for the parts of the scheme contained forms of knowledge each determined by a different principle. Since the parts were external to each other, and each had a distinct method of procedure, there could be no one systematic whole determined by a single method. Method is necessarily dependent on content, if the system is to possess that character of inner necessity which Hegel sought. But the various functions above specified, negative and positive reason, etc., were not to be abandoned as valueless when the new advance was made. Rather that advance proceeds along the lines indicated by them; they are in reality permanent factors in his system. But inasmuch as the defect of his present scheme lay in allowing each to do its work independently, he was bound to remove this defect if he would accomplish that purpose he has in view. And this could only be done, and would be satisfactorily done, if each factor were shown to be a $x$ function of a single activity, a moment in a single -1 process. Hence the other remaining problem to be settled was how to obtain such a method.

Now it is impossible to understand how Hegel overcame these three kinds of defects which rendered his second scheme unsatisfactory, unless we realise that no one could be removed without a corresponding alteration in the others. They were all necessarily involved in each other. It was at once impossible and useless for him to attempt to discover a true and thorough method of systematisation without taking account of the completeness of the content of the system; and similarly he could not determine the completeness of the content without immediate 
and essential reference to his fundamental principle. And it is again clear that the primary fact, on the meaning of which all else depends, is the nature of that fundamental principle itself. If once this is determined, all the other elements (the method and the contents) will appear at once, or be easily determinable; for on that depends everything else in the system. The first problem, then, is to determine the nature and meaning of his ground principle. That principle which henceforward is the securely established basis of his system is, as we have seen, that the primary Reality, or that Reality primarily, is Mind. ${ }^{1}$

The absolute Reality is not the mere Desert of Indifference; it is not the mere quantitative equilibrium of the opposed poles of reality (subject, object, etc.). It is one more than the other. One is actually higher than it, because embracing in itself what the other is. And therefore the Absolute can be expressed more truly by this one than by the other. Since that which is higher contains in itself as a moment what is characteristic of the other, the Absolute is primarily the higher of the two. This is what in reality is absolute, what is absolutely Real.

But if Hegel has once risen above the position of Indifferent Identity, has once established that there is a difference, mainly a difference in degree of reality, between these opposites, and that the difference is fundamental, he has thereby set himself a unique and distinct problem. That problem is to establish and exhibit this in philosophical, i.e. (for

1 The statements, apparently different in meaning, are for Hegel alternatives, because Reality for him is one, the Absolute is a single unity. 
him) systematic form. It does not and cannot remain a mere conviction; the other demands which he makes on philosophy, force him to work it out in detail. Philosophy, he held, must not be merely love of knowledge, but must be really knowledge. And it can only be called real knowledge if it is complete knowledge, knowledge of the whole. This is simply what it claims to be; less than this will not satisfy it. But knowledge of the whole must be a whole of knowledge, must be system, and must by the nature of the case be a necessary system. Philosophical truth is, and must be, system of philosophy.

Incidentally, therefore, any principle which claims to furnish philosophical knowledge, and yet cannot or does not furnish it in this form, is thereby on this ground alone self-condemned. Thus when we are offered as a principle, e.g. that we know the Absolute immediately by feeling or by Anschaunng, nothing more can by such a process be supplied, no construction, no exposition. But we do not thereby get philosophical knowledge, rather we get a substitute for all philosophy, not a system of truth, but that which renders any such system as dispensable as it is impossible. Indeed the satisfaction thereby sought is not the satisfaction of science, but rather that of religious enthusiasm, something nearer to cultured mysticism than explicit knowledge, not truth but rather edification. ${ }^{1}$

Hegel, then, must work out his new conception systematically. And this is the more necessary when the difference which he asserts is as vital as he believes it to be. For all finitude is embraced

1 Hegel has the school of Jacobi in view in this criticism. 
under one or other of the fundamental opposed realities, subject, object, etc. ; and hence the assertion of the superiority of the one over the other must affect all reality, be present throughout it, and must therefore be thoroughly established everywhere, if it is to be ultimately valid at all. Nothing less than this will satisfy; a mere general exposition of his contention will not suffice; he must show it to hold at every step where subject is brought into relation with object, mind with nature, etc. For take up reality at any point, and we shall find that there we have, ipso facto, a relation between the two opposites; the reality dealt with by us, as Subject, either belongs to the world of Nature only, or partly to one, partly to the other. But in any and every case that relation is in some form present; one opposite cannot be taken by itself without further reference, it must imply and be related to the other. Consequently, if this superiority is to be real, it must be shown to exist wherever that relation exists; it must be shown to hold, in short, of every phase or part of reality.

And it is not only necessary to do so, it is, Hegel believes, in the nature of the case quite possible to do it. For we have this relation appearing in different ways, in different spheres, embracing one order of fact at one place, another at another. We have it now, for example, as the relation of Percipient to Perceived, now as that of Observation to Observed, now as that of an assertion of a Law between Facts, or again in Conduct, in moral action. All these are different, and yet all imply and express this same fundamental relation. Now each of these because different can be treated separately and by itself; we 
can isolate it from others, and regard it simply as it stands. Hence we can examine each of these various forms where the relation holds, and show that in every form without exception this superiority is discoverable.

Hence, then, the maintenance of the supremacy of Mind is simply the other side to, has as its necessary complement, the complete and detailed exhibition of this supremacy throughout all reality. It means that Mind is to embrace its object. It is not to exclude it (that would be Dualism); nor to negate it (that would be Solipsism); nor to be on a level with it (that would be the Indifferentism of Schelling); it is to contain it in itself. This alone is Idealism. Now it was mainly to solve this problem and establish that position that Hegel wrote the Phenomenology of Mind.

Such being the general nature of the problem which he has to solve, it is not difficult to see that to accomplish his purpose the inquiry will conveniently fall into two parts. In one part he will be exclusively engaged in showing that Mind, when and wherever we find it in relation to an object, is actually "higher than" 1 its object, actually contains that object in itself, that only in so far as an object is the mind's own, is the mind's own self, is it an object for and over against mind at all. In such an inquiry there will be no need to confine attention to any one form under which this relation exists. Any and every form will have to be considered. It must be shown that wherever the relation exists, throughout the whole range of the life of Mind, an analysis of the relation will in all cases show that

1 This phrase will become more precise as we proceed. 
the essential character and content of an object is mind-constituted, mind-determined, that its being as an object for consciousness is the same as its being for itself, that its constitutive moments are determined by mind and for mind. Here, then, we have no special regard for the ultimate form under which such a relation is most truly expressed, or indeed is alone expressed truly and fully. This will of course be in the background of the inquiry all along, for it is the final result to be arrived at, and in a measure determines the inquiry from first to last. Still, because it is only at best one form of the relation, it will not in this part be treated in any other way except simply as a special form of the relation in question. For not merely the true form of the relation, but untrue, in the sense of imperfect forms of it, must be considered. In some cases, e.g. in Perception, the object seems and is ordinarily taken to be quite external to mind; the latter seems to have nothing to do with its constitution, it seems to exist by itself, it is merely "given" to mind from without. Yet this is a form of the relation of mind to an object, and for that reason alone must find a place in the inquiry. In others again, e.g. the Moral Order or Religion, the object seems entirely determined, or at least mainly determined, from mind itself, is a sort of eject of its own activity; but here we have also a relation of an object to mind of a certain distinct type. And between the apparent pure externality of the object to mind, and the apparent simple "manifestation" of mind in its object, there is room for considerable variety of forms of the relation, all of them actual relations, but all more or less imperfect (when 
judged from the final and true form). All these, then, must be dealt with separately, for all have claims to consideration, because in all of them mind is established in relation to an object. From the point of view of this part of the inquiry it is in the first instance of no importance what degree of perfection any relation may possess, what degree of inwardness its terms may have to each other; the determination of this degree is an after result, discovered in the course of inquiry and by it. The mere fact that the relation actually is discoverable falls inside the experience of mind; the mere fact that mind is related to an object, no matter how that object may present itself, or what special attitude mind may take up towards it, is all that is necessary to warrant the discussion in the inquiry of the relation thereby established. Every relation because it exists must be dealt with simply because it expresses a determination, a definite pulse in the life of mind. Every relation because it exists is necessary to mind, for in each and all mind is determined differently, and the richness of its experience is not summed up in any one only.

The question regarding the truth of any given relation thus does not take the form of whether it has any truth at all. The mere fact that mind is determined with reference to an object itself implies that it has truth, for any relation is a determinate part of the experience of mind, and is necessary to it. Now simply because necessary to it, each form of the relation is, taken by itself, true; for in each mind is closed with its object, is satisfied and rests with it. There is an "agreement between the mind 
and the object," 1 and the symbol or indication of this agreement is the "certainty" the mind possesses in dealing with the object in question-a certainty which is present in every form under which the relation appears. Since, then, every instance of the relation must be ipso facto true for mind, the further and second question is, what amount or degree of truth does each possess, what degree of intimacy is expressed by any given relation, how far does the object dealt with at any point realise or express the essential nature of mind, how far is the mind in dealing with the object explicitly aware of itself as being in its object, as being at one with it as well as its own self? To express it briefly and from another point of view, the degree of truth of a given relation between the mind and its object is determined by reference to, and in virtue of, the fundamental primacy and supremacy of mind in the relation; the fact that each relation does have truth at all, no matter what the relation be, is due to the inner unity of mind with its object in every case.

Looked at in this way, therefore, the inquiry deals with all actual relations between mind and objects because they are true and in virtue of their truth. But it at once distinguishes itself from two other inquiries which hardly concern it at all. It does not deal with the history of any given relation in itself, does not show how any relation arose, out of what factors or processes it was produced. Such a discussion is excluded because it is not the genesis of the relation that is philosophically important, but the relation itself, not the process but the product, not the origin but the actual meaning.

1 The ordinary conception of " truth." 
Nor, again, is the above inquiry concerned with the consequences which result or are obtainable when a given relation is established. Each relation is regarded simply as a particular form of experience with a distinct character, appearing in a way distinct from other relations, having conditions and a nature of its own. From such a treatment of the relation we can exclude all the detailed content of the particular sphere of experience constituted by the relation in question, and determined in all respects by it. For example, in the relation between mind and its object found in Perception we can analyse its nature simply as a relation, can determine its constitutive factors, can show that in it the object appears as a thing and its qualities, and is in this form a particular mode of the activity of mind; but in so doing we need not state what particular things and qualities (e.g. rocks, sounds, colours) there are in the sphere of experience to which Perception is appropriate. Similarly of the relation of mind to its object, e.g. in Morality. It is the form and character of any relation, not the varied content which it embraces and determines, that is considered in the above inquiry. It will therefore deal with all the different relations in which the mind can stand to its object, but will not include either the genesis of those relations or a systematic statement of all that is contained under them. To include the former would be at once irrelevant and extraphilosophical; to include the latter is impossible and unnecessary, for this would be to state all the details of all the sciences, and of all experience.

But it is clear from what has been said that if we are not to have here a genetic history of mind, nor 
an explicit system either of imperfect or perfect knowledge, of incomplete or complete truth, we have at least elements of both history of mind and of truth. For each mode considered by itself expresses an essential and necessary attitude of mind, and in each there is truth. All modes or relations of mind to objects are simply to be taken as they actually appear or have appeared, that is, we are to have a history of these various forms. And all such relations are regarded solely with reference to the kind and degree of truth they possess. Hence the inquiry is a historical analysis or analytical history of the kinds of truth of which the mind is capable.

Or again, if we consider the relation of mind to object as the essential characteristic of all that is named Experience, ${ }^{1}$ the inquiry in question may be named a Constructive History of the forms of Experience.

Once more, if we take consciousness to be the fundamental form under which mind exists, that which constitutes its very nature, the inquiry can be looked at as a Philosophical History of Consciousness.

Or finally, regarded as an analysis and statement of the functions, the activities of mind in its relation with reality, we may view it simply as a Transcendental Psychology. All thesevarious expressions merely indicate different aspects of exactly the same problem.

To carry out this inquiry is, then, the first part of that problem which Hegel was forced to undertake and to solve, if the principle he sought to establish was to be fully developed. Such an undertaking

1 Phän. d. Geistes, Vorrede, p. 27. 
was primarily what he sought to accomplish in his Phenomenology of Mind, the origin and purpose of which is contained in the general statement we have just given.

We must defer for a moment any further exposition of the content of the Phenomenology. It is of immediate importance to note that the analysis and discussion contained in it must have occupied from about $1803^{1}$ till the time of its publication, I 806-7. For it was from this time onward that the breach with Schelling became ever wider; and his examination of the various forms of experience seems at once to have created and confirmed his difference from him. All along he had maintained with Schelling that subject was one with object; in the Phenomenology he proceeded to examine and analyse this in detail.

It was this analysis that was the vital problem, on the answer to which depended the nature of the relation between these opposed elements of reality and the character of the unity which held them together. This inquiry alone could give Hegel any new result of his own, as it alone could establish a final philosophical position. Not that Schelling or Fichte, or even Kant, had not likewise maintained the "unity of subject and object"; nor had they neglected the inquiry into the relation subsisting between them. It was neither such an inquiry nor the fact of the unity which distinguished Hegel's problem from theirs, or made necessary his new and distinctive analysis. It was rather the character of the inquiry and the nature of the unity which dis-

$1 \mathrm{He}$ promises to have the Phenomenology published by the autumn of I805 (Briefe, i. 52). 
tinguished him from them, and which compelled him to re-undertake an inquiry and establish in his own way a result which in their general form were similar to those of his predecessors. For instead of, as in the case of Schelling, ${ }^{1}$ as also of Fichte, beginning consciously and explicitly with and from the bare absolute unity of the two stated in the form of a single principle, and thence "deducing" from this highest fundamental fact all the content of experience, Hegel neither starts from such a bare unity, nor does he even admit the validity of expressing in the form of a single proposition the principle of all philosophy. Schelling and Fichte start from the supreme fact, which should rather be conclusion and result than a starting-point; for a beginning in philosophy should properly be the simplest truth and not the highest. Hegel, on the other hand, takes up the position that if subject and object are one, then in all cases where in experience we find them in relation, we ought either to find them actually expressing this unity, or else by their imperfection, their incompleteness, their inner disagreement, revealing to analysis the presence in them of their unity in every case, and thereby pointing towards and "leading up to" that complete explicit unity which is their inmost reality. Let us then, he seems to say, instead of starting from the highest form of their relation, start from cases where they are obviously separate and opposed, and let us by examining these see where and why they fall short of, and how near they approach to, their essential unity. This was clearly a different procedure from that of either Fichte or Schelling,

${ }^{1}$ Viz. in Trans. Ideal. 
and held in itself prospect of a conclusion different in character, though not necessarily in principle, from theirs. The suggestion of such an inquiry may possibly have come from Schelling's conception of the content of philosophy being simply a history of self-consciousness, though it is manifestly suggested also as simply the reverse process of establishing idealism from that adopted by Fichte and Schelling.

There were, moreover, two secondary but very important reasons for undertaking the inquiry contained in the Phenomenology. There was first a consideration of practical importance. Hegel had a distinct, and in that sense a new, philosophical point of view and a new philosophical truth to lay before the world, and being new it was distinct from the ordinary conceptions of his immediate audience in the lecture-room, and of the larger philosophical public. If, then, he was to succeed in establishing the claims of his own view, if he was to get his new truth understood, he was bound to meet his audience half way. This implied that he should treat the forms of experience familiar to his audience, and deal with them in such a way as at once to appreciate their conceptions of these forms and indicate the significance which his own view compelled him to attach to them. This was the more necessary because each of those forms laid claim to possess a truth of its own, a claim which the natural consciousness was prepared to admit as absolute. Hegel admitted this claim on the part of these various forms to possess truth, and thereby stood on the same level with his audience. But by a pedagogic device he converted these several forms of truth 
discoverable in experience into steps by which he might lead his public up to his own final point of view. Thus he at once enriched and enlarged the conception of truth and of experience familiar to his audience by doing justice to each form in which the mind experienced truth, and by bringing all such forms within the sweep of his analysis; while at the same time he thereby conducted others to the position at which he himself stood. Looked at in this way the Phenomenology is a propædeutic introduction to Hegel's philosophy, the preparatory text-book to Absolute Idealism, ${ }^{1}$ the Pilgrim's Progress to the city of Perfect Light.

The other reason which made the inquiry necessary was theoretical. Hegel's philosophical point of view was in the first instance merely one among others which had also appeared in the course of history, and primâ facie had no more right to be considered final truth than any of the others. Yet it was of its very essence to lay claim to be the absolute and true philosophical position; all others were at best simply imperfect forms or precursors of it. Such a claim was not merely opposed to the similar contentions of other thinkers who had appeared in the past, and who likewise claimed to have the final truth, but came into abrupt collision with the views of his immediate antecedents and contemporaries, who equally claimed to have fashioned the final scheme. He was therefore bound to defend his claim and establish his position, and this could only be accomplished to his own satisfaction and that of others if he systematically proved the truth of his own view.

1 Phän. Vorrede, p. 2 I. 
Now only one method of proof was open to him. For he held, on the one hand, that his own view was the absolutely true, and on the other hand, that the views of others were likewise true, but imperfect. His proof, therefore, had to reconcile both of these positions. And this was only possible by showing that the truth the other views contained was true by being a form or expression of his own, and was imperfect because it did not completely, but only implicitly, contain his view, and was thus at the same time out of agreement with its own immanent principle. And on the other side he had to show that his own view actually and explicitly expressed the truth implied in the other imperfect views, and really contained whatever truth was present in them. This second part of the proof is merely the counterpart of the first, and indeed is obviously presupposed by the first itself. If, then, Hegel could establish both these claims, he would completely justify theoretically not merely to himself, but to the philosophical public, the claims he put forward on behalf of his own philosophy. Regarded in the light of this purpose, the Phenomenology may be considered the systematic proof of the standpoint of absolute idealism. ${ }^{1}$ It was, then, to accomplish all these ends, satisfy all these needs above indicated, viz. to remove the defects of his preceding position, to introduce and to establish his new conception, that the inquiry contained in the Phenomenology was undertaken. In what manner this first part of his problem was carried out we shall presently state.

It is not difficult to discern what bearing such an

${ }_{1}$ Logik, i. Einleit. p. 31 ; also p. 57 (ed. 184I). 
inquiry will have on the other two essential factors in philosophy, its content and its method. For while the systematic and exhaustive examination and demonstration of the principle of Hegel's philosophy form the problem of the Phenomenology, it must not be supposed that the inquiry is a by-product of his system, a mere introduction, external to it and independent of it. This we shall show later on more fully is not the case; and meanwhile we may merely note that Hegel himself considered that the work was a constitutive part of his system. ${ }^{1}$ It is inevitable, then, that the inquiry would determine both content and method as well as principle. Now all relations between subject and object, found in experience, are to be passed in review from the most extreme forms of opposition between those two elements, up to their closest and most explicit union. And in all of them subject and object are to be shown to be/ essential one, subject being higher than the object, including it and the determining ground of it. The whole content of experience will thus appear as moments or modes of the ground reality of experience, Mind. Since, then, all experience is to be embraced, since everywhere that unity between subject and object is to be exhibited, every content will have that place in experience which it is entitled to as a moment in the one experience of the one reality, Mind. Consequently on this new view, and as a result of this new inquiry, there will not be a merely abstract characterless "indifferent" identity; the finite varied

1 Briefe, i. 52 ; Logik, i. First Preface ad fin. note. The change of title there mentioned seems obviously due not to change of point of view regarding the work, but to external reasons. 
content of experience will not exist simply to be negated. Both the unity and the differences will be maintained and preserved, and the one by means and because of the other. Thus the only and complete content of philosophy will be the whole diversity of experience, which alone reveals, and where alone is found, the meaning and content of that Absolute which is the only object of philosophy. Not the Absolute per se as an identity indifferent to though uniting subject and object, but that Absolute only in and through its own wealth of varied content, is what henceforward is to be found in philosophy. The Absolute, because essentially and truly mind, is not merely at once substance and subject, but is pre-eminently and primarily Subject, ${ }^{1}$ a unity containing and revealing all its diversity to itself, and preserving it because possessing it as its self, and thus containing nothing but what it revealsthe whole content of experience. That the Absolute is Subject, not Substance, that all the reality of the Absolute can only be what it reveals, that all experience is just the laying out in extenso of the content of the Absolute-all these are mutually implicative or even convertible statements. This then will be henceforth the actual and only content of philosophy on Hegel's principle.

And it is clear that this advance which he is to take is just the counter-stroke of his previous negative attitude towards all finitude. Not merely does he maintain and preserve all finitude through and by means of the Absolute. The tendency of this new view even seems to be to do full justice to them at the expense of the Absolute itself. It is

1 Phänomenologie, Preface. 
clear, too, that this complete preservation of finitude is a necessary consequence of the supremacy of subject over object. But of this again.

With such a determination of principle and content, the method of philosophy must necessarily appear (if only, so to say, unconsciously and naturally) by means of, and in the course of, the inquiry itself. Not that Hegel could possibly be unaware of the method by which this "System of Experience" was to be constructed until he had well begun. He must certainly have had a conception of the course the inquiry was to follow from the start. But it is equally clear that he could only become fully conscious of the richness and full significance of that conception after it had been thoroughly and comprehensively used. This general conception was undoubtedly that of Development, a method which he had already suggested as the only appropriate one for philosophy, a method "neither synthetic nor analytic." This conception he found lacking even in his philosophical comrade Schelling, and it is stating their divergence from another point of view to say that the method of philosophy was the weapon of separation of the one from the other.

But what can development mean except that we must begin from the lowest form of experience, the form where subject and object stand furthest apart from each other, while still, all the same, standing in relation and referring to each other, and from that point work up and through all the varied relations of subject and object which will, and do, show various degrees of closeness of union between 
these opposite poles, till we reach a point where they are explicitly, and without any reservation, absolutely one? Granted that subject and object are identical, are one inseparable unity; granted that the Absolute is, and must be, the identity of these differences (and this is the cardinal certainty from which Hegel starts, a certainty which he maintained with confidence from the Jena period onwards), yet, though that is ultimate truth, the Absolute cannot, and must not be, "shot out of a pistol" at us. It is too rich and concrete to be either appreciated or expressed fully at the start, and, as it were, at a single stroke; we must begin at the lowest level of its reality and work from that. True, we begin with the Absolute; it is the terminus a quo of all genuine philosophy. But we must not begin immediately from and at the Absolute; it is for our inquiry, for the system, the terminus ad quem. Only at the end are we brought actually face to face with it in its full truth. Thus, then, the only beginning with which we can properly begin is at that point of experience (which throughout is determined by the fundamental unity of subject and object) where subject, mind, and object stand ostensibly far apart, while yet maintaining a connexion by referring explicitly to one another. And since, further, it is their fundamental unity that is the one final ultimate fact for the connexion of both, the one theme for our inquiry, the succeeding forms of experience will naturally be determined on the one hand from this starting-point, on the other from the ultimate goal; in other words, by the degree of explicit realisation of the essential unity of these two opposites named. Thus, then, the 
method consists in the systematic connexion of all the forms of experience, a connexion which exists because all have a place, and must be maintained in the one Absolute, and which is brought about by the immanent inner reference of the actual form of each (a form common to every experience, subjectobject) to its determining vital nature, the reference of its actual content to the ideal of all experience. Only thus will each form be limited by and connected with every other, and preserved in the one system of experience. The whole thus forms an organic development. Its moving vital principle is namable as Dialectic; and only by such a method can the demands of system be met and completely satisfied.

It is clear in what consists the advance in this conception of the nature of the method over that of the preceding period. Anschaunng and Reflexion are no longer different and contrasted functions of mind. They are fused into one single process without losing their essential nature (the expression respectively of the positive and negative content and processes of reason), yet without preserving their individual distinctiveness. The process of negating is that of positing, and this by one and the same act of reason. This advance is precisely what is necessary to remove that artificiality of contrast of these two functions.

But now no sooner will this inquiry of the Phenomenology be completed than another problem will present itself for solution, a problem already implicit in the Phenomenology all along, but only becoming prominent at the end of that inquiry. If the unity of subject and object is 
the one essential reality in all experience, and if the modes of this unity are just the modes of experience, then does not the problem suggest itself to state in systematic connectedness the inner identities as such, the modes of unity quâ unity, which have been the ground reality throughout the whole of the Phenomenology? We have these various concrete relations of subject and object in experience; can we not proceed further to extract or abstract the inner kernel of ultimate truth exhibited and preserved by all the several moments of experience, by each relation of subject to object, and constituting it a necessary pulse in the life of the Absolute? There is in every mode such a vital essence, namely, the identity or unity, which is the ground of the connexion of subject and object in each case. And each such unity will be a specific truth, the ultimate truth, namely, of each mode. The complete system of such unities will of course cover the same area as that of the Phenomenology, namely, the whole of experience, the content of the Absolute. The only difference will be that whereas in the Phenomenology we have the concrete, actual embodiment of experience, in the other inquiry we shall have nothing else but the abstract, "formal," conceptual, "pure" essentialities stripped of all direct reference to the diversity and tangibility of existent experiences, and expressed and connected in the form determined by their own character. The content of this new science being the inner reality of each mode of experience, and this inner reality being, as we saw, the principle of connexion of the various modes, it is 
further evident that the method which this new science will follow will be none other than that of the Phenomenology itself; it needs no other, and it can find none other. The only difference will be that the method will in this new science be exhibited in its ultimate and purest form; for here it is operating with and through a content which is itself "simple" and "pure."

But what else can this new science be but just what has been hitherto known as Logic? It will appear, and is indeed evident, that these vital essences can only be thoughts, notions as such; and these have been, and are always, the matter of Logic. But if, then, Logic is this ultimate and absolute science par excellence, it is clear that it will cease to be distinct from and to lie outside "Metaphysic," and will become an independent and self-dependent science. It will, again, cease to be divisible into Logic of understanding and Logic of reason; will cease to be a "negative Logic of reflexion," and will become in very deed the all-embracing science with a single absolute method -will be Speculative Philosophy in its truest form.

Thus the transformation of Hegel's principle, and the systematic establishment of its content, paved the way for, and necessitated his epochmaking Reformation of Logic. He was undoubtedly aware that this was his next step after the Phenomenology, which, he indicates to Schelling, ${ }^{1}$ is "merely the beginning." Not that there was no Logic at all similar to his own already given to the world. Fichte's Wissenschaftslehre and Schelling's Transcendental Idealismus were after

1 Briefe, i. 79. 
all merely attempts "to establish by itself Logic or Speculative Philosophy as a complete and independent science." 1 But neither of them saw at all clearly that this was really what they were trying to do; and in Fichte's case both principle and method were wrong, in Schelling's, while the principle was in a way sound, there was no proper method, no "development." ${ }_{2}$ The importance and significance of Hegel's reformation consisted not merely in the soundness of the principle and the perfection of the method, but in the careful and precise distinction of the problems of Logic. Logic with him ceases to be mixed up with the concrete forms and characteristics of the experience we find ready to hand. Logic becomes pure logic, deals with pure notions; Logic handles the conception as such. All that holds of existent experience, as embodied historical appearance of the Absolute, is dealt with in a distinct science-in the Phenomenology. Notions, thought-unities, in their "purity" and ultimate form, are dealt with in another science -in Logic alone. It was exactly that confusion of problems that characterised both Fichte and Schelling, and likewise Kant, whose work is in truth restricted to what characterises Phenomenology of Mind. ${ }^{3}$

How all these changes are brought about we must now proceed to determine.

1 Leben, pp. I79, I88, I89.

2 ibid.

3 Cf. Ency. $\$ 33^{2}$ (Ist ed.). 


\section{CHAPTER VI \\ THIRD STAGE-FROM I8O7 TO I8I2-I6- THE PHENOMENOLOGY OF MIND}

The problem of the Phenomenology is the "Inquiry into and Examination of the reality of knowledge." 1 This is not the only or the fullest expression for it ; others will meet us as we proceed, and some have been already indicated. But the above is, on the whole, the most accurate and precise, and we will therefore at the outset make clear what it means. To begin with, it must be noted that the discussion does not in any way concern the possibility of knowledge; it does not inquire whether there is knowledge at all or whether knowledge is of the "real." Hegel simply accepts in the first instance the fact that there is knowledge, and accepts this fact in much the same way that it is accepted by the ordinary consciousness. ${ }^{2}$ And with this he must also admit the claims of all forms of knowledge to be actual knowledge, at least primâ facie. Whether knowledge is possible, what are the conditions of possible knowledge, or, again, what are the limits of knowledge, he does not investigate. ${ }^{3}$

$1 W W$. ii. 64 .

2 ibid. 65.

3 Here, then, at the very start of Hegel's philosophy we find a fundamental difference between his conception of the problem regarding knowledge and that of Kant. For the Phänomenologie has the same philosophical significance as the Krit. d. rein. Vernunft. Hegel regards the 
Now knowledge taken in this very general sense is not, strictly speaking, merely "science," and yet is wide enough to include the latter. But it is science with which Hegel is primarily concerned, and this is its highest stage as speculative science, Philosophy. This ideal knowledge is present to Hegel throughout the whole argument, and is as much a reality for him as knowledge in general. He does not merely lead up to this conception; it is active all along. It was presupposed, as we saw, before writing the Phenomenology; and the conception of it is operative throughout the investigation. It is not an "ideal" of science which cannot be attained, it is actual science and the truest form of science attainable; indeed, strictly considered, it is the only true science. Only in this its highest form does knowledge become really science or "true knowledge." The phrase "reality of knowledge" has thus a double meaning. All knowledge is real knowledge which is knowledge at all ; and the highest, being a form of knowledge like all the other forms, is "real" in the same sense as they are. But just in virtue of this common element in all forms of knowledge it is necessary to signalise the difference between what is par excellence knowledge, true science, and what is ordinary knowledge. The distinction is secured

latter as a phenomenological inquiry, for it starts from and remains within the duality of consciousness and object. To this initial divergence we may fairly trace all that finally distinguishes the character and results of their philosophical positions. The difference between their conceptions and interpretations of knowledge is due to their conceptions of "truth." Kant seems to have considered that " truth" referred solely to science or systematic knowledge, in the narrow sense of the term (v. Krit. d. r. $V$. Trans. Elementarlehre, ii. 3). Hegel considered that the term applied to every sphere of experience, wherever we have a relation of subject to object. Hence for Kant there was only one kind of truth; for Hegel truth had many forms and differed in degree. 
by regarding true science as the only real knowledge ; in it we have knowledge "as it truly is," knowledge "really." And this twofold interpretation of "reality" gives rise, as we shall see, to a twofold conception of the problem. On the one hand it is an investigation into every form of knowledge, on the other an inquiry concerning true or absolute science.

When knowledge is taken in its widest significance there is only one general characteristic common to all its forms. It is that by which knowledge is knowledge, viz. the relation of a subject to an object, the presence of an object for and to consciousness. Such is, indeed, the ordinary conception of knowledge; but the ordinary view distinguishes between the presence of an object for consciousness and the existence of the object by itself, as it is apart from such a reference. And this distinction it expresses by maintaining that while in the former case there is certainly knowledge, only in the latter case, when we have the object as it is by itself, is there truth; for the truth is the essence of the object, the object as it is in itself without further reference. ${ }^{1}$ This general view of the difference between knowledge and truth Hegel agrees to adopt without close scrutiny, partly because it is the ordinary conceptions of knowledge with which he has to deal (and by accepting this he has committed himself likewise to the ordinary interpretation above given), and partly because it

1 This distinction obviously cannot be taken too strictly. For "truth" appears through "knowledge," and all knowledge has some truth. And this is the interpretation Hegel proceeds to put on it. Broadly, however, the distinction holds good-between the complete "truth" and approximate knowledge of it. 
provides him with a distinction of immediate use for his own inquiry or a point of departure for it. For it is clear that in that distinction between knowledge and truth we have the means at once of determining what true science is, and of investigating all other forms of knowledge as knowledge. ${ }^{1}$ This will become evident if we consider what is the relation between the two factors named.

All knowledge has for its content truth of some sort ; truth is not merely the goal or aim of knowledge, it is simply what any form of knowledge contains. Knowledge in general may be even asserted to be identical with truth. But this statement would be ambiguous, for if truth is taken to mean the whole truth and nothing less, then there is obviously a difference between knowledge and truth; and it was to assert this that the above distinction $^{2}$ was drawn. At the same time, however, it must be maintained that in some measure knowledge at all times, and in every form, claims to contain truth. Hence it is necessary to distinguish between the truth which there is for consciousness in every form of knowledge, i.e. the truth which is possessed by consciousness merely in virtue of its relation to an object, and the truth obtained by relation to the object in itself, the complete essence of the object, which may or may not in a given case be for consciousness, but which is all that the object is, " the truth" of the object per se.

Now it seems in the very nature of the case that these two forms of truth will approximate. I For, since all knowledge contains truth, and since "the

2 Between existence of object for us and existence by itself. 
whole alone is what is true," ${ }^{1}$ it is impossible to rest content in anything short of the complete truth. And it is equally manifest that this truth will be attained more completely by some forms of knowledge than by others, more completely according to the measure in which the object in itself is for consciousness. / Hence we can easily see that for every degree of approximation to the truth in its completeness there will be a corresponding specific form of knowledge. And thus we obtain the starting-point for Hegel's inquiry. Every form ${ }^{2}$ of knowledge, every mode in which an object is for and to consciousness, is different from every other just in the degree of identification of the object in itself with the object for consciousness, and can be investigated from that point of view.

Further, truth, according to the usual conception, consists in the "agreement of thought with its object." Translated into the above terms, this means that truth is the agreement of the object for consciousness with the object as it is in itself. If, then, the only truth is the whole, and if partial truth means merely partial agreement between the object for consciousness with the object in itself, the only complete resting-place for knowledge is where the agreement becomes absolute, where thought and the object are identical. Such an identification, therefore, is the truth of knowledge, "the absolutely true." Now this is precisely the meaning of Speculative Science in Hegel's sense; and with

1 Phän. p. 15.

2 "Form" here and throughout this statement of the Phän. (unless other. wise indicated $)=$ Gestalt . 
this as an ideal all other forms of truth and of knowledge can be compared. ${ }^{1}$

If we give these abstract statements more concrete shape we shall see at once their significance for the investigation we are considering. / Truth is realised when thought " agrees," "corresponds," with its object. But "thought" is simply the abstract expression for the Ego; for the Subject, or Mind, as Hegel is never weary of saying, is essentially Reason, Thought. Consequently that with which the object is to "agree " in order to attain truth at all (whether partial or complete) is the Subject itself. In absolute truth we saw thought, or notion, was to be identical with object. In Absolute Science, therefore, subject and object, mind, and its other, will be one. But if so subject will be to itself object, Ego will be to itself other Ego, Consciousness will be simply Self-Consciousness. In other words, the absolute truth of knowledge is the presence to consciousness of its own self. Selfconsciousness is the truth of that relation of mind to its object which constitutes knowledge. Only when the externality of the object to mind has ceased, only when thought is identified with its object, have we absolute truth or Absolute Knowledge; and such identity has no place except in Self-consciousness.

Now what object is it that the self has to itself in such knowledge? What is its "self"? This is nothing other than Thought. But if the presence of thought to itself is the absolute truth, then the truth of the object as it is in itself (above signalised as

1 In this way Hegel's inquiry may be said to rest upon, and to be justified by, the usual conception of the nature of truth. 
distinct from ordinary knowledge) must simply be Thought, the Notion. The object in itself is the truth of the object; for the object in itself is its essence, and this essence is just the notion of the object, the thought which constitutes it. If so, then, it is not the object in all its details, in all its plurality of content, which is expressed in its notion, but the essential meaning of the object, the object as it is an sich. Hence the self which is present to itself, and thereby constitutes absolute truth, must be the totality of the notions which constitute and determine reality as a whole. Thus the complete and systematic exposition of these will give Absolute Knowledge. Speculative Science, and only this, will satisfy the demand for the "supremacy of mind," "the omnipotence of reason."

/As compared with this ideal of science, ordinary knowledge presents a decided contrast. Here all we have is the presence of an object to and for consciousness; and this is distinct from the truth, from the object as it is in itself. In knowledge, as we usually find it, consciousness falls in some sense apart from and outside its object. / These are not so much identified as set over against and opposed to each other. Far from subject and object seeming identical, they appear separated by the "whole diameter of being." Still, let the difference be asserted to be as absolute as possible, it is evident, even from the view currently taken concerning their relation, that on the one hand consciousness has in knowledge some truth, that is, there is always some identity, some agreement, between subject and object ; and on the other, there is a closer intimacy, a nearer agreement between consciousness and its 
object in some spheres of experience than in others, though in none short of absolute truth is the distinction and opposition removed entirely. Now that there is truth at all implies that the essence of the object, the object as it is in itself, is in some manner or degree present to consciousness; and that the agreement should vary in extent simply means that consciousness can differ in its relation to truth.

These two facts, combined with that conception of absolute truth already outlined, not merely suggest the analysis of the various forms of knowledge with a view to establishing the degree of truth they contain, but indicate at the same time the line along which the inquiry is to proceed. For in the Phenomenology Hegel investigates knowledge with a view to discovering that kind of knowledge which is absolutely true. But to do this Hegel does not consider the object quâ object without reference to the subject knowing. ${ }^{1} \mathrm{He}$ has to investigate the relation established in any form of knowledge, the way in which mind (consciousness) appears when an object is present to it. In other words, it is consciousness in relation to object, and the form which that relation assumes, that is the object of his inquiry. All these forms are forms of knowledge, and the point of the investigation is just to disclose the true form, "the truth of knowledge." $X$ Now the truer form of knowledge meant a greater "agreement" between consciousness and its object, and vice versâ. Hence it is that, since in all knowledge there is, besides dis-

1 This is the point of view, e.g., of ordinary science which eliminates reference to the conscious knower as such. 
tinction of consciousness and object, "agreement" between them according to the truth contained in any given form, a change in the truth means a change at once of the object and of the forms of consciousness. A difference in the form of knowledge is only possible by a difference in both form of consciousness and object of consciousness. That this should be the case follows at once from the nature of truth and of knowledge. ${ }^{1}$ These are constituted by a relation, the former of the notion of an object to the object itself, the latter by the presence of an object to consciousness; and these two apparently different relations become, as we see, essentially one and the same relation by the identification of thought and consciousness. That relation, then, being necessary, it is obvious that a change in the degree or form of knowledge means a change in both terms through which the relation is constituted. And when, therefore, we investigate knowledge with a view to determining its truth (that form of it in which alone the goal of knowledge is absolutely realised), it lies in the very nature of knowledge that the determination of a "higher," a "truer" knowledge should mean an alteration both of the form of consciousness and of the object. ${ }^{2}$

Now there is only one way in which this inquiry can be prosecuted. It is assumed at the start that there is absolutely true knowledge, that there is only one such form of knowledge, and that all other forms of knowledge cannot give absolute truth. At best these latter contain only implicitly

1 The very wide meaning which is given to knowledge in this inquiry must be carefully kept in mind. It is the presence of "anything" (etwas) for consciousness.

2 Phän. pp. 66 ff. 
that absolute truth, and if we regard truth as one, the truth they do contain is truth in virtue of this implicit identity of their form with absolute knowledge. The investigation of these forms, then, with a view to discovering their truth can consist solely in the comparison of the truth of knowledge with the actual knowledge in a given case. And this comparison cannot and must not be external, in the sense that the standard by which knowledge is judged is brought to it from a sphere outside consciousness. The criticism is immanent. For the truth of knowledge and the knowledge itself both fall inside the one experience. It must not, however, be supposed that the conception of absolute truth is explicitly present at every stage or form of knowledge, and that by means of this the comparison is made. This is neither necessary nor possible; in fact that this should be the case would be absurd. It is not necessary, because every form of knowledge, as we saw, has its own specific truth, that which is the essence of the object presented in each case; by this alone the comparison can be made. And it is not possible, because the conception of absolute truth is not attained by consciousness till the end of the investigation itself. No doubt we may say it is absolute truth which is implicitly present in the truth possessed by any given form of knowledge; still this is not that which is actually present, and by which the truth of each particular stage of knowledge is determinable. Each mode of actual knowledge contains the truth of that form of knowledge ; the object ${ }^{1}$ as it is for consciousness, and that which consciousness in each case accepts as the essence

1 In the widest sense. 
of that object, are both in consciousness at every stage. Consciousness has in itself both the standard and the knowledge compared by the standard. ${ }^{1}$ The investigation is of consciousness by consciousness, and the inquiry just consists in examining whether the knowledge of the object corresponds with the truth of the object, both being present in consciousness.

It might, indeed, be asserted that the inquiry is impossible, for the only knowledge to be found is of the object as it is known, that it is impossible to get behind this to the truth of the object, the object as it is in itself; or again, that the only truth is just the object as it is for consciousness. But the mere fact that in consciousness there is knowledge of an object implies the distinction between this and the essence of the object itself. ${ }^{2}$

If, then, it is found by the above method of procedure that knowledge does not correspond to the truth, the knowledge must be altered. But this alteration is at once a negation of the former knowledge and the introduction of a change in the object, a "new truth." It is the latter, because the object formerly present to consciousness, and of which there was knowledge, was simply the object necessary to that form of knowledge and appropriate to it ; any other object would mean another knowledge. The change, therefore, in the knowledge arising out of the above comparison necessarily implies change in the object, would not be a change without it. But by this change consciousness becomes aware that what was previously regarded as the essence, or the truth in contrast to the know- 
ledge, is not in reality the final essence, but merely the essence appropriate to that stage of consciousness, not really the truth, but the truth "for it." This, in fact, is just what the change means. ${ }^{1}$

Again, it is the former (the negation of the previous knowledge), for that knowledge has shown itself not to correspond to the truth of the object present to it, and is in that sense false, and is removed and replaced by the succeeding knowledge. Still, it is not simply abolished as utterly false. ${ }^{2}$ The mere fact that the changed knowledge proceeds from, and succeeds to, the previous form means that this new knowledge gets its specific character from the preceding, and is therefore not the bare denial of it. It is the negative in relation to the preceding knowledge, has thus a content derived from the preceding, is not mere negative. In virtue of this the preceding form is, while negated, at the same time preserved, and maintains its reality in the succeeding, for it determines the character of the latter. And further, because the truth which is compared and contrasted with each form of knowledge is the truth of that knowledge and of no other, the changed form of knowledge is the direct and only outcome, i.e. the "immediate negation," of the preceding.

It is by the combination of all these factors, then, that the science of the phenomenal forms of experience is constructed and obtained. None are thereby omitted; all have a place in the context of experience. All are limited, finite, and in part untrue; yet their untruth does not mean their annihilation; their untruth means no more 
and no less than that by the immanent process of their own content (a process which is inevitable, because experience is a process, a living activity) each brings to view its inner truth, and becomes, therefore, absorbed in that truth. This again, because it is a new content of experience, establishes a new form of experience ipso facto, the negation of, but at the same time the result of, and therefore containing, the preceding. It is this character of negation as negation with a specific content, as a determinate result, not pure negation, which is the nerve of the process.

No other method could lead up to, by inner and immanent necessity, the truest form of knowledge; and only by it could it be ascertained that all modes of experience had been included in the system. By no other method, therefore, could the two ends of the inquiry be realised, to exhibit all experience as the organised content of the Absolute, and establish the position of Absolute Idealism, that Substance is Subject. And, again, this method would only be suitable for this purpose, * for the method is one with the content itself, is not brought externally to it, is essentially bound up with it ; to refuse to acknowledge the one is to deny the claim and meaning of the other. It is the content which imposes upon itself, and reveals itself through, this method; for that content being the moment of the one Mind with one experience which can abstract itself from any particular content, and yet posit each moment as itself, must thereby have its own immanent movement.

This process, then, is the inner critical exposition of the mind's content (experience) to itself, and is 
named a dialectic movement. It consists in nothing other than in bringing into explicit and complete distinctness that identity, through which, and in virtue of which, the opposed elements, subject-object, exist in inseparable unity throughout experience. Instead of leaving them opposed, and expressing them as is done in the judgment or proposition $X$ (where their separateness is emphasised), this method regards their identity, their unity alone. Hence the propositional form, and with it the process of proving by reference to and by means of "reasons" and "grounds," are sublated in but are not appropriate to the true speculative procedure. $^{1}$ It accomplishes by that movement of inner connexion what is otherwise established by more or less external proof. And just this insistence on complete and full presentation of that inner unity constitutes the distinctive feature of dialectic process as compared with that method which leaves to $A_{\text {nschamung }}^{2}$ the insight into that unity without exposing its entire content to view.

Such is the ground plan of this Science of Experience. All the forms, modes of mind are taken simply as they exist side by side, as facts in the history of conscious experience, as "appearances" of mind. Phenomenal they are too in another sense, that, namely, of being appearances of true and perfect science. ${ }^{3}$ In either or both cases the science which gives the analysis and synthesis of all these phenomena of mind's experience is accurately named "Phenomenology of Mind."

In passing from this general statement of the matter and method of the inquiry itself, we must

1 Phän. pp. 49 ff. $\quad 2$ e.g. as is done by Schelling. $\quad 3$ Phän. p. 6o. 
remove at least one possible obscurity which seems to hang over the investigation from the start. It is not evident from the above whether the process as described is to be found actually taking place in the consciousness investigated, or whether the several moments in the process are due to the significance ascribed to them solely by the consciousness investigating. Does the consciousness which is engrossed in actual experience become aware that on the appearance of a new truth, the form of consciousness, the form of knowledge must likewise be altered, that the new truth present to the mirror of consciousness implies that the mirror itself has likewise revolved, and must necessarily revolve with it? Clearly, the ordinary consciousness is not actually aware either of the process of change or the conditions by which it is effected, but solely of the fact that there is a new determination of consciousness. The change is produced by the inherent necessity of its own constitution and "in spite of itself." Consequently there is a moment of this experience which does not come to light in the consciousness immersed in actual experience, but only in the investigator. Still, this is obviously only a formal difference; for the content of each new truth must be present to the ordinary consciousness, must indeed be explicitly present. It is merely the process by which it enters and becomes aware of the truth, and so possesses a new experience, i.e. it is only the origination of the new forms, which becomes explicit to the investigator in a way which is not present to the consciousness which merely "has" the experience." This double reference of 
the problem gives rise to the double significance of the truth, the object in itself which appears in the investigation and is necessary to it. For the truth, while at first simply taken as distinct from knowledge alone, was seen to possess a twofold aspect, that in which it appeared as truth for consciousness, and that in which it was the truth apart from this reference to consciousness, and in virtue of which the mode of consciousness was changed and a new truth constituted. Actual consciousness is only explicitly aware of the former, the mind investigating is aware of both. The former is aware of the process after the new result is established, the latter while it is proceeding; the latter knows how a new, how a higher moment of consciousness is arrived at, why it is truer, and what the process aims at; the former simply knows that a new and higher result is obtained, and that a process has taken place. ${ }^{1}$

1 A simple illustration may help to make the above more concrete, which in itself, however, is obviously the ordinary process of experience. Take the course through which we gradually come to determine that the object perceived in the obscurity of a misty landscape is a human being. First, a mere thickening of the mist in a certain direction-"something there, a this, a form of matter." Then a definite shape maintaining its continuity amid external change-" a substance." The body moves-" there is force, activity, causality." The body moves of itself- "it has life." It is moving towards a certain point-" it has conscious purpose." And in external shape and activity it resembles man-" it is a human being, a self." Now every one of these different steps represents the adoption by consciousness of a different category, and by the different categories the nature of the object, i.e. " the truth of the object," is gradually arrived at, and finally determined. Each one is a truth for that stage, but the process at the same time is a growth towards the final truth, the nature of the object in itself. At one stage consciousness brings out one category; the content of perception changes, and thereupon, or rather therein, appears another category. The object is different at each stage, and is only ideally the same in all ; the change of category, e.g. from "substance" to "life," just means that the object is different, and therefore the consciousness of the object has changed. A change in the angle of incidence means a change in the reflexion, and in the object reflected. This 
It will not serve our purpose directly to furnish any systematic account of the actual argument of the Phenomenology itself. Our primary interest in it lies in its plan and purpose which we have already given, and more particularly in its conclusion. We must restrict ourselves, therefore, to stating in a sentence by what steps Hegel reaches the result of the Phenomenology.

Taking experience as it "naturally" presents itself, there are three primary and specifically distinct objects to which consciousness can stand in relation, with which it can identify itself. These, broadly distinguished, are $(a)$ what exists as object in space and time, as "external" to mind; $(b)$ the self, mind as such; and $(c)$ what is at once self and "external" object, what is neither of the former specifically, but is both at once. These three give the general attitudes of mind, known as Consciousness (of objects), Self-consciousness, and Reason. Each has its own special modi. In the first, for example, the simplest mode is that where Consciousness and objectivity meet at particular points, so to say, the stage of merely immediate awareness of objectivity -Sense-knowledge, sensuous consciousness. Another mode, again, is Understanding, where that original opposition is still found, but is implicitly overcome. And so on for the various modi of these three fundamental forms of mind.

Now the argument consists in beginning with

transition from category to category, from stage to stage in the development of the truth of this object is the unconscious and mysterious procedure of the ordinary or "natural" consciousness. It only knows the result ; the process takes place "of itself." Now to make the nature of this process explicit, and to show its inner necessity'-that is the aim of such an inquiry as the Phenomenology. 
that general form where the essential identity ${ }^{1}$ between the opposed elements in the relation is least asserted, namely, at the stage of mere consciousness. Moreover, it begins with that particular mode of consciousness in which there seems least of all identity, where mind and object stand furthest apart-at the stage named Sense-consciousness. ${ }^{2}$ It then proceeds by the method and means already indicated to show that one mode when examined leads on to and finds its truth in another, the modes of consciousness finding their truth in Self-consciousness, where the identity is more manifest, and this latter, again, finding its ultimate truth in Reason, where mind attains its richest expression, where mind is "at home with itself," its object being its inner self. Reason is thus the truth of consciousness, the highest mode of mind. It embraces all reality, and is all reality; in it objectivity ard subjectivity are one. This is, therefore, the final general stage of the whole inquiry.

But the argument is not yet exhausted. For when we first reach Reason, that identity is merely abstract and formal. The rest of the inquiry is then devoted to completely exhausting all that this, the chief result which was to be established, contains.

The procedure is again determined in the manner in which the three ground forms of the whole inquiry were established, namely, by reference to the distinctive spheres in which in the form of Reason mind

\footnotetext{
1 This, as we saw above, exists all through experience, which is simply the unity of subject and object.

2 The "this" of sense is as far from exhausting the nature of the object as of the subject. Yet it is in a "this" that subject and object meet in senseexperience.
} 
can stand in relation to its object, i.e. to itself. It is one with and is found in that kind of object which as a whole is named "Nature," which is immediately identical with it, but which quâ Nature, and because merely immediately present to Reason, is only implicitly identified with mind as Reason. Again, by consideration of the unity of Reason with Nature, we are led on to the unity of Reason with its self, selfconsciousness of Reason, concrete mind proper-the sphere of Ethical experience. From this, again, we pass to what is the truth of both the outwardness, the external identity of reason with Nature, and of the inwardness, the internal identity of Reason with its self. This is the completely explicit identity of Reason with all reality without exception, where individual mind is one with Absolute Mind, where the absolute Reality is absolute Reason, absolute Personality, Subject. This sphere is in the first instance that of Religion, and in the second instance that of Absolute Knowledge. This last, then, is the final and, without qualification, the truest mode of mind, the highest truth of experience, and the result of the whole inquiry.

This conclusion of the Phenomenology of Mind is of the greatest significance, not merely as regards the various forms of mind which have appeared in the course of the inquiry, but also in regard to Hegel's philosophy as a whole, and more especially, as we shall see presently, in regard to the Logic. It is essential, therefore, for our purpose that the import of "Absolute Knowledge" should be fully appreciated.

Let us recall the problem which the Phenomenology seeks to solve. We saw that it sought to state systematically all the attitudes which con- 
sciousness takes up towards what is presented to it as an object, and to exhibit the truth of each form which showed itself, and by consequence, therefore, to state that form which was, without qualification, the final relation which consciousness could take up to its object. The inquiry presupposed the separation of consciousness on the one side from the object of which mind is conscious on the other, and presupposed also the conception of truth which, equally with the other presupposition, is found in ordinary thought as it currently appears. By means of the connexion and the distinction between subject and object implied in these two suppositions the inquiry proceeds, and the stages of its movement are determined. It is in virtue of the fact that the object is for consciousness (and in that sense external to, separate from it) that it is possible for mind to be cognisant of its truth, and it is because in truth mind knows the object as it is in itself that the separateness of mind from the object can be shown and can be found to vanish.

Now it lies in the very nature of such an examination into the "truth of knowledge" that the results arrived at should in effect be double-sided in character. The inquiry affects mind on the one side and the object of consciousness on the other, and affects them simultaneously; a determination of the one implies a determination of the other. There is not merely a certain object present to consciousness, but a certain mode of consciousness peculiar to that object present to it; and these proceed pari passu. ${ }^{1}$ Hence it is that an analysis of the truth

1 This is simply because we are dealing with experience as such, and experience is at once subject and object. 
contained in a given moment or form of knowledge has reference to both sides of the relation constituted in and by knowledge. The truth of the object in any given case means also a truth of consciousness, a specific pulse or moment of its life, a phase of mental (spiritual) experience. The development of the one proceeds throughout side by side with the other; a higher truth in the one case means, at the same time and in the same sense, a higher truth in the case of the other. The knowledge of the truth and the truth of knowledge pass from stage to stage together.

Further, it results from the nature of the initial contrast between truth and knowledge that the inquiry should be a determinate process towards a definite conclusion. The "truth of knowledge" means not merely the truth at a given stage, but the final and absolute truth. In this sense also the inquiry has a double reference, a reference not merely to the nature and significance of the knowledge immediately under consideration, but also to the highest and truest form under which knowledge can appear in spiritual experience. It is just as true to say that the truth of any given form of knowledge determines the final truth as to say that the latter is what implicitly determines the former. For it is the nature of any given form of knowledge (except the first) to be the truth in the first place of what immediately precedes it, and by implication the truth of all that has gone before; that it should include it in itself as a moment in its own content, and thereby determined by itself. Thus, just as in any given case the truth in question is determined by what precedes, so the final form is the last 
determination of the truth, depending on because containing, and evolved out of, the preceding. On the other hand, again, it is equally and perhaps more obviously true that it is the presence of the final form as the ideal and end at each stage in the process which determines the truth of each form of knowledge. The mere fact that in each there is truth, and that this truth is not annihilated, implies that it shares in the nature of the perfect form of knowledge.

What this final form must be is evident from the contrast between truth and knowledge already mentioned. Since knowledge consists in the presence and yet opposedness of an object to consciousness, and since the consciousness of the object in itself (its truth) means the dissolution of the opposition between the object in itself and the object for consciousness, it follows that the final and complete truth of knowledge can only then be attained when the objectivity of the object and the truth of the object have been entirely and without reserve identified. Now the objectivity of an object just consists in its being for consciousness, in the maintenance of a selfsubsistence in contrast with, and in that sense apart from, consciousness; its presence to consciousness and its objectivity are interchangeable terms. But it only maintains that subsistence and apartness in so far as, and so long as, the contrast persists between the object in itself and the object for mind; because it is in virtue of the "in itself" of the object that it is possible for the object to subsist over against, to be for consciousness. If, then, this " in itself" which constitutes its positive substantiality becomes itself object of consciousness, is itself for 
consciousness, then clearly objectivity, opposedness of the object to consciousness, has ceased to exist. Thus we see that the final form of knowledge means and contains not merely the identification of the object in itself and the object for consciousness, but also the identification of the object itself with mind.

Reciprocally, again, such a conclusion equally signifies that mind is identified in true knowledge with the object; for since the opposition has vanished, the result leaves neither of the factors necessary to knowledge alone and by itself to constitute the perfect form of knowledge. The final truth of the object is the complete truth of mind; the ultimate being of the one is identical with that of the other. And this highest form is not simply an ideal to which all the preceding forms point and which determines the process of the inquiry; it is itself a definite actual form among other forms of experience. The truth of knowledge is at once the absolute truth of mind, that form in which it most completely exhibits its essential self, and the absolute content of objectivity, the ultimate essence of reality as a whole.

Now we have but to bear in mind these various aspects of the inquiry in order to make more explicit the special content of Absolute Knowledge. The three significant elements are: the double reference first mentioned, the character and conditions of the process of the inquiry, and the result at which it finally must arrive. Since the truth obtained at each stage registers a moment of the object as well as of mind, the deepening of the knowledge of the truth of the object means at the same time a mere explicit expression of 
the essential and ultimate content of mind. But since mind becomes explicit only to itself, this unfolding of its content is simply the increasing of the consciousness of itself by mind, the development of self-consciousness. And again, since the evolution of the content of consciousness is synchronous with the gradual disappearance of the distinction between mind and its object, the abolition of external objectivity is the establishment of complete self-consciousness; the objectivity which is there found is also and essentially subjectivity, and conversely. The process of the inquiry thus leads first of all to the assimilation of the object to the content of mind as such, and thereafter evolves into complete explicitness the entire nature of mind in all its determinate relations to itself; the whole argument being, therefore, a gradual approximation by mind to its own essential self.

We found the first steps in this self-consciousness actually reached when the moment Reason was attained; and thenceforward it will be noted mind is occupied solely and consciously with its self, in some one or other of the forms under which it is presented to itself. Reason is not simply a "function" of mind among other functions; it is a phase or form of actual mind. It is that form, namely, in which mind abstractly but explicitly expresses its oneness with itself. It is the first, the immediate, and therefore merely general statement of the mind's own nature; for the bare consciousness that its object is its self, and that itself is one with all reality, is the first moment in which mind appears explicitly as what in truth it is. Mind is not in Reason conscious of its self as distinct from 
the reality of which it is conscious; it is conscious of its self in all reality.

In Reason, therefore, mind first appears in its truth, having the character of universality, as conscious only of itself wheresoever and whensoever it has an object presented to it, as subjective and objective at once. And this, which is the first statement of the truth of mind, is the first indication of the result of the whole inquiry. For Reason is not merely the nature of mind, it is at the same time the nature of all reality. Reason is not to be set over against reality; that would take us back to the opposition already overcome. Reason is therefore the "truth" of objectivity. Reason pure and simple, however, is not completely realised mind, and it is thus distinct from further developments of mind. It is merely the first approximation to the ultimate truth regarding mind. In short, Reason is essentially mind, but Reason as such does not exhaust its truth. Only when Reason is further developed does it exhibit the complete reality of mind.

This step having been taken, the argument from this point onwards slightly alters in complexion. The further process of the argument consists in mind becoming more inward to itself, in the deepening of its consciousness of its own reality. The only development which remains possible must consist in the more intimate consciousness by mind of its self, a process by which mind is shown to be more concrete, richer in content, and which finally lays bare the absolute truth of mind, the highest form under which it appears.

All along, be it observed, mind is both ob- 
jectivity and subjectivity; its realisation of itself is not confined to a subjective sphere. Its explicit reality is essentially the negation of any opposition between the two. It may be said that in "Morality" the argument seems to have passed away from any reference to the objective sphere; but such a view can only be entertained when "objective" is restricted to a very narrow meaning (to what lies "outside" consciousness), and if so entertained the whole argument becomes meaningless. For mind has already been shown in Reason to be at home with itself and one with objectivity, even in that narrow sense in which objectivity is restricted to "nature" ; and Reason as it is more fully appears in "morality" and its allied forms, still more completely reveals the identification of mind with objectivity, the moral life being simply the "externalisation," the objectification of Reason. In these forms, therefore, mind is yet more explicit and more truly itself.

Further, because mind has been established as the one all-determining reality, this gradual process of realising its content reaches a stage (in the sphere of inner morality) where objective self-subsistent mind is opposed to the inner consciousness of its self which the individual mind possesses. Out of this contrast, which is also an inner though not explicit union, Religion arises. Now it obviously lies in the very nature of Hegel's principle as hitherto developed that the Absolute Reality, which is the object with which consciousness in Religion is concerned, should be convertible with Absolute Mind. This, after what has been said, hardly needs to be proved. But in Religion it is characteristic that 
emphasis is laid not so much upon the individual who is religious, but upon the object with which the religious mind is concerned, namely, the Absolute Reality. That is the one all-absorbing fact before the religious consciousness, before which the individual consciousness seems to fade into insignificance. In Religion, in short, the individual reality is transcended, and another reality asserts itself as higher than and containing in itself the transcended finite reality. Hence it is for this reason that in Religion mind reaches a deeper consciousness of its own reality, makes more concrete its inner nature, than was possible in the case of Morality. For in the latter mind is conscious of itself in individuals; its reality as the universal principle is explicitly and concretely exhibited in the sphere of finite individual minds, without direct implication in that result of the Ultimate and Absolute Mind which contains and is the fundamental reality of both the merely "immediate reality" with which Reason is concerned and of the self-mediated reality which appears in morality. But in Religion it is this ultimate Reality as such, in the totality of its content, whose nature is specially, indeed solely, determined. Instead of Absolute Mind being either implicitly present or insufficiently realised, we have in the religious consciousness its actual content as it is in itself made explicit and determinate. And the development of mind towards concreteness being simply the expression of its consciousness of itself, we see that in Religion Absolute Mind becomes actualised and self-conscious. In other words, in Religion we have the absolute nature of mind, as the ground reality of the world, completely and definitely expressed. 
Now we have just seen that Religion has its whole significance and its main interest in the Absolute Reality which is its object;/it eliminates the individual in the sense that the religious mind occupies the sphere of Supreme Reality, is consciously one with it, and claims direct relation with and cognisance of it. It places itself at the point of view of Absolute Reality. But if this is the nature of Religion, only a very short step is required in order to assume consciously and without qualification the actual position of the Absolute as such. In fact, such a step is already implicit in that transcendence of the individual just spoken of. And this step Hegel has no hesitation in taking. Indeed he was logically compelled to take it, not merely by the above consideration, but by the very nature of his principle, a principle which also made it easy for him to do so. For since mind has been established as the absolute essence of all reality, individual mind and Absolute Mind are thereby identified. And since the concreteness of mind consists in self-consciousness, we have in the selfconsciousness of individual mind the concreteness of Absolute Mind itself; the realisation of the one combines with it and expresses that of the other. When, therefore, in Religion the individual asserts and maintains its unity with Absolute Mind, and claims that in Absolute Mind it is conscious of its own life, that the Absolute Mind is its self, it is evident that the identification is as emphatic as it could be, and that the standpoint of the Absolute is deliberately assumed.

This position is still further secured when it is shown that the highest and final form of Religion 
is Revealed Religion. That this should be the highest form is simply the direct consequence of the nature of Hegel's fundamental principle. For given that Reality is essentially mind, and that the self-consciousness which appears in Religion finds the self of which it is conscious in the absolute essence of the world, it is in the nature of the case that the highest form under which that relation to the Absolute is expressible should be that of direct consciousness of its content and nature, or, in other words, should be the direct manifestation by the Absolute of its inmost reality to the mind whose self it is. If true religion is found where Absolute Mind is the self of the religious consciousness, it obviously follows that the truest expression for the relation established between the Absolute and the religious mind is that of "manifestation," immediate outgoing of its reality, direct "communication" of the content of the former to the latter. And this is precisely the character of " revealed" religion.

But while in Revealed Religion the standpoint of the Absolute as such is assumed without reservation (for otherwise it would not be revelation at all), yet in Religion the individual is not explicitly and positively eliminated. If this were the case it could not strictly be called revelation, for this implies necessarily relation to a mind which in some sense is distinct from the source of the revelation. Still, the individual is only preserved in a way which is compatible with the direct presence of the Absolute. This can be brought about only by the identification of the individual with the Absolute Mind, or, as it is otherwise expressible, of the human with the divine nature. And such a union 
Hegel explicitly maintains to be a reality of experience. But while this seems to reassert the separate existence of the individual, it really takes up the position of the Absolute in virtue of the inseparableness of the content of individual and Absolute Mind. Still the maintenance of that distinction is necessary to the religious life as such. ${ }^{1}$ Hence it is that in Religion the Absolute is not explicitly determined as it essentially is. In Religion the absolute content is merely "represented" (vorgestellt) to consciousness; it is not explicitly expressed in terms adequate to its nature, but in symbolic or incomplete form. The content is certainly revealed in its fulness, but the way in which this takes place is not the form which expresses that content in its truth. This insufficiency of the form to the content lies in the nature of Religion, which at once insists on as well as denies the distinction between absolute and finite mind.

Thus in Religion Absolute Mind is not determinately and absolutely self-conscious. In order to become so one step and one only is necessary, that the form in which it is conscious of its self should correspond and be adapted to the self of which it is conscious. But to obtain this the individual must be completely eliminated, and the Absolute Mind must be that for which and by which its own content is explicitly determined. But this result can be accurately attained where to its content is given the form of its inmost self. The absence of this is all that is wanting to that content as it appears in Revealed Religion; and to adopt this step is to express completely and truly the final

1 Religion being an experience necessary to finite consciousness only. 
nature of Absolute Mind. But to know itself in and through the form of self is to have as its object the self for which the object is present. And this is simply to realise its own notion, the notion of its self, that by which it essentially is. Now this self which knows itself in its own notion, and in that notion has realised itself, is Absolute Knowledge; knowledge of the content of Absolute Mind by Absolute Mind is perfect and final knowledge, is true Science.

Not, be it noted, merely knowledge about mind, nor, again, simply a knowledge which is for mind; it is a form or mode of mind which is absolute knowledge. Highest mode of mind is literally convertible with Absolute Knowledge; for here we are dealing with knowledge as a living activity, as an active process, not as a product. Here, then, Absolute Mind is completely explicit and concretely realised. And with this it is clear that the standpoint of Absolute Mind has been fully and unequivocally adopted. This knowledge of which we speak has no limiting reference to individual finite mind; it is solely the standpoint of the Absolute from which such knowledge is regarded, and from which the knowledge is furnished. It is without reserve infinite and perfect knowledge to which we have attained.

Such a point of view is again the logical and final outcome of the result arrived at in Revealed Religion; no other step was left to take, and this step taken was at once possible and necessary. Absolute knowledge is thus the necessary conclusion of the Phenomenology. It follows, indeed, from the two ground principles and vital contention of 
the inquiry, viz. that reality is essentially mind, and that mind is in its essence self-consciousness.

Thus in Absolute Knowledge the limitations of individual knowledge are removed; the conscious contrast and opposition between the object and the consciousness to which it is present have been completely overcome; "natural " consciousness has been conducted up to the point of view of true knowledge ${ }^{1}$ the various forms and moments of universal mind have been successively passed in review and made explicit to it as its own. ${ }^{2}$

This result, however, does not mean, indeed it seems both paradoxical and absurd to suppose it can mean, that when we reach Absolute Knowledge in the course of the inquiry we are literally transported out of all possible and actual contact with and relation to the individual self-consciousness which had to be regarded when dealing with Religion, and which, in fact, is the mind we as thinkers are in the first instance more immediately aware of. We saw that in Revealed Religion Absolute Mind was explicitly identified with the individual finite "human" mind ; that the content of the former is "revealed" to, and is identified with, that of the latter. Now this relation is double-sided; the very meaning of such revelation implied that the reality of both was actually the same in content; the individual was conscious of the Absolute as its self, the Absolute was conscious of its self in and through the individual. And it is admitted that the content of both Religion and Absolute Knowledge is the same. ${ }^{3}$ Hence, therefore, the further determination of that

1 Phän. pp. 21, 61.

2 ibid. pp. 2 I ff., etc.

3 ibid. p. 574 . 
content in the form of Absolute Knowledge is likewise and at the same time the determination of the content of our finite self-consciousness. We are bound to admit this if we would make all those elements consistent which we have already mentioned. But if so, we see at once that there is no inherent impossibility in the assumption of the standpoint of Absolute Mind, and no need to suppose that in such an assumption we are transported into a sphere out of touch with actual reality. The complete knowledge of self and by self which absolute knowledge furnishes is expressible by and is determinative of our own self-consciousness; that is to say, mind as we know it attains to and furnishes absolute knowledge. We might state this position otherwise by saying that while in both Revealed Religion and Absolute Knowledge the content is the same, and in both the individual is essentially identified with Absolute Mind, the content in Religion is regarded primarily as appearing to the individual; in Absolute Knowledge it is considered as it is in itself for mind perse. And this agrees with the relations existing between the "particular" and the "universal" individual which were indicated at the outset. ${ }^{1}$

Now it is not difficult to determine from the nature of Absolute Science what in detail the content of such knowledge will be. The knowledge in question is absolute, is knowledge of the Absolute. That which is absolute is mind, or, more particularly, mind in its own essence. Now it is this absolute essence which is asserted to be the self of the religious consciousness, and it is this essence which is the content of both absolute and individual mind.

1 Phän. pp. 21, 22. 
But the essence of mind, that which in it is both objective and subjective, is Thought, expressed as a multiplicity of thoughts. And thought which has the form of self, and therefore possesses that active movement of self-distinction and self-reference which is the nature of mind, is a Notion. ${ }^{1}$ In Absolute Knowledge, therefore, which is the realisation of the nature of mind, not merely is the nature of the knowledge the notion of Mind, but the knowledge supplied is simply of the notions which constitute the mind's own essence. Mind knowing its self (thought) in the form of self (self-referring unity), notion which is self-constituting, self-determiningthat is, the principle, nature, and content of Absolute Knowledge.

Since, then, it is only these notions constituting the essence of mind of which absolute knowledge consists, and since the individual mind in its inmost nature has been identified with Absolute Mind, we see that it is possible at once to attain to absolute knowledge without qualification, and yet in such knowledge still remain within the sphere of individual finite mind. The notions which are the ultimate content of finite mind are identical with those of Absolute Mind, and the determination of the notions of the former is the exposition at the same time of the essential content of the latter. The essence of individual mind is a competent guide to that of universal mind.

It should be noted, however, that the content of Absolute Knowledge is, as a matter of fact, in a sense circumscribed and limited. It is not all or every kind of knowledge ; it is, as becomes evident indeed

1 Phän. pp. 26, 42, etc. 
from the whole inquiry, one form or mode of knowing among the various other forms which have appeared in the course of this genetic history of knowledge. It is and furnishes a specific kind of knowledge, is one determinate relation of consciousness to an object, and for that reason is limited in character. The fact that it is solely with notions that it deals indicates of itself that its nature is restricted. It is noteworthy that as we approach in the inquiry towards true knowledge, the object of knowledge, that which is presented to consciousness, becomes gradually more universal and abstract in character. This lies in the nature of the problem. For the attainment of absolute truth means at once the extension of the area of experience covered by the object of knowledge, and the determination of that object as the absolute essence of reality as a whole. Only so is ultimate truth ascertained. But these qualifications are obviously limitations of the nature of the truth arrived at. It is not the whole of Absolute Reality in its detailed entirety that is professedly the content of Absolute Knowledge; it contains simply the essential content, the notions which are the ground realities of the Absolute. We may, indeed, go so far as to say that it is only such elements in the Absolute that could be known in their absoluteness, for only such elements are common to individual and Absolute Mind, only by these does individual mind share the life of Absolute Mind. That in Absolute Knowledge we have literally the Absolute as it is completely aware of itself in its infinity of detail, would be too grotesque and impossible for Hegel seriously to maintain. And in reality, as we have already shown, such an assump- 
tion is not by any means necessary in order to justify the claims of Absolute Knowledge.

The restriction just asserted requires, however, to be carefully guarded and qualified. For in a sense it can be maintained that such knowledge is not limited. It embraces within its compass the whole of reality. So far as it is only one form of knowing (though the truest) among the other forms which have appeared and which are necessary to mind, and again, so far as it deals merely with the notions of Absolute Reality, the knowledge is limited in character. But in the sense that it deals with the concrete essential content of all reality it is not restricted. 


\section{CHAPTER VII}

THE " PHENOMENOLOGY" (continued)PHENOMENOLOGY AND LOGIC

So far we have considered how the conception of Absolute Knowledge is arrived at, and what it means. We must now determine briefly the relation in which its content stands towards the other forms of knowledge which led up to it.

On this point we are not left in much doubt. To begin with, it holds in the case of Absolute Science, as also of every stage in the process of experience, that its truth contains in itself the truth of the preceding form of experience. The latter is not abolished in toto when we attain a higher stage. It is negated by its own more complete truth, what it ideally contains or implies. The very meaning of degrees of truth indicates that the lower exists with the higher; if this were not so the truths would be either of the same value, or altogether incomparable. In the present case, the later truth possesses within itself the preceding, and the highest, the absolute truth contains all the truth in the preceding forms of experience.

Now the principle in virtue of which this is possible may be expressed in two ways, from the point of view of objective Reality, or that of the 
subject of experience. In both cases the result is the same. Reality, as the ultimate object of experience, is present from the lowest stage of experience to the highest. In the various forms passed in review we are not dealing with objects out of all relation to each other; the object, e.g., in Sense-experience is not absolutely dissociated from that in Observation. If this were so these various forms of experience could not be successive stages in the evolution of the content of the object ; they would simply deal with different objects. To make of them a single whole there must be one object to which they all refer, and of which they are various determinatives. That one object is ultimate Reality ; this is the substantial material out of which the whole structure of experience is built, the point of reference for all the forms of knowledge, that about which there is knowledge. Now this Reality is in experience from first to last; the modes of experience are different ways of bringing it before consciousness. Its presence is revealed by each particular stage of experience, and also by the change from one form of experience to another. If its completeness is not adequately represented by any given mode, it asserts itself by compelling an alteration in the mode of experience which is to interpret it. Each stage contains Reality, but Reality more completely evolved contains the moments which exhibit it less completely, while. Supreme Reality contains all its moments. The identity, therefore, of ultimate Reality throughout the whole process guarantees the essential connexion between the various objects of experience, while the different kind of connexion is determined by the 
fact that Reality appears at the various stages with increasing fulness and completeness. It is true, as has been already pointed out, that each different mode of consciousness is a determination of the single life of the one individual mind present through all experience. Similarly each mode of reality, each object, is an appearance of a single ultimate Reality. The diversity of forms of this Reality does not, and, since experience is one, cannot affect its unity.

But this relation of Absolute Knowledge to the other forms of experience is made evident also when we consider the subject of experience. All the forms of experience are modes of a single consciousness, of the one mind which is operative in all experience. ${ }^{1} \quad$ Each reveals a phase of the life of mind, a mode of the Ego; but one reveals its reality more truly than another. They all agree, therefore, in being realisations of mind; they differ in the completeness with which they express its essential nature. That essential nature we saw was to be self-conscious. All these forms contain a truth of mind, a mode of its self-conscious life; and each is indispensable to its exhaustive expression. Even the highest mode is unable to exhibit the entire life of mind. The Self is the concrete whole of experience, and each form reveals a phase distinct from the others. Mind is too rich to be

1 Hegel regards this mind as on the one hand the " universal individual," i.e. the individual as the representative of humanity as a whole, which possesses all these various modes, has realised itself in all; on the other as the "particular individual" which has to pass through these various stages to completely realise mind (Phän. pp. 21, 22). These two points of view are blended in the inquiry itself, which may thus be interpreted in the light of either. 
exhaustively expressed by any one form of experience, and is equally too poor to do without any. The highest form, therefore, is not a substitute for the other forms of experience, but subsists with them. Its connexion with the others lies in the fact that it absolutely reveals the self which they only in part realised. But it is precisely the same self which is realised in all; its perfect expression must, therefore, contain all the truth it contains, namely, the truth of the other forms of experience. In the final stage, therefore, we have a twofold result; we have at once a highest truth and a definite relation of this truth to the lower truths of experience.

Now, from the considerations which we have adduced, it becomes easy to determine the relation in question. Every mode of mind contains and expresses a truth of experience; every one is essential just for that reason. Each is a specific moment in the living reality, mind. All of these modes together contain the whole truth of experience. But since in Absolute Knowledge mind knows itself, in the form of self, and mind is the entire and absolute reality, the complete knowledge of the self of mind must clearly exhaust the whole content of reality. None of the other forms considered possess this characteristic, for in none of them does mind profess to know its self as it is in itself; none of them, therefore, exhaustively embrace the whole area of reality, or express the whole nature of mind. Thus, then, Absolute Knowledge will not merely contain and make explicit the ultimate content, the absolute truth of reality ; it will also contain the whole truth of reality, will be the 
sphere of complete as well as absolute truth. But if so, then clearly as a form of knowledge it covers, when taken solely by itself, precisely the field exhausted by the whole inquiry of the Phenomenology. For this, as we have pointed out, embraces the whole truth of experience. But in that case, if the final form of knowledge has as its object the whole truth of which mind is capable, and if the whole sphere of truth has been exhausted by the various forms of mind which have appeared in the inquiry, then it is evident that the content of truth as it is laid bare in the former must be identical or correspond with the truth as it has appeared in the latter. It cannot be the same, for the reasons already indicated. The truth in the two cases must therefore correspond. In other words, the notions which make up the content of Absolute Science appear in the Phenomenology as forms of consciousness, as modes of mind. ${ }^{1}$ And this holds good of every form under which mind has appeared. ${ }^{2}$ For, as Hegel puts it, "as mind in its concrete existence is not richer than Science, neither is it in its content poorer." The whole of that truth which is necessary to completely exhaust the range of truth attained and possessed by mind must likewise be contained in a science which professes simply to furnish complete truth in its absolute and perfect form.

It must not be supposed that we have here two different truths of the one experience, or, again, two different experiences of one and the same complete truth. We cannot have the former, for truth is one, experience being one, and mind itself being a

1 Phän. pp. 43, 69, 575, 576, 582, 589, 590.

2 ibid. p. 590. 
unity. To suppose that we could have two truths would mean either that we had not exhausted the area of truth known to mind, or that the one mind could have totally diverse experiences. But the former alternative is excluded by the assumption that the Phenomenology had passed in review all the mind's truth, and the latter by the fact that one mind simply means one experience. Again, we cannot have two different experiences of complete truth for the like reasons. Absolute Knowledge is certainly an experience; but it is only a moment in a single experience. Absolute Knowledge as one activity of mind is one experience amongst others. When completely developed with all it contains it covers the whole area of experience. Consequently that which at once constitutes Science a determinate mode of experience, and yet makes it possible for it to embrace all experience, can only be the attitude taken up by mind in Absolute Knowledge, the character of the truth which it contains and reveals. Or, to put it otherwise, the truth appears differently in experience taken as a whole, and in Absolute Knowledge which embraces in its scope all experience. In the former (in experience) truth appears in concrete form as attitude of mind, as the body and substance of actual human life and history. In the latter (Absolute Knowledge) truth is divested of the palpable flesh and blood of the concrete manifestation of human experience, and appears simply as the vital energy of its substance, as its ultimate essence, its absolute and final meaning.

While, then, there is this distinction, it must not be supposed that there is any opposition between 
the form (particular manifestation) of mind as such, and the notion which in Absolute Knowledge is its essence, that a notion is external to the form of experience. On the contrary, the notion is not merely the resulting final truth of mind, it is also the inner reality of the form of experience itself. It is at once the culminating point of experience and the ground of experience. The movement towards the perfect form of mind does not merely complete itself in the notion, but the notion is the inner principle of that movement itself. ${ }^{1}$ Each concrete form of experience is in its essential nature a notion. ${ }^{2}$

This, indeed, is what we might have expected. For, on the one hand, it is mind's own inner and ultimate truth which is gradually evolved by the process of the inquiry, a result which by the very nature of the process could not be arrived at unless it were contained immanenter in the preceding forms ; and on the other hand, Absolute Knowledge explicitly professes to state the full and essential content of mind, and can only do so if its peculiar content is actually the inner truth of each phase of experience in which mind appears. In the one case, truth in its diversity is extended or spread out over, and in the form of, experiences of mind, which appear in the actual history of mind, and which differ from one another because they are experiences occupying different moments and spheres in its history. In the other case, truth is as a whole and at once contained in and expressed

1 Phän. p. 43 ; Logik, i. 8 ; WW. iii.

2 The notion is simply the formal unity of subject and object which are indissolubly bound up in every experience, for experience is just the union of subject and object. 
by a single distinct form of experience, whose characteristic it is to contain the whole essential content of mind, a content whose diversity consists in the determinate difference of one notion from another.

But in spite of this close connexion between the truth as it appears in Science, and the truth as it appears in concrete experience, we must guard ourselves against a mere identification of the two. We have seen that what appears as part or moment in Science has appeared and is found concretely as mode of mind's existence in experience. But it must not be inferred from this that we have merely to consult the latter in order to find the former, that we have merely to go over all the modes of mind as they have appeared, determine the essence of each of these, and express the result as Absolute Knowledge. In short, Absolute Knowledge is not simply and literally a reproduction in essentia of the modes of experience, a mere restatement sub specie aternitatis of the historical appearances of truth. There is no such merely step-for-step correspondence between them. The content of truth as it appears in Absolute Knowledge has a character of its own; without this, indeed, it would not be a different mode of experience. We have stated wherein this determinateness consists, and it is in virtue of this specific character that the development and systematisation of the content of Absolute Knowledge pursues a course of its own without any explicit reference to these modes of mind whose essence they are. "The pure notion," as Hegel puts it, "and its further development depend solely on its own pure characteristic 
determinateness." 1 That Absolute Knowledge will contain and exhibit the entire absolute truth of experience is thus guaranteed by the fact that it is mind in its essential nature which is to be expounded. The ultimate identity, therefore, between the complete truth as found in Absolute Knowledge and the complete truth as spread out over experience is thus guaranteed by the fact that it is the one and the same mind whose truth is expressed in both-in the former as essence, in the latter as concrete appearance. An explicit and deliberate reference to the latter in order actually to determine and evolve the content of the former is therefore at once irrelevant and unnecessary. In the last result they cannot but contain the same. Hence, while we may look for and will discover a general correspondence, a detailed agreement need not be expected.

In regard to one important factor, however, both the Phenomenology as a philosophical exposition of the modes of experience, and the exposition contained in Absolute Knowledge are in unqualified agreement-the method by which the constructive connexion is established, by which system in the two cases is obtained. This is the same in both. ${ }^{2}$ We saw that the essence of each form of mind was a notion, and the movement from one to another is primarily a notional movement. Again, it is the one mind whose complete truth is systematically expounded in each case. And for the attainment of system, of scientific coherence and connected development there is only one true method. The 
nature of this method as it is pursued in the Phenomenology has already been indicated. The only difference between the process of the development in the Phenomenology and that in Absolute Knowledge is not in the principle by which the development in either case is obtained, but in the nature of the object-matter dealt with by each. In the former mind is ostensibly divided from its object; and the discovery of the absolute truth of knowledge was found to consist just in the gradual approximation to final explicit identification of the two opposed elements. In the latter that opposition has been overcome, truth appears in form of truth, content and form of truth are identical ; and here the process of the system of Absolute Knowledge consists in the development of essential truth as such from its lowest up to its highest form. In the former this method of construction was applied to mind simply as concrete actual mind; in the latter it is applied to the truth of mind as truth." The method is bound to be the same, for the method was all along immanent in the content of the inquirythe method which has brought out each stage, and is the vital immanent activity of each stage itself. Hence the further development of the content of any particular stage, if it is to be really true, must follow the inner movement which has determined the essential nature of each stage itself. Only so could any stage develop its implicit content into system. And this is all that Absolute Knowledge can do if it is to become expressed in a system. It must, that is to say, simply develop its content in the character which that content possesses. We might have also a special development of other 
phases of experience, e.g. that termed Sittlichkeit in the Phenomenology, and call this special development the System of Ethics (or, as it is called later on by Hegel himself, the Philosophy of Law). Or, again, we might have similarly a special development of Religion, and call it Philosophy of Religion. Yet in all these cases we simply have application of one and the same method. Similarly it is this one method which must operate throughout the development of Absolute Knowledge, which is one mode of experience like these others, one offshoot from the root and main-stem of all experience, mind.

We have now stated as completely as is necessary for our purpose the character and content of $\mathrm{Ab}$ solute Knowledge. We have shown its place in the concrete experience of mind as an existent fact. We have seen that it is the inevitable and necessary outcome of the inquiry into the truth of mind, and have stated in what respects it differs from, and in what it agrees with, the preceding modes of mind.

The importance of a precise determination of absolute knowledge for the development of Hegel's Logic cannot well be over-estimated. For in fact, as must have become already evident, Absolute Knowledge is simply that science which appears in his system as Logic. ${ }^{1}$ Absolute Knowledge is not science in general, but science taken in its essential "abstract" content, science in its ultimate terms, the very notion of science. It is not a descriptive analysis of any and every science, but has the definite determination of a special science. It is science of the essential content of experience. Such a science was for Hegel Logic.

1 Phän. pp. 26 f., 42 ff.; Logik, i. 8, 31 ff. 
That this identification of Absolute Knowledge with Logic was in no sense an after-thought on Hegel's part is quite evident from the passages referred to, and indeed from the nature of Absolute Knowledge itself. But if, then, Hegel established the Logic as the final and complete truth of mind, and maintained precisely the same position when working out the Logic itself, the significance of Absolute Knowledge as stated in the Phenomenology for the determination of the nature and content of the Logic in the form in which we now have it is manifestly very great.

Between the appearance of the Phenomenology in $1806-7$ and that of the first volume of the Logik I 8 I 2, we have no writings published by Hegel to assist us in the discovery of the process by which the Logic, as such, was being constructed. We have, indeed, one publication which, while it did not appear in printed form till after his death, was, in its substance, produced during this interval. I refer to the Philosophische Propaedeutik. ${ }^{1}$ Interesting as are these collected notes of Hegel's lectures ${ }^{2}$ to the Gymnasium pupils in Nürnberg during his Rectorate (1808-16), and helpful as they are in the elucidation of some points in his scheme, it is for two reasons impossible to consider them of much value for the elucidation of the last stage in the development of his Logic. In the first place, the treatment of Logic which we find in these notes is in its main outline the same as that found in the final systematic statement, and in its details differs

1 Werke, xviii.

2 The lectures were begun in 1808 , and after continual correction finally, in 1811 , took the shape in which we now have them. Cf. Rosenkranz, Preface to "Prop." Werke, xviii. p. vi. ; Leben, p. 249. 
from it only in unimportant points. These notes, therefore, in no way indicate any better than the final Logic itself how his positions were obtained. In the second place, the form in which these notes were furnished was determined solely with reference to the needs and capacities of those to whom they were given. So that what does not appear in them cannot be assumed to have been absent from the mind of the author himself, or not to have been yet grasped by him; and what does appear in them was in its matter and method such as to be adapted to the intelligence of those who listened to it. Hence, for instance, it is significant that the inner and immediate connexion of one part with another, and its immanent development out of it by the strenuous application of the only true philosophical method, ${ }^{1}$ scarcely appear at all in these notes. What is found, and what indeed gives them their value, is primarily the precise distinction of one element from another, and the grouping of the elements under general headings - exactly what was necessary for the beginner in philosophy, but which for that reason was not a completely philosophical exposition.

In the absence, then, of direct assistance from any statement by Hegel himself between 1807 and I 8 1 2, we must seek to determine the mode of the construction of the Logic by such aid as the Phenomienology can supply. And that identification of Logic with Absolute Knowledge which we have already mentioned furnishes a satisfactory and

1 There is hardly any indication of an explicitly adopted philosophical method at all in the Propaedeutik. Yet Hegel's method had been used in constructing the Phänomenologie, and its importance recognised. 
entirely trustworthy clue by which to attain this object. For not merely is this identification consciously made in the Phenomenology, but it is ratified and repeated in the statements made in the Logic itself. This indicates, indeed, that Hegel had attained his final philosophical position by 1806 (or perhaps a year or two earlier, for the Phenomenology was written between 1803 and 1806 ), and that the general scheme and plan of his system was explicitly present to him from that time onward. This general scheme, as well as the fundamental point of view, do not seem in any important respect to have been altered at any subsequent period. We are justified, therefore, in passing from the Phenomenology at once to the construction of the Logic. We need not pause to gather up the results hitherto attained, or to indicate in what respects development in his view has taken place. This will be better dealt with after the discussion of the Logic itself.

We propose, then, to show how, from the nature and import of Absolute Knowledge, the construction of the Logic arose and was determined. And we shall try to exhibit this first of all with reference to the general nature of the Content of the Logic; and secondly, with regard to the Method pursued in the Logic.

But to begin with, it is necessary to state as clearly as possible the relation in which the Phenomenology stands to the Logic, as far at least as this has not already been dealt with. We have considered, from the point of view of the Phenomenology, the relation in which Absolute Knowledge as a mode of mind stands to the other modes 
of the mind's experience. We have now to consider from the point of view of the Logic what relation the whole inquiry in the Phenomenology bears to the purpose of the Logic. It is the same problem regarded from two standpoints; in the one case from that of Phenomenology per se, in the other from that of Logic per se. We must carefully guard ourselves, therefore, from trespassing on ground already covered.

Absolute Knowledge or Logic, then, is, like every other mode of knowledge of which mind is capable, in the first instance a fact which exists in the experience of mind. It is not itself unreal; it is an actual mode of concrete mind; not the only mode, but one which exists beside others. It is one form of experience, and appears as an existent fact in the history of mind. ${ }^{1}$ This is what is common both to Absolute Knowledge as treated in the Phenomenology and Logic as a fait accompli in the system. This aspect of the Logic, we shall see, is of vital importance.

In the next place, there is a more inner connexion between Logic and Phenomenology. The latter professes to be the ante-chamber to the former, and the former "presupposes" the latter. ${ }^{2}$ The sense in which the Phenomenology is to be regarded as the presupposition of Logic is not difficult to determine, if we bear in mind the nature of the two sciences in themselves. The Phenomenology is the philosophical statement of the modes of experience which mind possesses; it takes the modes simply as modes, merely as existent facts in experience, and criticises and systematises them.

1 Phän. pp. 583, 585.

${ }^{2}$ Logik, i. 3 I f. 
Logic deals with the absolute truth of the highest mode of mind. The first science (the "Science of Experience"), therefore, deals with this highest mode simply as a mode; the second science is an exhaustive exposition of what this mode contains. Consequently the object-matter of the two sciences is not the same. Each science is $q u \hat{a}$ content sui generis. If this were not so, the first step in the Logic would be the immediate outcome of the last of the Phenomenology, whereas the Notion of Science is only found towards the end of the Logic, and the beginning of the Logic is determined by turning back to the beginning of the Phenomenology. ${ }^{1}$ The Phenomenology, then, can be the presupposition of the Logic only in the sense that it deals with the form of the science of Logic, the character of the content found there. This character, as we have seen, is that in it we have the absolute unity of truth with certainty, and of thought with reality, of Notion (Begriff) with Being $(\operatorname{Seyn}) . /$ Such a unity is presupposed in Logic, and is not established there. Logic starts under the assumption, and its whole procedure depends on the assumption, that the opposition of these elements has been entirely removed. The very meaning of "pure truth" requires and implies this; and the whole of the Logic from first to last contains pure truth, and that only. If, then, it contained anything implying that opposition, it would not contain what it professes to deal with. Thus that initial presupposition regarding the character of the content of Logic cannot, by the very

\footnotetext{
1 " Being" in the Logic is the naked essence of mere "sense-experience," with the analysis of which the Phenomenology begins, $v$. infra, chap. viii. Note A.
} 
nature of the science, be established inside Logic itself; but allowing Logic to start from it, the various notions with reference to which this assumption holds good, can be completely determined and connected. But for the very reason that the specific content of Logic is not self-evident, is a philosophical truth, and is presupposed by Logic, it requires to be justified, and systematically established. And this not merely for the sake of other minds than the author's, i.e. those who do not primâ facie accept it, but for the sake of the unity and completeness of the system itself, which, just because claiming to exhibit absolute truth, must show that it already in some sense contains also other truths as well.

It is thus the nature of the subject-matter of Logic which the Phenomenology philosophically establishes and determines in the manner we have shown. It is, therefore, the presupposition of the Logic in the sense that it establishes as a truth what Logic assumes at the start and throughout the system ; it proves and justifies the presupposition of speculative Logic. Neither the presupposition nor the proof of it is an express part of Logic itself. Logic as a science could be presented without any such justification of its point of view, and is in fact carried out without any reference to that presupposition. ${ }^{1}$ The content of Logic has the same character at every step and moment of the system, at the end as well as at the beginning. That character is implied in the construction of Logic in the same sense in which extension as the character of space is implied in the science of Geometry. It 
is simply the essential nature of space for Geometry, its ultimate datum. What Logic deals with just consists of such elements as possess that quality of being "pure truth." If there are no such elements, if the notion of Absolute Knowledge is meaningless or false, the whole structure of Logic as understood by Hegel must collapse completely. That there are such elements is what the Phenomenology establishes; if that result is true the principle of the Logic must be sound. What those elements in extenso are, and what are their relations-this is exhibited in the Logic. Hence the truth of the point of view of Logic, the validity of the conception of the nature of its subject-matter, (the ground notions of experience), is determined by the Phenomenology and falls outside Logic itself. But, this being granted, the truth of the Logic as systematic science does not depend on, and is not guaranteed by the fact established by the Phenomenology; the Logic guarantees its own truth, is a self-closed science. The Phenomenology "justifies" the claim of Logic to deal with absolute truth. This is only secured by systematic consideration of all forms of truth found in experience, the truth contained in Logic being shown to be the ultimate truth of experience. The "justification" is therefore a "deduction"; Logic is the outcome and final truth of experience. Thus, then, the Phenomenology is the philosophical presupposition of the standpoint of Absolute Idealism; the Logic is its systematic exposition. The former is the Critique of Experience; the latter is the Metaphysic of Experience.

There are other senses in which we may regard 
the Phenomenology as the presupposition of the Logic. We may, for instance, take it to be the process by which the individual is led up to the standpoint of the Logic. In this sense it is, for the individual approaching the system, the first step to the understanding of it. It undoubtedly has this function; but this subjective purpose cannot be supposed to exhaust the nature of the work; it is determinative of its aim, but not constitutive of its content. The Phenomenology is an objective science, a philosophical "Science of Experience," is necessary to the system, not a mere introduction to it, and is called by Hegel himself the first part of the "System of Science." 1 If it had only this subjective significance, it would be singular that it should be regarded as an integral part of the system of Idealism, still more that it should be considered to be in a sense the whole system. We might, again, say that the Logic historically presupposes the Phenomenology. But this is really irrelevant, and is dependent solely on the author's own method of exposition. To be first in time is not necessarily to be a condition of truth.

Finally, we must determine the relation in which the content of Logic stands to that of Phenomenology. Both cover the whole of realityin the one case as the content of actual experience, in the other as the content of absolute truth; in the one case as concrete appearance, in the other as ultimate reality. Each science is complete in itself, and is self-determined, and yet each goes over the same field. No sphere of reality, therefore, lies outside either. But in that case each can be regarded 
as containing the whole of Hegel's philosophy $;^{1}$ each ${ }^{2}$ contains the system as a whole in a different form. And this, paradoxical as it seems, is true, though it is only partially true; for each, while containing the whole system, is itself merely a part of that system.

But though each science can be regarded as covering the whole system, this does not mean that the system has two beginnings, nor, again, that there are two systems. It is one and the same principle which is present in both sciences; in the one science (Phenomenology) the principle appears explicitly as a result at the end of the inquiry; in the other it is explicit at the beginning; in both cases it is operative throughout. The difference of science, as we have seen, lies in the difference of immediate object-matter, and the difference of beginning is determined by that object-matter. There is, as Hegel insists, no absolutely first philosophical science, though in each philosophical science as such we must begin at the absolute beginning for that science. ${ }^{3}$ There are, indeed, differences in value for the system between these two sciences; for the one (Logic) states in ultimate form the complete and absolute truth contained in the system, while the other contains the truth of the system in the concrete forms of actual experience, the essence of which, as we saw, is itself just the ultimate form as it appears in Logic. But this does not render either science superfluous for the complete systematic statement of Idealism.

\footnotetext{
1 Logik, i. 8. The change made in the title later does not seem in any way vital.

2 Cf. Phän. pp. 589 ff. ; Logik, iii. 25 f.

3 Cf. Briefe, Theil i. 354 ; Ency. (Ausg. i.) § 30.
} 
It is not, then, the area, the extent of reality covered by each science, which makes them distinct, but the aspect of reality which is regarded in the two cases. And when we ask what constitutes the distinction, the answer has already been indicated. In the Logic, mind, the whole of whose experience was passed in review in the Phenomenology, expresses the content of its experience in that form which for mind is ultimate (because mind is there most at home with itself) and absolute (because selfsubsistent). But this form is just the notions, the thoughts, which constitute its essential nature $q u \hat{a}$ mind. Mind per se is not a void, nor is it a tabula rasa. It has a determinate content, thought, which is that by which mind is mind. And since thought was proved constitutive of all the various forms of experience, the reflexion in the medium of those notions is bound to cover the same area of reality as the previous science. But we have already anticipated that development of Logic out of this conception of Absolute Knowledge, which we now proceed to state.

\section{Note}

The place of the Phenomenology in the various forms of the System.

From the fact that in the Encyclopadia "Phenomenology of Mind" is a subdivision of the "Philosophy of Mind," it has been supposed that the Phenomenology of 1807 was afterwards not considered by Hegel to be an integral part of his System, and must therefore be regarded as at most of significance for the uninitiated only. 
There is much to be said against this view. In the first place, in the "Philosophy of Mind" the section described as "Phenomenology of Mind" takes up a stage in the development of Mind in general, and deals with this simply as a stage; it does not work out the full significance of this, nor all that it contains. It deals with it primarily on its subjective side, i.e. as a stage in the development of consciousness as such. In the Phenomenology of 1807 the full significance of that stage is worked out ; it is the stage where we find what is called "Experience." Hence the full analysis of what it contains is the socalled "System of Experience," Phenomenology. If we care to draw a somewhat doubtful distinction, the "Phenomenology of Mind" in the Encyclopadia may be said to deal with consciousness in its subjective aspect; in the construction of 1807 , Phenomenology deals with consciousness in its objective significance.

Again, Hegel made the "Phenomenology of Mind" a part of the "Philosophy of Mind" in the Propaedeutik, which first took shape in 1808 , a year after the publication of the Phenomenology. It is therefore unlikely that his interpretation of its significance changed so soon. And this is confirmed by the fact that, though he treated "Phenomenology of Mind" in this manner in the Propaedeutik, we find that the Phenomenology of I807 still had its original significance; for it is described in the preface to the first edition of the first volume of the Logic (I8I 2) as the first part of the System of Science.

In the next place, the Phenomenology of I807 is constructed primarily by the same method as the rest of Hegel's Philosophy. Now, for Hegel, 
systematisation by the dialectic method is synonymous with being an integral part of the System of Idealism. We have therefore as much right to take the Phenomenology to be an integral part of the System as, e.g., the Philosophy of Law. In fact, the same argument which would show that he changed his views regarding the former would equally prove that he altered his ground in the treatment of the latter.

All that we can maintain then is, that the purpose of the treatment in the two cases is different, and that this is due to the aspect of "Consciousness," (which is the stage of mind to which Phenomenology applies), dealt with in each case. But this does not necessarily mean any change of point of view on Hegel's part. The difference really lies in the point of view from which the same fact is regarded. "Phenomenology of Mind" as it occurs in "Philosophy of Mind" may indeed be said to bear much the same relation to Phenomenology as a completed "System of Experience," that the Phenomenology of I 807 bears to the Logic, in the way above described. The "Philosophy of Mind" shows the place in the life of spirit of the stage of "Consciousness in relation to an object," much as the Phenomenology of 1807 shows the place of Absolute Knowledge in the System of Experience. 


\section{CHAPTER VIII \\ ORIGIN AND NATURE OF THE CONTENT OF THE LOGIC}

THE foregoing statement of the nature of Absolute Knowledge and of the relation of the Phenomenology to the Logic will enable us without much difficulty to determine more specifically the nature of the content of Logic itself. It is the content which we must determine first of all, because, though the method is the life and soul of the Logic, the content is its substance and is logically prior to it.

We see, to begin with, what is meant when Logic is regarded as the content of Reason. Reason is the last general stage in the evolution of the experience of mind. It is here that mind begins to realise its highest life and purpose, which is to be at home with itself in its object. It is because of this, indeed, that reason has been considered both by common thought and by philosophy to be the highest type of mind, that the supreme goal of the world's life is a "rational soul," a mind which with an objective environment is still within itself. Now wherever such a complete harmony is found in experience, there we have the life of Reason manifested in the history of consciousness. But if it is realised anywhere, surely it is obtained when 
mind has for its object the very notions by which it grasps (begreifen, Begriff) the meaning of an object at all. If in such forms of experience as the Moral Life, Law, Institutions, or, again, Religion or Scientific Inquiry, mind finds itself bound up in indissoluble union with its object, takes its object to its heart and gives it its own, then indeed must it be in the highest sense at home with itself when it has to deal solely and alone with the means by which that union can even be effected. In Logic, however, this is precisely the object considered. The fundamental conceptions by which any and all experience, i.e. relation between mind and object, can be constituted are the only subject-matter of the science. Such a science, therefore, is clearly a part of the life of Reason, and indeed the highest form of that life attainable by mind. This aspect of the nature of Logic, however, must be guarded from misunderstanding. In the first place, Logic is but one expression of Reason among the vast variety of its forms which are revealed in experience. In ordinary thought reason means, perhaps, primarily the purely formal activity of the mind, the activity found especially in ratiocination ; reason is identified with reasoning. It is true that a further analysis corrects this limited interpretation of reason; for common opinion would also allow that a mind with "sound instincts" but without the capacity for consecutive thought was "endowed with" reason, was a "reasonable mind." Still its main conception is that reason means reflexion; the larger conception is regarded sometimes as different in kind from the other, or at least as not connected with it. Now for Hegel Reason has not this limited signi- 
fication; he does not restrict Reason to the sphere of mere "Logic," to reflective activity only. It covers a much wider area of experience ; is present, in fact, wherever mind is to any extent conscious of itself in its object. Hegel thus considers as forms of Reason spheres of experience which common thought does not, at least explicitly, identify with reason, e.g. the Family, the State, Religious Life. In such cases, if any explanation were offered at all, common thought would probably regard these forms of experience as due to "impulses," "instincts," or "feelings." And yet, in spite of the apparent difference, Hegel's view is essentially at one with common thought; for if it were asked why such types of experience were not found, say, among brutes, the answer would doubtless be that they were due to that which distinguished man from brute, namely, reason. Reason would thus be acknowledged to be, as Hegel claims, the determining reality in all these modes of experience. It is, then, only as one form (the highest form) of the life of Reason, and not as its sole expression, that Hegel regards Logic as the construction of Reason.

Again, we must not look upon Reason as a - "function" of mind, Logic being one of its products. This indeed is the common view, but not at all Hegel's. And the difference is plain. A "function" is a determining component of what has an independent value, or, again, is more or less isolated activity of what can exist without it. In both cases the relation between the function and that which has the function is regarded as external. How far ordinary opinion would really admit this implication of its view is not easy to determine. For Hegel, 
however, Reason is mind itself, the realisation of its essential nature Mind does not have Reason; it is Reason. No doubt Reason is not all that mind is, for mind appears also, e.g., as sense-consciousness, and Reason is not sense. But on Hegel's view ( $\mathrm{I}$ ) sense is likewise a mode, a realisation, and not a function of mind, and (2) in the form of Reason mind is most completely realised. In short, Hegel's position is directly opposed to any mechanical interpretation of mind, either as an agent with certain "faculties," or as an instrument with certain "functions," the agent or instrument being something apart from, or over and above, what it does. The very meaning of mind is to manifest what it is, and to be what it manifests.

From this we see that Logic is not, properly speaking, the "product" of Reason. This conception is open to precisely the same objections as that just mentioned. Rather Logic is Reason made completely explicit; they are the same concrete fact looked at now as merely existing activity, now as systematically complete activity. The relation of Reason to Logic is perhaps adequately described as that of duvals to evepreia; they are continuous with one another, form a single whole.

The recognition of this essential identity of mind with Reason, and of Logic with both, is of supreme importance for the comprehension and appreciation of Hegel's system. It is one of the fundamental points in his whole theory, and is in itself a philosophical position of the greatest value. Few, if any, have seen so clearly as Hegel the living unity of spiritual facts with spiritual activity, of thought with the objective result of its activity, of science 
with the mind which manifests itself in science. To him ideas no less than emotions take to themselves hands and feet and move about the world. And thus the Logic is not the mere excrescence or by-product of the activity of mind, but the kingdom of truth, where the Spirit at work in experience reveals, and in revealing exhausts, the substance and meaning of its inmost life.

The general determination of the content of Logic as that of Reason does not, however, carry us very far towards the understanding of it. It follows from what has just been stated that Logic is further, as Hegel puts it, "the crown of the life of mind." For the goal of experience is for mind to be in its activity completely self-conscious, at one with itself in its object. Now if in Reason mind has attained that stage in which its experience is essentially a harmony of content, then certainly in Logic that harmony is most complete and absolute. For there mind has for object the very ground conceptions in virtue of which experience is even possible at all. These notions are the pulsebeats of its entire activity; they constitute its essential nature, and express the vital energy of its own being. To know them, therefore, is to make its own self its object. The conceptions do not "belong to" mind; they are mind, they are the foci of its activity, determinate realisations of its self. For they are universals and they are unities. Now the principle of universality in experience is just the self, mind, which is present throughout all aspects and forms of experience, and present, therefore, throughout each form by itself. The fact that a single self does extend its presence over every 
area of experience is the very ground of the fact of universality in experience, the condition of its possibility. But for the fact that it is one and the same self which pervades the flux and multiplicity of experience, there would be nothing but a ceaseless procession of disconnected phenomena, not the experience of a mind ; there would, indeed, not even be a succession, a process, there would be neither details nor phenomena, for all these only have significance by reference to something permanent, something general, something to which they can $\rightarrow$ appear as phenomena. The self, then, is the principle of universality in experience, for it is, par excellence, the universal, the all-containing ground of an experience in any sense whatever. Now the conceptions which form the content of Logic being universals, are precisely the expressions for the appearance of a single self in experience. A given conception is just the self as it is present in and throughout some one area of experience. They could not be universals unless the self were continuously present in experience; and their universality simply means that they are definite realisations of the self. In short, the conceptions as universals are specifications of that which in experience is the fundamental universal-the self for which experience exists at all.

Again, and in the same way, the self is the ground of unity in experience; for the elements which make up experience are determined as parts of a single experience. A single experience means the experience of a single self; the self being one, the experience is one. Not that we can separate in reality the unity of the self from the unity in experi- 
ence; they are an indissoluble reality. The unity of the self is only logically prior to, and distinguishable from, the unity of experience. A single self is the condition of a single experience; and there is no other kind of experience except that of a single self. Now, the notions are unities, for they are the very means by which diversity is not mere diversity but is brought under a common, i.e. unifying, principle, possesses a single quality or character. A notion is the ground of order; it is the identical content in different phenomena. They must, therefore, be determinations of that principle which is the unity of all experience, and the basis of all unity in it, namely, the single self which constitutes it. The notions are specific unities, because. they are forms of this ultimate single unity; and, again, because they are unities, the self must be found realised in them.

Thus, then, we see how it is that in Logic we have the most complete form of the self-consciousness of mind, "the crown of the life of mind." In the content of Logic mind is knowing its essential self, its constitutive and ultimate moments. And it is knowing these not as something alien to itself, but as what actually possesses its own distinctive nature-universality and unity. As Hegel puts it, in Logic mind "knows itself in the form of its self"; these notions are its specific realisations, i.e. its specified self, and they are in the form of self, i.e. are universals, unities, identities. Further than this mind cannot possibly be developed, and with the Logic, therefore, its experience as a process of and towards self-consciousness must close. 
And here we discover, from another point of view, why Logic should be called ultimate science, absolute knowledge, and so on. That it is knowledge is of course obvious after what has already been said. It is clearly both possible and necessary to deal with notions per se, have them as a specific object of knowledge; for it is one thing to use a notion to explain facts of experience, it is quite another to examine the meaning of that notion itself. $^{1} \quad$ And the one kind of knowledge is just as valuable, quâa knowledge, as the other. Knowing what a notion is, and knowing what it does or can explain, are both important forms of knowledge. That, again, knowledge of the notions is "absolute" knowledge is evident when we observe that the object which the mind knows is relative to nothing but the mind itself. In all other knowledge notions are present; for only by notions (universals) is there knowledge at all. But in Logic we have only notions before us. The object is not in any sense independent of the mind, which knows it; mind does not refer to what lies beyond the circuit

1 IVe only have knowledge, and we always do have it, when we have a union of an immediate element with a process of mediation, or, to use the ambiguous Kantian expression, where we have something "given" on which we are to exercise reflexion. Now both factors are required and are found in the System of Logic. The notions are the mind's own self; and since it is self-conscious, the notions are directly present to it, they are that of which it is conscious, its immediate, its "given," "its facts." That they are immediate, simply means that the self is conscious of them, it is their character as objects of knowledge. That they are in content universal, is irrelevant to their being immediate. Because again the self is conscious of them, and in that sense conscious of its (complete) self as distinct from each particular notion, it can relate them to itself and to one another-mediate them. It can do so simply because it is self-conscious, unity in difference in a conscious form, and must maintain the unity through and in distinction. And finally, because in both factors the self is in its truest form (universality), the system of knowledge produced by the union of immediacy and mediation is the highest form of necessary knowledge. This is the Logic. 
of its own inner life. But if knowledge deals solely with the self which knows, it is entirely self-constituted, self-determined, and self-contained. To be completely self-sufficient, however, is precisely what is meant by being absolute. And such knowledge is likewise ultimate or final, for the reason that it deals simply with what is ultimate in experience, the inner content of the self.

This characterisation of Logic as ultimate and absolute knowledge is no mere serious bombast on Hegel's part. It is rather a bare statement of fact, regarding the nature of the Logic as a science. The statement, indeed, might be true of any other "Logic." For surely the last object we can possibly know is just knowledge itself; the last kind of knowledge is the knowledge of what knowledge in general means. But this is precisely what any Logic which is in earnest with itself tries to furnish. Every Logic, therefore, gives absolute knowledge in Hegel's sense; for in all such cases the mind is unrestricted, independent both in its objectmatter and in its procedure-and that means the knowledge furnished is absolute. [If we would keep clearly in mind that "absolute" does not necessarily characterise the range of truth attained by the Logic, but refers to the kind of knowledge contained in it ; that the term is due not to any claim on Hegel's part to have once for all.exhausted the whole range of truth, but simply to the peculiar nature of the relation between the subject knowing and the content known in the Logic, we shall see that Hegel's conception of Logic as absolute knowledge is both intelligible and accurate. The objections to, and even contempt for, it can only have arisen through 
ignorance of its precise significance. It is mere confusion to identify absolute knowledge with omniscience; the latter refers to the extent of knowledge only, the former to a specific kind of knowledge. So that, even if omniscience were a form of or involved absolute knowledge, absolute knowledge does not necessarily involve omniscience.

But in the next place, how is the diversity of the content of the Logic to be obtained? This has already in part been indicated. The content of Logic is the inner self of mind. But it does not follow because one mind is present throughout experience that there is only one form of experience. The Ego does not exhibit itself as the continuous reappearance of a single naked identity. The mind reveals itself in many ways, lest one pure notion should corrupt its life. But, again, the plurality of content in the experience of mind does not involve that the self is merely the point of reference for the various forms of experience, that to which they all "belong," but which itself remains apart from them. The Ego dominates the reality of each; it is not a formal unity, regulating experience from without, it is the active unity constituting every moment of it. It does not direct the course of experience, it identifies itself with its life; for indeed the life of experience is in one view precisely the life of the Ego itself. But if, then, the unity of the self does not preclude diversity of content, and if the Ego is identified with the content of experience, then we see at once how the diversity of the content of Logic is derived. In Logic mind is most completely self-conscious. But its self embraces the whole of reality, the totality of experience; for it 
constitutes every form and phase of it. Since the experience of the self is manifold, the universal principles by which it makes experience possible must be likewise manifold. The content of the Logic, therefore, is rich with all the variety which reality as a whole contains. The fact that in the Logic the Ego is conscious solely of itself, and in one form only (that of the notion), does not render meaningless or eliminate the diversity of the world. On the contrary, mind could not be conscious of its self in Logic unless it exhibited the infinite diversity which make up the fulness of its life. The self which is the universal in experience appears in a plurality of universal forms ; they determine the definite modes of its experience. But these universals are simply the notions which make up the Logic. Logic, therefore, necessarily contains diversity because the self has manifold universal ways of realising itself. ${ }^{1}$

Connected with this diversity in its content is another important aspect of its nature which calls for attention. It is a fundamental peculiarity of the notions in the Logic that they are at once conceptions pure and simple, and unities of diverse elements. Experience is essentially a unity of subject and object; subject and object are its ultimate elements, experience itself is the concrete indissoluble unity of these elements. Now a notion is the ground of the unity of subject and object in any given form of experience. Notions are simply the ultimate conditions of the possibility of this unity, and so of experience. Without them subject and object are for

1 Any other interpretation of experience would be either Scepticism, Solipsism, or Identitätssystem. 
ever divided by the whole diameter of being. In concrete experience, however, we must distinguish subject from object; we can separate the one from the other. For while it is true that any experience is impossible without them, it is also true that the subject is not aware of all objects at the same time; the subject can take up all the attitudes found in experience, but not all at once. Hence we must not confound the general unity of subject and object with the particular unity of these elements; the former is always and absolutely necessary for experience; in the case of the latter we can separate subject from object. ${ }^{1}$ But with the notions such a separation is impossible in any sense. In the notions the distinction between subject and object collapses in the unity which is the basis of their connexion. And the reason is obvious. For the separation, logical or real, between subject and object cannot hold good of that which is their unity; the conditions of the possibility of actual experience cannot contain the separation of the elements which compose that experience itself. To put it otherwise: experience is the single concrete reality, the unity in experience is the ground of distinction of elements within it ; the forms of this unity, therefore, cannot be affected by the distinction to which the unity itself gives rise. Hence, then, we see how it is that in the notions of Logic the opposition which characterises the modes of actual experience disappears, and we have content which can be described as neither objective nor subjective, but both at

1 For example, when mind is absorbed in Sense-Perception, it is not taking up the attitude of Reasoned Knowledge or of the Moral Life. We can, therefore, separate the subject of all experience from the object which it has or would have in a particular experience. 
once. In Logic we deal simply with the ultimate principles of unity in all experience, which can contain no opposition in themselves because they are the very means of removing all opposition whatsoever. Thus because we take the principles as principles, the universals (conceptions) as universals, Logic deals with "pure" notions (reine Begriffe); and because their content shows no opposition, is undifferentiated, they are self-contained, "simple" (einfache Begriffe).

But, on the other hand, we must not lose sight of the significance they possess in virtue of their being unities. The fact that they are notions pure and simple does not lift them out of the reach of experience. If this were so they would not be unities constitutive of $i$, and we should be again inside the opposition which they themselves overcome. But if they are unities of the ultimate diverse elements (subject and object), then they have precisely the nature of experience as such when contrasted with its elements. Starting as we must from experience itself, the subject as such or the object as such has only real significance by reference to the other; by itself it is "abstract." But experience is the unity of both, it is the whole reality; in contrast with them it is "concrete." The notions are also the unity of both ; they therefore are essentially "concrete," not abstract. To be an ultimate unity is, in fact, to be concrete. ${ }^{1}$

And now we see at once what is meant by the "concreteness" of the notions, and by "reality" as

1 This conception of the notions as ultimate unities is essentially in agreement with Kant's " $a$ priori synthetic notions." That they are "unities" means that they are "synthetic," and being "ultimate" they are $a$ priori. Cf. Logik, iii. 28. 
attributed to the content of the Logic. When a notion is described as the "unity of thought and being," we must carefully note that "thought" and "being" are here regarded as the abstract elements of experience. "Thought" in ordinary philosophical parlance is considered the sphere of the subject, of subjectivity, "being" as that of the object, of objectivity; both being taken per se. They, therefore, are essentially synonymous with subject and object as employed above. A notion is the identity of "thought" as one abstract element, with "being" as the other. A notion, therefore, is not a thought as the subjective element in experience, any more than it is a "being" "outside" thought. It is the principle by which this opposition is ultimately constituted into a unity. For related they must be, otherwise they could not even be thought of as opposed; an opposition presupposes a ground. But they are not merely related, they are united in experience. The proof of this and the nature of this unity were furnished in the Phenomenology. But that which unites them cannot be itself either per se; and it can only be both at once. Thus for Hegel, while a "thought" may be "abstract," a notion is always "concrete." 1

And, again, the notions have "reality." They do not lie outside experience, they are immanent in it, are constitutive of it. But if so they have at least as much title to be regarded as "real" as any other element of experience. They have, indeed, more claim to be so considered, for they form the ground-

1 The importance of all this is of course seen most clearly in the use made of it for the "ontological proof" of the existence of God. 
plan of experience itself; they are the essential content of concrete experience. And only in this sense are the notions real. The term "reality" is admittedly ambiguous, and hence the difficulty of understanding what is meant by notions being real. " Notions," it is said, "cannot be seen and handled, they are not visible to sense, as, e.g., rocks and trees are, the reality of which no one doubts. Or, again, they are not forces which, though not seen, at least act; notions are merely the devitalised shades of living individuality." It is true that the notions are not "perceived," and also true, as Hegel himself admits, that they are devoid of all sensuous content $;^{1}$ but this does not necessarily destroy their "reality." "Reality" can have three general meanings: (I) sense reality, (2) ideal reality, e.g. when we speak of a Law of Nature, or a Natural Law, or, again, the Constitution of a State, as real, (3) individual reality, e.g. a given human being. Now a notion is confessedly not real in the first sense; and it is obviously not real in the last. It is impossible for a universal to exist as the dust of sense, and equally impossible for us to mistake the beckonings of a spirit from the vasty deeps for the warm embraces of a living person. But it must be admitted that notions are, real in the second sense. Even if we regard them merely as "principles" in the ordinary signification of the term, i.e. as ideally constructed determining forms, they would be considered real; for every principle which determines experience is taken to be a "real principle." But it is not merely to be

1 Propaedeutik, §§ I, 2, 4, 5 ; Logik, i. 44. " "Das System der Logik ist das Reich der Schatten, die Welt der einfachen Wesenheiten, von aller sinnlichen Concretion befreit." 
decided by appealing to current terminology; for since experience is a living reality, an active process, the conditions by which experience itself is carried out must surely possess the vitality of experience itself. By themselves, no doubt, they are not experience, not a substitute for it ; as a matter of fact we never find them by themselves. But since these notions constitute the essential meaning of experience, and since the process of experience (as presented in the Phenomenology) is, we saw, "at bottom a logical process," experience in itself exists in and through these conceptions. Shall we then say that the organism is real but not its pulse-beat, that the music is real but not the plan of its harmony? And finally, the ultimate reality, as was shown, is Subject, is a self. But the self is a universal, and reveals itself in universal modes; and when it knows these modes as universal (i.e. in the form of its self), it appears as Logic. Can we then maintain that the self is ultimate reality, and not also the very forms which constitute its life? That they are the content of the Ultimate Subject means that they are not pale passive shadows of a living reality, but the active determining laws of its procedure. By them the mind realises itself through experience. The notions are the conditions of its actuality (Wirklichkeit). We cannot create the world of sense out of the ultimate conditions of there being a world at all, nor can we by any arrangement of notions pure and simple furnish individual beings. But the notions have their own unique reality, the reality of that which orders sense and determines the process of individuality.

We may still maintain with truth that the notions 
are abstracted from experience, and therefore are not reality. But we must distinguish abstraction which is ultimately false from abstraction which is still ultimate truth. Where we have one element of experience cut loose from the concrete life of experience (e.g. where subject is taken per se apart from object), there, says Hegel, we have false abstraction; we restrict the content considered to one aspect, and cut it out of its actual connexion with the whole, which alone is true, for the "truth is the whole." I But where the content dealt with is considered as determining and determined by the whole, as explicitly involving the system of experience to which it belongs, that content though abstract is a true abstract, for it is ${ }_{n}$ concrete as experience itself. Thus the notions because not taken as subjective nor as objective, but as constitutive of experience as a whole, are ultimate truths of experience, and not mere abstractions / If we say they are still cut off from, e.g., sense, we have to observe (I) that abstraction in some form is the only condition of knowledge at all. We cannot talk about the universe in general or as a whole, we must deal with it in its various constituents, in detail. This is the very condition of human reflexion. Even to consider the universe as a whole is itself an abstraction, for thereby we explicitly eliminate the part as such. (2) If, again, we insist that abstraction in any sense cannot be reality, then it is clear that by reality here will be meant individuality, and that in this sense there is nothing real but experience as a whole, in its completeness. There is no doubt truth in this view, but if this is the only

${ }^{1}$ Phän. d. Geist. Vorrede, 15. 
reality to be spoken of, then reality entirely eludes the grasp of any knowledge at all. We never can by any act or process of knowledge lay hold on such a reality; for we may know the universe step by step, and part by part, or we may deal with the whole as such (in Philosophy), where we have before us solely its general fundamental content, not the completed individuality which alone is the Absolute. These are the only two kinds of knowledge, and neither, therefore, gives us the fulness of the life of the one Absolute. Either, therefore, we must proclaim knowledge to be a mere by-play in the system of the universe, or else allow that, because the universe is real in its parts as well as in the whole-real in the echo as well as in the thunderbolt-knowledge which takes it point by point does give us reality. But to allow this is to grant that reality has more than one meaning. (3) We must emphasise the distinction between the abstraction which eliminates all reality from the abstraction which is simply a form or sphere of its content. The Logic deals with abstractions only in the latter sense.

We have, perhaps, said sufficient in explanation of the reality attributed by Hegel to the notions-one of the most difficult and most vulnerable points in the system, and also one of the chief objectives of attack by its opponents. We shall recur to it again in our final chapter. Meantime we see that the reality possessed by the notions opens up in another way the possibility of diversity in the content of Logic, already mentioned. The notions are the determining principles of all modes of experience; their reality, therefore, is as diverse as the modes which they determine. 
CHAP.

Because the notions are synthetic unities in experience, they are concrete, real; because they are present throughout all experience, they are diverse.

From the foregoing it is not difficult to settle the disputed question regarding the "reference to experience" implied throughout the Logic. The ordinary view put forward, partly as interpretation of its content and procedure, partly as objection to its ostensible pretensions and purpose, is that the Logic is constructed by a necessary but covert and implicit reference to the facts of actual experience, that it claims to move in a purer medium than ordinary facts, but it is only possible by a continual recurrence to this world it seems to ignore. So far as there is any truth in this view, it is too general to be of any value either as interpretation or as criticism. For if it means that at every step Logic is really inside experience, and deals with its content, then, indeed, this is self-evident; Hegel himself professes explicitly to be dealing with nothing else. But if it means, as it ostensibly does, that at each step the writer of the Logic "in his own mind " appeals to the detailed facts of experience in order to find out how to proceed, that he looks to actual experience to give him the cue to discover the notions, then unquestionably this is a complete misconception of the Logic. For the very nature of the notions makes it necessary that when dealing with them we should already and thereby be dealing with experience. Experience does not lie outside them, they lie inside experience, they are its essence. It is truer to say, then, that experience implies the Logic, than that the Logic implies experience. In Logic we do not need to appeal 
to experience, because we are already in it. The Logic, therefore, is constructed by reference solely to the determinateness of each notion itself; this is all, indeed, that is required to make construction possible, and only by so doing can we obtain that peculiar necessity characteristic of Logic as a science. Such a construction will not be "in the air" if we simply grant at the outset that the notions are not mere thoughts, but the essence of experience -a position which was established in the Phenomenology.

Only one question regarding the content of the Logic remains to be considered-what is that mind whose essential content is expressed in the Logic? The Phenomenology established that the ultimate ground of experience was mind, was subject, not substance. The subject here meant is Ultimate Subject, the Absolute as Subject. Now in Religion, we saw, the point of view of the Absolute is adopted by the individual (finite ${ }^{1}$ ) mind; it identifies itself with the Absolute, regards the Absolute as mind which reveals itself to finite minds. But absolute knowledge simply carries one step further this confession of oneness and identification. It is the self-consciousness of the Subject as such, not as for us, but as it is in itself. Such knowledge, therefore, is not a knowledge by us about the Absolute; nor again is it simply a "possession" of the Absolute. It is actually Absolute Mind conscious of its own self as it essentially is. The Logic can be nothing short of this, if it is to realise the two ends of the Phenomenology - the attainment of the ideal of

$\mid 1$ Only a finite mind can be religious. 
knowledge (the identity of truth with certainty, of mind with object), and the exposition of the highest Reality for mind, the Reality found in Religion. And the two aims are one because that Reality is mind, and the ideal of knowledge is pure self-knowledge. [But if Religion is a valid experience, then Logic can attain this result, for it simply makes explicit the implications of the religious consciousness. Logic, then, is the self-consciousness of the Absolute Subject. Absolute Knowledge would not be absolute unless it were the actual expression of Absolute Reality, and this again could not be Absolute Subject unless it knew itself in the form of self, in Absolute Knowledge. Hence it comes about that to attain the ideal of knowledge, to furnish truly objective knowledge, and to know the Absolute as it knows itself, all mean precisely the same thing. ${ }^{1}$ No doubt the Logic is the thought and work of the individual (finite) thinker, of Hegel personally, and of those who undertake the same task. But since, when the highest truth is attained, the mind is one with its object, all limitation of knowledge to finite consciousness is explicitly removed, there seems, according to Hegel's view, no meaning in the assertion that knowledge still belongs solely to the finite minds by whom it is constructed. That truth is known to finite minds does not make the truth itself finite. For if so, at least the truth that it is finite cannot itself be finite in that sense, for this truth implies that we know what is not finite; i.e. we do actually admit that knowledge of finitude need not be finite knowledge. And, indeed, it is difficult to understand how the truth, e.g., that "God is" can

1 Cf. Phän. pp. 55 I f. ; also above, chap. vi. 
mean anything different to God from what it does to us. The fact, therefore, that Hegel constructed the Logic does not lessen its claim to be the actual self-consciousness of Absolute Mind, provided we accept this with the reservations already stated. ${ }^{1}$ So far as the part played by the individual mind in such knowledge is concerned, his function, says Hegel, is merely to "look on " (zusehen). ${ }^{2}$

But now, if the above is an accurate statement of what the Logic deals with, it is clear that Hegel's Logic is not Logic as understood by his predecessors and contemporaries. Formerly Logic was concerned with "thoughts" only, while to Metaphysic was allotted the discussion of the nature of "being"; and this distinction of provinces Hegel himself, as we saw, held in the earlier stages of his development. But if the content of Logic is to be at once thought and being, subject and object, it is clear that the distinction of these spheres of interest in philosophy falls away and Logic is at the same time a Metaphysic. ${ }^{3}$ And such an identification Hegel explicitly makes.' It covers the area of Logic in the old sense, and also the various branches of former Metaphysic-Ontology, Cosmology, Pneumatology (Psychology), and Theology. The content of these philosophical disciplines forms, in fact, the greater part of Hegel's Logic, namely, the first and second parts entitled "Objective Logic." The content of Logic as hitherto understood is dealt with in the course of the "Subjective Logic," 4 which forms the third and last part of the Logic.

1 See above on Absolute Knowledge.

3 Logik, i. 26 f., 35, 51, 52, 55; Propaedentik ( $W W$. xviii. 93, 94).

* For the explanation of "objective" and "subjective" Logic $v$. Note A. 
It is not, therefore, the objects dealt with by these several philosophical sciences which distinguishes Hegel's Logic from preceding systems, but the way their object-matter is conceived. Formerly the "world," "soul," "God" were treated as substances given and ready to hand, which had certain commonly accepted "attributes," "forces," etc. which had to be connected and explained. Hegel, however, considers the notions employed simply as notions, does not take any substrata of fact for granted, ${ }^{1}$ but examines the meaning and connexion of the very conceptiołs, "qubstance," "attribute," "force," etc., without limitktion to any specific subject-matter such as "world" or "soul." When, therefore, the notions are thus taken in their nakedness as notions, it is clear that the discussion of them holds more clearly of Logic in the old sense than of Metaphysic in the old sense, for Logic is traditionally regarded as concerned with notions. And, indeed, if "Metaphysic" is regarded as dealing with ultimate reality, and ultimate reality is reason, is notion, the identification of Metaphysic with Logic is a simple and natural change of terminology. Hegel, too, had already the authority of Kant for the change; he regards Kant's Transcendental Logic as corresponding, at least in part, to his own "Objective Logic," ${ }^{2}$ and considers his Logic to be in the direct line of succession from Kant and his followers. ${ }^{3}$ Thus, then, whereas in preceding philosophy, and also in Hegel's earlier thought, Logic either preceded or was subordinate to Metaphysic, now Metaphysic is absorbed into Logic and identified with it.
1 Logik, i. 52.
2 Logik, i. 49.
3 Cf. Logik, i. 30, 35, 49-52. 
But Logic is more than Metaphysic in the ordinary sense of that term. In virtue of its intimate relation to religion, out of which, indeed, it may be said to originate, the Logic may be regarded as the philosophical exposition of the object of the religious consciousness. But if so, the Logic can be considered as at once Theology and Revelation; and Hegel states almost in so many words that it is both. The Logic, he declares, contains "die Darstellung Gottes wie er in seinem ewigen Wesen vor der Erschaffung der Natur und eines endlichen Geistes ist." ${ }^{1}$ Such an exposition is what a genuine theology at least attempts to furnish. And, again, throughout the Logic, he continually indicates the theological reference of the science by his recognition of the notions as determinations, as "predicates" of the Absolute. This will be found from beginning to end of the Logic. ${ }^{2}$ That the Logic may be accurately described as Revelation seems equally evident from Hegel's own words. In general, indeed, this can be readily admitted when we consider what is really meant by Logic being the selfexposition of the Absolute Subject. Revelation means simply the making evident or outward of the inner life and truth of Absolute Spirit ; and this is what the Logic actually professes to do. Hegel's own statements on the point, however, are unambiguous. "The true form of mind," he says, " is just to be what is revealed or manifest" (das Offenbare); this is its very notion. ${ }^{3}$ But mind in Logic is manifest to itself in the form of self.

$$
{ }^{1} \log \text {. i. } 33 . \quad 2 \text { v. e.g. } \log \text {. i. } 69 \text { ff.; iii. } 317 \text { ff. }
$$


Hegel, indeed, goes further than this general identification of Logic with the idea of Revelation; he declares especially that "Revealed Religion" is itself "Speculative Knowledge." "God," he says, " is only attainable in pure speculative knowledge; $\mathrm{He}$ is found solely in that knowledge, and is that knowledge itself. For $\mathrm{He}$ is Spirit (der Geist); and this speculative knowledge is the knowledge given in and possessed by Revealed Religion. The former knows $\mathrm{Him}$ as thought (or in His pure essentiality), and knows that this thought has both being and existence. This existence, again, it knows as the negativity of its self, consequently as self, as a particular and as a universal self. But this is simply what Revealed Religion knows." 2 All this makes sufficiently clear that Logic is Revelation in the essential meaning of that term. But it is evident also that "revelation" is not here used in the restricted and ordinary sense of the word. Hegel's interpretation no doubt contains, and has deliberately in view, the current acceptation of the term; but it contains more and goes deeper. This alone, indeed, would justify what otherwise seems rather like philosophical quixotism.

This intimate connexion of Hegel's Logic with Theology again confirms what was said above regarding the influence of Religion as a supreme determining factor in Hegel's development. We pointed this out at the start of his career; and here in his final system we find not merely Religion one of the highest modes of experience, but the very

1 Phän. p. $55^{2}$.

2 ibid. p. 552. This apparently unqualified identification of Logic and Religion must of course be interpreted in the light of the essential distinction of Logic from Religion indicated above (pp. I86 ff.). 
highest is, in a sense, a Revelation. This is no mere accident in Hegel's philosophy. It stamps an original insight of Hegel's mind with the character of a logical necessity.

Such, then, is the general content of Hegel's final Logic, as this originated out of the position attained in, and established by, the Phenomenology of Mind. If we gather the foregoing into a single sentence we shall see at a glance how the conception of the Logic as the organism of truth came into existence. Given that Reality is simply the totality of experience, that the truth of experience is its essence, and that its essence is Reason; given, again, that Reason is mind's essential nature, that knowing itself in the form of self is true self-knowledge, and that self-knowledge consists in knowing its constitutive Notions ; and given, finally, that the one Absolute Mind, which is Reality, is in nature and substance the same as individual mind-given these general positions, and the Logic as the systematic exposition of the ultimate experience-content of Absolute Subject takes shape and form before us. The soul of this organism lies in the Method by which its members are fitly joined together. The origin and nature of this we must now proceed shortly to state.

\section{Notes}

\section{A. The origin of the Subdivisions of the Logic.}

The origin of the threefold division of the Logic into the Logic of Being, of Essence, and of Notion is not difficult to find. We have seen that Logic has to furnish the fundamental conceptions 
underlying the various forms of experience, the various ways in which subject and object are united. None of these can be ignored, and all have their value. Now from the Phenomenology ${ }^{1}$ it appeared that there are three specifically distinct forms in which the object can stand related to the subject: lit may stand over against the self as something opposed to the self (Consciousness of Objects);

(2) it may be the Ego itself (Self-consciousness); and it may be both identified with the self and objective

(3) to it (Reason). Or, to put it otherwise, in the first, mind is absorbed in the external object as it immediately is, without definite consciousness of distinction. In the second, the self turns back upon itself, the mere immediacy ceases or is transcended, experience divides itself into a conscious duality. In the last, the experience is that of the self become immediate to itself, its content which is subject and inward is become objective, mind is absorbed in its object, and that object is its self. The first is the phase of mere perceptive consciousness (Wahrnehmung), the second is that of consciousness of distinction, of judgment (division, $U r$-teil), the third that of comprehension (Begreifen), of reasoning consciousness, or, more specifically, of Inference. These three moments of knowledge are not imaginary; they are actual forms of experience ; and "science" itself in the narrower sense of the term proceeds by these three stages. In knowing an object we first "see" it, "get an idea" of it. Then starting from that as our immediate basis, we proceed to reflect about it, to turn from it into ourselves, i.e. become conscious of our own selves

1 Cf. also Phänomenologie in Propaedentik, WW. xviii. pp. 79-8I. 
with reference to it. This is the stage at which we seek to "explain" the phenomenon: we construct hypotheses and assumptions regarding it, which, as we say, are our own, exist in our own minds; and in the end we select from among them after passing through the doubt and perplexity of "probable explanations." All this clearly can only be possible if we are self-conscious, can within ourselves create a distinction of ourselves from the whole "objective world," and be conscious of ourselves apart from it. No such process of "explanation," of devising hypothesis, etc., could take place in a being limited to the stage of mere consciousness. While, finally, having "found" our explanation we proceed to "infer" from one characteristic in the object to some other, or from one state of the object to another at some future time or in the present. But this means that we regard the thoughts or principles by which we "explain" the object, and which have originated from ourselves after going through the second stage, as actually constitutive of the object itself, as existing not simply "within" us (at the stage of self-consciousness) but "without" us. And that we find our inference "correct," i.e. "verified by experience," guarantees the objectivity of the principle, and at once brings to light as well as justifies the ground on which all rational knowledge depends-the union of self and object in a single rational system which is controlling both. It is because subject and object together share the life of the same Reason that "inference" regarding the "objective world" is possible at all. To infer that one thing will follow upon another in the world is to assume that the world is the embodiment of a 
reasonable plan, which has come for the time being into our conscious possession, and which we thus use to connect one part with another.

Now all these three moments are necessary to complete knowledge, and the last contains the two preceding, in the sense in which Hegel understands this expression, i.e. not as abolished, but as maintained in their essential significance. Hence in that science (Logic) which is to comprehend the ultimate conceptions on which all knowledge is based, must be contained those which are fundamental and determinative in each of those grades of knowledge. To discover what these are we have but to reflect on what constitutes the content of knowledge in each case. When objects are "perceived," and our experience of them merely immediate, the essential characteristic is simply that they are; they "are there before us," they " are so and so," whether qualified in a certain way, or limiting one another, or in a process of change, or with a certain size, etc. The constitutive conceptions stated quite abstractly are thus those of mere immediacy, of Being in general. All those conceptions, then, which are determinative of immediate knowledge, are formulated and systematised in the first part of the Logic, which is called therefore the Logic of Being. These are Being, Nothing, Becoming, Quality, Quantity, Existence, Number, Measure, and the like. In all these the same fundamental characteristic is to be found. They are conceptions of what simply is, of what comes first to hand, of what is immediately presented before the distinction of appearance from inner reality takes place in knowledge. 
This latter distinction arises when mind separates a permanent core of substance in the object from what the object is just "as it comes," is aware of a continuous unity connecting changes or discrete phases. Such a separation is discovered and produced by leaving the mere immediate reality, or (to put it otherwise) looking beyond what is simply presented, and holding this in suspense while we relate it to the enduring reality which supports it. But when we thus turn away from the merely immediate we can only fall back upon ourselves. In other words, we re-flect upon the object, and this reflexion is made possible because we can make a distinction within ourselves, because we are self-conscious. Self-consciousness involves distinguishing a momentary content of self from a permanent unity underlying it, and it is this which renders possible the distinction of permanent from apparent in the object. Reflexion, then, starts from the distinction of these phases of the object, and quâ reflexion it remains within, is concerned solely with, their separation. It arises out of various questions ${ }^{1}$ and appears in many forms. Thus when we have Consequences we ask for and find Grounds, with Differences we must have an Identity, with Accidents we have Substance, with Effects we have Cause, etc. They are brought out by "reasoning," by doubt, by Raisonnement of every description. But in each and all the same general characteristic is present,

1 It may be said, in fact, that reflective knowledge begins with the shaping of a question. For a question presupposes conscious distinction of self from objects. With the question arises the distinction of truth and falsehood; and the existence of a question is contemporaneous with the existence of judgment. Hence it is that the judgment, the distinction of truth and falsehood, the existence of a question, all imply one another. For they all have their source in the distinction of self from objects. 
namely, a distinction of essential nature from outward appearance. Those ultimate conceptions then, underlying this process of reflexion, are grouped under the general head of the Logic of Reflexion or the Logic of Essence (the second part of Logic), and whatever complementary conceptions arise out of the distinction on which this process is based, will find their place in this section. Such are Essence and Appearance, Identity and Difference, Thing and Qualities, Content and Form, Actual and Possible, Necessary and Contingent, etc.

While, finally, when mind does not simply apprehend the object in its immediacy, nor hold in distinction the phases of its content in mutually implicative yet contrasted antitheses (which, though it cannot abandon, it does not overcome); but grasps its content in such a way that its inner principle determines its particular appearance, its immediate reality is permeated by its mediating ground-then mind fully comprehends the object, distinction is known to be transient, and mind is fully at home in its object. The stage of grasping or comprehending the object is that of Begreifen, of constitutive Notions (Begriffe), notions which are moments in the life of mind and determinative of the object, in which therefore mind and object, immediacy and mediation, insight and reflexion, are indissolubly one with each other. All the forms in which this stage of knowledge is realised find in this third section of the Logic their ultimate notions, and this section is therefore called the Logic of the Notion. Such forms are those of "Conception" as such, of the process of Syllogism and Inference, of the principles determining the pro- 
cesses of "Nature," Mechanical, Chemical, Purpose, of the supreme Ideas which determine Reality as a whole, etc. In all these the same fundamental features are present.

Such then is the way in which the various subdivisions of the Logic were determined or discovered by Hegel. He describes the first two parts as the "Objective Logic," and the last as the "Subjective Logic." But he distinctly warns us to place no great stress on this form of characterisation. He adopts such expressions because they are "usual" in treatises dealing with the subject, but he declares they are "the most indefinite and for that reason the most ambiguous expressions." 1 And when we bear in mind what the conclusion of the Phenomenology means we can see the point of his remark. $\mathrm{He}$ includes "Essence" under "Objective Logic," because though "Essence denotes what is inward, yet it is better to restrict the character of Subject expressly to the Notion." " Here again we see the terminology is largely adopted for convenience, as well as precision. He points out, too, that his "Objective Logic" covers the ground for the most part of Kant's "Transcendental Logic," but differs from the latter in function and character-a difference due to Hegel's general principle, and indicated in his criticism of Kant. ${ }^{3}$ Further, ${ }^{4}$ his "Objective Logic" takes the place of the old "Metaphysic," more especially of the Ontology, but also of the Psychology, Cosmology, and Theology so far as they sought to illuminate such ideas as "Soul," "World," and "God" by conceptions of reason.

${ }^{1} \log$. i. $W W$. iii. pp. $48,52$.

3 v. Chap. iv. pp. $100 \mathrm{ff}$. 
But Hegel's Logic takes these realities in their pure conceptual form apart from their popular representation. For that reason his Logic is the proper criticism of such ideas.

In the above explanation of the origin of the divisions of the Logic we must not suppose that since only the last division deals with the "Logic of the Notion" the other two should have no place in a science of ultimate conceptions. This would be a confusion. The Logic from first to last, as we have seen, contains nothing but notions. Hegel, indeed, did mark the distinction between the divisions by naming ${ }^{1}$ the first the discussion of the "Categories," the second that of the "Principles of Reflexion" (Reflexionsbestimmungen), and the third that of the "Notions"; but we saw that this was merely a matter of terminology. We have in the Logic solely "pure notions." The fact that in the first two the conceptions are the ultimate conceptions at work in the incomplete forms of knowledge, does not render their presence in the Logic less important or invalid. For incomplete forms of knowledge are still knowledge, and the Logic is to contain the fundamental notions underlying all knowledge complete as well as incomplete. And all such conceptions must be Notions just because they are conceptions specifically for Absolute Knowledge, or Logic, in which, as we have seen, the distinction between subject and object has been removed, and which therefore belongs solely to reason, whose characteristic it is to be at once subjective and objective. We may state the matter shortly by saying that, whereas the difference between

\footnotetext{
${ }^{1}$ In the Propaedeutik, p. 93.
} 
Perception, Reflexion, and Reason is a difference in completeness of realisation of the essential aim of knowledge as a historical fact in experience, the categories or notions underlying such forms of knowledge express in different degrees the content of pure or absolute Truth. How such notions are actually related we have already tried to show.

\section{B. The changes of content in the various forms of the Logic after I807.}

Hegel's Logic appears in a slightly different form in the Propaedentik, in the larger Logic, and in the various editions of the Encyclopadia. The divergences are mainly of two kinds: the order or arrangement of the conceptions, and the number of them. The differences in regard to the former are on the whole much slighter than in the case of the latter. After the larger Logic (1812-16) there is in fact no change of any significance in the order in which the notions are expounded. This is what we might expect when we bear in mind that the Logic of the Encyclopadia is nothing more than an abridged version of the complete Logic, confessedly adapted for the students attending Hegel's Lectures at the University.

The most striking differences in both arrangement and completeness of the content of the Logic are to be found in the Propaedeutik. But these differences must, as we have already remarked, be interpreted in the light of the purpose of the Propaedeutik, and do not necessarily indicate any change at all in Hegel's views of the subject. This is the more certain when we bear in mind (I) that Logic appears 
in different forms in the Propaedeutik itself. Logic was taught in two classes at the Gymnasium, the "middle" and the "higher," and was expounded differently to each. (2) Hegel taught Logic in this way at the Gymnasium from I 808-I I, while during at least a part of this time he must have been writing his larger Logic, the first part of which (the Logic of Being and of Essence) appeared in I8I2. Yet the complete exposition of the larger Logic was apparently not allowed to affect the peculiar character of the Logic taught to his pupils. All through the Propaedentik, further, it is clear that he is more concerned to make the various conceptions clear and precise in themselves than to show their inherent connexion with each other. This being his purpose, the order in which they were presented and the completeness in the exposition were of slight significance compared with the importance of enabling the pupils to understand the meaning of familiar notions - such as "being," "something," " existence," "negation," etc. And from this point of view the Propaedeutik is extremely instructive.

If we take in detail some of the differences of the Logic of the Propaedentik from the larger Logic, we shall note more particularly that "alteration" 1 (Veränderung) stands in the place of "Infinitude," and that "finitude" as such does not appear. Again, "Number" is not mentioned in dealing with "Amount" 2 (Quantum), and "Measure" (Maasz) is not subdivided. Under "Actuality" 3 (Wirklichkeit) only Substance, Cause, and Reciprocity are dealt with. In analysing the notions 
of Purpose, Mechanism, and Chemism, the last two are in one place ${ }^{1}$ discussed after Purpose, and in another form ${ }^{2}$ of the Logic of the Notion are not mentioned at all. It is remarked as noteworthy by Rosenkranz in his Introduction ${ }^{3}$ to the Propaedeutik that, in analysing the "Ideas" in the Logic of the short Encyclopadia given in the Propaedeutik," Hegel, while mentioning the "Idea of Knowledge," "passes over in silence the Idea of Conduct (die praktische Idee)." But this Idea, the Idea of the Good, or of Conduct (Handeln), is explicitly mentioned in the Logic as given to the "Middle class," ${ }^{5}$ and also in the Logic of the Notion given to the "Upper class." 6

The internal divergences in the forms in which the Logic appears in the Propaedeutik, and their difference from the more complete Logic, indicate the limited purpose of the analysis in the case of the former, and are merely significant of the freedom with which Hegel treated his subject.

In a similar manner must be interpreted the main divisions of Logic given in the Propaedeutik. In one place ${ }^{7}$ he says that "thoughts consist of three kinds: (I) Categories, (2) principles of Reflexion (Reflexionsbestimmungen), and (3) Notions (Begriffe)"; the first two making the "Objective Logic" and covering the ground of "Metaphysic" in the old sense; the last the "Subjective Logic" or Logic in the narrower sense. But again ${ }^{8}$ he says that "Objective Logic is the science of the notion (Begriff) 'an sich,' or of the Categories," while

1 Propaedeutik, p. 140.

4 ibid. pp. $166 \mathrm{ff}$.

7 ibid. p. 93 .
2 ibid. p. 164.

5 ibid. p. 120.
$3 W W$. xviii. p. xix.

6 ibid p. 142.

8 ibid. p. 123. 
Subjective Logic is "the science of the notion as such or as notion of something." Elsewhere ${ }^{1}$ he further says, "Logic falls into three parts: (I) Ontological Logic, (2) Subjective Logic, (3) Analysis of the Ideas (Ideenlehre). These different ways of stating the nature of Logic are really different in nothing more than terminology, but they indicate the absence of any restraint in his expressions, and especially his desire to fit in Logic, as he understood it, with traditional and current philosophical discussion. In this way, too, we should interpret his statement ${ }^{2}$ that "Logic is the science of pure understanding and pure reason. . . . The object-matter of Logic (das Logische) has three aspects: (I) the Abstract or aspect of understanding, (2) the Dialectical or the aspect of negative reason, (3) the Speculative or that of positive reason." This does not mean that there are three different kinds of notions, nor does it mean that understanding and reason are separate sources of truth. He means simply that there are distinguishable moments in each notion, and that they correspond to certain distinct functions of the mind ordinarily accepted, which are commonly understood and were previously taken by himself to be separate from each other. In this statement, in fact, we find an expression for the position he took up after the Second Period in his development, and see by what principle he overcame the difficulties in his previous views, and reconciled his former with his final position.

In the Logic of I8I 2-I 6 we again find a similar reference to the terms Understanding and Reason. ${ }^{3}$ The "determinate notion" is there described as the
1 $W W$. p. 149.
2 Propaed. p. 148.
$3 W W$. v. $31,32$. 
"sphere of mere understanding"; while "reason" is the "sphere of the Idea." Yet as we have seen, the Logic as such is the content of Reason. There are no notions of understanding per se in Logic as finally interpreted by Hegel.

The changes of content in the Logic throughout the various editions of the Encyclopadia seem to have been the outcome of his successive Lectures on the subject. Hegel throughout his career as a teacher was continually struggling to express the same ideas in new form, and in any case to get rid of stereotyped formulæ. This accounts for the abundance of illustration, especially in the third edition of the Encyclopadia. The alterations in his exposition of the Logic mainly consist in elaboration or illustration, and do not contain in arrangement or general content of the Logic any difference from the larger Logic of i 8 I 2.

The general conclusion which we draw from these changes in the substance of the Logic in its successive forms is that we have no claim to regard Hegel's Logic as a finished and unalterable body of truth, the validity of which, as a whole, stands or falls with the validity of each part of it, for the light of reason does not come by verbal inspiration; that the various alterations do not affect the value of the principle and method, but are the result of them; and that no stress can be laid on the seeming finality which is characteristic of the system. 


\section{CHAPTER IX}

ORIGIN AND NATURE OF THE METHOD OF

THE LOGIC

THE fundamental characteristic of the Method of the Logic is its necessary and essential identity with the content just described. This Hegel continually emphasises; and, indeed, it is in virtue of this that the method can be, as Hegel claims, the only true philosophical method. For if the construction of a system is really not furnished by some means outside the system-an external agency due in the long run to the fact that our mind acts and works in some way apart from the process of the reality we know and seek to systematise-then clearly the system is determined by its own content and from within, i.e. is, in a legitimate sense of the term, "self-constructed." " But a self-constructed system of ultimate truth is not simply a philosophy, it is philosophy in its final shape, it is philosophy in the form which has attained the goal of all philosophy. On the method, therefore, depends the possibility of absolute Idealism as a system, just as on the character of the content depended Absolute Knowledge as a reality of experience. ${ }^{2}$ With the validity

1 Log. i. 39.

2 Knowledge might of course be absolute and yet not systematised. 
of the method Hegel's system as a system stands or falls. We need not be surprised, therefore, at the stress he lays upon an accurate method, ${ }^{1}$ or the confidence with which he regards his own. He does not hesitate to declare ${ }^{2}$ that though he might wish the method more completely worked out in detail, he is sure at the same time that it is the only true method to be followed.

It is not difficult to see what is meant by this identity of content with method. In the Phenomenology it was established that mind was the determining principle in experience as a whole, and in each part of it. Experience, as it appears, is the unfolding of the actual life of Spirit in all its manifold forms. Now not merely in each form, and not merely, again, in the whole was mind present, but itself determined the process from stage to stage, itself made the transition from form to form, and was that transition as much as the forms into which it passed. But if so, then since the content of the "System of Experience" was constituted by mind, the connexion between its parts which made the system possible is similarly constituted. In other words, the Phenomenology is self-constructed and self-determined. It is one and the same mind which fashions the many expressions of experience into a single connected context, and which owns them as its experience. There is, therefore, no separation between the matter of the system and its mode of constitution.

But it is clear from this that the method of construction must likewise pervade each part of the system as a part; that is, it must be the moving

1 Phän. pp. 36 ff.; Log. i. 37 ff.

2 Log. i. 39. 
principle of each mode of experience. In fact, since experience from beginning to end is essentially a process, the method of connecting its elements is the essential nature of that process itself. It is immanent in each and all, and not transcendent. Hence of the last stage in the life of experience this also holds. In Absolute Knowledge, therefore, the process active throughout it is the same as the activity throughout all experience, and its method of operation is the same. Thus, then, we see that in virtue of Logic being a determinate mode of experience falling within the scope of the Phenomenology, its content and its method by their very constitution are one and the same reality.

Indeed, it is more evident in the case of Logic that this must be so. For there, as we have just found, the mind's self (universality) appears simply as universal, in the form of Notion. The self in such knowledge is the object of knowledge. Nothing falls inside such a mode of experience but the essential nature of mind. Hence the act of knowing and the content known, being moments of one and the same self, in one and the same mode of experience, the method (which determines the process of knowing) and the content which is its object, are indissoluble.

But if we bear in mind this inner unity of content and method, it becomes perfectly clear what the general nature of the method must be. We find that the method operates not merely in the Phenomenology and the Logic, but also throughout the Philosophy of Nature and Philosophy of Mind, as also throughout subdivisions of these, such as the Philosophy of Law. And it operates through- 
out all these diverse phenomena solely in virtue of one fact-that they are all determinations of mind. This is the single principle common to them all, and is the foundation of their reality. But if the method is likewise found in each and all of these various sciences, it must be because it is the essential nature of mind to operate in this way. Thus we arrive inevitably at this result - that the method is simply the inner activity of mind itself, the only and the necessary form which its procedure can take. Mind is essentially a living activity ; experience is nothing if not the explicit expression of that activity. But activity must take a definite and a self-consistent form if it is to be the activity of the same reality. The method is neither more nor less than the simple rhythm of that process, the measure to which the life of mind beats time. The method, therefore, cannot be external to mind, cannot determine its procedure from without, for it is precisely how mind really works. Mind is not a single unit in the scheme of things; it is the whole of experience. It must therefore hold its varied content together, arrange it, determine it, etc. And the way it connects its elements together is just its method of procedure in experience.

And now we see again why Hegel should have laid such stress on his philosophical method. He professes in the method to have found the essential rhythm of the movement of mind. But if this is known, then the last obstacle in the way of the construction of an absolute system is removed. For if we know the ultimate principle of experience, and also the way experience is organised by this principle, then clearly the goal of philosophy is 
within sight of attainment. There can be no doubt about the absoluteness of such a system, nor any hesitation about its finality at least in substance, if not in detail. Such a system gets rid entirely of "subjectivity," of the errors which inevitably arise from arbitrariness in method and procedure. It is complete in itself and self-contained, because selfdetermined. In it alone do we have what all science - and all philosophy aim at, completely objective knowledge. This method is the only condition of the possibility of such knowledge. Thus the method is essential to Hegel's fundamental contentions. That - Reality is Subject, that mind is the foundation of all experience, the reality of Absolute Idealism, the existence of objective knowledge-all these positions are indissolubly bound up with the truth of the method. In fact we may say that the method and these principles mutually imply each other. If the method can be admitted to operate, then Reality is Subject, and objective knowledge is obtained; while, again, to attain to objective knowledge is ipso facto to employ this method, and to assert that Reality is Subject.

But while the fundamental character of the method above stated makes it quite evident in a general way what the method professes to be, and is of supreme importance for the interpretation of it, we are not thereby assisted in determining how the method actually goes to work, more especially in Logic. For light on this we again turn to the Phenomenology. We saw that the Logic dealt with the determining notions of all concrete experience, and that consequently in Logic we covered the same area of reality as was systematically 
connected in the Phenomenology (viz. all Reality itself), but considered solely the ultimate nature, the essential content of the various modes of experience. The content of the Phenomenology, therefore, is essentially the content of Logic, and the . process of experience is at bottom a logical process. ${ }^{1}$ We are entitled to conclude, then, that what the method is in the Phenomenology it will also be in the Logic, and that its characteristic features as found in the former will have their counterpart, or, if we choose, their duplicate, in the latter. Now we saw that when the analysis of a given mode of experience brings to light the inner truth of that mode, a truth which is other than the actual truth possessed by that mode itself, the presence of this new truth to mind brings about and necessarily requires a change of attitude on the part of mind itself, a new mode of experience. ${ }^{2}$ The alteration of the ray of truth implies an alteration in the reflecting medium. Thus when consciousness, after exhausting the meaning of mere Sense, finds its truth in a universal element in sense, e.g. a Quality, it signifies its attainment of this new truth by a new mode of conscious experience-Perception. It passes from the one stage to the other by a change of conscious attitude, an Umkehrung des Bewusstseins. This procedure must have its counterpart in Logic. It will correspond, in fact, to the change from one notion to another in the Logic. Thus the transition, the Uebergang, from notion to notion is the logical expression for the Umkehrung des Berunstseins in the Phenomenology. The latter is the form in which mind passes from stage to 
stage and, in passing, connects stage with stage of -its concrete experience; the former is the manner in which the moments of ultimate truth are built into the structure of Absolute Knowledge.

Now since this Umkehrung is the nerve of the process in the Phenomenology, we shall find the clue to the meaning of the "transition" from notion to notion in Logic in the procedure of the method in the Phenomenology. We cannot, of course, find a point-for-point similarity between them; for the content of the Phenomenology is not as it stands that of Logic. Each proceeds on its own account, and is self-contained. Still, it is at least precisely the same general method which operates in each $;^{1}$ and that method as found in the Phenomenology exhibits more palpably and clearly its modus operandi, simply because the content is there more concrete and tangible. We shall, therefore, allow the latter to throw as much light as possible on the "transition" in the Logic; and we shall feel the more justified in doing so when we reflect that it was undoubtedly the nature and the use of the method in the Phenomenology which originated the method in the form found in Logic.

The essential elements, then, in this " transition" to which we must call attention are (I) the idea of truth underlying Hegel's procedure, (2) the kind of relation subsisting between the contents connected, and (3) the end attained by the transition.

Ordinary opinion and popular philosophy may not have any very precise conception of what it means by truth, but at least it considers that there 
is only one form and kind of truth, and that anything different from this is either not truth or is falsehood. This position may be taken up in different ways by different thinkers. Sometimes by truth is meant simply Scientific Truth. Morality in such a case is regarded as something occupying an entirely different sphere of experience; it is not concerned with truth, but with "instincts" or "impulses." This may be said either by way of repudiating morality, or merely to exclude it from the area of truth. Similarly, again, Religion or Philosophy is on such a view excluded from "truth" -the former because it is "practical," the latter because it deals with "ideas" only, not with "immediate facts." Or, again, in scientific truth, only one phase of science is regarded as giving truth, namely, that in which the law or principle of the facts is stated. The mere facts are not truth, but "something given," the "material" of truth. Or further, in opposition to this, the view may be held that only the moral life gives "truth," that science is at best systematised metaphor. In any of these cases, and they are all examples of the same position, truth, strictly understood, is relegated to one area or attitude of experience; the rest of experience is simply excluded from it.

Now with all this Hegel's conception of truth , presents the most decided contrast. The root idea of the Phenomenology is that no one phase of experience is alone capable of containing truth. Every form of the life of mind has its own specific truth, which is only one of the rays which illuminate experience. None of these can exhaust the entire truth; for the full truth is the whole of experience, 
and each of them is only a moment of it. "The Truth," as Hegel continually insists, "is the whole." All forms of experience contribute to the expression of the truth, but truth cannot be exhaustively expressed by any one of them; only the full blaze of all experience can reveal the completeness of its D. glory. Not even does Absolute Knowledge profess to contain the entire truth.

Experience, therefore, according to Hegel, is too rich, and is in each phase too real, to be expressed by any one kind of truth Truth is simply all - experience. And it is not difficult to understand how, for Hegel, this should be so. Experience is constituted by the interrelation of subject and object; wherever we have this there we have an attitude of mind, and there consequently we have a form of truth, for "truth is agreement of $\checkmark$ mind with its object." It is the one mind which $\checkmark$ stands related to diverse objects. Each relation is essential to it, and each contains its own truth. . Hence only the manifold relations to its objects exhaust its life, and reveal its truth. The truth is the whole because only the whole exhausts the forms of activity of the one mind, which has experience.

Now with such a conception of truth there is only one way in which a comprehensive system of truth can be constructed. In the case of the ordinary view of truth above stated, system is obtained by determining the facts by a principle, and either rejecting what does not agree with it, or modifying the principle in such a way as to comprehend the facts. But if, as in the present case, no phase of experience can be omitted, the only manner in which connexion is either possible 
or necessary is to show their inner relation simply as forms of experience. The truth of one does not cancel the truth of another; consequently to systematise them we must accept each at its worth, and weave them somehow into the seamless robe of the one Reality. The only alternative is to make a classification or a catalogue of the modes of experience. And, as we saw, Hegel accomplishes this systematisation by showing that the one mind present throughout experience connects its various attitudes in virtue of the fact that the explicit content of one is the implicit content of another (preceding) attitude. Mind passes necessarily to a new attitude in order to be fully aware of what was implied in the preceding. By this simple means, therefore, Hegel at once does justice to his conception of truth, and his demand for system. The Umkehrung des Bewusstseins is the nerve of the inner connexion of the content of the Phenomenology, and derives its meaning and importance from the idea of truth on which the "System of Experience" is based.

Hence the signif-ance of "transition" in the Logic. It is the necessary condition of the realisation of a system which is to contain truth in the above sense. All its moments are to be truths, and itself is to be the whole organism of truth. It is to cover all experience, and is ipso facto the whole which is the truth; and it is to deal with the essential content, the inner notion of each mode, which because a form of experience is eo ipso true. The truth which is the whole is not something over and above the truths of experience; it is simply the latter in their unity. The only way to construct the system of such notions is to show their essential 
connexion as expressions of one and the same mind, which both is the specific notions as such, and itself is the movement from one to another. And this is done when the notions "pass into" one another. The fact that we are dealing with ultimate notions, essential content, does not mean that these are complete in themselves, or that no connexion of them is possible. Though ultimate they are still realisations of that which is the ground reality of all of them, the self, and hence are necessarily related as forms of a single unity. Mind in each notion determines itself differently, but it is always the same self which is determined.

Such, then, being the purpose of "transition" from notion to notion, we next ask how exactly is the process brought about? what starts the movement? There is only one answer-the existence of opposition, discord, contradiction. All change, we may say, generally is due to disturbance of equilibrium within a given whole. We find this in a physical system where there is disparity between attraction and repulsion; or, again, in the conduct of life with its contrast of end and desire, attainment and actuality. It is so in all concrete human experience; in knowledge we see it where the consciousness of an ideal of explanation compels the scientist to accumulate his facts, to deepen his insight into their relations, to heal the gulf between discreteness and complete connectedness. The very expression "search for truth" indicates a process which has its impulse in a felt contradiction. Now the Phenomenology showed how this contradiction appeared and was removed in the various stages of actual spiritual experience. The one 
mind which has experience only realises its complete life in the whole of experience. But in each mode in which it appears it is realising itself, for each is pro tanto experience. Yet with nothing short of the whole of reality will it rest satisfied, only with the whole is it completely at home with itself. Hence the antithesis between the fulness of its completed life, and the insufficiency of any one special mode of it, both creates other modes in which it must realise itself and compels it to pass from a less sufficient to a more complete form of experience. This opposition, which operates perpetually throughout concrete experience, ${ }^{1}$ and is absolutely necessary to it (because it is the same self whose life is realised both as universal and as special or particular), is the motive force which initiates and maintains the process of experience, and produces the continual conversion of conscious attitude ( $U m$ kehrung) which appears throughout it.

And the process in Logic is similarly constituted. Here we deal with the ultimate content of the self; but it is one and the same self which determines itself in diverse ultimate (i.e. distinct and irreducible) forms. It is only really itself when its entire content is exhaustively expressed, when its whole self in its universality is the self which it knows. Anything short of this will not be a notion adequate to its essential nature. Hence the contrast between its complete essential reality and a

1 It is not, of course, necessary that each individual should possess all the modes of experience completely; and, again, the fact that different stages of civilisation reveal diversity of grades of experience, experience being less complete and varied in the lower forms of civilisation, and so on-this and other similar facts do not affect the general nature of experience as thus conceived by Hegel; nor do they even affect the accuracy of his own systematisation of it. 
determinate essential notion compels that one mind, which possesses both and realises itself in both, to leave its inadequate realisation and proceed to a more complete expression. This process is inevitable if the same mind must (and does) seek to express its self in its entirety, and at the same time in a special form. The one being as essential to its nature as the other, each in fact being its own essence, the opposition between these two forms of its self is inseparable from its very life; and with that opposition the process, the "transition," which it creates and necessitates. We must not regard the notions as entities somehow created by but external to the self; they are the self in its essential form. And since they all express its life, the contrast between the more adequate notion and the less adequate is really the contrast between the self more completely and less completely expressed. Hence the change from notion to notion.

But we must here guard against an error of interpretation. This "transition" is not brought about at each stage by opposing the full tide of the self to a single wave of its truth. This is at once unnecessary, and hardly possible. It is sufficient to produce the alteration, if greater completeness in any sense and to any degree is contrasted with less. It is absurd to suppose that the entire life of mind is explicitly opposed to each determinate notion. What we really have is some implicit totality alongside an explicit mode or phase of it. The mere determinateness of the notion itself involves this implication. We do not have before us explicitly the notion of "Becoming" when we are dealing with the determinate notion of "Being"; this 
would already assume the actual presence of what is to be shown to be a result after a process. If this, indeed, were the modus operandi, it would be little better than a mere pretence. We only become aware of the notion which is more complete but implicit after making it explicit through this process. The fact that it is this notion and not another which is the result produced, shows that this was implied in the notion from which we started. The one mind knows both the explicit and implicit notion, for it knows in experience the totality determined by them both. But it, so to say, does not bring out the implicit notion till the explicit has been exhausted, does not feel the need of the more complete till the less complete has actually been found insufficient. The self is of course aware of the concrete reality of which all notions are determinations ; for, since Logic is the "after-thought" of experience itself, it presupposes the concrete life of mind described in the Phenomenology, where we have already made use of the notions systematised in the Logic. But since Logic is a kind of knowledge sui generis, the process of the Logic starts de novo. The self in the Logic does not simply gather notions miscellaneously and ask how these are to be put together to form a whole. On the contrary, it does not really know what is the notion which is more adequate until it has by analytical scrutiny brought out the meaning of that notion which is less complete. When the latter is exhausted, then the more adequate comes to light, proceeds out of it; i.e. the one mind "passes over" from one realisation of its self to another.

So much, then, regarding the "transition" from 
notion to notion. The foregoing now leads us to consider the kind of relation subsisting between the notions in this process. That relation is briefly what Hegel calls "negation," "negativity." The meaning of this important conception cannot, after what has been said, remain very obscure. We must again recall the fact, already emphasised, that the notions are the self in determinate ultimate form, and are concrete (in the sense explained). They are not bare "ideas," but the essential meaning of actual experience. Now, since they are all necessary to experience, necessary to express the full meaning of mind, the self is unable to dispense with any. Its process from one to other does not therefore mean that it abandons, or annihilates, the notion from which it passes; it must still in some way take the latter into the new notion, for this notion proceeded from and arose out of the other. The self, however, is now realised in a new and more complete expression of itself; it was for this reason that it made the transition from the other notion. And in this lies the meaning of the "negation" of one notion by another. "Negation" does not here mean simple exclusion, as, e.g., light excludes darkness, as A excludes not-A. The negative is always determinate in itself, is not mere negation, but has a specific meaning of its own. It is negative of something. Hence what such a negative will be depends on what is negated. In the negation the "something" is still implied and contained. ${ }^{1}$ The process from one to the other

1 Thus, e.g., the alteration of one's course of life is not mere abandonment of the former ways; it takes a specific direction, a direction determined by reference to the old course. This must be so, since both past and present fall inside the experience of the same self. 
involves this; for the first notion, the transition itself, and the new notion are all continuous with one another; they are phases of the life of one and the same self, which must express itself in and through all of them. It was in this sense that negation was conceived in the Phenomenology, when, e.g., Morality "passed into" Religion, or Sense-consciousness into Perception. The latter did not exclude the former. To do so would have been to lose a part of experience. It would also render the later form itself meaningless; for Perception, e.g., without Sensation is impossible. Because Sensation is a mode of experience it cannot be destroyed; but because Perception realises more fully the relation of the self to external (sense) objects, mind leaves mere sense for Perception; it "negates" sense. The negation of sense is, therefore, not the destruction of it, but the preservation of it in another form, a form more conformable to the mind's essential nature. Negation is not annihilation, but sublation (Aufhebung). So in the pure notions of Logic. When a notion "negates" another, it determines it still further. All negation is simply determination. It is the same self which must realise itself in all these notions, and all realisation is necessarily positive.

But if this is the essential character of the relation of one notion to another, why is this called " negation"? How can a notion be shown to be the "other" of another notion? In short, how is "otherness," as distinct from simple difference, determined? For the answer we must refer again to the nature of the self which is the ground of the notions. The self, as we saw, embraced all experi- 
ence, and is conscious of self in so doing. Hence it contains in itself all diversity, and yet is conscious of that diversity as its own, as its self. It is at once the source of the plurality and opposition found in experience, and the unity of all opposites. This it must be to constitute one experience. The self is therefore necessarily both the identity and the diversity, the unity and the plurality, which together make experience what it is. But these are the very type and form of all opposition whatsoever, and they are the cardinal antithesis of reality, for they both constitute and give meaning to all the diversity it contains. And, moreover, opposition is the essential nature of the terms themselves. Identity only has significance, only is by being set against difference; and difference has no meaning except in opposition to an identity. Their very existence involves their antithesis; they are locked in ceaseless conflict to prevent each from committing suicide. Thus, then, we see that the deepest opposition in experience lies rooted in the concrete life of the self. Self-consciousness, which is the nature of mind, just consists in unity in diversity; to be conscious of self necessitates distinction, while to be conscious of self asserts an identity throughout the whole process.

And what is thus true of concrete experience is true of the notions in Logic. The notions are the self in its essential and ultimate form. A notion, therefore, is the unity of identity and diversity; it is one and the same, and yet has content, is different. This is involved in the "concreteness" of the notions already explained. They are not "abstract" or "formal" thoughts; they are constitutive of experience, because determinate moments of the 
self which moulds experience. Now it is in this opposition of elements, which lies in the very nature of every notion, that we are to find the source of the "negative," the "other" of a given notion. The "other" would not be an other unless it implied an identity of content between itself and that with which it stood in contrast ${ }^{1}{ }^{1}$ and, again, it would not be an other if its content were absolutely identical with its opposite. Thus the notion in its diversity is the "other" of the notion in its identity (and conversely), because it is one and the same content which exists in these two forms. The notion quâ identical is necessarily opposed to, is the "other" of the notion quâ diverse. That it is the same notion throughout does not make this contrast either meaningless or impossible. It would be meaningless if identity were not as such distinct from diversity, and it would be impossible if there were not contrasted elements in each notion. On the other hand, again, it is because in each case we deal with one and the same notion that a given notion has only one "other," and that therefore there can only be one step from one notion to its negative. A notion $q u \hat{a}$ identity can only be opposed to itself $q u \hat{a}$ diversity. These are its only and its essential elements. A negative can, therefore, only be either of those, according to the element we start from. And this is in part the source of the "necessity" in the construction, to which we shall refer presently.

It must be noted that this process of determining negativity applies not merely to the content of any

1 To take a palpable example: a nation is not an "other" to the sea which girds the borders of its territory, but only to a spiritual corporation like itself- " another" nation. 
given notion, but also in the same way to the relation of all the notions in the Logic. We evolve 1 notion from notion by the same principle by which we determine the constitutive elements of a given notion; [for the Ego, which is the life of all the notions, bears the same relation to the diverse content of the Logic as a whole which one notion holds o the elements it contains; it is the same self which is being determined from first to last.] One notion, therefore, is the negative, the "other" of another notion in virtue of the same fundamental opposition which is operative in every notion. And, again, what the negative shall be depends entirely on the notion. The notions are all moments of the Ego, but they are not the same in content. The process from one to another, therefore, while determined in the same formal manner, cannot produce the same result. In one case, e.g., we have the antithesis of Quality and Quantity, in another of Essence and Appearance, or, again, of Mechanism and Chemism -all constituted by the same ultimate relationship, but all differing in content. ${ }^{1}$ We must therefore determine the connexion of one notion with another by reference to the specific content of each notion.

From the foregoing we can easily understand the course pursued by the method. We begin with the notion simply as a notion; we take it in its mere self-identity, its bare universality. This is necessarily the first moment, because the notion is primarily a universal, a self-identity. But this first moment already implies the second. For to take the notion as mere universality is to determine it, and deter-

$$
1 \text { Cf. Ency. § } 240 .
$$


mination is only possible by reference to another moment. Determination because specific implies contrast, opposition, negation. We have therefore as our second moment the antithesis, the negative of the first, explicitly stated-diversity, particularity. This is found merely by making clear what was contained in the first; it is the result of analysis. 1 delermm But, again, this moment necessitates a third. For now we have the two constitutive moments of the motion over against each other; each is negative of the other; the first is the other of the second just as much as the second is of the first. The notion is split into a relation of negatives, of terms, each of which is negative to the other; it is in crmplete inner contradiction with its self. But thension of opposite elements does not lead to the disruption of the notion. The fact that these opposites exist in the same notion demands and emphasises the necessity for that unity in which they exist as opposites. Mere diversity of content and complete opposition of elements requires the reassertion of that unity which makes their opposition possihle Here negation itself calls for negation, and indeed implies its own negative-namely, the underlying unity. The third moment is therefore the reinstatement of the identity, the universal, the positive. For, like the first negative, this third step (negation of the negative) is not bare negation, but determinate negation, negation of definite diversity, and this means assertion of positive unity. This last step, being due to the relation of one moment to the other, can be regarded as a synthesis, in contrast with the former analytic moment. But we 
cannot consider this contrast as absolute, for it is clear that in each case we have both analysis and synthesis. In the first we have synthesis, for the relation of the "other" to the immediate identity from which we start is essentially synthetic. In the second we have analysis, for its aim and result is to bring out the unity underlying the opposed elements. The method from first to last is at once synthetic and analytic; the difference between the moments is one of emphasis only. In the first negation we establish more directly by analysis of the original identity, a diversity implied in it. In the second we insist more particularly on the synthesis of the elements ostensibly opposed, and bring out their unity.

Such then, stated simply and shortly, is the actual procedure of the method from step to step in the Logic. If we bear in mind that these various moments arise from the nature of the self which moulds experience, and are due solely to the assertion and counter-assertion of the diverse constitutive elements in its single concrete reality, the process ceases to be the obscure enigma which it is so often considered. It is the same Ego which is operative from first to last, and this determines its every moment; for the moments of the method are the rhythmic systolation of self-consciousness. This determines the meaning and purpose of "negation," which may be regarded as the nerve of the process. ${ }^{1}$ Not merely in each notion, then, but from beginning to end of the Logic, precisely the same procedure determines the construction of the system. It operates in diverse content, for the notions are different at each stage;

1 It is for this reason that it is named "Dialectic"; v. infra. 
but it is always the same formal procedure, for it is the same self which realises itself in each notion. By this means, therefore, the main parts of Logic (Being, Essence, and Notion) are determined, no less than each category at the various stages of the process. The nature of the beginning as well as the end of the system are likewise discovered by the same law.

We cannot, however, state how in detail these stages are determined. To do so would in fact require a reconstruction of the whole system. We can only point out the sources from which Hegel drew the various notions of the Logic. These are -(I) the Phenomenology; (2) Language, which he regarded as the embodiment of notions; (3) the different Sciences with which he had long been acquainted; (4) the History of Philosophy. ${ }^{1}$ We cannot maintain that the Logic is constructed simply by repeating in abstracto the life of experiencethis idea we have already dismissed; but, on the other hand, we must not suppose that Hegel's Logic sprang bodily out of his own mind. This would, indeed, make Hegel either a superb conjurer or else the creator of the world-according as we regard the result. Hegel had experience behind and before him, and out of this by the severe struggle of reflexion he shaped his system.

The Phenomenology, as we saw, is the presupposition of the Logic, and unquestionably guided Hegel to some extent in the construction of it. Thus the beginning of the Logic may be said to give the ultimate notion underlying Sense-experi-

1 To a certain extent (4) is contained under (I), but it is too distinctive to be regarded as subordinate. 
ence-that of mere immediacy (the beginning of the Phenomenology). The immediate determination of the Ego ${ }^{1}$ is simply that it is; its primary notion is mere Being. In concrete experience, sense, the first mode of consciousness, is that which is merely felt ; and mere feeling is immediacy pure and simple. So, again, the end of the Phenomenology is Absolute Knowledge, and in the Logic the last notion is just the notion of Logic itself, the notion of Absolute Knowledge, the Absolute Idea. ${ }^{2}$ No doubt in such cases the notions of the Logic were directly suggested by the argument in the Phenomenology. But such a parallelism cannot be pressed far, and certainly cannot be found in detail.

Language, again, enabled Hegel in no slight degree to discover the categories - so much so that in some cases the analysis seems not logical but etymological, and the interpretation of a notion the mere recording of its current or historical signification. For Hegel language embodied the thought of human experience. " Language has compressed within it what man has made his own, and what he has fashioned and expressed in speech contains, either embedded or elaborated, a category: so natural does Logic come to him, or rather it is his own very nature." ${ }^{3}$ And Hegel regarded the uncorrupted Teutonic of his own mother tongue as peculiarly adapted to reveal those ultimate conceptions which he sought, while at the same time he renounced any affectation of purism, any supposition that the German language was the only authorised medium for the communication of

1 Or indeed, we may say, of anything and everything.

2 v. infra.

${ }^{3} \log$. i. Io ff. 
absolute truth. He thus found the material of Logic, to a large extent, already to hand in the language and literature of his countrymen, and hence had to create neither the notions nor the terminology in which to express them. He had merely to re-discover their meaning and connect them systematically. Neither the substance nor the form of the Logic was, therefore, regarded by him as esoteric. "Philosophy," as he says, ${ }^{1}$ "requires no special terminology"; and again," "the object-matter of Logic and its expression are the common stock of knowledge." His Logic can thus be regarded in a sense as a systematic analysis of the abstract terms of ordinary speech. ${ }^{3}$

To Science Hegel was also largely indebted in the construction of the Logic. The system does not deal with a peculiar order of ideas, but with current ideas in a peculiar way; nor is the system spun on the loom of Hegel's mind without any acquaintance on his part with the facts to which the notions referred. It would certainly be absurd to attempt to substitute omniscience for the want of science, or to make up for ignorance of the actual world with its throbbing activity, by becoming a past master in the knowledge of a world with which we have no concern. Far from this being true, Hegel's Logic is the outgrowth of a prolonged study of science and no slight familiarity with its facts and principles. And, indeed, such or similar knowledge must be possessed before the student is able fully to appreciate the analysis of the notions dealt with by the science of Logic. ${ }^{4}$ The notions because concrete must carry with them all the meaning attached to them by
${ }^{1} \log$. i. II.
${ }^{2} \log$. i. 12.
${ }^{3} \log$. i. 43.
${ }^{4} \log$. i. $42 \mathrm{ff}$. 
ordinary Science. His knowledge, therefore, of scientific conceptions furnished Hegel with precisely the formed material required for the Logic.

Finally, it is impossible to ignore the assistance derived from the History of Philosophy in the discovery and connexion of the categories. Hegel had long held that there is in the last resort but one philosophy which lives throughout the whole of its history, that philosophy is a necessary spiritual expression of mankind and not a collection of casual opinions. If to this we add his other view that there is but one Reason, one Spirit operating in human history, moulding its direction by an inner necessity, we can see how easy it was for Hegel to regard the History of Philosophy as realising at various stages determinate notions of Reason, as dealing with specific determinations of the Absolute. ${ }^{1}$ The principle of each so-called system is an ultimate notion, and therefore an element in Absolute Truth. And not merely so, but the relation of system to system in the course of the History of Philosophy points to the kind of connexion which subsists between notions. A succeeding system does not annihilate its predecessor, it lays emphasis on a new truth, corrects its "onesidedness," and more completely realises the whole truth. This is acknowledged by each system which aims at construction, and was in fact an obvious conclusion to draw from the history of systems, each of which professed to express truth. But such a relation between one thinker and another undoubtedly suggested not merely the kind of connexion which

1 Gesch. d. Philos. i. Einleit. : "The succession of Systems of Philosophy in History is the same as the succession in the logical deduction of determinate notions of the Idea." 
existed amongst categories, but the actual order of that connexion. There was an inner necessity governing the history of philosophy, which compelled a certain system to appear after another. This inner necessity lay in the nature of Reason. Hence Hegel had already in concreto the order of the categories expressly determinated by the natural and, in a sense, unconscious process of Reason itself. All that he required was to lift the notions represented in the various systems into their simple abstraction and express their connexion in its ultimate form. Thus, e.g., we have the course of early speculation embodied in the notions Being, Nothing, and Becoming; while in later thought, again, Substance, Causality, and Reciprocity represent the historical sequence of Spinozism, Kant, and Fichte. But again, as in the case of the relation of Logic to the Phenomenology, while the connexion between Logic and the History of Philosophy is direct and profound, a complete parallelism cannot be established between the course of the one and that of the other. ${ }^{1}$

We come now to the last question concerning the method: what is the end of the process itself? The end is, in a word, Self-knowledge. The purpose of the Logic from first to last is to make explicit and systematic the ultimate content of the Absolute Self; and the goal to which it tends is simply exhaustive knowledge of the Absolute. This determines the process at every step and gives it continuity; for it is the same self which is active in the method at each stage, which defines each

1 Hegel's statement (loc. cit.) does not necessarily imply a point-for-point identity between the course of the Logic and that of the History of Philosophy. 
notion and passes to its negative. And herein lies the inner necessity of the construction. It is impossible for the knowledge to be complete unless the various moments of the self are passed in review. Self-knowledge requires that there shall not be, and cannot be, a leap from an inadequate notion to a completely adequate. The self does not correct the incompleteness of one notion by a fully complete notion, simply because it does not know the fully complete till it has passed through all the more or less complete. Hence the advance is not made by the Ego bringing all the riches of its life to shame the poverty of any single notion; it is by exhausting the content of one notion that the need is felt for passing to another. Every moment of the Ego must therefore be known before full self-knowledge is obtained, for every notion is a truth, and every truth is essential to its life. And this completeness is secured when, by inner necessity, the self finds each moment of advance in the immediately preceding. Completeness of knowledge, therefore, implies the compactness of a necessary connexion.

But this process is not merely one in which the self gradually exhausts its own content; its goal is the attainment of a notion in which self-knowledge is adequately and fully realised. This must be the final result, because the advance from one notion to another is determined by the fact that the notions express with different degrees of completeness the self which realises itself throughout the whole process. Each notion negates, and in negating contains the other, is more concrete than it; the self is, therefore, more fully realised in the later than the preceding notion. But if so, the final 
notion must be at once complete self-knowledge and one determinate notion among others. Now this is only possible on one condition-the process must be that of Development, of Evolution. We found in the Phenomenology that each stage led onwards towards the final truth of experience, whose mind was completely at home with itselfAbsolute Knowledge. Each mode had its value and place determined by reference to this end, and each gathered into itself the truth of the preceding. So in the Logic. The last notion contains the truth of all the preceding, and is itself the absolute notion of complete self-knowledge. This notion Hegel calls the Absolute Idea. But if this notion contains the whole of what precedes, if that is its specific content, then it is clear that the Absolute Idea is simply the notion of the Science of Logic, the notion of Absolute Self-knowledge. This notion, because the final notion, looks back to what has preceded for its content; while again, since every notion is an ultimate realisation of mind, none can be excluded from the idea of its self-knowledge. Hence the Absolute Idea is the Logic itself expressed as a single notion. And such is Hegel's explicit interpretation of it. ${ }^{1}$

If we recall the conclusion of the Phenomenology, we shall see that this result is inevitable. For if Logic is to state the ultimate content of all experience, then the ultimate truth of mind can only be the notion of Absolute Truth itself, i.e. the notion of Absolute Knowledge with which the Phenomenology concludes. But, again, such a result is the consistent outcome of the whole Logic. That science aimed

${ }^{1}$ Log. iii. 317 ff., 34 I ; see Ency, $\$ 243$ (3rd ed.). 
at complete self-knowledge. But self-knowledge, when attained, is a determinate realisation of mind, is a determinate notion; the end is, therefore, attained in the notion of that end itself. The ideal of self-knowledge is realised only in the notion of that ideal, for all other notions are approximative, and only such a notion focusses in a unity all the scattered rays of truth. The complete tale of the notions can only be finished by the notion of the whole which has been passed in review.

But this result must not be misunderstood. We must bear in mind that throughout Logic we are dealing with a concrete reality-mind. We are evolving its content. Hence the self-knowledge attained is not an external knowledge of mind; it is the realisation of a concrete self. The end, therefore, is not bare knowledge, but the development of a spiritual reality. The Absolute Idea is the selfmanifestation of Absolute Spirit; it is Supreme Personality explicitly determined. The Absolute Idea is Absolute Subject known in the form of its self (as notion). The course of the Logic is the progressive determination of itself by Absolute Subject; the Absolute Idea being the whole Logic, is the exhaustive statement of the Absolute. The Logic is thus at the same time Metaphysic. The process of the Logic does not merely lay bare in extenso the ultimate content of experience; it is also the ever-deepening penetration into the nature of the Absolute. So that with the end we have at once the greatest extent of reality and intensity of meaning, most comprehensive objectivity and deepest subjectivity. As Hegel 
puts it," "das Reichste ist daher das Concreteste und Subjectiviste, und das sich in die einfachste Tiefe Zurücknehmende das Mächtigste und Uebergreifendste. Die höchste zugeschärfteste Spitze ist die reine Persönlichkeit die allein durch die absolute Dialektik . . . alles in sich befaszt und hält . . ." The logical expression for this Supreme Personality is the Absolute Idea, which is the "only object and content of philosophy," ${ }^{2}$ and of which Logic is " the self-movement."

Such, then, is the method of the Logic in its origin, its process, and its end. There is perhaps no single term which completely expresses all that it means. The term Dialectic describes one essential element in it - the process of negativity by which it operates. Dialectical the method unquestionably is, not in the sense of discovering and establishing contradictions, but in the sense of thinking and resolving them. Dialectic is the method of reason, and reason is negative, for it is infinite and, therefore, the negation of finitude. ${ }^{3}$ And, again, contradiction lies in the very heart of the notion. "To think contradiction is the essential moment of a notion " ; ${ }^{4}$ while to resolve contradiction is the very condition of truth, and the very life of spirit. ${ }^{5}$ Such a dialectic method is the only one possible for Absolute Idealism; for only mind, free self-conscious subject, can negate, and in negating remain positive and unite the contra-

1 Log. iii. 339.

3 Log. i. $13,42$.

5 The contradictions here meant are those whose opposite poles are identity and diversity, unity and difference. These are undoubtedly the type and foundation of all contradiction; but that they are the only forms of contradiction is not so evident. $v$. Note A. 
dictory elements. It is only by such a process that a person is subject, is free and self-conscious. Dialectic is the kernel of true individuality and the ground of Absolute Truth, for "upon it rests the possibility of removing the opposition between notion and reality, and establishing their unity which is truth." ${ }^{1}$

But, on the other hand, "Dialectic" can hardly be said to exhaust the meaning of the method. For (I), e.g., the beginning is established by the method, and the beginning is not itself a negative; (2) the negative is only one aspect of the content; every notion is likewise positive; $(3)$ the process as a whole is a development, and a development is at least as much positive as negative. Dialectic, in short, only lays emphasis on one feature in the method-the immanent reference of one content to another.

The process may also be quite accurately described as the Union of Analysis and Synthesis. These are in ordinary knowledge distinct forms of procedure, and together they exhaust all possible methods of knowing. In speculative knowledge they are combined, for there we deal from first to last with the whole, with the individual concrete reality, which is essentially a unity of identity and difference. And here again we see that only when the self is the supreme principle of the system can such a method be applied; for mind is itself the concrete unity of identity and difference.

Again, we may regard it as a continuous application of the Syllogism. For the process is essentially mediate ; its whole purpose is to leave nothing 
standing as a mere immediate, ${ }^{1}$ but relate each element to some other, and so mediate its truth with another. Only thus is complete systematic construction possible; but mediation is essentially syllogistic and inferential. And since by such a process the result attained is a conclusion, is deduced from a beginning, the method can also be called Deduction. The Triplicity, however, which is constitutive of the syllogism and characteristic of the method, cannot be absolutely insisted upon, for this is purely external; the process might well enough be regarded as a Quadruplicity. ${ }^{2}$

Finally, it may simply be regarded as the realisation of the successive moments of Self-reflexion. We have first the self in its immediacy, the notion in itself; then its distinction from itself, the notion for itself; and lastly, the completely explicit and concrete notion, the notion in itself and for itself. These are the moments of every notion, and every notion is a realisation of the self-conscious Subject.

All these aspects of the method are equally important; and each throws a separate light on the character of the process.

\section{Notes}

\section{A. Contradiction.}

The Principle of Contradiction is of so much importance in the method of Hegel's system that it may not be unimportant to bring out its meaning by

1 As Hegel roundly declares, "There is nothing in heaven, or nature, or mind, or anywhere, which is not at once and as much immediate as mediate. Immediacy and mediation are inseparable" (Log. i. 56). This applies to the beginning of the Logic as well as to every step. Cf. $\log$. i. $57 \mathrm{ff}$.

2 Log. iii. 334 . 
stating it in a slightly different manner from that found in the foregoing chapter.

Hegel's own declaration on the subject is sufficiently explicit: "All things," he says, when summing up the essential significance of the Principle of Contradiction (Log. ii. I, Kap. 2. c. Anmerk. 3), "are in themselves contradictory." "Contradiction is the root of all living activity, the spring of all movement." "Everything concrete, every notion, every determination, is in its very nature a unity of different and distinguishable moments, which pass into contradictory by the difference being determinate and essential." From such statements it is at any rate plain ( $\mathrm{I}$ ) that contradiction, here referred to, does not take place simply in the mind of the individual thinker, cannot be merely subjective; (2) that contradiction is not an accident in experience, and does not arise through caprice or misfortune, but is essential-it lies "in the nature of things"; (3) that the removal of contradiction is rather the process of realising the complete truth than the indication of falsehood, for contradiction is not so much an error as a mode of manifesting the truth.

Now most of the objections to Hegel's view are based on the assumption that contradiction is a characteristic solely of the finite individual mind. In fact our finitude is revealed, it might be said, essentially in the experience of contradiction: we would not fall into contradiction and confusion unless we had a limited and therefore incomplete view of truth (i.e. of the whole), which, though inadequate, we are yet bound to assert to be true. Contradiction is thus considered on this view to fall inside 
the particular mind of each, to be "subjective." From this follows the assertion that contradiction is a process of our thought, and not of things, not of the objective world; that contradiction is "logical" and not "real"; and finally, that there is a fundamental distinction between opposition in logic and opposition in reality. Whether the distinction between thought and reality arises from the restriction of contradiction to our finite intellectual procedure, or vice versa, we need not stay to inquire. It is for our purpose sufficient to note the suggestive fact that the two positions are bound up together.

The source of such objections seems to lie partly in a confusion and partly in a prejudice. The prejudice is, that it is supposed impossible that the whole course of reality can be held responsible for a conflict between our human ideas or ideals. The confusion consists in identifying all the mental processes in which we are conscious of presentations, e.g. imagination, with the process of thought proper. As regards the first, we have merely to remark that it cannot well be taken seriously even by those who hold it. For in human experience it is a commonplace little understood that there is nothing higher than the highest. It is this alone which gives value to any aspect of experience, and only on this can distinctions of worth be founded. Now the highest, or at any rate one phase of the highest, is our Ideal of Truth, of knowledge. If Reality, or anything in heaven or earth, refuses to justify or openly rejects this ideal, two courses are open to us as rational beings. We must either unreservedly condemn what so asserts itself, or declare experience worthless do and unmeaning. Needless to say we invariably 
take the former alternative. But to do this is to hold our ideals to be not something subordinate to reality, but to be that to which reality itself must conform. Therefore reality cannot be indifferent to a conflict which is necessary to the realisation of that ideal. From which it follows that if contradiction is in any way essential either to the attainment or expression of our ideals or conceptions, contradiction must be regarded as constitutive of concrete experience; and hence reality cannot escape but must itself contain contradiction.

As to the confusion spoken of, let us consider three possible cases where "ideas" are related, and where, therefore, contradiction may take place: (I) an idea which is purely imaginary may be related to one which has a reference to reality; (2) both ideas may refer to reality; (3) both ideas may be purely imaginary.

Now in regard to the first the relation is strictly one of exclusion: the content of the two ideas is " inconsistent," is "contradictory." In the second, contradiction may again take place; though both ideas independently refer to reality, yet their relation may not. In the third, properly speaking, there is no contradiction, be the relation what we please. I may assert that, in this imaginary world, an individual has no hands and yet lifts bodies with his hands. True, we say that this is contradictory, but when we say so we mean it is contradictory not as imagined but as having a possible reference to reality. Strictly, in the world of mere imagination anything may be related in any way to anything else; here contradiction has no significance. And the applicability or inapplicability of contradiction is precisely 
what distinguishes a work of art from a work of mere imagination. The former is a possible reconstruction or combination of elements of the real ; and there we can speak of inconsistency. In the latter there is no such reconstruction, and hence no contradiction. Now it is because we can have imaginary ideas, and relate them in various ways (sometimes to reality, sometimes not), that contradiction is supposed to be purely subjective. Because we can use ideas which do not hold of reality, and because "our own" ideas may be themselves inconsistent, it is argued that contradiction is wholly subjective, and does not refer to reality. But this is to confuse the source from which our ideas are derived, with the implicit or explicit reference to reality of those ideas. Where we find such reference, there, as we have just seen, we can speak of contradiction; where there is no such reference there is no contradiction possible. In both cases the ideas may be derived from imagination, which is undoubtedly subjective. But such derivation is quite irrelevant to the use we make of them, to the reference in which we place them. To say, therefore, that because our (subjective) ideas may conflict with reality, contradiction only applies to our ideas, is to ignore the fact that it is not because they are our ideas, but because they are referred to reality that contradiction takes place; and that in so far as they are simply our ideas they do not contradict at all. Hence we conclude that it is in reference to reality that contradiction is to be found, and not in our mere ideas.

So much by way of answer to the supposed subjectivity of contradiction. 
But, again, when it is maintained that contradiction infects our finite experience, this is taken as a condemnation of finite experience, the assumption apparently being that contradiction is an infirmity which cannot be attributed to anything but our own finitude. Now this is a perversion of the truth. And it is even admitted to be so. For in spite of such a position, it is still held that we do know the truth, and that this truth is valid of reality. If the truth we know is "objective," and yet contains contradiction (for no partial truth is allowed to be completely true), then surely it should be admitted that contradiction is objective; and in fact this would be granted if the proper relation between finitude and contradiction were perceived. $\mathrm{We}$ are not finite because we fall into contradiction; on the contrary, we fall into contradiction because we are finite. Stated quite generally, finitude is not derived from the fact of contradiction; contradiction proceeds from the fact of finitude.

Now the former view is held by those who consider that contradiction holds of our finite experience only; the latter view is Hegel's own position. It therefore admits all the truth contained on the other side, but does not admit the ground on which it is based. If we clearly understand then what Hegel means by making contradiction depend on finitude we shall at once see the full significance of his interpretation of the principle.

His position is in reality very simple. "Finite," he says in the note above referred to, "means contradictory." "In general, finite things are essentially (an sich selbst) contradictory; their nature is to fall to pieces within themselves (in sich), and to return 
back into their ground and source." The characteristic which he here emphasises becomes clear if we reflect on what a finite thing claims to be. To be finite is to be limited; to have determinateness, to be of a definite specific nature; but that is not all. What is finite also means to insist on the selfsufficiency of the limited sphere within which it is enclosed; to maintain the substantiality and, indeed, the completeness of a single individuality. Its determinateness is not simply to shut it off from other finite things, but to shut it up within itself and make a solid whole of it. There is no point in its claiming to have a bound set to it, unless it means that within that bound it is self-contained, and has nothing to do with anything else. Its being determinate means that it does not trespass beyond a certain range, and that it does not need to do so: it is sufficient for itself. Both of these elements are essential to the meaning of finitude; but it is selfevident that they are contradictory. For to have a boundary, necessarily implies something else which is there to limit the finite; a boundary, in fact, is always between two things, is never for one thing alone. And not merely so, but the character of that which lies beyond the boundary determines the nature of the boundary itself. To be determinate is to be specific, to be limited in a certain manner, which depends on that which sets the limit to what is determined. In other words, the nature of that which lies beyond a finite thing pervades the nature of what is finite. It gets its specific meaning from the determinateness which characterises it, and this is derived from what it excludes. But if it thus lets in the content of what all the while by being 
finite it professes to exclude, the walls around its own finitude have fallen down, and with them have gone its self-containedness and self-sufficiency. But again by that very claim to a substantial completeness which it makes, and must make, it has likewise contradicted itself. For to be limited is for ever to point to an inherent instability and insufficiency in its own nature. To claim that because it shuts out, therefore it is completely shut in, is to hold that blindness is equivalent to self-illumination. To be finite is just not to be self-contained, but to be for ever transcending itself. To claim to be complete is for the finite to claim to be not finite at all but infinite.

In all this, therefore, the finite is essentially contradictory ; its nature is just to be contradictory. But we see here what "contradictory" means. It is not something indeterminate, but something definite. When the finite contains contradictory elements, the elements which contradict refer specifically to each other. The content of the one: pervades the content of the other. The "limit" set to the finite gets its content from something beyond this finite thing, is implied in it, and is indeed what compels it to break up the restrictions which constitute it, to abandon them even while remaining within them. Its contradictory is in short its opposite, what is specifically opposed to it as it stands in its finitude, and which opposite is implied in it, is referred to by the constitution of its determinate nature, but is not actually explicitly contained within it.

Take, for example, any trivial finite object, say a metal hammer. As it stands it seems and in a sense is complete in itself, finished and self-contained, 
a solid fact in the world. But let us look at it more closely, taking its qualities to pieces, so to say.

? We ask for the meaning of the flat, smooth surface at one end of the long axis of the instrument. Its meaning is not found in the tool by itself, but in something else, namely, a resisting, i.e. opposing surface which must lie outside the hammer. Nay more, the kind of resisting surface is also referred to or implied in the face of the hammer, namely, a surface of a certain degree of determinate resistance as well as superficial area. Thus the hammer is not used to beat the air or pound water; for this other instruments and surfaces are required. The surface of the face of the hammer, therefore, does not, as it seems at first sight, exist for the hammer itself but for something else, i.e. its opposite; its "being for itself," which as a finite object it must have, lies in its "being" at the same time "for an other," i.e. a specific definite other, not an other in general. And further, the bringing of these opposites together means also the denial of self-sufficiency, and, pro tanto, the breaking up of finitude-a result completely achieved when, e.g. the face of the hammer ceases to be of further "use." Similarly of the other qualities of the object. So, generally, we must say that the apparent self-reference and self-completeness of this finite object is only found in going beyond itself, i.e. something which destroys the sufficiency of its finitude. And it is important to notice that this reference to opposite qualities, or qualities of opposing objects, is absolutely essential to the meaning of such a finite object. The qualities of the hammer are only found when the hammer is in action, and can only be interpreted by reference 
to its action. In Aristotle's language its $\tau \grave{o} \tau^{\prime} \hat{\eta} \nu$ eiva lies in its actual or possible fulfilment of its function, and rather in the actual than in the potential. But when the instrument is in play, its qualities come out, and then we see the external reference essentially implied in the qualities of the object, in the manner above illustrated.

The same result will be found if we look at an organism, the highest type of natural finitude. Its organs are formed with reference to the world of nature around it. For example its digestive apparatus only has a meaning by reference to specific equally finite objects outside itself. And again by using these objects it builds up its system, i.e. strengthens its finite individuality, but at the same time uses up its finite "energy," and tends towards its own dissolution. In its process of living it is dying; in seeking to maintain its reference to self, it is bringing out only more completely its essential reference to its other.

Now that is what Hegel means by the contradiction of finitude; and by the finite holding its contradictory in itself. Contradictory means simple real opposite in the sense illustrated. It is not opposite in general, nor any kind of opposite. One thing is not opposed to anything we choose to name. To hold this, and say, e.g. that this tree is opposed to the pyramids, or the planet Neptune, is to confuse opposite with distinction or difference in general. All finite things are distinct, but all are not opposed. What an opposite is will depend on what the finite object is, and also in what relation the object in question stands or can stand.

The opposite which, e.g., a man has or implies, 
can be found by taking various aspects of his individuality. As a body in space he is opposite to any spatial body in general, quâ spatial. As a spirit his opposite is Nature, Externality as such. His organs of sensation in general find their opposite

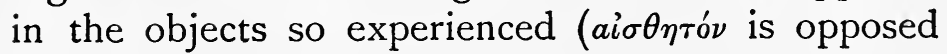
to $a i \sigma \theta \eta \tau \iota \kappa o ́ \nu)$, and the specific organs of sensation find their specific opposites. As a member of a state he finds his opposite in the universal will. As a member of specific organisations in the state he finds his opposite in what he realises as a member of such organisms-a workman, a master, a servant. And so on. And these various opposites, it must be observed, are all implied in a given man as such, for they all pervade his very essence, constitute him what he is, which could only be different if his finitude were different.

In short (and that this is the root of the whole matter must have already become evident), the fundamental factor in contradiction or opposition is, as Hegel is continually asserting, the unity, the identity underlying the opposites. It is only those opposites which can be and must be united in a common ground, that imply one another. They refer to one another and "pass into" each other, because they share a common life. They are opposite solely in virtue of the one identity determining and containing them. Without identity, no contradiction. Thus the two statements, "the grass is green," "the hill is not green," do not contradict, simply because there is no single finite reality to which they both refer. Similarly, and in general, no qualities can conflict, unless there is a unity within which to stand opposed. The 
identity is in each case some finite reality, and there we will always find contradiction in some specific form, because, in the way just indicated, finitude necessarily contains opposites.

This then is the significance of Hegel's doctrine of contradiction, of the unity and mutual implication of opposites. He does not mean that any finite thing is the opposite of anything else. It is the thing in a specific reference that has and implies an opposite. He means that a finite thing determined in a specific manner is the opposite of something else also determined, and so specifically implies its opposite. He does not hold that we can make contradictory statements about the same thing and yet assert both to be valid of it in the same sense and at the same time. He would allow, just as much as his critics, that to say "this road leads due north," and at the same time "this same road leads due south"; or "this man is a German," and "this same man is not a German," would be palpable nonsense. Both do not hold good at the same time, and Hegel was quite aware of this obvious truth. What he contends for is, that this road as leading north does, because it is a determinate direction, imply, refer to, and contain its opposite-leading south; this man as of a determinate racial connexion does imply another form of racial connexion, otherwise he would not be a finite being of a specific race at all. The man, therefore, does contain these opposites. Which of them is emphasised at a specific time is a matter of detail in experience, and does not affect the general principle. When one is emphasised, then the other does not hold in that sense. But that the finite reality in question 
contains or implies opposites in Hegel's sense, is seen in the very fact that these opposite predicates, e.g. German and not-German, can be stated of the same subject. And this is the point of Hegel's denial of the Law of Excluded Middle in his ingenious analysis of the law in the note (Anmerk. 2) to the section on Contradiction ( $\log$. Bk. ii., Absch. I, Kap. 2, C). We cannot, he maintains, hold that there is no third between $b$ and not- $b$ as predicates of $\mathrm{A}$; for we are actually implying a third, namely, that $A$ being either $b$ or not- $b$ is in a real sense both, just because it is capable of being either. Thus, in the illustrations above given, the man, quâ human being, contains both German and not-German; road $q u \hat{a}$ direction contains north and south.

It may, in this reference, be further remarked that the source of all forms of contradiction is found in the existence of real contrary opposites in Hegel's sense. Thus the so-called contradictory opposites $\mathrm{A}$ and not-A are not a specific kind by themselves. They are the extreme form of concrete opposition, and because extreme, the opposition is indeterminate: not-A may be anything we please. Because in the extreme form the opposition is essentially indeterminate, Hegel rightly holds that no one really thinks or speaks according to the "Law of non-Contradiction." Since, then, there is this continuity between all forms of opposition, the foundation of all being the real opposites inherent in finitude, we cannot draw a hard and fast line between so-called "logical negation" and "real negation," logically opposite predicates, (X is red and not-red), and predicates "really opposite," ( $\mathrm{X}$ is hard and soft, young and old). This is some- 
times ${ }^{1}$ done to save Hegel's position in the eyes of the "formal" logicians. The so-called "logical negation" likewise holds of the real. For we can say, and say with truth that, e.g. "the leaf is both red and not-red,"-namely, it may be, "glossy," (not-red being indeterminate can mean, as we saw, anything you please). And if it holds of the real, the opposition has its basis in "real" opposition. "Logical" opposition is in fact "real" opposition simply expressed indeterminately.

We have taken certain forms of finitude in the above, to bring out Hegel's meaning. His principle, however, applies universally to all finitude in all its forms. It would be easier to show what he means in the case of a given finite process. For the essence of process, e.g. growth, just lies in a finite object passing from one determination to another, to its opposite. Process in general just means a union of opposites, a passing from what is to what is not; or, expressed in more specific form, it is a passing, say, from activity to rest, or vice versa; from youth to old age, etc. Contradiction, opposition, therefore, as Hegel says, is the very nerve of the movement of finitude. Even Hegel's opponents, e.g. Trendelenburg, ${ }^{2}$ admit that movement is a denial of the law that opposites cannot be united, that a thing cannot be and not be. But Hegel's principle is equally applicable to all finitude, no matter how it appears. In the same sense, therefore, as above, it applies to the notions of the Logic, which because distinct are finite, and

1 As e.g. by A. Bullinger in Hegel's Lehre vom Widerspruch. I may say that the view of Hegel's doctrine above stated is in the main the same as that expressed in this masterly little essay.

2 Vide Log. Untersuch, ii. 154. 
lead to their own immediate opposite in the way indicated.

This union of opposites is precisely what Hegel means by "a synthetic unity," in the Kantian sense. The synthetic unity is obtained a priori in the Logic, because the notions are a priori in his sense. But synthetic unity in general, identity of contraries, is the kernel of reality and the world's process, and so far from our being "unable to think contradiction," we can never, if we would think truly, think anything else.

\section{B. Development.}

The term Development is somewhat ambiguous, and as applied to an absolute method may seem even untenable. It may not, therefore, seem out of place to deal with one or two aspects of the conception.

In development we must have a single identity existing in and maintaining diversity of content. It must also reveal itself through that diversity by a process in which the underlying principle (the identity) is more completely realised at one stage than at another. Unless these various aspects are preșent we cannot be said to have development. Hence we exclude from this conception mere change, as also bare uniformity (continuity), or again unity in difference but without process. $^{1}$ It is irrelevant what the identity consists in, whether it be an organism, an idea, or a plan ; if it expresses itself in this manner it 'develops.'

Now there are two general ways in which de-

1 The mere presence of purpose is not sufficient for development. We must have in the object concerned internal qualitative change in relation to the purpose. For example, shooting a bullet at a target is not developing the bullet. The development takes place, if anywhere, in the marksman. 
velopment may take place, the difference consisting in the way in which the content is expressed. The types of these two forms are found in the process of Inference, and in the Growth of a living organism. The inner unity of a given area of truth is gradually exhibited by showing how individual elements are necessarily connected with each other through their dependence on a single principle. The means of making this unity in diversity articulate is inference, and, the process being from less to more complete, it is development. In an organism again its diverse activity is held together by and is the expression of a single unity which aims at more and more complete realisation, and spreads out the diversity of its content in a temporal series of events ("stages of growth "). These two modes of development are quite distinct. The latter, we say, is in time, the former is out of time. No doubt the inference does take place in some one's mind. But the point is, that in the one case the connexion of parts is only possible because of time, in the other the connexion, as a relation of whole to part, is independent of the temporal order, and is brought about simply because the principle is actually operative in all its fulness through the parts, and is not in process of being made actual in them. In both cases the principle (the unity) becomes explicit; therein consists the development. But in the one its content is always complete ${ }^{1}$ (for otherwise there could be no inference), in the other it comes to be so at a specific time.

The development which characterises the

1 We cannot infer, at least in the highest types of inference, unless all the elements are fully known; and we, in any case, only infer from what is known. 
dialectic method belongs to the kind of which we have taken inference as the type. Hegel himself, as we have seen, considers the process of the method as the successive application of the syllogism. The end or unity to be made completely explicit is the unity pervading experience as a whole, i.e. Self-consciousness, Spirit. All the forms of experience are connected with each other because they are in our experience ; but since they express this single unity in different ways, they realise it in its completeness in different degrees. Hence the development consists in connecting them with each other through their graded realisation of the principle pervading all. Take the case of Logic, which is experience in its aspect of pure reason. The supreme unity here is the notion of reason as such, as pure self-consciousness; this notion is called Absolute Idea. All the conceptions in the Logic are ways in which this Idea expresses itself; it is the determining principle throughout. But some more fully than others realise its nature; hence the connexion between the notions is exhibited as that of a gradual approximation to the Absolute Idea. This is the best, indeed, as Hegel says, the only proper way of connecting them together. For only such a method does justice to the two forms of connexion existing amongst the conceptions-that all belong to one active principle, and that all express that activity in different degrees. The varied content of reason has not all the same value; hence Logic is not a bare system, a mere orderly arrangement. And again, we do not become aware of the central truth which is evolved, simply at the end of the process, and so to say all at once. The whole con- 
tent of reason can be, and complete insight must be, perfectly well known from first to last. There need be no unconsciousness regarding the development at all ; as is invariably the case with development in time. It may be that the learner, or even the writer of the Logic, is not completely aware of all the stages in the process of attaining the end, that he is unconscious to some extent of what is coming next. But this is irrelevant to the character of the connexion itself. If we know all the notions, and are perfectly clear regarding the fundamental principle they reveal, we must still connect them in this manner. We do not, as has been mentioned, take the notion which is the supreme end, and use this at every step to find out the next stage of advance. This is unnecessary. For each stage leads to what is immediately higher than itself; and the latter is sufficient to determine the advance at successive stages. It is, moreover, impossible to use the Absolute Idea at each stage, for the Absolute Idea being the most concrete, is in reality the whole content of reason itself, the whole of Logic, and is not something apart from the content.

Again, it is characteristic of this development that each stage contains the preceding but does not annihilate it or destroy its own essential significance. Here once more we find a feature similar to what is present in inference. Though we connect part with part through their common presence in a whole, and thereby destroy their individual isolation, this does not abolish their meaning altogether. That remains as an integral element in the significance of the whole. So in the dialectic method, one 
notion has less significance for the complete expression of the Absolute Idea than another; but the content of the latter is only found when we know the lower conceptions which it implies and in a real sense contains. The lower in short does not exist solely for the higher; the higher though higher is not the sole truth, and has not the only right to be. All truth because true is necessary to express the full meaning-the Absolute Idea; and this holds in spite of differences in the degree of truth.

This brings out a difference between dialectical development and development in time. In the case of the latter an end is aimed at which when reached remains in sole possession of the field. The previous stage out of which it comes is not only transformed, it is abolished altogether; it has performed its function, exhausted its life in bringing about a higher stage of the individual. Thus an oak is not also and at the same time the acorn out of which it has come. The individuality of the organism as acorn passes away into its individuality as oak; the latter does not contain the former in any real sense whatsoever. The former, as we say, has been; its existence has passed from actuality into history ; and the oak as an organism is the unity of its members, not the unity of the stages of its history. It is, in fact, because each of these stages are as such completely organic in themselves, and pass away with the production of a new stage, that we think of the history or temporal development of an organism at all. If all the stages existed at once, and existed always, and in the same individual, there would be no passing away, which is of the essence of time and of history. Development then in time is towards the realisation 
of an individual which exists at the expense of the forms of individuality out of which it has come. In dialectical development, on the other hand, the higher cannot exist, and cannot have its own complete meaning, unless the lower is maintained as well, and preserved at the same time as its own existence. Advance here is not by death but by preservation of life ; one conception is " negated," not to be lost in another, but to be found there in a truer form-truer because more definite and determinate. To put the contrast quite shortly: in development in time a lower stage exists for the sake of the higher; in dialectical development the lower exists by means of the higher.

This is true if we take development in time over a longer period than the history of one organism. The evolution of certain kinds of organisms is brought about by the elimination of the forms not possessed of the self-preserving variation, and the evolution is proved precisely by pointing to the history of the type, which is strewn with the relics of vanished forms and exhausted species.

Finally, another contrast between organic and dialectical development is seen in the way the development is brought about. In the former a new individual arises out of the relation of one individual to its environment. Exhaust the content of this individual by interaction with its environment, and it passes to another stage of individual existence. The environment must be specific, that its individuality may be determinate. The more intense its individuality, the more energy of resistance and assimilation it possesses, the more certainty is there of its leading to a higher form of 
organic life. Put shortly, to develop the individual in time strengthens its individuality. In dialectical development the process is quite different. We develop one notion not by making it finite, but by making it infinite. To discover what a notion is connected with, we take it for more than it is ; to discover the determinateness (i.e. the limitation) of a given notion, we make it absolute. When we take a single notion which determines one place of experience and apply it to the whole, to the Absolute, when in short we make a finite conception absolute, then we discover all that it contains and what it does not contain, what it is and what it is not ; itself in its " negative." "Being" taken as the exhaustive expression of the Absolute gives us simply "Nothing"; "Substance" similarly treated becomes "Causality," a relation between Substance in its own content. The reason of this lies in the fact that each is universal, but being still of a definite content it is not the whole, it is particular. We seek therefore to exhaust its universality by making it absolute, and this can and must be accomplished since we are conscious that it is, as against the whole, limited in content. And in the very act of exhausting its content, by finding how much of the fulness of the Absolute it really possesses, we bring out its limitations, we find its limit. This must be definite; the notion must specifically imply or suggest something else, some other specific notion which definitely limits it. And since the whole contains both, and we are at the point of view of the whole, they are necessarily connected as determinations of the whole, while the one is "higher than" the other because the lower in the very act of exhausting 
its content implies something richer than its own. Thus then in dialectical development we emphasise the universality of the elements considered; in temporal development individuality.

But while from these different points of view we can distinguish the two kinds of development, we have still to ask whether there is any connexion between them. The question referred to is not whether the dialectic process first " came into being in time" ; ${ }^{1}$ but rather whether in the process of time we can have dialectic, and conversely whether in the development of the truth time is necessary. On the one hand it seems impossible to have development at all without time, while on the other a dialectical development seems to destroy the significance of time. The very meaning of one element succeeding another implies the specific order we call time. Nor can we avoid the difficulty by distinguishing between precedence in thought and precedence in time. This would be the simplest method if the elements in question had the same value. But the point is, that in development the elements have different values arranged in a scale, which must always be determined in the same manner. Development only takes place in one direction, so to say. We can show that the lower implies logically the higher, and the higher logically the lower.

${ }^{2}$ This is the question discussed by Mr. M'Taggart in his Studies in the Hegelian Dialectic, chap. v. I cannot admit that this form of the question is legitimate, for it necessarily regards time as something equally valid and ultimate with truth itself, a position which, as Mr. M'Taggart allows, is certainly not held by Hegel. Mr. M'Taggart's argument refutes itself when at the close of it he demands a "higher synthesis" of imperfection (the time process) and perfection (the dialectic), for this implicitly denies that the time process is ultimate, as he assumed at the outset of his argument. But should his form of the question be regarded as legitimate, then certainly his arguments against the dialectic beginning in time are irresistible. 
But development is only from lower to higher ; there is no development from higher to lower. Now time likewise is only in one direction, and there is no doubt also that the development of truth, whether in the mind constructing the Logic, or in the one mind pervading philosophy throughout its history, does take time, and takes place in time. For when we have got the complete truth, development ceases, and as long as we have not, it continues; but these are terms implying time. On the one hand, it has to be noted, in the process of events? in the world there is no repetition; there may be development, but it only takes place once in all its fulness of concrete detail. In the development of truth, however, we can always return upon our course after we have arrived at a result, and can repeat it, knowing and indeed affirming that the development of it has exactly the same significance that it had at first or will have at any future time when we repeat our argument. This means that while the development always takes place in the mind of the thinker in time, yet the course of the development is not dependent upon any given time. But strictly there is only one time order, that in which the events of the world occur. Therefore we conclude that in the sense that the value and certainty of the development of truth does not depend on this one time order, that development is not a temporal development. It takes place in time, but its validity is independent of it. ${ }^{1}$ Moreover, when we trace the development of a principle or a truth, e.g. in the History of Philosophy, we

${ }^{1}$ Whether we can hold that there is only one time order is another question, the solution of which would hardly perhaps affect the point here discussed. 
are not in the position in which the mind of Europe was, whose history is thus traced. To get the development we must have the whole before us, the beginning and the various stages of the process. This is true likewise of development in the case of an organism. We cannot say it develops unless we know the stages through which it has passed, and in some degree the end at which these stages aim. To the organism which is absorbed in the temporal process, change is all that takes place; development is at best afterthought, or after-discovery. But to those who know the development, all the stages are present. This means, again, that to be conscious of development is to overcome the conditions of time, which are those of annihilation and obliviscence. Thus, then, we may show that the development in time is a dialectical development, but the truth of the connexion we establish does not depend on time. For if the ideal expressly sought and realised in dialectic development is not manifested, or is even contradicted in temporal experience, this will not render the less logically necessary and valid the connexion of its stages. That there will be no such contradiction, must rest on the assumption of the identity of the reason in History with the reason in the Logic. While again the fact that the dialectical development of the process of history can be repeated in thought, i.e. as a process of truth, while the process of history happens but once, indicates that the truth of the dialectical development may both refer to a temporal process and take place in time, and yet be valid independently of it.

We may conclude, therefore, (I) that dialectic 
development does take place in time, for it takes place at least in the mind of the thinker, and is held by Hegel to take place in the mind at work in the History of Philosophy ; (2) that its validity as a species of systematic connexion does not depend on, because it is not limited by, the actual temporal order of the world; for it goes back over and requires us to be conscious of the stages of the past, and therefore in it we are conscious of the whole process; and it can repeat its stages, which the world process cannot do. In either case, however, the conception of any development is confined to and implies finite reality, and cannot hold of infinite reality. ${ }^{1}$ For to make it possible we must begin at a lower form and proceed to a higher; when we arrive at the end, or stand at the point of view of the whole, the meaning of development ceases to apply, for the process it involves has vanished.

1 Vide infra, Chap. xii. 


\section{CHAPTER X}

RELATION OF LOGIC TO NATURE

We have now completed the History of the Principle, Method, and Content of Hegel's Logic. With the publication of the Logic (1812-16), his conception of its nature and problem was finally established. Thereafter, while various re-statements of the Logic were published (in the successive editions of the Encyclopaedie), his point of view and his interpretation of the content remained unaltered. There are indeed differences, ${ }^{1}$ sometimes significant, between the Logic of 1816 and that of the first edition of the Encyclopaedie (I8I7), and between the latter and the second and third editions of the same work. But these variations are dictated mainly, if not solely, by the exigencies of an Encyclopædia of Philosophy, which had to be at once comprehensive in content and curtailed in exposition, and consequently demanded brevity and compression. It was primarily, as Hegel announces, a handbook for the students attending his lectures, not a completed manual for the enlightened masters of philosophy. It bears, in fact, precisely the same relation to his students at the university which the Propaedeutik had to his pupils at the Gymnasium

1 v. note $\mathrm{B}$, Chap. viii. 
in Nürnberg, and fulfils the same purpose and function. ${ }^{1}$ It is, therefore, in the nature of such a work that variations in the form of re-statement, modification, and amplification should occur in the successive editions, that it should change as the experience of the teacher suggested and the needs of the student demanded. The alterations in his Logic must thus be viewed in the light of the general character of the work itself, and cannot, as we have already pointed out, be regarded as indicating any variation in conception or interpretation.

Before passing to indicate the general significance of the result at which Hegel has now arrived, and to deal with some of the more important features of the Logic, we must endeavour to show the relation in which the Logic as a whole stands to the other parts of his system, the Philosophy of Nature and of Mind. Much obscurity has gathered round their connexion, and for this Hegel's own wavering and insufficient statements are in no slight degree responsible. It seems even surprising that what to the student appears such an essential and important step in the attainment of a complete system should be dismissed in a brief paragraph.

Some light is thrown on the subject if we consider how the problem of their connexion arose. As we pointed out in a previous connexion, ${ }^{2}$ Hegel did not start with any one science and its objectmatter, and thence proceed to evolve the other sciences out of the first. On the contrary, following

1 The publication of an Encyclopædia at all may have been suggested by the use of the Propaedeutik at the Gymnasium.

${ }^{2}$ pp. $22 \mathrm{ff}$, $64 \mathrm{ff}$. 
tradition, he started from the fact that Nature and Mind were distinct forms of reality, separately dealt with by the different branches of philosophy-Philosophy of Nature and Philosophy of Mind respectivety.t. And not only were these assumed at the outset to be distinct from each other, [but both were taken also to be distinct from Metaphysic (the other branch of philosophy, however named).] No one had philosophical priority over another. It was, therefore, only when the demand for complete system was made that the problem of the connexion between these various parts arose. The primary fact in the history of Hegel's system is the separation of Logic from Philosophy of Nature and of Mind; it was the ideal of an absolute system which required Hegel to establish a relation between them. The connexion therefore was, in time, a secondary consideration. This to some extent accounts for the apparent discontinuity between Logic and Nature; the kind of connexion subsisting among the elements of the Logic does not lead us to the connexion between Logic and Nature. The latter seems attained by a leap rather than by a gradual transition.

It is further of importance to note that the various forms in which the relation between Logic and Nature is expressed vary with the stages in the history of his system. In the earliest recorded statement ${ }^{1}$ of their connexion the fundamental fact is concrete Mind itself. This appears in its first moment as the mere Idea, dealt with in the final part of "Metaphysic," and in its "other" as Nature, which is thus a realisation of Mind (not of the Idea). 
The relation between Idea and Nature is explicitly determined from concrete Absolute. Mind. In the Phenomenology, ${ }^{1}$ again, where the aim is to exhaust all modes in which mind appears, Nature is the form to which Mind passes in order to get rid of the limitation implied in pure self-knowledge. In the latter we have a relation, but a relation is a limitation, and "to know this limitation is to know how to sacrifice it." To do so, mind breaks down the barrier, externalises ${ }^{2}$ itself "in the form of indeterminate events," and becomes Nature. Nature is here the externalisation of the notion of Mind in its process towards complete realisation. In both the statements, therefore, the explanation starts from concrete Mind.

With the assertion of the supremacy of Logic in his final system, a change of interpretation takes place. Nature is now the direct outcome of the Idea. The Idea even "creates Nature." ${ }^{3}$ The attempt is therefore made to pass directly from the notion of Logic as such to Nature. There is a difference between the statement of the relation in the larger Logic (which is on the whole the simplest) and that of the first edition of the $E n$ cyclopaedie, and between this again and the third edition; but the general view is at least intended to be the same. ${ }^{4}$ The Idea, ${ }^{5}$ because embracing all the essential content of reality, has mediated all content, and is thus in itself the sublation of all mediation, i.e. is pure immediacy - the point from which the Logic started. The Idea is in its totality Being, and as such is Nature, for the totality of what

1 Phän. pp. 589, 590.

4. Note, p. 321 .
2 Entäuszerung. 3 Logr. iii. 26.

5 Log. iii. 342, 343. 
is, is simply Nature. In this process the Absolute Idea in its entirety merely "releases itself" ${ }_{1}$ from the "subjectivity" of the pure notion, lets itself $b e$, and it becomes Nature. Here it is evident that the transition has taken this form as the necessary consequence of Hegel's position that the ultimate meaning of all reality is Notion, and that the fundamental science is Logic, the construction of the philosophy of Nature itself being essentially (like that of the Phenomenology) a logical construction, for the notions mould its material. ${ }^{2}$

It is unquestionably, therefore, Hegel's ostensible purpose to connect Logic with Philosophy of Nature by a direct and immanent transition from one to the other. Only in this way could he claim to have established an absolute system of the different philosophical sciences. It was not sufficient to connect Logic with Nature by some external process; the character of "the only possible method of philosophy" demanded that the connexion should be found in the immediate content of Logic itself.

But while this is Hegel's express aim, we must carefully note the nature of the relation itself. Hegel distinctly declares ( $\mathrm{I}$ ) that the transition is from the notion of the Logic as a whole (the Absolute Idea) to the notion of Nature as such. Nature is the idea in the form of "otherness." ${ }^{3}$ (2) He distinguishes this transition from that be-

\section{Sich entläszt.}

2 Log. iii. 26, ". . . diese concreten Wissenschaften (of Nature and Mind) welche das Logische oder den Begriff zum innern Bildner haben und behalten, wie sie es zum Vorbildner hatten."

3 Ency. $\$ 247$. 
tween one notion and another in the Logic; for the Absolute Idea cannot as such have any further determination, for every determination is already in it. It is complete in itself, absolutely self-determinate. ${ }^{1}$ And, indeed, it is evident that the Logic cannot at once be the closed system it claims to be, and yet require as a science some completion from without. Moreover, in addition to these express statements of Hegel's, we may point out (I) that even if the Logic were not in itself complete, Nature as such could not be the step which would furnish completeness. For the content of Nature is per se distinct from that of the Logic; as Hegel admits, relatively to Nature, Logic is a "formal" science, philosophy of Nature being "concrete." 2 But if Nature were in this sense necessary to Logic, its content would have to be homogeneous with that of the latter. (2) Again, if the Logic actually covers, as it professes to do, the whole of reality, then all the essentially constitutive elements of Nature must be found in the Logic. And this is actually the case. The determining notions of Nature are "Mechanism," "Chemism," and "Teleology" (Life), and these fall inside the analysis of the Logic. If, as Hegel declares, ${ }^{3}$ the notions are the archetypes of Nature, or if Nature be, as he elsewhere expresses himself, an "applied Logic," 4 it is plain that its content must be dealt with by the Logic. But this being the case, so far from Philosophy of Nature completing the content of Logic, its own content must in some sense be already contained within the Logic. Similarly, mutatis
${ }^{3} \log$ : iii. 342.
2 Log. iii. 26.
3 v. p. 316 , note 2 .
4 Ency. § 24; too much stress cannot be laid on this expression. 
mutandis, of Mind. (3) Furthermore, it has to be observed that if the "Idea" in its entirety is to pass over into Nature as its truth (in the sense required by the method), then we ought, as in every other case of the application of the method, to find contained in the higher truth all the content of the preceding moment. But as a matter of fact all the content of the Logic is not found sublated in that of Nature. Nature does not contain, e.g., the notions of "Knowledge," "Goodness," or even those of the "Absolute," or "Actuality." For this reason the relation of Logic to Nature cannot be considered to be determined by the method in the same way as the relation between the parts of the Logic itself. Hence both from a consideration of the actual character of the two sciences, as well as from Hegel's own words, we see that the connexion between them cannot be regarded as the same as that of a transition of one notion to another.

What, then, is the connexion? There seems only one view which will at once do justice to Hegel's intention (i.e. to attain absolute system) and take account of the qualifications above noted. It has to be admitted that Hegel sought to determine the relation of the three philosophical sciences by precisely the same method as operated in each separately. At the same time each of these sciences was by the nature of its specific content distinct from the other. Hence the first point to note is that the connexion between them is really established outside each science specifically; one science is not the continuation of the other. The connexion is between each science as a whole, and the next in 
its entirety; and for this reason alone the determination of their connexion cannot be looked for in each science itself which contains all the content of that science. Thus we must look upon that part of each science (Logic or Nature), where the connexion is stated, not as dictated by the actual science itself, but by another point of view, that, namely, of the entire system of philosophical sciences. Or, to put it otherwise, the connexion between Idea and Nature (or Nature and Mind) does not really originate with Idea itself (or in the other case with Nature), but with the concrete Absolute Mind of which all these are moments, and which underlies them all. This will account for the fact (otherwise somewhat inexplicable), that in the section of Logic (as of Nature) preceding that in which the "transition" is stated, the last stage of Logic (as of Nature) is expressly determined, and the Logic, therefore, strictly concluded, while in the next section we are led to regard the Logic as in a sense not yet in reality completed. The connexion will on this view lie not between the last notion of the one and the first of the other, but between the notion of the whole of the one and that of the whole of the other.

This being so, the relation is brought about by the same method we have hitherto known. We start with the Absolute Mind, which is the one all-containing Reality. We have then, first, this Mind in itself, in its pure self-identity, its mere universality. This is the Notion of Mind as such, 2.e. the Notion of Notion-the Absolute Idea. But the Absolute in its bare identity, its naked universality, implies and demands the Absolute as mere 
difference, mere particularity. Pure difference is pure diversity, and pure diversity is mere externality, "out-of-one-another-ness." But this precisely describes Nature with its absolute multiplicity, its mere diversity, in Space and Time. From this the next step is easy. The discrete moments collapse into their primal unity, which is both the inwardness of the Notion and the outwardness of Nature, mere reference to itself, and mere reference to anotherself-reference, or concrete Mind:

The above seems an explanation of Hegel's meaning, which is at once sympathetic and intelligible. We thus see why Hegel should adopt different terms in stating this relation from those used in relating other notions. For the conception of Mind "expressing." itself in its diversity is for the most part accurately represented by such phrases as Entäuszerung, Entlassen, by which he describes the process. And this explanation, too, does justice to the early as well as the later attempts to express this connexion, that of the Phenomenology no less than that of the various editions of the Logic.

We have, however, to guard ourselves against an error. The above must be regarded not as stating a process which actually "takes place" in the life of the Absolute, - this is almost too gross a misunderstanding. "Taking place" holds only of nature where of everything we can say "it occurs," and therefore cannot hold of the Absolute. The Absolute is not first pure Notion and then pure Difference. Nature is never separated realiter from Mind. The relation as stated is simply the attempt to determine for speculative science the inner con- 
nexion amongst the constitutive elements of Ultimate Reality, by a principle and method of explanation held to be universally valid. ${ }^{1}$ Such, then, is the place of the Logic in Hegel's final system of philosophy.

\section{Note \\ On the different statements of the relation of Logic to Nature.}

The first of these is given in the Phenomenology, p. $590 \mathrm{ff}$. After stating that in Absolute Knowledge mind has "the highest freedom and certainty of its knowledge of itself," Hegel proceeds: "Still this expresses the relation between certainty of self and the object, which, because standing in relation, has not obtained its complete freedom. The knowledge in question not only knows itself but its own negative as well, i.e. knows its limit. To know its limit means to know how to sacrifice itself. This sacrifice is externalisation, wherein mind comes expressly to be mind through the medium of the free caprice of events, and beholds simply its self externally as Time, and similarly its existence as Space. This last process (is) Nature."

In Logik, iii. p. 342, 343 the statement runs :-

"In that the Idea establishes itself as absolute unity of the pure notion and its reality, and thus encloses itself in the immediacy of Being, it is

1 Hence it is that (v. Ency. §§ 575-577) Hegel represents the relation between Logic, Nature, and Mind as a Syllogism, where ground, middle, and conclusion can be alternately Logic, Nature, or Mind.

These paragraphs also seem to bear out the view we have taken above of the way in which we must regard the relation of Logic, Philosophy of Nature, and Philosophy of Mind. 
Nature, the totality in the form of Being. In this, however, there has been no becoming, no transition, like what is found when the subjective notion in its totality becomes objectivity. . . . The pure Idea ... is rather absolute liberation, for which there is no further immediate determination, which is not just as much secured within it, and already notion. No transition, therefore, takes place in this liberation; mere Being by which the Idea characterises itself remains for it perfectly transparent, it is notion remaining within itself in a determination of its own. The process then must be rather taken to be this: that the Idea freely lets itself go, in perfect security and at home with itself. Having regard to this freedom, the form which it definitely assumes is likewise entirely free, namely, the absolutely selfsufficient externality of Space and Time."

The relation is stated in a slightly different form in the first edition of the Encyclopadia, $\S$ I9I: "The Speculative Idea," Hegel says, "being for itself Idea, is thereby infinite actuality, which in this absolute freedom does not merely pass over into Life, nor does it, as is the case with finite knowledge, see Life in a reflected form. But rather, remaining absolutely true to itself, it decides (sich entschlieszt) to let go (entlassen) the moment of its particularity, i.e. the form in which it first exists as determinate and as other, (which moment is the Idea in its immediacy, its own reflex); and thus

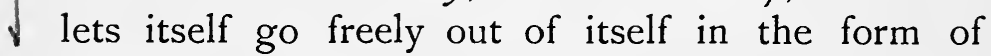
Nature."

The last part of the statement in the first edition is precisely the same as that in the last part of the relevant paragraph in the third edition, 
$\S$ 244. There is some difference in the first part, which in the third edition appears in this form: "The Idea, which is for itself, when looked at in its unity with itself, is direct insight (Anschauen); and the Idea with this insight (die anschauende Idee) is Nature. Being in the form of insight, however, the Idea stands in the one-sidedness of immediacy, or negated by external reflexion. But the absolute freedom of the Idea is that it does not merely pass over into Life, etc. . . u supra. 


\section{CHAPTER XI}

RETROSPECTIVE-THE HISTORICAL SETTING OF HEGEL'S LOGIC

$\mathrm{WE}$ are now in a position, after the perspective we have gained from the preceding historical inquiry, to appreciate more completely the influences which have moulded the form of Hegel's final Logic; and when all these are taken into account the Logic is seen to be, not a unique intellectual abnormality due to some extravagant pretension to omniscience, but the natural, even the inevitable, outcome of the spiritual environment and attitude of its author.

Hegel was himself, what he said of every one else, the child of his age, and his work only in part his own. Every fibre of his being had thrilled in sympathy with the wild hurricane of spiritual energy which had broken over Europe, scattering the dust-laden conventionalities from which life had long fled, clearing the moral atmosphere, and snapping for ever the bonds of groundless authority. The storm passed; but the word which had gone forth from the throat of the tempest was yet borne in the sound of the still small voice, which carried encouragement and wisdom to the troubled spirits of an awakening world. That word was Freedom, which henceforth became the rallying- 
cry of the new epoch. Every grade of society felt the shock, for the popular imagination was roused by seeing the new forces take shape in that form, which great ideas must ever assume if they are to be believed by the people-social revolution. And what first appeared as a political upheaval gradually spread till it swamped every sphere of moment to mankind-moral, religious, intellectual. In all cases the course of the movement was the same. Man's life was pulverised into its elements, cut loose from the past, and left in the naked simplicity of nature, and to the efforts of his individual reason. The primary instincts and demands of his spirit were admitted and honoured, and with these he was sufficient for all things. Alone and face to face with the appalling activity of the universe, he must, from the singleness and solitude of his individual life, weave the seamless robe of his own destiny.

This attitude of splendid audacity, which the first realisation of the idea of Freedom assumed, had its defenders and interpreters. On the basis of this conception of the principle Rousseau and Kant deliberately sought to reorganise man's elementary beliefs into a new spiritual world, to compel the individual to admit a new necessity in the changed spiritual order by building afresh the fabric of his life. By the former the principle was employed as the foundation of a practical working system of social duties and political rights, inculcated with all the clearness and effectiveness of passionate conviction. With Kant it was made the ground-idea of a philosophical reconstruction of man's place in the world. And with unwavering confidence the principle was carried out to its issues by the incisive 
precision of intensity of belief on the one side, and by a strenuously logical intellect on the other. God was banished beyond the world, while the individual reason ordered all within it. Of so slight significance was God to the world that the very existence of such a Being was at best a "postulate" of human reason. "Social and political life have their end and purpose in the individual from whom they themselves arise," said the one who was spiritually incapable of any social life whatsoever. "Man is a law unto himself and legislates for nature," was the cardinal contention of the Prussian iconoclast.

The principle enunciated by Kant was, in the same sense, still further elaborated by Fichte, who was perhaps the first to realise the essential philosophical significance of the new conception. At the same time he was so convinced of the practical value of the "new way of ideas," that he sought with all the impetuosity of the propagandist to inspire the "meanest intelligence" with its truth." Fichte did not shrink from the essential implications of abstract individual freedom. God was no longer outside the world, but identified with it. So far was God from being independent of man that the very notion of God was a production of man's self.) Cutting himself loose with easy assurance from traditional belief, to which, in spite of his principle, Kant was still unconsciously in bondage, Fichte did not swerve till the position of the Copernican metaphysics was firmly established, and (man was made in very truth the centre of the universe.) The Ego was the Absolute without qualification.) No longer was there to be a sacrifice of "things in

\footnotetext{
I v. Sonnenklarer Bericht.
} 
themselves" made on the altar of the Unknown God; for the altar itself was removed, and nothing was allowed a place in the temple of man's experience but what embodied a form of his self-conscious life. The social order, the object of religion, nature itself, found their fons et origo in the individual Ego, and could be "reflectively deduced" from it.

But a new movement now set in. Other forms of the free expression of human activity began to claim attention, and these powerfully modified the conception of individual freedom. On the one side the dignity and value of natural piety with its effective strength and unpretentious wisdom roused the attention of those whose interest in freedom lay not in its abstract possibilities but its actual attainments; on the other the new Hellenism kindled the delight in natural life merely for its own sake, with all its wealth of detail, and drew the finer spirits of the time to find the ideal of living in an ideal of beauty, and to seek this ideal in the pulsing activity of actual experience. The former turned men's eyes to the past (a necessary result of any appreciation of religion), and reawakened an interest in history. The latter expressed itself in that glorification of human deeds and human beings which was the chief theme of the newer poetry, and in the worship of the types of artistic beauty inherited from antiquity.

To give expression to the inner meaning in all this wealth of fact, fancy, and experience was what gave ostensible unity of aim and purpose to the philosophic poetry and poetic philosophy of the Romantic School, whose philosophical spokesmen were primarily Jacobi and Schelling. Once again 
(the Ego is placed at the heart of the world, and nature and experience interpreted in the light of free self-consciousness.) But against the severe logic of the Reflexions-philosophie of Kant and Fichte is set the insight and intuition of the poet; for strenuous analysis is substituted the free play of imagination; in place of the necessity of a careful construction is found the immediacy of feeling. Nature is transformed by fancy and emotion into the living embodiment of personality. For science we have mysticism; for logic, emotion; for reflexion, Anschaunng; for philosophy, love of wisdom; for realisation of truth, Schwärmerei. Such in result was the attempt of the Romantic School to satisfy its two fundamental principlesthat experience was a living whole, and that its meaning was found in the unity of self-consciousness?

Such an exchange of the wisdom and understanding of science for the feeling and fancy of poetry, the abandonment of the patient scrutiny of the one for the impromptu insight of the other, in the delusive belief that thereby the life of reality was more fully revealed, was certain to bring its Nemesis-confusion instead of distinction, incoherence for system, vagueness and indefiniteness for accuracy and precision. Now it is at this point that Hegel comes to the front to lead philosophy out of the inevitable impasse at which it had arrived in the hands of Romanticism. His own system took its rise as a deliberate reaction from the philosophical nebulosity of this school, and his effort to save philosophy from its friends is one of the primary factors determining his construction. In part the same ideas and influences which had given 
birth to Romanticism set the problem for Hegel also. He acknowledged the completeness and selfsufficiency of the natural religious consciousness, admitted that experience was realised in the direct immediacy of life itself, and reasserted the cardinal contention of the whole movement - that the ultimate principle of experience is the Ego, Spirit. He too was keenly alive to the essential significance of the Greek ideal as the embodiment of free natural activity.

But, on the other hand, Hegel saw that the supreme error of Romanticism was its repudiation of system, which to Hegel was equivalent to renunciation of science; for system and philosophic science were for him synonymous. And this was due to the fact that they had ignored the essential instrument of scientific construction, mediating reflexion, and had laid exclusive emphasis on mere immediacy, mere intuition; that is, they had dispensed with the distinguishing factor of the philosophy of Kant and Fichte-understanding, demonstration, reason. Hegel's opposition to the school therefore consists essentially in recovering the ground held by the philosophers of individual freedom, Kant and Fichte, in making their position completely his own, and in thoroughly recasting their fundamental principles.

Hence Hegel's problem. On the one side was the immediate experience of life, of religion, of art, each in their manifold forms, in all of which reality was felt in its richness, its intensity, its sufficiency, and out of which came the natural wisdom of common life, the penetrating insight of the religious consciousness, and the sweetness and light of poetic intuition. On the other side was the equally 
important experience of reflexion, operative everywhere, pervading everything, analysing, distinguishing, relating, demonstrating; from which arose science, and for the complete realisation of which comprehensive system was absolutely imperative. And at the root and basis of all experience, of reality in all its forms, was the one supreme principlethe Ego, self-conscious spirit, the exhaustive free expression of which was just experience itself.

Now the question how all this was to be systematised resolved itself for $\mathrm{Hegel}$ into the question, what precisely is the absolute method of philosophy? Method and system essentially involved each other. It was the absence of any determinate method which condemned Romanticism and made its attitude impossible, ${ }^{1}$ and it was the possession of an accurate method that enabled Hegel to save philosophy from its inevitable ruin. What then must the method be? Hegel's answer is as simple as it is effective. (It is to unite in a single act and process these two opposite sides of experience above named-immediacy with mediation. Intuition shall be one with understanding, "Reflexion" shall be fused with Anschaung. Immediate experience shall breathe the breath of its life into the forms of reality separated by reflexion, and these shall of themselves become the single living soul which is the Absolute. The activity of reflexion shall be endowed with the actual vitality of concrete experience. Thus, just as in life there are no gaps, its whole process forming so thorough a continuity that even to name a distinct element is in a way to falsify its nature, so the single process which is to systematise experience shall 
simply reproduce that indissoluble continuity which is its inalienable characteristic. Experience shall not so much be reflected as reflect itself; the system constructed will be self-constructed. And such a method is at once necessary and possible, because self-consciousness is the ground-principle of experience itself. For self-consciousness is in reality precisely that unity of immediateness and mediation. It is consciousness of self, and therefore contains the difference implied in mediate reflexion; it is self of which there is consciousness, and therefore is the unity, the identity of immediate Anschaunng.

Only by such a method could Hegel avoid the indefiniteness of Romantic philosophy on the one hand, and the externality, the formality, the lifelessness of mere reflexion on the other. Because of the presence of immediacy the process was that of reality itself. And this is the ground of his condemnation of the "abstract" understanding, which by its very nature can only reproduce in painful detail the isolated members of living beauty. Because it is also a process of reflexion, distinction, relation, the result is not a mere capricious intuition, nor the hazy confusion of an identity which is the mere " night in which all cows are black." While again because it is the living reality of experience which shapes the construction, we have a system which is at once truth and reality, knowledge and fact.

Hence the Phenomenology, and after this the Logic, in which the same dialectic method operates. The method of truth is dialectic, because History, Nature, and Experience are one and all dialectic to the core. ${ }^{1}$

1 "Das Wahre ist so der bachantische Taumel an dem kein Glied nicht trunken ist," Phän. Vorrede. 
Hence the identification of Logic and Metaphysic which is the absolute system of truth, and the most perfect (i.e. freest) expression of self-consciousness.

Thus, then, does Hegel gather up in himself and his system the guiding aims in the life of his ageits deep ethical fervour, its responsive sympathy with natural faith, its ambitious comprehensiveness, its self-confidence, its profound idealism. Its rootidea is Freedom, and Hegel's system is the demonstration of the truth of that notion, and his Logic the flower of free self-consciousness. Every form of human faith, again, was regarded as pro tanto justifiable, and Hegel establishes the right of every faith to be by exhibiting their various forms as modes of the realisation of religious life, while he reconciles religion with philosophy by showing religion to be the expression in the concrete immediacy of Vorstellung of the union with the Absolute which philosophy demonstrates. It is because the reconciliation takes this form that there is no "Idea" of religion in the Logic; for both Religion and the Logic exhibit the same fact in different ways. ${ }^{1}$ Further all the boundless daring of the time found its fitting consummation in a thinker who spelled out the vast meaning of the universe, and knew what were the secrets of the Absolute "before the creation of nature or any finite spirit." While finally he established its unwavering idealism, not merely by showing that the one Reality is the revelation of a single Selfconsciousness, but also by demonstrating that precisely this principle had been the guiding light of philosophy throughout all its history.

i Log. iii. 318 ; so too does Art. 


\section{CHAPTER XII}

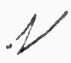

\section{CRITICISM}

IT may not be inappropriate to complete this historical inquiry by some remarks on the more general features of the position which Hegel takes up in his final Logic. It would be out of place in a work of this kind to give a detailed criticism, involving a special analysis of the parts of the system. ${ }^{1}$

We have to ask, in the first place, whether Hegel has really accomplished the end he set himself to attain. Does he establish his position? and will that position meet the needs which are to be satisfied? Hegel claims that Logic is the final outcome of Experience, and the goal at which it aims. For here we have self-consciousness most completely expressed, and self-consciousness is the ground of Experience. In Logic we have all Experience behind us, for out of this Logic comes, and is Experience at its highest mode of existence. In the system of Logic Experience gives itself utterance in its ultimate truth. Now, that, for Hegel, is taken to be not our knowledge of Absolute Truth,

1 This has been done in part by Mr. M'Taggart in a series of articles in Mind, N.S., Nos. 22, 23 (vol. vii.), 29 (vol. viii.), and 34 (vol. ix.). These deal more particularly with the third part of Hegel's Logic-the Notion. 
but the Absolute's knowledge of itself. $\mathrm{He}$ holds this in virtue of the identification of the individual with the Absolute, which appears in Religion, and is simply brought to the daylight of knowledge in the form of Logic. The content of Religion and of Absolute Knowledge is precisely the same; the attitude towards the Object alone distinguishes them. If that is so, then what is presented as the content of the Absolute in Logic must be the expression of the Absolute of Religion. But the former is simply the formulated truth of Experience; hence Experience must be identified with the Absolute of Religion. This follows inevitably from Hegel's view, but it is not difficult to see that it places either Religion.or Logic in a doubtful position.

For what does the attitude of Religion imply? On Hegel's view it involves a contrast as well as an identification of the individual with the Absolute Mind. The individual shares the very life of Absolute Spirit - hence the significance of "revealed" Religion. But still the opposition between the two remains unremoved; and this means that the object of Religion transcends the individual, has a self-subsistent life of its own. This is recognised by the religious mind in this, if no other way, that the Absolute Spirit is not regarded as having an attitude towards the individual similar to that which the latter holds towards it. Or, in other words, the Absolute Spirit is not "religious" in any sense of that term; Religion is an experience wholly inside the life of finite individuals. In no way can it be maintained that the individual "worships" or "acquiesces in " a power which is merely the projection of its own self. And to identify God with either the "moral order of the 
world," or even with the rational order of Experience as a whole, is not merely inconsistent with the essential characteristics of Religion (submission, reverence, etc.), but is illogical. For it involves the paradox, which at first Fichte defended with his splendid audacity, but finally abandoned, that man creates God in order to prove $\mathrm{His}$ existence, or rather that man establishes His existence by creating $\mathrm{Him}$, and makes the ground of his Experience the consequence of that Experience itself. If the order of Experience is God, then whence the need of the idea of God at all ? The activity of the self determines that order, and nothing more exists or is required. The attempt to go further is simply a confession of the incompleteness or, as Hegel puts it, the "finitude" of the starting-point. And Hegel himself does not admit such a conception, and is far enough removed from the attempt to evolve God out of finite consciousness. Rather he denies altogether the adequacy of beginning with anything except the whole.

But if so, then the Absolute of the religious mind goes beyond the individual. (His Experience in time, therefore, cannot, for Religion, exhaust the full life of God, and the content of Experience cannot be identical with the meaning of the Absolute of Religion.) Hence we conclude that the body of truth which makes up the Science of Logic does not and cannot express the complete nature of that Absolute found in Religion, and from which also Logic professedly starts. Either, therefore, we look in vain for the content of Absolute Mind in the Logic, or we must give up the meaning of Religion from which Absolute Knowledge proceeds. Hegel's 
deliberate aim and purpose will allow him to do neither of the two; for the former implies that the end he set himself-scientifically to construct Ultimate Reality-has not been successful, while the latter implies a breach with human Experience which he cannot admit. Hegel may be allowed to be on safe ground when he regards the Absolute in Religion as transcending the individual; and when he falls back upon Experience for the contents of Logic, he is again maintaining a defensible and intelligible position. (But when he regards the object dealt with in the two cases as the same, the inconsistency is too perilous to be left unnoticed.

Furthermore, the kind of knowledge which is furnished in Logic would not reveal the nature of Absolute Spirit. Logic deals with the "pure" universal content of mind. But in Absolute Spirit we have only what is concrete, neither universal simply, nor abstract nor formal. The concrete life of Experience in all its varied forms is certainly more adequate to the content of the Absolute than the abstract expression of one particular form of Experience. For Religion the Absolute is "revealed" through sense as well as through thought, in the distortions of nature as much as in the completeness of the type, through moral disaster and defeat as well as through the secure goodness of a perfect life. It is because the activity of the Absolute is so manifold and complex that Experience is so rich and diverse. If it therefore takes all the forms of Experience to tell the complete meaning of the life that pervades it, we cannot expect to find in any one, be it even the highest, such a full expression of the truth of Absolute Spirit. The conception of degrees 
in the realisation of truth implies, as we saw, not merely that the highest implies all the others, but that all are necessary to reveal the entire truth. But such a conception is inconsistent with the claim of the highest to contain most perfectly the concrete life of the whole. No doubt the Ultimate Reality throughout Experience is Spirit, and no doubt also in Logic mind is completely self-conscious. But this does not mean that in Logic the concrete life of the Absolute is perfectly or exhaustively contained. The perfection of the knowledge given in Logic is not equivalent to the living processes through which the Absolute Spirit manifests itself in Experience.

This brings us at once to consider what is perhaps the key to Hegel's whole position - his conception of the relation of Knowledge to Reality. That in the Logic he is dealing with the Absolute Spirit is not proved, and, even if it were, that the Logic does perfectly reveal the Absolute is untenable; but both positions are in the long run traceable to his view that knowledge and reality are identical. It is not difficult to see how Hegel arrived at this position, and what he really meant by it. He does not of course mean that all reality exists only in its being known in the processes of science, and that his own philosophical works, or, for short, his Encyclopadia, is a substitute for the universe, a kind of world extract. Nothing so transparently absurd could be accepted by Hegel. The first point then to determine is his interpretation of "reality." That for him was simply synonymous with immediacy. In immediate experience we are sharing in, are indeed fused with, the very being of the world. To be "real" is to be absorbed in 
our direct living experience. We do not merely "touch" reality there, we are real in that way, and reality is what it is in that aspect of Experience. ${ }^{1}$ And this holds throughout the various forms in which Experience appears. There is not simply one mode of immediacy, there are as many modes as, there are types or kinds of Experience. Thus we have an immediate in Sense-experience (e.g. in colour, sound); we have an immediate in intelligent "Observation" (e.g. of an animated organism, an electric spark); we have again an immediate in Morality (e.g. conscience, social "instincts"); and so on. Wherever, in fact, we have an object present to the subject, there we have immediacy. And since Experience is constituted by the subject-object relation, immediacy is a factor found throughout the whole range of Experience. All this is evident from the Phenomenology and needs hardly to be further elaborated here. $^{2}$

This immediacy, then, is the bed-rock of reality. It is obvious that what is immediate must be immediate for consciousness. Only in the case of conscious experience does it have a meaning, just as only if there is immediacy is there a conscious experience. But in human Experience we have not simply consciousness; its essential characteristic is

1 This point has been developed in recent metaphysical discussion. See especially Bradley's Logic and Appearance and Reality, Bosanquet's Logic, i. $76 \mathrm{ff}$, and Professor Seth's Man's Place in the Cosmos, pp. $206 \mathrm{ff}$.

2 This presence of immediacy in all types of Experience has hardly been sufficiently emphasised in recent analysis. Immediacy has been almost universally limited to sense-immediacy. This seems an error in method, and renders the problem of interpreting Knowledge in all its forms hardly soluble. It is this limitation, for example, which has given rise to the attempt to construct the Moral Order out of sense data. But why should not an "Ideal" be immediate as well as a "feeling"? Hegel's view seems an immense improvement on all this. 
self-consciousness. All experience to be our Experience must be, and always is, accepted by and transformed into the tissue of the self by the conditions of order and arrangement which determine its activity. This reference to and determination by the unity of the self is not an accident or a superfluous addition to the processes of Experience; it is absolutely necessary if our Experience is to be that of self-conscious, i.e. rational, beings. It is as necessary to our Experience as immediacy itself. But this process of self-reference is not one of immediacy; it is that of active determination by a single principle, ordering Experience into a single whole. It is forming or transforming a whole through or by means of a unitary centre; it is a process of mediation. Self-consciousness is the very condition of all mediation whatsoever. ${ }^{\top}$ Mediation, therefore, is as necessary in self-conscious Experience as immediacy. " "There is nothing," says Hegel, "nothing in heaven or in nature, or in mind or any where else, which does not contain immediacy as well as mediation."

The above, then, holds true of all our Experience, and hence of Science as a particular form of that Experience. And so far we seem on familiar, or at least defensible, ground. But here begins Hegel's characteristic development of this position. All Experience involves the relation of subject to object, and all Experience is fundamentally the life of mind; it finds its meaning and explanation in self-consciousness. Now in the Phenomenology it was further shown that

1 v. Chap. ix.

2 This is the essence of Hegel's criticism of Kant and is a position of profound significance. The denial by Hegel that "things-in-themselves" have any meaning is simply a consequence which follows directly from it. 
self-consciousness finds its most perfect expression in Absolute Science. In other words, that while all Experience is the realisation of self-consciousness, Science is its truest form; it is "the crown of the life of mind." Therefore, said Hegel, the immediacy of Experience is the immediacy of Science; the mediation constituting and constructing Experience is the mediation of Science. What is immediate to life in indissoluble union with environment (in the widest sense of the term) is the same as what is "given" or "immediate" in Knowledge. In other words, Reality in its essence is a process of Knowledge.

Now it is safe to say that such an identification is absolutely groundless. To assert that the whole teeming life of the world, with its boundless activity, its inexhaustible wealth of content, is for knowledge literally "given" in its entirety, and only exists as so "given"-this is surely the mere perversion of Experience in the interests of a speculative preconception. "The "given," which is the immediate in knowledge, is always and is necessarily isolated. It must be a "this" or a "that," a "here" or a "there," one idea or another idea, before it can become an object for knowledge at all. But the immediate in Experience, that immediate which is reality, is absolutely continuous with itself, and admits of isolation in no sense whatever; the immediacy is indissoluble, otherwise Experience simply ceases to be. This single immediacy of Experience we simply cannot have in knowledge; if so, knowledge would not be knowledge, but Experience. Nor is it necessary for knowledge that we should have it. Knowledge 
is not construction but reconstruction of Experience, and for reconstruction we must begin with fragments, while fragments must come separately and in isolation. Experience again, on the other hand, is the compact and inexhaustible mine of fact to which knowledge ever recurs, which it seeks to fathom, but cannot by its very nature deplete, the reproduction of which in its immediacy may be said to be its aim, but must ever remain its ideal, for the attainment of it would mean its own annihilation.

Moreover, such a position is in reality not warranted by the argument drawn from the course of Experience as traced in the Phenomenology. That argument goes to show that while in Experience there is always an immediate, yet the immediate is specifically different in each type of Experience. In each case there is reality, and in each case mind is the centre and circumference of Experience. But the form of reality varies with the type of spiritual experience. The reality for Senseexperience, for example, is assuredly not the reality for Moral-experience. Thus the content of Science is necessarily different from that found in other forms of Experience. Its immediate is an immediate to that peculiar form of Experience. This immediate is Thought, or, in its purest form (as Hegel says at the conclusion of the Phenomenology), the Notions found in Logic. In thought, no doubt, mind is at home with itself, i.e. is perfectly conscious of self; but that only the more emphasises that this immediate in the experience we call knowledge is not the only immediate, is only one form amongst others. Because knowledge deals with that specific immediate, 
has its being in that immediate, knowledge is obviously reality, for thought is one real mode of Experience; and in that sense Hegel's claim for the notions to be "concrete" and "real" is, as we shall see, perfectly justifiable. But that admission does not alter the difference between the immediate in knowledge and that found in other forms of Experience.)

The confusion seems to have arisen because Hegel overlooked the fact that the Phenomenology in which he proves that the final form of self-conscious experience is pure consciousness of self, is itself a construction of knowledge. Experience as such does not work out the argument; it is the specific activity of knowledge which brings it about. And surely it was even inevitable that a scientific inquiry which sought to find out the highest form of Experience, should find that form in the Notion of Science itself; for what was really being sought from first to last was just the idea of that type of experience (namely, knowledge) which was constructing the whole of Experience. It could not terminate in anything else, for the simple reason that reflexion about Experience presupposes, i.e. has behind it, Experience, and in that sense is above it, i.e. is its highest expression, and therefore must find the goal of Experience in its own ideal. But to suppose that this process of knowledge by which we construct Experience is the actual process of Experience itself, because the idea of knowledge is only determined at the conclusion of the inquiry, may have made the confusion we speak of natural and simple, but it is confusion none the less.

This identification of knowledge and Reality was, we seem forced to maintain, a fundamental 
claim of Hegel's system, ${ }^{1}$ and this we must unhesitatingly regard as the $\pi \rho \hat{\omega} \tau o \nu \psi \psi(\epsilon \hat{v} \delta o s$ of his philosophy. It is the root of much that remains untenable, and much that is ambiguous in the system. The supposition that Experience proceeds in its actual life by a method deliberately adopted for purposes of Science, makes it impossible for us to know whether in actual Experience (as traced in the Phenomenology) we are dealing with Science; or again, whether in what is admittedly a pure science (the Logic) we are dealing with reality. The beam dips now to one side, now to the other, and we are at a loss to find an unhesitating answer to a question of the first importance. (And the uncertainty is due solely to the gratuitous assumption that because knowledge deals with the immediate, therefore it is reality. We say "gratuitous" because, as will presently appear, Hegel's system regarded simply as knowledge can be admitted, or at least be best defended, when we eliminate this implication altogether.

It is the source again of Hegel's entirely futile attempt to transcend, by knowledge, the finite consciousness of the knower. Because in knowledge we are supposed actually to have Reality, absolute objectivity of knowledge is secured, individual subjectivity is annihilated, Reality "knows itself," and the finite knower can be altogether ignored: at best he merely "looks on" at the process by which Reality constructs its own system! If this were a highly forcible way of laying stress on the absolute certainty of demonstrable truth, it would

1 It is easy to see how it arose from the conception of Anschaunng above indicated. 
undoubtedly be admissible; but when it is asserted as literal fact it is quite delusive. Does it follow that because something is necessarily true for every one, that therefore it is true for nobody in particular, but is true "for itself alone"? As well maintain because every loyal member of a state acknowledges the same sovereign, that the sovereign is monarch "in himself," and would remain so if the whole state collapsed. It is certainly astonishing to find the arch-apostle of Absolute Knowledge adopting the tactics of pure agnosticism. Because something is independent of any given mind, says the latter, it is independent of all, and therefore "in itself" unknowable. Because, says Hegel, something holds for all, it is independent of any one, and therefore is true "for itself"!

But the fundamental fallacy we are considering is seen most clearly in the content of Logic itself. In the Phenomenology the content transcribed into knowledge is concrete, being the process of Experience itself, and the identification we speak of seems more specious and less objectionable. But that the content of Logic can be held to be at the same time the Absolute, even in its essence, must give us pause. The content is admitted by Hegel himself to be in a legitimate sense abstract. To regard it as "formal," even to name it "essence," still more to consider it as the "shadow" of reality, is surely to mark off with perfect definiteness Logic from the sphere of fact. For Reality is precisely that which is neither "essence" nor "shadow," but the free and full activity of life itself." The Absolute is only real in its entirety,

1 Natur hat weder Kern

Noch Schale

Alles ist sie mit einem Male.-Goethe, Dem Physiker. 
and only under qualification are we entitled to regard its elements or aspects as real. Elements, moments in fact of any kind, still more when formal, are not the Absolute; they are specific determinations of it for purposes of finite knowledge. The Absolute, as such, is neither essence nor appearance; it is nothing less than the whole in its completeness. And Hegel is in reality keenly alive to the difficulty his view of knowledge meets with here. It is for this reason that we have such contradicting predicates applied to the notions. He corrects the "abstractness" of notions by affirming their "concreteness." But this merely emphasises the difficulty ; for that "concreteness" is not allowed to prejudice their "abstractness," it merely names their worth as abstractions; it does not give us back the Reality we have from the outset "left behind." And the same is true of the "degrees of concreteness" of the notions which we find in the course of the Logic. That Hegel should have regarded the content in this light merely indicates once again the ambiguity of his position, for Reality, even to Hegel himself, has in and for itself no degrees of concreteness. The "truly real," says Hegel, "is Subject" ; and there is only one Subject, which is always and alone real. Furthermore, this difference in concreteness of the notions does not alter their nature as notions; they remain notions from beginning to end. The fact that one notion implies or contains other notions does not make it other than a notion.

To suppose again that merely because the notions constitute a system we thereby have Reality is too obvious an absurdity. A system of unrealities is not real because it is a system, any more than 
the ghostly army of a defeated marshal's dreams would fight the battles of the morrow. Nor, further, when we regard the notions as "objective" do we make them real, unless we confound objective for Knowledge with existence in fact. They may be independent of "us," but the "independence" of a phantom does not give it part or lot in the world of time and space. Essentialities again they may be, but absolutely real essences they cannot be ; for an essence as such is not absolutely real. When from such essences Hegel would, as he states, "produce reality," the ineffectuality of his whole contention is at once proclaimed. For if the notions "produce reality," in what sense can they already be reality? The only "reality" which in fact they do produce is the "reality"-of another notion. And to "create" Nature from such notions is surely mere metaphor. Even to pass in thought from Logic to Nature seems to have caused Hegel no small difficulty, if we may judge from the repeated changes made in the statement of the transition, all of which tend towards the minimising of the self-containedness of thought, and imparting into the "Idea" that incompleteness which implies a reference to something else. ${ }^{1}$ But even such logical implication is not equivalent to evolving the teeming multiplicity of Nature from the "shadow world" of the notion which to begin with is not itself reality. Nay more, Hegel's own words condemn the suggestion; for if Nature is anything it is pure diversity, which is mere contingency. Yet this very contingency falls outside the notion, cannot be determined by it, and the inadequacy of

\footnotetext{
${ }^{1}$ v. note to Chap. $\mathrm{x}$.
} 
contingency to realise the notion constitutes the Ohnmacht der Natur, and sets limits to philosophical explanation. ${ }^{1}$

But it is needless to expand the objection further ; enough has been said to establish its validity. ${ }^{2}$ The source of the error in the case of the Logic is again Hegel's identification of mere immediacy for knowledge with Reality. The immediacy of fact peculiar to the diverse forms of Experience is eliminated from the notions, and for this reason alone it might be thought that the notions could not be "real"; but by Hegel this is overlooked. Their immediacy consists solely in their presence to the self, and they are so presented because constructed by the self. They are known as the essence of the self, but this neither clothes them with the full reality of the self nor with the full Reality of the world. They are isolated expressions of its activity, not full embodiments of its life. They are doubtless its inalienable determinations, and are immediate to the self, for the self-determinations of mind can only be immediate for mind ; only there do they exist. But they are not the self in the single completeness which is alone its reality;

${ }^{1}$ Ency. : Philos. d. Natur, § 250 ; also Ency. § 24.

2 Perhaps the criticism in the immediately preceding paragraphs may seem somewhat overweighted and ungenerous, more particularly in view of the interpretation put upon the Logic in the earlier chapters, and the essential value of his position, which, as will be presently seen, is readily acknowledged. And no doubt the above criticism only concerns a certain tendency or strain which runs through the Logic. Since, however, Hegel lays such unqualified stress on the reality of the Notions, and even seeks to treat them as real literally at the expense of the rest of the world (see the introductory chapter to the third volume of the Logic), the foregoing criticism seems quite justified, and the results of such a position must be pointed out. Still it is unfair to condemn the Logic in toto (as, e.g., Haym seems to do) on account of this tendency. The above criticism, it will be evident, follows much the same line as that taken in Professor Seth's Hegelianism and Personality. 
nor again are they the reality of things, for these are individual, and a notion, however concrete, is, as we maintained above, always a notion, i.e. a universal. The Sache an sich selbst which Hegel identifies with the notion is in reality nothing other than-a notion itself. And when Hegel regards the notions as real, because they live and mould themselves into system "by their own activity," the confusion is only the more transparent. They live certainly, but only because endowed with the life of the real mind which is active in them and through them, and apart from which they have neither force nor being. That the system of such notions should be "absolute reality," objective science, "true of itself" and "self-constructed," becomes manifest illusion when it is pointed out that such notions only are in and for a real self, and that their so-called self-movement is brought about solely by the deliberate activity of that concrete individual self which was to be eliminated! The notions are doubtless necessary for experience, and their construction an essential expression of human knowledge, but it is surely only by self sophistication that we can take the Fata Morgana of a philosophical perspective for the living activity of Absolute Spirit.

Another general feature of the Logic which calls for consideration is the Method by which it is constructed. This method is not taken to be peculiar to Logic, but is merely found there in its purest form. The method is that of Absolute Idealism, in whatever sphere that may be realised. It claims to be the means by which the standpoint of Idealism is established, to be not so much self-evident as selfproved by its "success" to be the process of Reality, 
and to be the only method of completely expressing and systematising the truth. Now in Hegel's view all these essentially involve each other; and it is strictly impossible to say which is for him logically prior. If the method is true, then it is the only method of truth. If it is true, it is the very process of Reality; and since it has been used in the Phenomenology it has proved the standpoint of Absolute Idealism; while if it is actually shown to systematise truth and to be the process of Reality what further proof of its validity is required?

It is difficult to suppress the suspicion that there is some fallacy in this procedure. And in reality it is easily discovered. The fundamental fact is the relation between the method and Idealism. Hegel does not regard the standpoint of Idealism as selfevident; for it was the aim of the Phenomenology to establish it. And it seems as certain that the validity of the method is not self-evident. We demand a proof of this, and Hegel in so many words holds it is proved, because it is the only method according to which Idealism can proceed and be systematic; that is, the validity of the method depends on the validity of the standpoint of Idealism.) But the latter was established precisely by this method. The validity of the one thus depends on the validity of the other, and the argument is an obvious circle. If then we are to hold both as valid we must either not guarantee the one by means of the other, or regard them as synonymous, i.e. allow that the method is just the process of Absolute Idealism.

Strictly speaking, Hegel cannot maintain that Idealism is in any proper sense established or 
"proved" by this method in the investigation of the Phenomenology. For the method is not a method of inquiry at all, but the reverse. It is only a method which can come into operation after investigation, after the finished result of Experience and specific ("scientific") knowledge has been obtained. It cannot claim to establish anything " new," unless ordering what has already been obtained is regarded in that light. Ut professes to be the explicit union of analysis and synthesis in a single process ; and this can only be carried out if the contents to be known, i.e. systematised, are alveady consciously and definitely determined. In the detailed knowledge of experience this is not found, nor is it possible. For (if so the whole process of scientific investigation would be unnecessary. In such investigation we must proceed by consciously separating analysis and synthesis.) The former (analysis) takes place by making use of inherited experience, language, terms, "proved" principles, etc.; the latter (synthesis) takes the form of "suggestion," "hypothesis," "construction," probable "explanation," etc. The process, therefore, by which the dialectic method obtains its end, and that by which scientific inquiry works, are so distinct that in no strict sense can we regard the former as one of investigation at all. Investigation implies and presupposes the unknown and indeterminate; Hegel's method is unworkable unless what is handled is not merely known, but completely determinate.

If this is so then Hegel is not justified in regarding his standpoint as proved in the Phenomenology. For this is not strictly a voyage of discovery, but a direct systematisation by a method already possessed. 
And for that reason we cannot admit that Hegel has achieved one of the main ends which determined the writing of the Phenomenology, namely, proving to the world that Idealism was the only possible standpoint which can be adopted. It was indeed well and appropriate to begin with the "ordinary consciousness" as it finds itself, if he wished to lead it up to Idealism, for it was the ordinary consciousness that he has to convince. But it is surely taking the ordinary consciousness at an unfair advantage if he constrains it to avow that it is idealistic by a method of which it is unaware, or which it, at least, does not admit. If he wishes to convince the ordinary consciousness by starting from what it knows and admits, he is certainly bound, in order to attain his end, to adopt for that purpose the method of proof which it would also admit. Otherwise how could the result be accepted? Hegel was no doubt right in starting from the ordinary forms of experience to lead us up to Idealism, for " the Absolute must not be shot out of a pistol at us." But we on our part, if we are to be satisfied with his view, should also insist that we must not be shot out of a pistol at the Absolute. Hence, then, it is impossible to allow that in the proper sense Hegel has "proved" absolute Idealism in the Phenomenology; for this is constructed by the method of Idealism itself. And indeed, as we have seen, the Phenomenology is in reality part of his Absolute System; it in a sense is the whole of that System.

In what way, then, can it be maintained that Hegel proves his point of view, and establishes the validity of his method? For undoubtedly he claims to do both. It is not done by getting outside the 
system; for anything outside the System is irrelevant to its validity, it must belong to a different level of truth or insight from that on which Idealism stands. That is to say, Hegel does not allow that his System is merely transformed common-sense, which can be understood by, and will approve itself to, its canons of evidence. He maintains at once that it is a distinctive system of truth, and that no method but that peculiar to the System can test its truth, for any other method accepts as self-evident what for that System is not admitted to be such at all. And, moreover, any method of determining truth which might be adopted should find its place inside that System itself. But since there is no way of proving the truth of any view unless we stand in some way outside it, it is clear that Absolute Idealism does not admit of being proved at all, and rightly claims that it cannot be so proved. For if it is Absolute Truth, then to admit that it can yet be "tested" were to admit that its truth is not absolute.

Here then the System stands on a paradox, which meets all those who seek to grasp it, or to examine it. The System because absolute contains its own criterion of truth, and any other which falls without it is invalid, because not part of Absolute Truth. But if we are to examine the System, if we are ever to accept it as true, we must in some valid sense be outside the System to begin with; for in order to accept it we must make use of a method which at least we do not find to begin with in that System itself. It must approve itself, standpoint and method, to us and our way of thinking before we can accept it. All education and inquiry 
presuppose this, and without it are impossible. Either, therefore, the System cannot be judged to be true at all, or it cannot claim to be Absolute Truth in the sense it maintains. The danger which threatens an Absolute Idealism which defends itself by such means is, that so far from its being admitted to be Absolute Truth, it is impossible to say whether it is true in any sense at all.

And this difficulty ceaselessly perplexes interpreters of Hegel. It has seemed that, to paraphrase for our purpose Jacobi's remark regarding the category of causality in Kant's system, without admitting that the System was Absolute Truth, we cannot remain in it, and when we admit it we cannot enter it. But indeed the claim is quite baseless and impossible. No system of human knowledge can so usurp the authority of reason as to determine the conditions, not under which it shall proceed, but under which it can be accepted as truth. A specially constituted court of appeal is in the kingdom of reason a contradiction in terms. And indeed Hegel gives up the claim when he says that the proof of the validity of the method is found simply in the "success" with which it is carried out in the construction of the system. For "success" is not an absolute standard, but implies essentially the relativity of the truth of the whole process. It is relative in two ways, not merely to the individual using the method who must have a specific conception of what will satisfy the ends he sets before him, but also to the individual judging the result. The latter is thereby admitted to be capable of determining the validity of the result precisely because he possesses the condition of making a decision regarding it, namely, a standard 
of success. Even if we grant, then, that this method does enable Hegel to construct the system of Idealism, this, on his own admission, is no absolute guarantee of the finality of the result, and therefore the absolute validity of the method is imperilled when this is made to depend on the success in working it out.

It is impossible for Hegel to overcome the inevitable limitations under which he works, and which indeed are those of knowledge in general. When he seeks to avoid them altogether by declaring that the method is absolutely valid because it is seen by the argument of the Phenomenology to be the process of history and experience his contention is quite futile. Indeed it is almost incredible that Hegel could have maintained it. For it is a transparent petitio principii. $\mathrm{He}$ wishes to prove the absolute validity of the method by appealing to the course of experience whose very process has already been determined by the method itself, and the system of which he has constructed by means of that method. We do not discover the method by simply opening our eyes upon reality. To determine the "course of experience" we must make use of some method. But when we have done so our construction is a system of knowledge, and can be tested as a system of reason. It cannot claim to be the process of experience and to suppress in advance all criticism by maintaining that it has attained the limits of possible knowledge.

The source of those claims which Hegel makes on behalf of the method is really to be found in that identification of knowledge and Reality above referred to. It is because of this that he asserts 
that the absolute "knows itself" in the Logic, that the method is the veritable movement of Reality, at the reproduction of the process of which in the system of Absolute Knowledge the individual simply "looks on." Yet it is precisely here that, by the strange irony of Truth which would mock the efforts of even those who would do it most service, the contrast between knowledge and reality becomes most pronounced. Let us grant Hegel's contention that Reality reflects itself, that the Absolute knows itself in his System. A little consideration soon shows that such a conception of science overleaps itself.

For, in the first place, if it were true, the ultimate process of Reality would be simply a process of knowledge; Experience would be solely self-knowledge. In that case it would be impossible to distinguish between a process of knowledge and the course of events ${ }^{1}$ the one would literally $b e$ the other. But, if so, the position is logically indistinguishable from pure Subjectivism, and our self-knowledge of the Absolute turns out to be convertible with mere Solipsism. The logical result of making our knowledge so objective as to be Reality is not that we are nearer Reality, but that there is no reality to know, is not that we transcend ourselves and attain the Absolute, but that we never transcend ourselves at all. ${ }^{2}$

In the next place, if we make this claim regarding the process of knowledge the science con-

${ }^{1}$ We could not distinguish between our knowledge and the knowledge by the Absolute, because that is ruled out by the assumption that the individual is excluded.

2 Moreover if Experience were simply knowledge it would be impossible to speak of a knowledge of Experience. In fact in such a case Knowledge would be quite superfluous. That Knowledge is necessary to us shows that it cannot be Experience. 
structed is not in reality knowledge by finite human consciousness, but the Absolute's knowledge of itself. But apart from the fact that such knowledge would again raise precisely the question put aside, namely, the relation between our finite knowledge and absolute knowledge, it is quite evident that for us as human beings such knowledge is not so much "too high" as simply valueless. We have no concern with any other knowledge but what holds for us, and serves our ends. We could not accept it because we could not know what we should be accepting, still less could we criticise it or affirm it to be true. The attempt, therefore, to get beyond finite knowledge, in order to supply truth as it is for the Absolute, is so far from fulfilling its purpose that it defeats the very aim of philosophy itself, which is to satisfy a human need.

While again, if the process were that of Reality, then it would necessarily follow that the Absolute itself passes through the process of gradual selfknowledge. But this, which is even as it stands incredible, contradicts Hegel's own contention that the Absolute Subject is the "truly real," is self-determining, self-complete, and has its purpose ever in itself. It is somewhat astonishing that a thinker who held that philosophy arises as the recollection, the "after-thought" of a departed epoch, and builds its temple on the ruins of the past, should have identified the recorded memory of a vanished life with the ceaseless process of the Absolute.

But apart from these objections, we found above that the Phenomenology itself proceeds from the fact that the immediate in one type of Experience is not the same as that in another, and that in science it 
is specifically different from that found in the form of the life of mind.) Now this characteristic distinctness in science becomes still more evident when we consider the "absolute method" by which it has to proceed. In order that this may operate upon the content to be systematised that content must have been already formed in a definite and specific manner by the course of Experience itself. The content of Logic, for example, presupposes not only Experience in the general sense, but the results of the various sciences dealing with aspects of Experience, Number, Measure, etc. Without that completeness in its "material," its "datum," the method cannot be used at all. It is not a method of investigation, but of construction. Its immediate must be of a specific kind, and must be consciously admitted to be so before the kind of system determined by this method can be formed. But if the method necessarily" makes such a presuppositicn nothing. could more decisively mark off the procedure of the system of Idealism from the actual process of Experience and events. ${ }^{1}$ Experience as a whole contains what we choose, and may even justify our choice; but to take our choice for Experience itself is surely mere confusion. This, indeed, might be allowed to be self-evident when it

${ }^{1}$ It is this contrast between Absolute Knowledge (the Logic) and Reality which lies at the root of the common objection to the Logic that it is out of touch with actual experience, that it needs something to complete it in order that it may be experience. This has been expressed by Mr. M'Taggart in the view that in order that the Logic can hold good there must be some immediate datum, something given over and above the abstract notions. I do not agree with this way of stating the difficulty; for such a process would be quite external ; it would simply leave the two side by side. I deny that Absolute Knowledge could give Experience under any condition. Moreover, I think that on Hegel's view the Logic does contain immediacy, the only immediacy which is relevant to it ( $v$. infra, pp. 367,368 ). 
is admitted that Science is a distinctive form of Experience. For the process of mediation depends on the immediate content known, and the method which holds for Science might even à priori be regarded as inappropriate for Experience as a whole. The method is that which will subserve a specific purpose, namely, the achievement of a complete system of ultimate truth; and apart from that has no significance.

Further, Hegel's claim that the method is the objective process of Reality is for him synonymous with the elimination of the individual in the construction of the System. If this meant no more than that the individual is to suppress his special point of view, with its "prejudices" and "opinions," then undoubtedly it would be valid, though even then it would be an ideal aim. But Hegel means more: the individual simply "looks on" at the process. Now in the case of any method of intellectual procedure we might well deny that the activity of the individual thinker does not determine the result ; but in the case of such a method as Hegel's the assumption that he eliminates the individual is quite delusive. The system is simply the expression of the labour of the individual thinker strenuously seeking to realise a conscious ideal of truth. The movement of the notions, the analysis, and the relation of them, do not take place of themselves; nor does the whole pass like an uncontrollable phantasmagoria before the mind. The movement is the very expression of the energy of the self which is moulding such content into a whole, which is realising its own unity in an ideal form. At every step this self is actually present, for at every step its aim has to be satisfied by the pro- 
cess in question. This need not of itself render, from the very start, all the efforts of human reason to attain universal truth futile. It is the only condition under which we can attain truth, and we do attain truth by that process in spite of the limitations of the individual. But it does make it impossible for any system of truth to claim finality on the ground that the individual has been eliminated from the process of constructing it.

But further, to admit that the activity of the individual is thus essential amounts in reality to the admission of a personal equation in the construction of the Logic, and indeed of any absolute system of philosophy. It directly affects the content of the system. For if it is true that no man can rise above his age, it is even more true that no man can transcend the environment of tradition, culture, interests, and ideas which make him a member of a given nationality. The thoughts of every nation become embodied in language, and thence become the heritage of its children. To these conditions Hegel and Hegel's Logic must both submit. But if so, the conclusion is plain that we can have no guarantee, indeed it is a priori impossible, that either the number or the meaning, or the kind of categories embodied in the language of the German nation, and systematised in the Logic, furnish a complete and accurate transcript of the ultimate truths of human Experience. Nay more, what guarantee have we that Hegel himself has exhausted or can exhaust the notions even of his own experience? Any such suggestion of infallibility is a mere gratuitous assumption. ${ }^{1}$ The

1 Too much stress cannot be put on the objection so often made against Hegel, which is based on differences of nationality and culture in different 
limitations of the thinker to his nation and stage of culture may not be entirely fatal to his claim to state the truth, but it certainly makes against any claim to deliver the complete system of Absolute Truth.

The personal equation again_appears when we ask how the connexion, more particularly the necessity in the system, is to be determined? What guarantee have we that one notion must lead to a certain notion and no other? It is obvious that what a given mind shall find in a notion, what meaning it will have for him, depends entirely on the degree of insight and the extent of knowledge he has at his command. It is impossible it should do otherwise, for notions, on Hegel's own interpretation, are not counters which have a fixed value and always ring the same sound, they are results of experience, and are therefore endowed with the possessions brought from the past by each human spirit. Should Hegel reply, and quite fairly, that the thinker with the most complete experience will determine the connexion necessarily, and in a manner which will be seen to be inevitable by the individual of less complete experience, then we can only answer that this all the more emphasises the fact that the presence of the individual with a determinate experience is absolutely essential to the construction of the system.

But, indeed, this attempt to transcend the individual altogether, and give the last word of truth,

nations. For if pushed too far it would make all scientific knowledge doubtful simply because it is the possession of a given nation. It does not follow because a Hottentot is incapable of understanding the proof of the law of gravitation that this is doubtful or false. If this were so, stupidity could refute all science whatsoever. 
ignores the very end of knowledge, as well as the conditions under which it works. There cannot be for us any absolute science in the sense of a literally completed exposition of Absolute Truth; and as long as this remains as certain as it is self-evident, we must allow for the activity of the individual in the construction of the science, and therefore deny the claims of the Logic to be a finished system of absolute knowledge. And Hegel himself admits as much, and the course of the history of the Logic makes it plain. For both in the first volume of the Logic (1812) and in the last (1816), he expressly apologises for the imperfections of the work, and claims, in view of the unusual obstacles in the way of a reformation of Logic, indulgence for its shortcomings. ${ }^{1}$ The Logic, he admits, "is capable of more completeness and elaboration in detail." While again, the repeated changes which Hegel made in the successive editions of the Logic, indicate with sufficient clearness that the Logic can in no sense be regarded as a single changeless organism of truth, that there is no completeness in its exposition, and that from first to last it is subject to the limitations of the individual thinker, who indeed is the concrete reality determining the process in this realm of shades.

Finally, regarding the general value of the method in the system, we may remark that the conception of degrees of truth which is essential to the nature of the method is inconsistent with any absolute Idealism in the sense of a completed system. Undoubtedly the principle of degrees of truth is an integral element of any idealistic theory. For 
Idealism is indissolubly bound up with our judgments of value, and these again necessarily imply degree of approximation to a standard. Hegel's method, therefore, is certainly idealistic. But that very principle of degrees of truth is the expression of, and rests upon the essential finitude of the human spirit, which seeks by means of it to determine the meaning of the Whole and its place in the Universe. It is because man's life lies between complete attainment and proximate realisation that the conception possesses its significance. At either extreme, taken by itself, the principle ceases to apply. The Absolute per se has no degrees, and cannot be constituted by them. Its life must be of equal value to it in the part as in the whole; its activity is "full and perfect in a hair as heart." The Absolute Subject, as Hegel puts it, is "truly real." While again, at the lowest level of the world's life, that of mere sentiency, there can again be no degrees, for such life has no being for itself at all. But in man's life the conception is of fundamental importance. His life has an existence for itself, is self-conscious, yet at the same time is not consciously the whole, but exists for the whole, i.e. has in part its existence for an other. That conception is the admission of his incompleteness, but also the condition of his further development. And this implication of an essential relativity in the conception is seen in the development of Hegel's own system. It is precisely because of the contrast between the completed whole and the particular results obtained that the system proceeds from Logic to the notion of Nature, and thence to Spirit, only to return again to Logic. The Logic is hardly said to be complete, when this is corrected 
by a reference to Nature, and similarly from Nature to Mind. And when Hegel declares that the process is that of a cycle of truth, so far from thereby indicating its absoluteness and finality as he seems to suppose, he merely brings out more completely the source from which knowledge determined in such a way proceeds, for that cycle may "return into itself," but it never rests in itself. No doubt we have the conception of completeness-a conception of the totality, at the realisation of which we aim, and the approximation to which the principle of degrees of truth emphasises, for otherwise the process would not take place at all. But that conception is not completely expressed, for this would render the presence of a standard meaningless. When Hegel, therefore, claims that the method determines the different degrees of truth, and presents a complete system of Absolute Truth, he is contradicting either the aim of the method or the content of Absolute Truth.

The foregoing objections do not, however, seriously damage the real value of Hegel's general position, or of the Logic in particular. They are directed against certain aspects of the system which were in large measure, if not entirely due to the historical conditions in the midst of which Hegel's philosophy was developed. For that philosophy reveals unconsciously its own historical limitations almost more than any other scheme of thought. It was directly produced at once in conscious agreement with a systematic principle which was currently accepted, and at the same time in deliberate opposition to the interpretations and misinterpretations to which that principle had been subjected. Out of 
these two combined, arose that tendency towards "absoluteness" in the form and content of his system, which influenced Hegel so strongly as to lead him to adopt those positions against which our argument has been mainly directed.

Taking science to mean essentially system, what, however, he really aimed at was, strictly speaking, simply to justify and establish the necessity for science, and its absolute objectivity. For him, as a philosopher who takes all Experience to be his province, this assumed the form of "demonstrating" the logical coherence of the content of Experience. But carried away by the demands he made on himself, and by the success of his efforts in realising them, he overlooked the significance of the fact which he had himself emphasised, that philosophy arises out of a human need. Thereby, as we have seen, he overreached the truth. But in spite of this his essential purpose was nevertheless secured. He went so far as not only to make Experience a process of Logic, but to identify our knowledge with the self-consciousness of the Absolute Spirit. This did not, however, make it impossible for him to establish what was of such vital importance-the objectivity of knowledge. And this, it seems to me, Hegel has certainly accomplished by an analysis of Experience as profound as it is ingenious.

Stated shortly, his "proof" will amount to this: That knowledge may be shown to be absolutely objective it is necessary to show that the reality within which knowledge is found, namely, selfconscious life, is the Ultimate Reality of Experience. For if this is done, then it would follow that the conditions by means of, and under the constraint 
of which knowledge is carried on, will necessarily be ratified by the whole, of which we as finite knowers are parts. That is, to establish the position in question it is first of all essential to show that experience is throughout spiritually determined. This is what Hegel sought to do in the Phenomenology. All forms under which the immediacy of experience appear show themselves upon analysis to be permeated and transformed by the activity of Spirit, to be, in short, spiritually constituted. Before this everything in heaven and earth yields up its secrets, and in the process by which experience is reconciled to Spirit, the veil which formerly hid the inner temple of things-in-themselves is rent in twain from top to bottom. But if this is so, then in realising those conditions by which in the activity we call Science (Knowledge), we must proceed if we are to work out in detail the inner unity in diversity which constitutes self-consciousness, we cannot but be completely at home, not merely with ourselves, but with the whole. Nay, more, to be at home with ourselves is just to be at one with the whole. There is no opposition between the immediacy of knowledge and the process of reflexion; they necessarily permeate each other. And the more the knower is absorbed in the object, the more does? he become aware of the self which knows, while at the same time this objective activity is essentially self-knowledge-consciousness of self.

In this manner then, simple as it appears, Hegel solves his problem; and with this solution the opposition previously supposed to exist between knowledge and the world of things, the very question of the "relation between knowledge and 
reality," vanish, or at least cease to disturb the toilers in the fields of knowledge, whose daily labour is their perpetual refutation. No matter in what particular sphere knowledge operates, there will always be an immediate transfused by the process of self-consciousness, the process of mediation, and merely to function by the principles through which self-consciousness realises unity in diversity is not simply to make ourselves agree with the whole, but, ipso facto, to be in harmony with the whole. ${ }^{1}$ This is true of all knowledge, and is true also of knowledge of the whole, Philosophy, or, as Hegel calls it, Logic or Absolute Knowledge. Here, indeed, it is more especially true; for here we deal consciously with the content of self-consciousness as this has been evolved and manifested in the course of experience, and deal with it by a method peculiar to the treatment of self-consciousness as such. Philosophy is not so much thinking in general as self-thinking.

We may express Hegel's result in different ways. The least satisfactory are those which to any extent introduce a suggestion of some distinction between knowledge and reality. Hegel's own expressions when he seeks to state his essential point of view are extremely treacherous precisely on this account. Indeed they betray continually the powerful influence upon his mind of the method and position of Kant, and are simply the heritage he took with him from a point

1 In all this it will be seen how much Hegel is in agreement with Kant. Whatever principle expresses the indissoluble unity of self-consciousness is ipso facto a "necessary" principle of experience, and constitutive of it. That is Hegel's restatement of Kant's "Transcendental Deduction." "Necessity" for both Kant and Hegel just lies in the unity of self-consciousness, $v$. infra p. 370 . 
of view he abandons and seeks to disprove. When he speaks of notions being the "true reality," or being the "essences" of the real, as being "truer and higher than, because containing sense," and so on, the essential truth of his result is obscured under the mediæval realism of its expression, or its value is lowered by the suggestion of the dualism he wishes to break down. And when again he takes up, in stating his view, such positions as we criticised above, then certainly he falsifies entirely his real achievement. It might be expressed by saying that in Knowledge Experience is reflecting itself in and through us as self-conscious beings. But this personification of Experience seems to pervert the truth itself, and makes so little of that individual life for which the ideal of knowledge may be something of a passion, that it cannot be regarded as entirely satisfactory. The term Experience, moreover, is used too loosely to make the statement of much value. Nor again are we much more successful if we speak of knowledge being the reproduction in us of an Eternal Self-consciousness, the chief objection to which seems to be that it identifies the ideal so completely with the actual process of knowledge that it makes error itself meaningless or inexplicable. Perhaps the simplest expression, which is also more in the manner of Hegel, would be that in his view knowledge is the realisation of experience in the form of reflexion. And when we bear in mind the meaning attached to the terms "realisation " and "reflexion," we may find this expression not only simple but adequate to his theory.

Now when we regard the result of Hegel's inquiry in this light we shall find that most of the 
objections urged against it above cease to hold, while at the same time much of his System as it stands can be accepted as tenable. The Logic in particular thereby becomes not merely a possible science, but admissible, and it may be even valid, as knowledge. For it can now be considered as simply the attempt to systematically connect the ultimate notions by which self-consciousness, in its process of reflexion upon the various aspects of experience, reveals itself. Xts object-matter is as possible as any other matter of knowledge. The conceptions used in the process of mediation can themselves be further mediated and constructed into a whole. And such a science will be self-complete in the sense that we do not require to go beyond it to make it intelligible or legitimate. The notions are immediate to the self reflecting on them; and such knowledge of them is therefore both concrete and true. We do not require to think of some further sense-datum to which the notions "refer" in order to render the science of Logic valid. As it stands it is quite valid, for we have all that is necessary for valid knowledge, namely, an immediate element (notions present to the self), united with and transfused by a process of mediation (relation of these notions to one another). That is all we have in any kind of knowledge. It is therefore unnecessary to demand, as Mr. M'Taggart does, that to make the Logic valid there should be given from without some datum to supplement this "ideal" construction. Certainly the construction is "ideal," but it is still knowledge, knowledge, namely, of mere universal notions. No doubt such knowledge is meagre in the sense that it does not give much "new." But this is in the 
nature of the case. The Logic is not an extension of experience, still less an extension of knowledge. It merely states more precisely and systematises what we are already supposed to be acquainted with. The knowledge furnished by the Science of Logic consists simply in connecting and constructing these notions, not in increasing their content; this is already determined, otherwise it could not proceed. But within these narrow limits the Logic is still a definite kind of knowledge, and justifiable in the form in which it appears.

For a like reason again we do not require to assume, as Haym ${ }^{1}$ after Trendelenburg holds, that Logic is impossible without a perpetual reference to history and experience; nor to maintain with them that because this reference is unconfessed and surreptitious the apparently ideal construction is an imposition. The notions must have already been "used" in the determination of experience by various forms of knowledge before they could appear as part of the Logic at all; and because of that they already in themselves have meaning, have a content. They are, so to say, a conceptual remembrance of the various spheres to which they apply, and have significance in themselves on that account. For we do know what we mean by "Quality," "Substance," without imagining a particular sense-form which we should determine by means of these notions. If not, knowledge is sheer paradox; for we should determine sense by such notions, and then admit that we did not know what the notions meant by which we determined sense. And when it is argued against Hegel that the Logic is fraudulent because of the "implica-

1 Hegel u. seine Zeit, pp. 317 ff.

2 B 
tion" of experience, it is perhaps sufficient to reply, as Hegel himself would do, that it would be worse than fraudulent if it did not have such an "implication."

But not only could the content of Logic be admitted to be a possible object of science, but the Method of construction might be similarly capable of defence from this reinterpretation of Hegel's point of view. For it is simply the attempt to combine in the movement of a single process the continuity which pervades the life of self-consciousness with the different ways in which it expresses its activity. Self-consciousness is a continuous unity throughout all knowledge, and yet the forms in which it knows are different. The reality which we know is individual, and all knowledge, we may say, simply seeks to render individuality intelligible by showing the inner relation of its constituent momentsidentity and difference. This result knowledge accomplishes, and can only do so, by the conceptions, or notions of self-consciousness. Now the ground as well as the possibility of the procedure of knowledge just lies in the fact that the supreme form and type of all individuality is self-consciousness, and there those ultimate elements, identity and difference, fall apart in the form of a conscious distinction inside their unity. If, then, the actual process by which these two are made organic to each other can be employed as a method of constructing the system of the notions which render Experience intelligible, then we shall certainly reproduce in scientific form the continuity which is the essential nature of self-consciousness. And this, we saw, is how Hegel's method really proceeds to work. Such a method is bound to show the inner necessity which binds the notions 
together. For necessity simply means the continuous unity of diverse elements, and the very source and principle of necessary connexion lies in that activity, as comprehensive as it is irresistible, by which self-consciousness makes an absolutely continuous whole of the profoundest contrariety which makes up its content. And when this necessity is actually produced, then one moment must "lead on " to another, and the System will be not a structure so much as a continuous whole, an organism, or rather a spiritual unity. It will unite in itself the continuity which characterises insight with the discreteness which characterises the activity of reflexion. It will further be an objective method, a method not external to the content but absolutely determining it, for it is the ultimate process of self-consciousness, as the notions are its ultimate contents.

Hegel then is quite justified in regarding this as the absolute method of philosophical construction, for obviously no higher method is conceivable than that which reveals the very pulse-beat of self-consciousness itself. And it is the only method of philosophy, for the principle of all experience is selfconsciousness, and philosophy has strictly to do with self-consciousness as a whole, in its complete expression. The method, therefore, will be capable of securing that comprehensive completeness which philosophy demands. It is thus precisely a philosophical method, not a method of ordinary science, still less of ordinary knowledge. It is only possible, as we saw, if the content known is of a specific kind adapted to it. It cannot widen knowledge, but simply comprehend it (begreifen).

The method, therefore, does not "presuppose" 
experience in any other sense than does the Logic as a whole. It is simply the essential process of selfconscicusness made a conscious method of procedure in philosophical knowledge. The objection urged against it by Trendelenburg, ${ }^{1}$ that it really proceeds by taking as its analogue and unacknowledged presupposition the figure of "spatial motion," might be regarded with amusement if it had not been taken seriously. Spatial movement is so far removed from the inner organic relation of an identity with its differences that the only point in common between the two seems to be the word process. To suppose that Hegel sought by his method to imitate or reproduce the continuity which characterises mechanical movement, would mean that he ignored the profound difference between mere change of position in the absolutely homogeneous medium of space, and inner determination of the content of an organic unity by its essential constitutive principle. The conditions and processes of knowledge are so utterly different from those by which spatial movement is produced that it would be useless and impossible to attempt to. obtain any aid from the latter in securing the ends of the former. For any thinker to confound the two would be grotesque; but for a thinker, who made his supreme principle even higher than that of mere purpose, to be incapable of distinguishing in his methods between a mechanical and a spiritual process is incredible. The supposition again that he was simply misled by the metaphor of "movement," by which he character-

1 Logische Untersuchungen, i. pp. 39 ff. (Auf. 2) ; see also the same author's pamphlet, $d$. logische Frage in Hegel's System, Essay I. 
ises the process of the dialectic method, hardly deserves consideration. In point of fact, as we have seen, the fundamental end of the method is not to bring about a "movement" of the notions, but to establish continuity among them. The whole of Experience is a continuity; "motion in space" or any other "movement" is only one form of realising continuity. It is unity which is the ground of continuity, and therefore of the method, not movement, which at best merely symbolises it.

Finally, we see how the content and method of the Logic and of Hegel's philosophy as a whole are thus made dependent on his ultimate principle that Experience is fundamentally a spiritual unity. These three, the principle, content, and method, are in reality the primary elements of his System, and if we admit these when modified in the way above suggested we leave the System as a whole no less valuable in reality than its author in the extravagance of his claims desired it to be. Only on such a view as Hegel's, we may admit, can knowledge and all that it means be explained. What we have insisted on is simply that the process of science must not for a moment be taken to be equivalent to the fulness of the life of Experience itself, and therefore the complete realisation of the nature of the Absolute must remain for knowledge even at its best an impossible achievement. Nay more, it must even be maintained that the ideal of human knowledge itself will ever continue an ideal, unrealised as long as change and diversity are the essential consequences of our having experience at all. But this none the less does not convert our knowledge into mere symbol or guesswork, nor does it make our efforts 
to render the Absolute intelligible of none effect. Necessary connexion is synonymous with truth, and that truth appears at different stages and in different degrees does not make it untrue, but only less than the complete truth. So far again is the Absolute from being unintelligible or inexpressible by finite self-consciousness, that every moment of truth is, ipso facto, at the same time a definite realisation by knowledge of the actual nature of Absolute Spirit. ${ }^{1}$ We do not require to go beyond our self-consciousness to know God, for the kingdom of truth is within us, and the more completely the truth is known, the more will it appear in the form of "pure" self-consciousness, and therefore the more nearly will it approximate to being "revelation." The Absolute further lives and is to be found in the processes of Nature and History; only thus indeed can we give permanence and security to human ideals and purposes. All this it is Hegel's undying honour to have sought to establish, and such a result is obtained directly from his principle and his method.

It is the application of these to Experience which distinguishes Hegel's position abruptly from that of Spinoza. Hegel's philosophical principle compelled him to preserve finitude in all its forms, for Spirit, self-conscious Subject, is precisely that which must make endless diversity organic to its essential unity; only so would it

1 This is essentially what Hegel seems to mean by the " ontological proof" of the existence of God, on which he lays such stress. It is merely the assertion that in such a question as the existence of God, ground and consequent, which are the conditions of "proof," are mutually convertible. It just avoids being a tautology because of the conscious distinction of finite from absolute Self-consciousness. 




BINDING SECT. OCT 281968 ersity of Tut Receipt

James Black d significance system

significance of Hegel's

For renewals call $416-978.0450$

Have a great day'. 
